CARLOS EDUARDO KEUTENEDJIAN MADY

DESEMPENHO TERMODINÂMICO DO CORPO HUMANO E SEUS SUBSISTEMAS. APLICAÇÕES À MEDICINA, DESEMPENHO ESPORTIVO E CONFORTO TÉRMICO 
DESEMPENHO TERMODINÂMICO DO CORPO HUMANO E SEUS SUBSISTEMAS. APLICAÇÕES À MEDICINA, DESEMPENHO ESPORTIVO E CONFORTO TÉRMICO

Tese apresentada à Escola Politécnica

da Universidade de São Paulo para obtenção

do título de Doutor em Ciências

São Paulo 


\title{
DESEMPENHO TERMODINÂMICO DO CORPO HUMANO E SEUS SUBSISTEMAS. APLICAÇÕES À MEDICINA, DESEMPENHO ESPORTIVO E CONFORTO TÉRMICO
}

\author{
Tese apresentada à Escola Politécnica \\ da Universidade de São Paulo para obtenção \\ do título de Doutor em Ciências \\ Área de Concentração: \\ Engenharia Mecânica de Energia e Fluidos \\ Orientador: \\ Prof. Dr. Silvio de Oliveira Júnior \\ Co-orientador: \\ Prof. Dr. Paulo Hilário Nascimento Saldiva
}

São Paulo 
Este exemplar foi revisado e corrigido em relação à versão original, sob responsabilidade única do autor e com a anuência de seu orientador.

São Paulo, de janeiro de 2014.

Assinatura do autor

Assinatura do orientador

FICHA CATALOGRÁFICA

Mady, Carlos Eduardo Keutenedjian

Desempenho termodinâmico do corpo humano e seus subsistemas: aplicações à medicina, desempenho esportivo e conforto térmico / C.E.K. Mady. -- versão corr. -- São Paulo, 2014. $168 \mathrm{p}$.

Tese (Doutorado) - Escola Politécnica da Universidade de São Paulo. Departamento de Engenharia Mecânica.

1.Conforto térmico 2.Exergia (Análise) 3.Temperatura corporal I.Universidade de São Paulo. Escola Politécnica. Departamento de Engenharia Mecânica II.t. 


\section{DEDICATÓRIA}




\section{AGRADECIMENTOS}

Ao Prof. Dr. Silvio de Oliveira Junior, por todas as conversas, orientações e conselhos que fizeram com que este trabalho se concretizasse. Agradeço, também, a amizade, paciência e abertura para expor ideias e por toda a confiança depositada em mim. Sua orientação contribuiu, e muito, com meu amadurecimento acadêmico e para as minhas escolhas das próximas etapas.

À minha esposa, Melissa Hukai Mady, amiga, companheira, ouvinte e conselheira. Obrigado por toda paciência, carinho e apoio incondicional nos últimos dez anos juntos; é muito bom poder contar com alguém para tudo. Essa conquista também é sua.

Aos meus pais, Charles Mady e Maria Carolina Mady, que colocam os filhos à frente de qualquer expectativa pessoal. Ao meu pai que me ensinou o conceito de família, aconselhou e apoiou em todas as decisões da minha vida. À minha mãe por me ensinar a encontrar meus defeitos nos semelhantes, por tentar entender o que eu faço e por sempre me apoiar. Esse passo na minha vida devo principalmente a Vocês e essa conquista é, também, de Vocês. Ao meu irmão e à minha cunhada, Fernando e Maristela Mady, indispensáveis companhias para o resto da minha vida, obrigado pelo apoio. À minha avó Edda Keutenedjian, que sempre apresentou um enorme brilho nos olhos ao falar do "neto da Politécnica".

Ao Prof. Dr. Mauricio Silva Ferreira, por todas contribuições, diálogos e por me "emprestar" o modelo para esta tese. Ao Prof. Dr. Cyro Albuquerque Neto, pelo trabalho que fizemos em conjunto e por abrir portas para os resultados experimentais. Ao Prof. Dr. Jurandir Itizo Yanagihara por abrir portas, dar conselhos e aceitar trabalhar em parceria. Agradeço muito aos três. Ao Dr. Tiago Lazzaretti Fernandes, por compartilhar os dados experimentais que tornaram esse trabalho mais completo. À Profa. Dra. Silvia Azucena Nebra, pelas "dicas", artigos, livros e sugestões construtivas para este trabalho. Ao Prof. Dr. José Guilherme Chaui Berlinck, pelas sugestões construtivas para esse trabalho e por abrir portas para próximos trabalhos. Ao Prof. Dr. Otávio de Mattos Silvares por ter aceitado o convite e por ter aberto portas.

Aos amigos e companheiros de sala com os quais tive o prazer de trabalhar. Ao Julio, pelas discussões acadêmicas desde o início do trabalho, ao Luiz pelos conselhos, diversos emails e discussões, à Izabela que desde que entrou para o tema só contribuiu positivamente, ao 
Juan que deixava a sala alegre, Pablo pelo intercâmbio musical e Yamid, pelas discussões políticas.

Aos amigos e amigas de pós graduação pelos almoços e cafezinhos: Luciano, Olivia, Marcos, Matias, Ovandir, dentre outros.

Gostaria de registrar um especial agradecimento àqueles que contribuiriam para a minha formação e escolhas nos últimos 10/12 anos: ao Prof. Alfredo Stavale Sobrinho, que, além do empurrão inicial, seus conselhos me ajudam e guiam até hoje. Prof Dr. Roberto Martins de Souza, com quem aprendi os primeiros passos da vida acadêmica e a pegar gosto por tal caminho. Ao amigo Waldey Sanchez pela oportunidade aberta e pelos inúmeros emails e conselhos dados. Sou-lhes grato pela orientação e amizade.

À Fundação de Amparo a Pesquisa do Estado de São Paulo (FAPESP) pelo apoio na forma de bolsa de doutorado, processo: 09/17578-0. E ao revisor pelas sugestões, sempre muito educadas, que contribuíram para esse trabalho. 


\section{RESUMO}

A análise exergética é aplicada ao ser humano para avaliar a qualidade dos processos de conversão de energia no corpo e seus sistemas, assim como nos processos bioquímicos do metabolismo. Sabe-se que a vida tem um início, um desenvolvimento e um fim, ou

seja, um típico exemplo de processo irreversível. Como tanto a idade cronológica como a entropia gerada são grandezas positivas (caminham no mesmo sentido), esta última passa a ser denominada de "flecha do tempo" (arrow of time). Assim, a partir da aplicação da Segunda Lei da Termodinâmica, torna-se possível desenvolver e aplicar índices baseados no conceito de exergia destruída/entropia gerada e rendimento exergético para diferentes áreas do conhecimento como medicina (comparação de técnicas de hipotermia), esportes (teste ergoespirométrico) e engenharia (conforto térmico). Para tal, propõe-se um modelo do corpo humano que leva em conta a transferência de exergia para o ambiente, a qual é causada pela radiação, convecção, vaporização e respiração. O metabolismo exergético é calculado com base na variação da exergia de três reações de oxidação: carboidratos, lipídeos e aminoácidos. Para condições ambientais transientes, calcula-se a variação temporal da exergia do corpo, e ainda, o máximo trabalho que o corpo pode executar a partir da hidrólise do ATP (adenosina trifosfato). O corpo humano aproveita aproximadamente $60 \%$ da exergia dos macronutrientes ingeridos na forma de ATP, $5 \%$ é dissipada na forma de calor e o restante destruída. Se o indivíduo estiver em repouso, toda a exergia da molécula de ATP é destruída ou dissipada na forma de calor. A exergia destruída tende a diminuir em função da idade tanto para condição basal como também para atividades físicas. Calculou-se que a exergia destruída durante uma vida equivale a $3091 \mathrm{MJ} / \mathrm{kg}$ (ou entropia gerada de 10,2MJ/kgK). O rendimento exergético, no entanto, diminui em decorrência da idade para condição basal, porém aumenta durante atividades físicas. Pode-se ainda afirmar que o corpo destrói menos exergia e é mais eficiente quando submetido a condições de alta temperatura operativa e baixa umidade relativa. A análise exergética acarretou em interpretações complementares ao balanço de energia, pois, a partir de sua aplicação, foi possível distinguir corredores de acordo com o nível de atividade física, ou seja, corredores mais bem treinados podem realizar mais trabalho para o mesmo valor de exergia destruída. Finalmente, foi possível identificar diferentes técnicas de hipotermia tomando por base a comparação das eficiências exergéticas.

Palavras-chave: Exergia destruída, análise exergética, corpo humano. 


\section{ABSTRACT}

Exergy analysis is applied to the human being aiming to assess the quality of the energy conversion processes that take place in the body, its several of systems and in biochemical reactions involved in these processes. It is known that life has a beginning, a development and an end, therefore, it is a typical example if irreversible process. As the chronological age and entropic generation are positive quantities (increases in the same direction), this last one is named "arrow of time". Hence, it becomes possible to obtain indices based on the concept of destroyed exergy and exergy efficiency for different areas of knowledge such as: medicine (different techniques of hypothermia), sports (ergoespirometric test) and mechanical engineer (thermal comfort). To this end, it is proposed a model of the human body which takes into account the exergy transfer rates to the environment associated with radiation, convection, vaporization and respiration. The metabolism exergy basis is calculated based on the exergy variation of the reactions of oxidation of three reference substances: carbohydrates, lipids and amino acids. For transient environmental conditions it is calculated the exergy variation of the body over time. Moreover, it is possible to calculate the maximum work that can be obtained from the hydrolysis of ATP (adenosine triphosphate). This procedure was applied to a thermodynamic model of human body for basal conditions and to experimental results of runners during different level of physical activities. The human body uses about $60 \%$ of the exergy of nutrients to obtain ATP, the rest is destroyed or dissipated as heat. Destroyed exergy rate tends to decrease as a function of lifespan (for basal conditions and during physical activities). The destroyed exergy during lifespan was calculated as $3091 \mathrm{MJ} / \mathrm{kg}$ (or entropy production of $10.2 \mathrm{MJ} / \mathrm{kgK}$ ). The exergy efficiency decreases as a function of age in basal condition, but it increases during physical activities. The destroyed exergy rate is smaller and the exergy efficiency is greater for high operative temperatures and low relative humidities. The exergy analysis led to additional information regarding the First Law of Thermodynamics, because from its application it was possible to differentiate runners according to their training level, for the same destroyed exergy better trained subjects could perform more work. Finally it was possible to distinguish different techniques of hypothermia from the concept of exergy efficiency.

Keywords: Destroyed exergy, exergy analysis, human body. 


\section{ABREVIATURAS E SIGLAS}

CLO unidade de resistência da roupa

IAT índice de atividade térmica

$L L \quad$ limiar de lactato

$P M V \quad$ voto médio estimado

$P P D$ porcentagem estimada de insatisfeitos

$V L \quad$ virada de lactato 


\section{LISTA DE SİMBOLOS}

ATP Adenosina trifosfato

$A D P$ Adenosina bifosfato

A área $\left(\mathrm{m}^{2}\right)$ ou afinidade

Ad área superficial do corpo $\left(\mathrm{m}^{2}\right)$

$\dot{B} \quad$ fluxo de exergia (W)

B exergia do corpo $(\mathrm{J})$

$b \quad$ exergia específica $(\mathrm{kJ} / \mathrm{kg})$

C espécie química qualquer

$[C]$ concentração molar de uma espécie química qualquer $\left[\mathrm{mol} / \mathrm{m}^{3}\right]$

c calor específico $(\mathrm{kJ} / \mathrm{kgK})$

$c_{p} \quad$ calor específico à pressão constante $(\mathrm{kJ} / \mathrm{kgK})$

E energia do volume de controle $(\mathrm{J})$ ou potencial de redução (V)

F $\quad$ constante de Faraday $(\mathrm{kJ} / \mathrm{Vmol})$

$f \quad$ razão entre área do corpo vestido e nu (-)

G energia livre de Gibbs (J)

$g$ energia de Gibbs específica $(\mathrm{kJ} / \mathrm{kg})$ ou aceleração da gravidade $\left(\mathrm{m} / \mathrm{s}^{2}\right)$

$\dot{H} \quad$ fluxo de entalpia (W)

$h \quad$ entalpia específica $(\mathrm{kJ} / \mathrm{kg})$

I força iônica $\left(\mathrm{mol} / \mathrm{m}^{3}\right)$

$k \quad$ condutibilidade térmica $\left(\mathrm{W} / \mathrm{m}^{2} \mathrm{~K}\right)$

$k_{i} \quad$ constantes do sistema de controle, constante de equilíbrio de uma reação

$\dot{M} \quad$ metabolismo energético (W)

$\dot{m} \quad$ vazão mássica $(\mathrm{kg} / \mathrm{s})$

$\dot{N} \quad$ número de mols $(\mathrm{kmol} / \mathrm{s})$

$p \quad$ pressão $(\mathrm{Pa})$

$P C I \quad$ poder calorífico inferior $(\mathrm{kJ} / \mathrm{kg})$

$P_{i} \quad$ grupo inorgânico fosfato

$\dot{Q} \quad$ taxa de transferência de calor $(\mathrm{W})$

$R \quad$ constante universal dos gases $(\mathrm{kJ} /(\mathrm{kmolK})$

$r \quad$ razão entre fluxos de exergia, ou índice exergético (\%)

$\dot{S} \quad$ fluxo de entropia $(\mathrm{W} / \mathrm{K})$ 


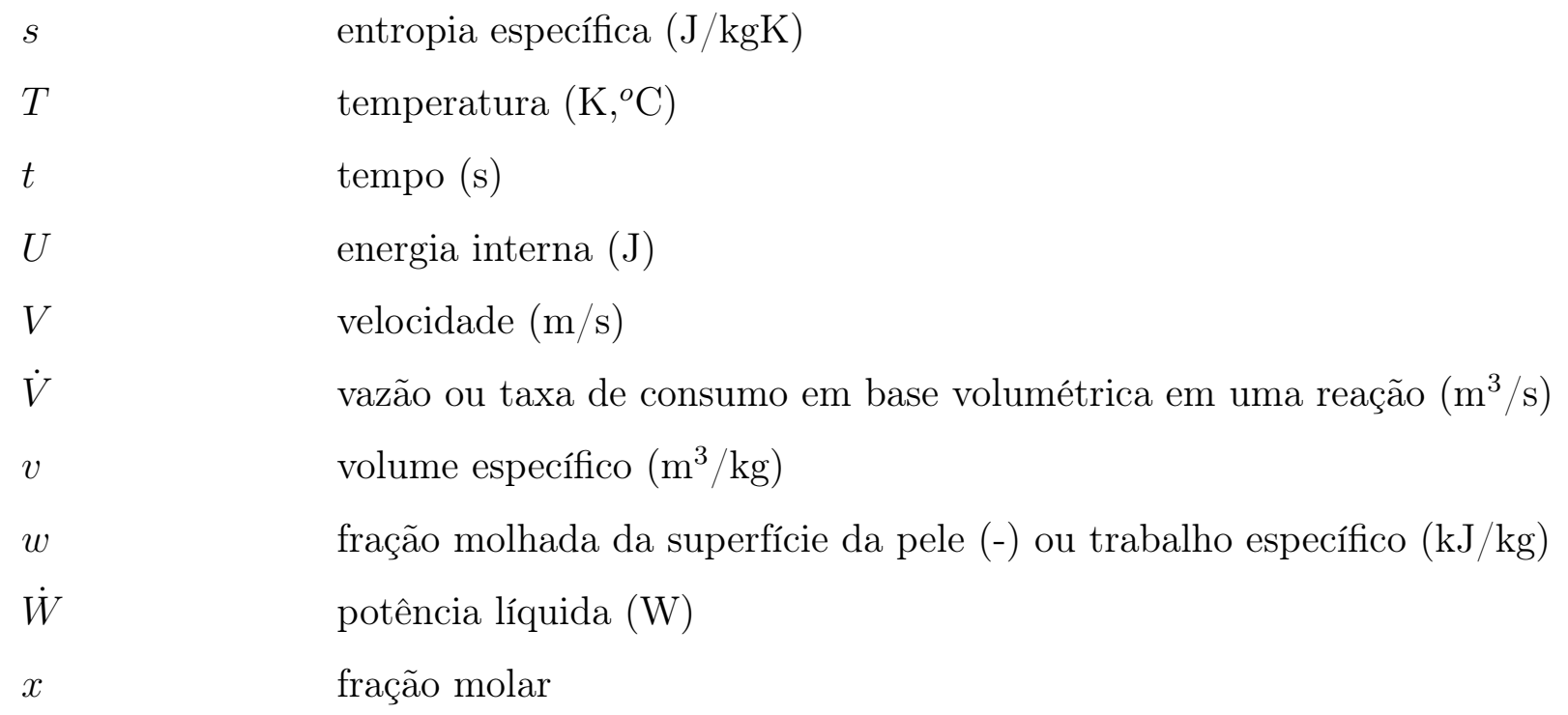

\section{Letras Gregas}

$\beta$

$\gamma$

$\eta$

$\lambda$

$\mu$

$\omega$

$\rho$

$\phi$

$\psi$

\section{Subscritos}

0

00

$a m i$

ar

b

$b l$

c

$c l$

carb

conc

dest relação entre exergia química e poder calorífico (-)

coeficiente de atividade (-)

eficiência (\%)

índice exergético de renovabilidade (-)

potencial químico $(\mathrm{kJ} / \mathrm{kmol})$

umidade absoluta $\left(\mathrm{kg}_{\text {vapor }} / \mathrm{kg}_{\text {arseco }}\right)$

massa específica $\left(\mathrm{kg} / \mathrm{m}^{3}\right)$

umidade relativa do ar (\%)

potencial elétrico (V)

estado de referência

estado de referência para exergia química

aminoácidos

ar, ou ar ambiente, ou arterial

exergético

sangue

convecção

roupas

carboidratos

concentração

destruído 
e $\quad$ vaporização

ef efetivo

en energético

ex expirado

ger gerado

hip hipotermia

hy hipotálamo

lip lipídeos

M associado ao metabolismo ou metabólico

$m$ músculos

o operativa

$P \quad$ produto de uma reação

$q$ químico

$R$ reagente de uma reação

$r \quad$ radiação

rev reversível

res respiração

$s \quad$ superfície da pele ou reservatório de sangue

$t$ tecidos

sw suor

sh tremores

vap vapor de água

ve venoso 


\section{Lista de Figuras}

1.1 Níveis de organização - baseado em Uzunian, Pinseta e Sasson (2002) . . .

2.1 Volume de controle. Os índices e, s referem-se à entrada e à saída. Os termos $H, S$ e $\mu$ são entalpia, entropia e potencial químico, respectivamente. Obtido em Pellegrini (2009) . . . . . . . . . . . . . . .

2.2 Componentes da exergia. Obtidos em Pellegrini (2009) baseado em Kotas (1985)

2.3 Representação das exergias físicas e químicas para uma mistura de dois componentes. Obtido em Pellegrini (2009) . . . . . . . . . . . . . . . . . . 10

2.4 Representação do método de cálculo da exergia química padrão de um hidrocarboneto. O método é válido para qualquer substância que não esteja no ambiente de referência. Figura baseada em: Kotas (1985), Szargut, Morris e Steward (1988) e Moran e Shapiro (2009) . . . . . . . . . . . . . . 12

2.5 Fórmula química do ATP, com o grupo adenina, ribose e trifosfato. Obtido

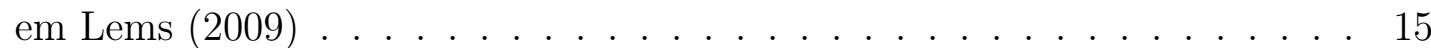

2.6 Três possíveis caminhos para o catabolismo do ácido pirúvico (piruvato). Baseado em Lehninger, Nelson e Cox (2005) . . . . . . . . . . . . . . . . 18

2.7 Esquema da cadeia transportadora de elétrons que gera a força prótonmotriz necessária para produção de ATP. Adaptado de Lems (2009) . . . .

2.8 Quebra de um ácido graxo saturado com número par de carbonos. São removidos até restar somente o grupo acetil. Adaptado de Lems (2009) . .

2.9 Diferentes formas do ATP consideradas por Lems (2009) nos cálculos exergéticos. $\mathrm{O}$ composto $\mathrm{H}_{4}$ ATP é a forma neutra. As outras possuem prótons dissociados e ligações com íons magnésio. Os números foram usados para facilitar a exposição das reações . . . . . . . . . . . . . . . . . 32

2.10 Sistema respiratório e térmico dividido em dois volumes de controle. Obtido por Albulquerque-Neto et al. (2010) . . . . . . . . . . . . . . . . 33 
2.11 Exergia destruída no corpo quando em atividade física. Obtido por Albulquerque-Neto et al. (2010) . . . . . . . . . . . . . . . 34

2.12 Sistema respiratório e térmico em apenas um volume de controle. Obtido em Henriques (2013) . . . . . . . . . . . . . . . . 34

2.13 Eficiência exergética do corpo e do pulmão para diferentes níveis de altitude e aclimatação. Obtido em Henriques (2013) . . . . . . . . . . . . . 35

2.14 Modelo proposto por Muñoz-Diosdado (2010): (a) ciclo cardíaco; (b) gráfico da pressão em função do volume no ciclo . . . . . . . . . . . . . . . 36

2.15 Representação do consumo de oxigênio decorrente do nível de atividades, para cálculo do máximo consumo de oxigênio. Baseado em Silva e Santos (2004)

2.16 Áreas de interesse no estudo da hipotermia, baseado em Dine e Abella (2009) 47

2.17 Tipos de dispositivo para resfriamento do sangue: (a) circulação extracorpórea ou cateter resfriado com solução salina obtido em Dae et al. (2003), (b) desenho esquemático de um bypass cardiopulmonar obtido em Cooley, DeBakey e MorrisJr (1957) . . . . . . . . . . . . . . 49

2.18 Resultados do resfriamento de sangue intravascular em seres humanos. As curvas limites representam os desvios padrões e a curva central os valores médios obtidos por Dixon et al. (2002) . . . . . . . . . . . . . . . 50

2.19 Resultados da circulação de sangue extracorpórea de sangue em cães, comparado com resfriamento externo do corpo, obtido em Behringer et al.

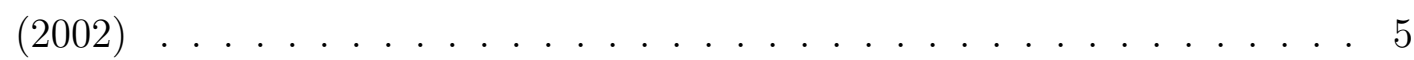

2.20 Taxa de entropia gerada pelo metabolismo decorrente do tempo de vida do peixe Nothobranchius guentheri. Resultado obtido por Balmer (1982) . . . 53

2.21 Taxa de entropia gerada pelo metabolismo em função da temperatura ambiente obtida por Balmer (1982) . . . . . . . . . . . . 53

2.22 Variação da entropia gerada por unidade de área em função da idade, obtida por Aoki (1991) . . . . . . . . . . . . . . . . . 5 
2.23 Variação da entropia gerada por unidade de área em consequência da temperatura ambiente, obtida por Aoki (1991) . . . . . . . . . . . . 54

2.24 Modelo do corpo humano com respectivos fluxos de massa, de calor e de entropia com o meio ambiente. Proposto por Rahman (2007) . . . . . . . . 55

2.25 Resultados da entropia gerada em decorrência da atividade física da pessoa. Obtido por Rahman $(2007) \ldots \ldots$. . . . . . . . . . . . . 56

2.26 Resultado da exergia destruída pelas condições ambientais. Obtido em

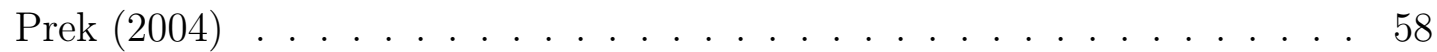

2.27 Resultados da exergia destruída em função da sensação térmica. Obtidos em Simone et al. (2011) _ . . . . . . . . . . . . . . . . . . . 59

2.28 Resultados da exergia destruída e performance em decorrência sensação térmica. Obtidos em Wu et al. (2012) . . . . . . . . . . . . . . . . . . 60

2.29 Correlação entre PMV e PPD. Retirado de ISO7730 (2005) . . . . . . . . . 61

3.1 Modelo esquemático do corpo humano com respectivos subsistemas . . . . 62

3.2 Representação do metabolismo celular com a hidrólise e formação do ATP 73

3.3 Degradação dos nutrientes do corpo divididos em três etapas fundamentais: oxidação dos nutrientes, formação do ATP e uso do ATP . . . . . . . . . . 75

3.4 Representação do modelo de sistema térmico do corpo. Adaptado de Ferreira $(2001) \ldots \ldots \ldots \ldots \ldots$. . . . . . . . . . . . . . 84

3.5 Divisão em seções e camadas do tronco (em escala) e membros superiores. Retirado e adaptado de Ferreira (2001) . . . . . . . . . . . . 85

3.6 Representação do sistema circulatório com entrada e saída de sangues arterial e venoso . . . . . . . . . . . . . . . . . . 86

3.7 Esquema representativo da indução da hipotermia, usando-se o sistema de circulação extracorpórea . . . . . . . . . . . . . . . . . . 93

3.8 Modelo de apenas um cilindro representando as camadas do corpo . . . . . 98 
3.9 Temperatura das camadas no modelo de: (a) Ferreira (1997) para duas taxas de perfusão sanguíneas, (b) presente modelo . . . . . . . . . . . . . . 99

3.10 Consumo de oxigênio, produção de gás carbônico e velocidade da esteira obtidos no teste ergoespirométrico do corredor 10 . . . . . . . . . . . . 101

3.11 Representação esquemática para análise exergética dos corpo, com respectivos parâmetros de entrada, equações principais, para aplicações numéricas e experimentais . . . . . . . . . . . . . . 105

4.1 (a): Cálculo de $\dot{M}, \dot{B}_{M}$ e $\dot{B}_{Q_{M}}$; (b) relação entre o metabolismo energético e exergético. Ambas as figuras são para o corredor 10 . . . . . . . . . . . 109

4.2 Razão entre o metabolismo calculado, considerando-se a oxidação das proteínas $(M)$ e sem se considerar a oxidação das proteínas $\left(M_{p}\right)$ para o

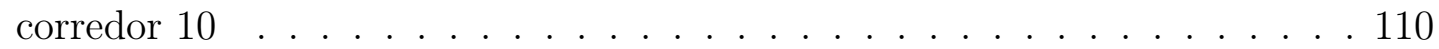

4.3 Razão entre o metabolismo "sedentário" e o metabolismo basal para idades

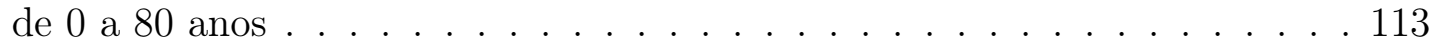

4.4 Temperatura de neutralidade térmica em função da idade (a) para um adulto de 18 a 80 anos; (b) para os dados antropométricos da sociedade brasileira entre 0 e 80 anos . . . . . . . . . . . . . . . . 117

4.5 Exergia destruída e rendimento exergético do corpo em função da idade da pessoa para o modelo de Ferreira e Yanagihara (2009a) (a) e para o modelo simplificado $(\mathrm{b}) \ldots \ldots \ldots \ldots \ldots$

4.6 (a) Exergia destruída por unidade de área; (b) fluxos de exergia para o ambiente por unidade de área em decorrência da idade da pessoa para o modelo simplificado . . . . . . . . . . . . . . . . . . . . 118

4.7 Exergia destruída por unidade de massa "acumulada" durante uma vida para condições basais e para condições sedentárias . . . . . . . . . . . . 119

4.8 (a) Exergia destruída e (b) fluxo de exergia associado ao metabolismo integrados em função do envelhecimento . . . . . . . . . . . . . . . . . 120 
4.9 Exergia destruída e rendimento exergético em função do tempo para um degrau de temperatura para: (a) temperatura operativa menor do que a de neutralidade térmica; (b) temperatura operativa maior do que a de neutralidade térmica . . . . . . . . . . . . . . . . . 123

4.10 (a) Temperatura do hipotálamo; e (b) da pele em função da temperatura operativa e umidade relativa . . . . . . . . . . . . . . . . . . 124

4.11 Fluxo de energia para o ambiente, como função da: (a) temperatura operativa e umidade relativa; (b) temperatura radiante média e temperatura

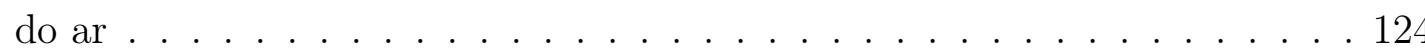

4.12 Fluxo de exergia para o ambiente, como função da: (a) temperatura operativa e umidade relativa; (b) temperatura radiante média e temperatura do $a r \ldots \ldots \ldots \ldots \ldots \ldots \ldots \ldots \ldots$

4.13 Exergia destruída, para o modelo nu, como função da: (a) temperatura operativa e umidade relativa; (b) temperatura radiante média e temperatura

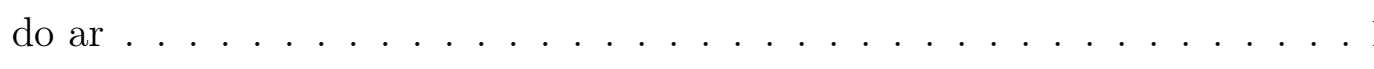

4.14 Rendimento exergético, para o modelo nu, como função da: (a) temperatura operativa e umidade relativa; (b) temperatura radiante média e temperatura do ar . . . . . . . . . . . . . . . 12

4.15 Exergia destruída, para o modelo vestido $\left(0,155^{\circ} \mathrm{Cm}^{2} / W\right.$, ou $\left.1 \mathrm{CLO}\right)$, como função da: (a) temperatura operativa e umidade relativa; (b) temperatura radiante média e temperatura do ar . . . . . . . . . . . . .

4.16 Rendimento exergético, para o modelo vestido $\left(0,155^{\circ} \mathrm{Cm}^{2} / \mathrm{W}\right.$, ou $\left.1 \mathrm{CLO}\right)$, como função da: (a) temperatura operativa e umidade relativa; (b) temperatura radiante média e temperatura do ar . . . . . . . . . . . 127

4.17 Constantes $\mathrm{k}_{1}$ e $\mathrm{k}_{2}$ do sistema de controle, em função da exergia destruída e do rendimento exergético . . . . . . . . . . . . . .

4.18 Constantes $\mathrm{k}_{3}$ e $\mathrm{k}_{4}$ do sistema de controle em função da exergia destruída e do rendimento exergético . . . . . . . . . . . . . . . . . 
4.19 Constantes $\mathrm{k}_{5}, \mathrm{k}_{6}$ e $\mathrm{k}_{7}$ do sistema de controle em função da exergia destruída e do rendimento exergético . . . . . . . . . . . . . . . . . . 130

4.20 (a) Temperatura do hipotálamo; (b) metabolismo energético em função do tempo para uma vazão adotada de resfriamento de $10 \%$ do reservatório central e de reaquecimento de $10 \%$ da de resfriamento . . . . . . . . . . 131

4.21 Temperatura do hipotálamo em função do tempo para: (a) resfriamento do sangue a uma vazão de 2,5, 5, 10 e 20\% da massa do reservatório de sangue; (b) reaquecimento a uma vazão mássica de 2,5, 5, 10 e 20\% da vazão de resfriamento (adotada como 10\% do reservatório central) . . . . . 132

4.22 Exergia destruída (a) e rendimento exergético (b) em função do tempo para uma vazão adotada de resfriamento de $10 \%$ do reservatório central e de reaquecimento de $10 \% \ldots \ldots \ldots$

4.23 Fluxo de exergia para o ambiente em função do tempo para uma vazão adotada de resfriamento de $10 \%$ do reservatório central e de reaquecimento

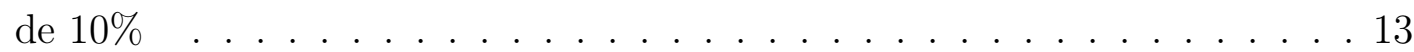

4.24 Exergia destruída em função do tempo para: (a) resfriamento do sangue a uma vazão de 2,5, 5, 10 e 20\% da massa do reservatório de sangue; (b) reaquecimento a uma vazão mássica de 2,5, 5, 10 e 20\% da vazão de

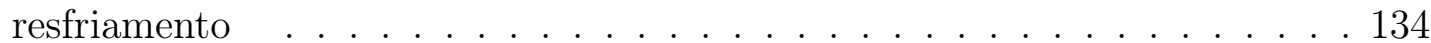

4.25 Rendimento exergético em função do tempo para: (a) resfriamento do sangue a uma vazão de 2,5, 5, 10 e 20\% da massa do reservatório de sangue; (b) reaquecimento a uma vazão mássica de 2,5, 5, 10 e 20\% da vazão de

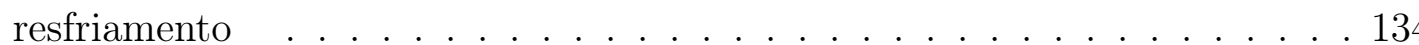

4.26 Fluxo de exergia para o ambiente (a) e (b) e variação da exergia do sangue (c) e (d) em função do tempo para resfriamento e reaquecimento do corpo, para resfriamento do sangue a uma vazão de 2,5, 5, 10 e $20 \%$ da massa do reservatório de sangue e reaquecimento a uma vazão mássica de 2,5, 5, 10 e $20 \%$ da vazão de resfriamento . . . . . . . . . . . . . . . 135 
4.27 Variação temporal da exergia do corpo em função do tempo para uma vazão adotada de resfriamento de $10 \%$ do reservatório central e de reaquecimento

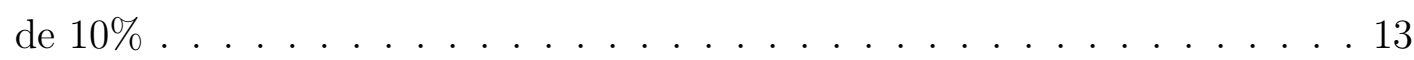

4.28 (a)Temperatura do corpo em função do tempo; (b) variação da exergia do corpo em função do tempo para resfriamento de sangue por meio de cateter

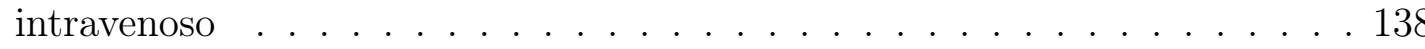

4.29 (a)Exergia destruída do corpo em função do tempo; (b) eficiência do corpo em função do tempo para resfriamento de sangue por meio de cateter

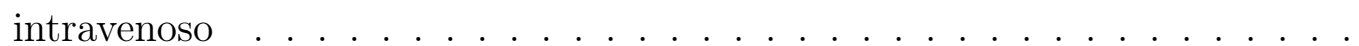

4.30 Razão entre (a) fluxo de exergia para o ambiente e a exergia metabólica; (b) fluxo de exergia associado ao metabolismo e a exergia metabólica em função do tempo para resfriamento de sangue por meio de cateter intravenoso . . 139

4.31 Temperatura do hipotálamo para o resfriamento da pele com água sob temperatura de $15^{\circ} \mathrm{C}$, com o sistema de controle ligado e desligado e (b) resfriamento usando-se do dispositivo de circulação extracorpórea com sistema de controle ligado e desligado . . . . . . . . . . . . . . . . 140

4.32 Temperatura do hipotálamo para o resfriamento da pele com água sob temperaturas de $32,30^{\circ} \mathrm{C}$, comparando-se às outras duas técnicas de resfriamento . . . . . . . . . . . . . . . . . . . 141

4.33 (a) Exergia destruída; (b) rendimento exergético para: o resfriamento da pele com água sob temperaturas de 32,30 e $15^{\circ} \mathrm{C}$, cateter intravenoso e resfriamento de sangue . . . . . . . . . . . . . . . . . . . . . . . . 142

4.34 (a) Temperatura interna; (b) temperatura da pele em função da velocidade do teste para corredores na esteira . . . . . . . . . . . . . . . . 143

4.35 (a) Fluxo de energia liberado para o ambiente (convecção, radiação, vaporização e respiração); (b) Fluxo de exergia liberado para o ambiente (convecção, radiação, vaporização e respiração) em função da velocidade do teste . . . . . . . . . . . . . . . . . . . . . . . . 144 
4.36 (a) Fluxos de exergia devido à radiação e convecção; (b) exergia associada à vaporização e respiração em função da velocidade do teste . . . . . . . . . 144

4.37 (a) Metabolismo exergético por massa; (b) exergia destruída por massa; e (c) razão entre a exergia destruída e metabolismo exergético em função da velocidade do teste . . . . . . . . . . . . . . . . . . . . . 145

4.38 (a)Eficiência energética líquida; (b) eficiência exergética; (c) razão entre as eficiências exergética e energética líquida; e (d) razão entre as eficiências exergética e energética em função da velocidade do teste . . . . . . . . . . 147

4.39 Metabolismo exergético, trabalho máximo que pode ser executado pelo corpo (variação da energia livre de Gibbs na hidrólise do ATP) e fluxo de calor causado pelo metabolismo em função do tempo . . . . . . . . . . . . 148

4.40 Para o corredor 11: (a) razão entre a exergia destruída e a exergia metabólica; (b) rendimento exergético; (c) Razão entre o fluxo de exergia para o ambiente e fluxo de exergia associado ao metabolismo com a exergia metabólica; (d) trabalho realizado e exergia metabólica . . . . . . . . . . . 149

4.41 (a) Razão entre exergia destruída e exergia metabólica; (b) rendimento exergético como função da idade . . . . . . . . . . . . . . . . . . . . . . 150

4.42 Razão entre o fluxo de exergia associado ao metabolismo com o metabolismo exergético: (a) em função da velocidade do corredor; (b) em função da idade do corredor . . . . . . . . . . . . . . . . . . . . . . 152

4.43 Razão entre o fluxo de exergia associado ao metabolismo com o metabolismo exergético para condições basais . . . . . . . . . . . . 153

4.44 Razão $W / W_{M A X}$ em função da: (a) taxa média de dissipação de exergia associada ao metabolismo; (b) razão entre a taxa de dissipação de exergia e metabolismo exergético .

4.45 Razão $W / W_{M A X}$ em função da: (a) taxa média de destruição de exergia; (b) razão entre exergia destruída e metabolismo exergético . . . . . . . . . 154 


\section{Lista de Tabelas}

2.1 Produtos formados na quebra de um mol de glicose na oxidação celular . . 21

2.2 Produtos formados na quebra de um mol de ácido palmítico na oxidação celular, baseado em Gilbert (2000) _ . . . . . . . . . . . . . . . 23

2.3 Balanço de exergia do processo de oxidação da glicose. Proposto por Lems

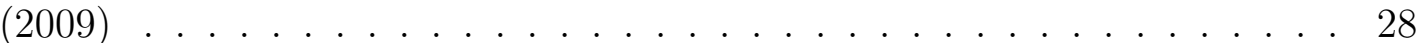

2.4 Balanço de exergia do processo de oxidação do ácido palmítico. Proposto por Lems $(2009) \ldots \ldots \ldots \ldots \ldots \ldots \ldots$

2.5 Exergia do ATP, ADP e $\mathrm{P}_{i}$ e respectivos efeitos do meio intracelular nos valores de exergia química, obtidos por Lems (2009) . . . . . . . . . . 32

2.6 Consumo de ar obtido por Hardy e DuBois (1938) . . . . . . . . . . . . 43

2.7 Fluxos entálpicos e trocas de calor pela pele obtidos por Hardy e DuBois (1938)

2.8 Fluxos de entalpia e trocas de calor pela pele obtidos por Ferreira (2001) . 44

3.1 Variação da entalpia das reações de oxidação da glicose, ácido palmítico e proteínas $(\mathrm{kJ} / \mathrm{kg})$ na forma como ocorrem no corpo . . . . . . . . . . . 68

3.2 Variação da energia de livre Gibbs quanto às reações de oxidação da glicose, ácido palmítico e proteínas $(\mathrm{kJ} / \mathrm{kg})$ na forma como ocorrem no corpo . . . 69

3.3 Propriedades termodinâmicas da oxidação completa (formação de dióxido de carbono, água líquida e nitrogênio) de 95,8\% dos aminoácidos . Dados obtidos em Cortassa et al. (2002), Szargut, Morris e Steward (1988) e ocorrência média de cada aminoácido na natureza, obtidos em Lehninger, Nelson e Cox $(2005) \quad \ldots \ldots \ldots$. . . . . . . . . . . . . . . . . 69

3.4 Propriedades termofísicas das camadas. . . . . . . . . . . . . . . . 98

3.5 Dimensões e volumes de cada camada, baseado em Ferreira (1997) . . . . . 98 
4.1 Variação da entalpia, energia livre de Gibbs e exergia das reações de oxidação dos 95,8\% dos aminácidos até a formação de dióxido de carbono, água líquida e ureia . . . . . . . . . . . . . . . . . . . 107

4.2 Exergia química da glicose, ácido palmítico e composição entre a exergia química das proteínas e da ureia $(\mathrm{kJ} / \mathrm{kg}) \ldots$. . . . . . . . . . . . . 107

4.3 Variação da exergia das reações de oxidação da glicose, ácido palmítico e proteínas $(\mathrm{kJ} / \mathrm{kg})$ na forma como ocorrem no corpo . . . . . . . . . . . 107

4.4 Metabolismo energético e exergético calculados com base nos dados obtidos por Hardy e DuBois (1938) para dois casos: com a oxidação de proteínas $\left(M, B_{M}\right)$ e sem a oxidação de proteínas $\left(M_{p}, B_{M_{p}}\right) \ldots \ldots$. . . . . . 109

4.5 Duração do teste, metabolismo energético, exergético, fluxo de exergia liberado para corpo devido ao metabolismo e razão entre o metabolismo exergético e energético. Valores integrados por todo o período de atividade

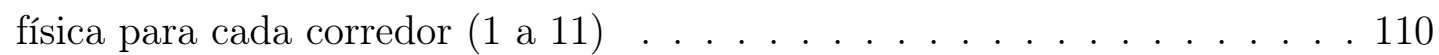

4.6 Número de mols de ATP produzido para oxidação das diferentes substâncias, variação da energia livre de Gibbs, das reações por mol de nutriente e rendimento metabólico de cada nutriente . . . . . . . . . . . 111

4.7 Valor do metabolismo como função da idade da pessoa em anos . . . . . . 112

4.8 Idade, altura, massa, em função da idade para brasileiros, obtidos em IBGE (2010). Metabolismo basal, área superficial e metabolismo por unidade de área calculados . . . . . . . . . . . . . . . . . . . . . . 112

4.9 Massa, entalpia e exergia dos fluxos relacionados à alimentação . . . . . . . 114

4.10 Massa, entalpia e exergia de cada fluxo do ar . . . . . . . . . . . . . 114

4.11 Massa, entalpia e exergia de cada fluxo mássico . . . . . . . . . . . 115

4.12 Variação da Massa, entalpia e exergia de cada fluxo de líquidos . . . . . . 116

4.13 Fluxos de Energia e exergia para o ambiente . . . . . . . . . . . 116

4.14 Termos da análise exergética integrados durante uma vida de 0 a 80 anos . 119 
4.15 Metabolismo exergético e exergia destruída das diferentes partes do corpo na condição de neutralidade térmica $\left(30^{\circ} \mathrm{C}\right) \ldots \ldots$. . . . . . . . . . 121

4.16 Fluxos de exergia do sangue das diferentes partes do corpo na condição de neutralidade térmica $\left(30^{\circ} \mathrm{C}\right)$ e razão entre o fluxo de saída pelo fluxo de

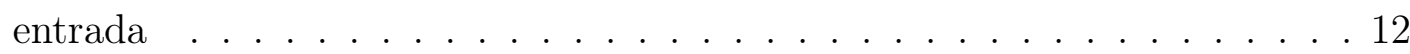

4.17 Termos das análises energética e exergética na condição de neutralidade térmica $\left(30^{\circ} \mathrm{C}\right)$ e umidade relativa de $50 \%$. Na primeira coluna, é dado o valor absoluto, na segunda, o valor percentual para $M=79,1 W \ldots$. . . . 122

4.18 Variação da exergia do corpo no processo de resfriamento, reaquecimento e no ensaio global . . . . . . . . . . . . . . . . 136

4.19 Índice exergético para o processo de resfriamento e reaquecimento . . . . . 137

4.20 Índice exergético para o processo de resfriamento e reaquecimento . . . . . 139

4.21 Duração do teste, metabolismo exergético, fluxo de exergia para o ambiente, variação da exergia, exergia destruída e trabalho executado integrados por todo o período do teste por unidade de massa para os corredores (1 a 11). Na última coluna, estão indicadas as eficiências exergéticas para todo o teste150

4.22 Tempo em repouso, razão entre a exergia destruída, trabalho executado, fluxo de exergia para o ambiente e variação da exergia com a exergia metabólica durante os cinco minutos iniciais do teste . . . . . . . . . 151

4.23 Número de mols consumidos de ATP durante atividade física e máximo trabalho que se pode realizar na hidrólise dessa quantidade . . . . . . . . . 152 


\section{Sumário}

1 INTRODUÇÃO 1

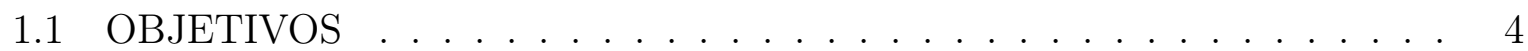

1.1.1 Objetivos da linha de pesquisa . . . . . . . . . . . . . 4

1.1.2 Objetivos específicos do trabalho . . . . . . . . . . . . . . . 4

1.2 ESTRUTURA DA TESE . . . . . . . . . . . . . . . 5

2 REVISÃO DA LITERATURA 6

2.1 ANÁLISE TERMODINÂMICA . . . . . . . . . . . . . . 6

2.1.1 Primeira lei da termodinâmica . . . . . . . . . . . . . . . . 6

2.1.2 Segunda lei da termodinâmica . . . . . . . . . . . . . . . . . 6

2.1.2.1 Princípio do aumento de entropia . . . . . . . . . . 7

2.1.3 Análise Exergética . . . . . . . . . . . . . . . . . . 8

2.1.3.1 Cálculo da exergia química de um gás perfeito presente no ambiente de referência . . . . . . . . . . . . 11

2.1.3.2 Cálculo da exergia química para outras substâncias . . . . 11

2.1.3.3 Eficiência Exergética . . . . . . . . . . . . . . . . . 13

2.1.3.4 Indicadores termodinâmicos . . . . . . . . . . . . . . . 13

2.2 ANÁLISE TERMODINÂMICA NA ESCALA CELULAR . . . . . . . . . 14

2.2.1 Respiração celular . . . . . . . . . . . . . . . . . . . . . . . 14

2.2.1.1 Metabolismo dos carboidratos . . . . . . . . . 17

2.2.1.2 Metabolismo dos lipídeos . . . . . . . . . . . . . 21

2.2.1.3 Metabolismo das proteínas . . . . . . . . . . . . 23

2.2.2 Aplicações da Segunda Lei em uma célula . . . . . . . . . . . . . . 23 
2.2.2.1 Geração de entropia em células saudáveis e com câncer . . 24

2.2.2.2 Rendimento metabólico . . . . . . . . . . . . 26

2.2.2.3 Analise exergética da quebra da glicose e ácidos-graxos . . 27

2.2.2.4 Mudança da referência termodinâmica para estado próximo ao real da célula . . . . . . . . . . . . . . . 28

2.3 ANALISE TERMODINÂMICA NA ESCALA DE SISTEMAS E ÓRGÃOS 31

2.3.1 Sistema Respiratório . . . . . . . . . . . . . . . 33

2.3.2 Aplicação da Segunda Lei em órgãos e sistemas . . . . . . . . . . . . 33

2.4 ANALISE TERMODINÂMICA NA ESCALA DO ORGANISMO . . . . . 36

2.4 .1 Metabolismo energético . . . . . . . . . . . . . . . . 37

2.4.1.1 Metabolismo e duração da vida . . . . . . . . . . . . 37

2.4.1.2 Equações para cálculo do metabolismo basal . . . . . . . . 38

2.4.1.3 Medição do metabolismo - calorimetria indireta . . . . . . 39

2.4.2 Análise da capacidade funcional durante atividades físicas . . . . . 41

2.4.2.1 Indicadores na ergoespirometria . . . . . . . . . . . . . 42

2.4.3 Experimentos e modelos do sistema térmico do corpo humano . . . 43

2.4.4 Hipotermia . . . . . . . . . . . . . . . . . 44

2.4.4.1 Técnicas de resfriamento do corpo . . . . . . . . . 47

2.4.4.2 Parâmetros de resfriamento do corpo . . . . . . . . . . 48

2.4.5 Aplicação da Segunda Lei em organismos . . . . . . . . . . . . . . . 51

2.4.6 Indicadores termodinâmicos existentes . . . . . . . . . . . . 58

3 DESCRIÇÃO DO MODELO

3.1 ANÁliSE ENERGÉTICA E EXERGÉTICA . . . . . . . . . . . . . . 66

3.1.1 Cálculo do metabolismo em base energética e exergética . . . . . . 66 
3.1.1.1 Cálculo da taxa de consumo de nutrientes . . . . . . . . 67

3.1.1.2 Cálculo do metabolismo energético . . . . . . . . . . . 67

3.1.1.3 Cálculo do metabolismo exergético . . . . . . . . . . . . 68

3.1.1.4 Propriedades Termodinâmicas . . . . . . . . . . . . 68

3.1.2 Metabolismo celular e máximo trabalho . . . . . . . . . . . . 71

3.1.2.1 Hidrólise ou formação do ATP . . . . . . . . . . . . . . 71

3.1.2.2 Máximo trabalho disponível para o corpo . . . . . . . . 72

3.1.2.3 Metabolismo celular e o ATP . . . . . . . . . . . . 73

3.1.3 Taxas de transferência de calor e fluxos de entalpia para o ambiente 75

3.1.4 Transferência de exergia para o ambiente . . . . . . . . . . . 79

3.2 ENTROPIA E ENVELHECIMENTO . . . . . . . . . . . . . . 80

3.3 BALANÇOS DIÁRIOS DE MASSA, ENERGIA E EXERGIA . . . . . . . 82

3.4 MODELO DO SISTEMA TÉRMICO DO CORPO HUMANO . . . . . . . 83

3.4 Efeito $Q_{10} \ldots \ldots \ldots \ldots \ldots$

3.4 .2 Sistema de controle . . . . . . . . . . . . . . . . . 88

3.4.3 Análise exergética aplicada ao modelo . . . . . . . . . . . . . . . 89

3.4.3.1 Análises transientes . . . . . . . . . . . . . . . . 89

3.4.3.2 Análise exergética de cada elemento . . . . . . . . . . . 91

3.4 .4 Indução da hipotermia ao modelo . . . . . . . . . . . . . . . . . 92

3.4.4.1 Indução de hipotermia via dispositivo de circulação

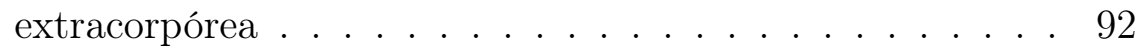

3.4.4.2 Resfriamento com inserção de cateter intravenoso . . . . . 94

3.4.4.3 Resfriamento da superfície da pele . . . . . . . . . . . 96

3.4.4.4 Proposição do índice exergético . . . . . . . . . . . . . . . 96 
3.4.5 Simplificação do modelo do sistema térmico . . . . . . . . . . . . . 97

3.5 TEStE CARDiOPUlmonAR (ERGOESPIROMÉTRICO) . . . . . . . . 100

3.5.1 Análise energética e exergética aplicada ao teste ergoespirométrico . 102

3.5.2 Fluxograma para aplicação da analise exergética no corpo humano . 104

\section{RESULTADOS E DISCUSSÕES}

4.1 METABOLISMO ENERGÉtICO E EXERGÉTICO . . . . . . . . . . . 106

4.1.1 Propriedades termodinâmicas e equação do metabolismo .... . 106

4.1.2 Cálculo do metabolismo energético e exergético . . . . . . . . . 108

4.1 .3 Rendimento metabólico . . . . . . . . . . . . . . . . . 111

4.1.4 Metabolismo e envelhecimento . . . . . . . . . . . . . . . 111

4.2 BALANÇOS DIÁRIOS DE MASSA, ENERGIA E EXERGIA . . . . . . . 113

4.3 COMPORTAMENTO EXERGÉTICO E ENVELHECIMENETO . . . . . 116

4.3 .1 Exergia e duração da vida . . . . . . . . . . . . . . . 117

4.3.1.1 Limitações da análise . . . . . . . . . . . . . . . . . . . 120

4.4 SEGUNDA LEI APLICADA AO CORPO SOB DIFERENTES CONDIÇÕES

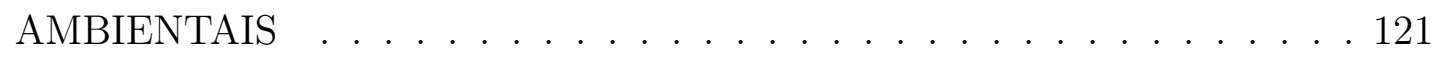

4.5 ANÁLISE EXERGÉTICA DO SISTEMA DE CONTROLE DO MODELO 128

4.6 INDUÇÃO DE HIPOTERMIA . . . . . . . . . . . . . . . . . 130

4.6.1 Resfriamento de sangue via circulação extracorpórea . . . . . . . 130

4.6.2 Resfriamento por meio de cateter intravenoso . . . . . . . . . . . 137

4.6.3 Resfriamento da pele . . . . . . . . . . . . . . . . . 140

4.6.4 Comparação dos métodos de resfriamento . . . . . . . . . . . . . 141

4.7 ANÁliSE EXERGÉTICA DA ATIVIDADE FÍSICA . . . . . . . . . . . 142 
4.7.1 Termos da análise exergética em função do tempo e integração numérica . . . . . . . . . . . . . . . . . . . . . 146

4.8 ANÁliSE DOS PRODUTOS DO METABOLISMO: CONDIÇÕES BASAIS E DURANTE ATIVIDADE FÍSICA . . . . . . . . . . . . . . 151

5 CONCLUSÕES

5.1 SUGESTÕES PARA TRABALHOS FUTUROS . . . . . . . . . . . . 158

REFERÊNCIAS 


\section{INTRODUÇÃO}

As aplicações da Primeira Lei da Termodinâmica em sistemas biológicos são datadas da segunda metade do século XVIII, como discutido por Passos (2009). Nesse período, Lavoisier e Laplace publicaram o tratado "Mémoire sur la Chaleur" no qual estudaram correlações entre o oxigênio inspirado e a energia perdida pelo corpo, contribuindo assim para as primeiras ideias acerca do balanço de energia e de suas aplicações no corpo.

Passos (2009) afirma que tais conceitos foram retomados pelo médico alemão Julius Robert Mayer (1814-1878) que, em 1840, estava a serviço da marinha holandesa na Ilha de Java. Em seus estudos, notou que o sangue de pacientes sujeitos a climas tropicais era mais claro do que aqueles sujeitos a climas temperados, passando a associar essa diferença da cor com a maior quantidade de oxigênio no sangue de pessoas submetidas às temperaturas do clima tropical (acarretada pela menor oxidação dos alimentos para manter a temperatura do corpo constante). Dessas observações concluiu-se que a energia mecânica dos músculos provinha da energia química dos alimentos, sendo intercambiáveis a energia mecânica, a energia perdida para o ambiente e a energia química. Portanto, por meio de uma aplicação em fenômenos biológicos, mostrou-se a validade do princípio da conservação da energia ou Primeira Lei da Termodinâmica.

Em todos os processos reais, a energia não pode ser criada nem destruída, ela é sempre conservada. Na verdade, ela é transformada, tornando-se menos adequada para servir como fonte para realização de trabalho. Como enunciado por Szargut (2005), tornase necessária a definição de uma outra grandeza física para estabelecer a qualidade no processo de conversão de energia.

A exergia é um padrão de qualidade termodinâmica, pois quantifica o máximo potencial de realização de trabalho que é possível executar, com base em uma determinada forma de energia e por meio de iterações somente com o meio ambiente no qual o processo está inserido. Em um processo estipulado, ou sequência de processos de conversão de energia, as irreversibilidades acarretam a redução da qualidade da energia, com consequente ocorrência de impactos ambientais e incremento de custos de produção. A análise exergética consiste, então, na avaliação da qualidade de conversão de energia em um dado processo por meio da determinação de suas ineficiências, utilizando-se dos conceitos da entropia gerada ou exergia destruída.

Como mencionado por Oliveira (2013), uma das aplicações mais peculiares e interessantes da Segunda Lei da Termodinâmica é o entendimento de sistemas biológicos em seus diferentes níveis de organização (Figura 1.1): células, órgãos, tecidos e corpo (organismo). Szargut (2005) descreve que novos campos para aplicação da análise exergética aparecem 
continuamente, sendo a análise das perdas de exergia em organismos vivos um assunto que pode contribuir para esta área do conhecimento. Dentre eles, destacam-se o entendimento: da eficiência exergética de vegetações ser baixa, do corpo humano possuir destruição de exergia elevada e de organismos mais idosos transformarem os alimentos em exergia útil em uma proporção menor do que em organismos mais novos.

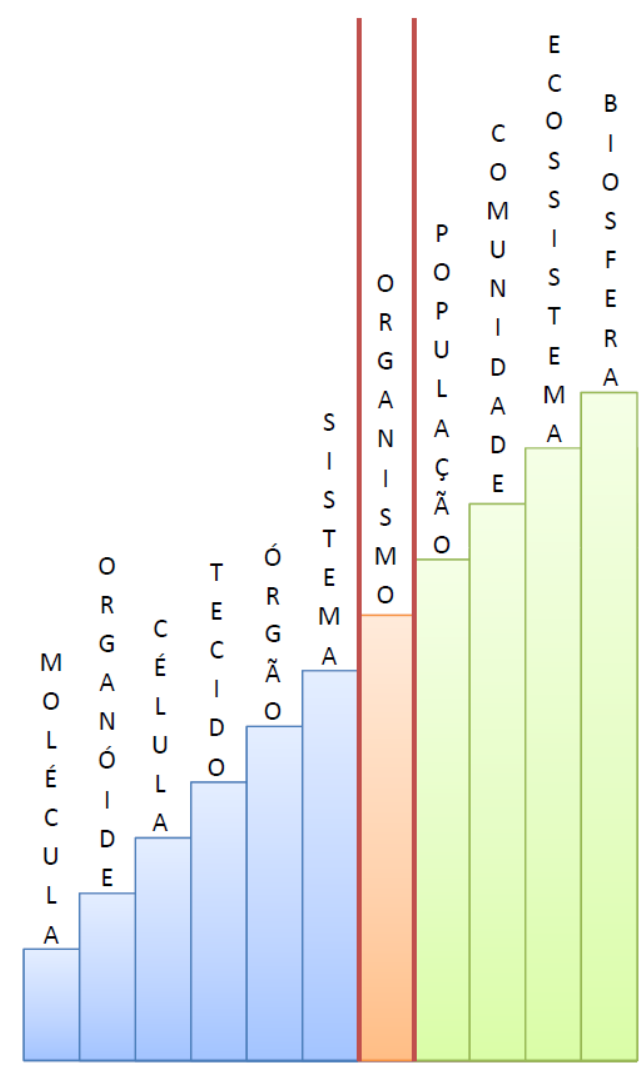

Figura 1.1: Níveis de organização - baseado em Uzunian, Pinseta e Sasson (2002)

Zhen (1996) afirma que a Segunda Lei da Termodinâmica é uma das leis mais profundas e significativas da física, pois pode nos dar pistas para o entendimento da vida. Sabe-se que essa tem um início, um desenvolvimento e um fim. Em outras palavras, o envelhecimento é um típico exemplo de um processo irreversível. Como para um sistema isolado tanto a entropia quanto a idade cronológica tendem a um mesmo sentido (aumento), a geração entropia do corpo foi denominada de "flecha do tempo". Segundo Hershey (2010), o ser humano nasce, cresce e morre; indo de um estado de elevada ordem, que vai se reduzindo, até chegar a um estado de máxima desordem (ou morte). Dentre as causas de tais irreversibilidades, pode-se salientar que as mesmas reações químicas que garantem a vida a partir da degradação de nutrientes são irreversíveis e responsáveis pelo envelhecimento e por garantir que o sistema biológico nunca volte ao estado termodinâmico anterior. Como a entropia indica o grau de desordem de um sistema, ao se compararem duas pessoas de uma mesma idade cronológica, a que possuir uma geração de entropia maior está caminhando mais rapidamente e com uma menor eficiência para uma morte natural.

De acordo com Muñoz-Diosdado (2010), organismos possuem uma relação contínua entre 
os diferentes sistemas regulatórios para que a informação seja trocada constantemente nos diferentes níveis de organização, o que viabiliza que o corpo se adapte a mudanças no ambiente e realize uma série de atividades. Existem trabalhos de aplicação da Segunda Lei em diferentes níveis de organização, das quais as principais aplicações são para obter correlações de conforto térmico e comprovação do princípio de mínima geração de entropia.

No nível celular, destaca-se o trabalho de Luo (2009) que analisou que a entropia gerada em uma célula com câncer é sempre maior do que em uma saudável (no entanto, o processo de degradação da glicose é menos irreversível para células com câncer, porém a uma taxa maior). Alguns autores aplicaram a Segunda Lei em organismos (de forma mais específica no corpo), dentre os quais se destacam Balmer (1982), Aoki (1991) e diversos outros, os quais mostraram que diferentes espécies de seres vivos, incluindo o ser humano, tendem a um estado de mínima geração de entropia. Batato et al. (1990) que, além de ter sido o primeiro a aplicar a análise exergética no corpo, propôs um modelo para esse tipo de análise. Prek (2004, 2006), Prek e Butala (2010) e Simone et al. (2011) que correlacionaram a exergia destruída com condições de conforto térmico; AlbulquerqueNeto et al. (2010) e Henriques (2013) que relacionaram a exergia destruída nos pulmões com a exergia destruída nos tecidos durante atividade física em diferentes altitudes, dentre outros.

Este trabalho está inserido nesse contexto com o objetivo de propor um modelo para análise exergética do corpo humano e seus subsistemas. Quase todas as aplicações da literatura fizeram a análise do sistema biológico com base apenas na exergia destruída ou entropia gerada. Assim, além de se usar a destruição de exergia como indicador de qualidade, também se usará a análise da eficiência exergética do corpo humano. Foram propostos outros indicadores de qualidade baseados no conceito de exergia para relacionar resultados com áreas do conhecimento como medicina, engenharia mecânica e esportes. Tal modelo leva em conta a forma como o corpo degrada os nutrientes para obtenção de energia, transferências de calor e entalpia com o ambiente e variações temporais da energia do corpo. O estudo de subsistemas do corpo como, por exemplo, o metabolismo celular agregou à análise estabelecendo um limite superior de capacidade de realização de trabalho. 


\subsection{OBJETIVOS}

\subsubsection{Objetivos da linha de pesquisa}

A linha de pesquisa tem por objetivo a comparação do comportamento termodinâmico de um indivíduo, órgão ou célula saudável com outro que esteja sujeito a patologias, a fim de contribuir com diagnósticos e indicadores baseados no conceito de exergia destruída e eficiência exergética.

\subsubsection{Objetivos específicos do trabalho}

Este trabalho tem como objetivo propor um método para aplicação da análise exergética no corpo humano e seus sistemas (célula, órgão, dentre outros), com a finalidade de sugerir e aplicar indicadores baseados nos diferentes termos da análise, para distintas áreas do conhecimento dentre elas:

- Indicadores na medicina: Relacionar pontos de mínima destruição de exergia e máximo rendimento exergético com técnicas de hipotermia, na tentativa de classificar as técnicas de resfriamento. Essa área do conhecimento na medicina ainda se mostra incipiente no que se refere às áreas relacionadas com fenômenos de transporte, e modelagem termodinâmica, sendo o único trabalho encontrado o proposto por Brett (1972). Portanto, essa aplicação agrega tanto para obtenção do comportamento térmico do corpo sob hipotermia como para o comportamento exergético.

- Indicadores de performance: Comparar a exergia destruída e rendimento exergético de diferentes corredores sob distintos condicionamentos físicos durante atividades físicas. A partir desses resultados, torna-se possível se realizar uma análise do metabolismo celular e do corpo durante atividades físicas, como um processo de conversão de energia cujo produto principal é o trabalho com uma dissipação de energia relacionada ao calor liberado pelas reações metabólicas.

- Indicadores de conforto térmico: Relacionar pontos de mínima destruição de exergia e máximo rendimento exergético com condições de conforto térmico. Essa área vem sendo foco das principais publicações, nas quais a proposição da exergia 
destruída como indicador de conforto se constitui no principal foco da área.

- Validação do princípio de mínima geração de entropia: Analisar o comportamento da exergia destruída e do rendimento exergético com o passar da vida para condições basais e durante atividade física. Será realizada a integração da exergia destruída para a proposição do indicador "idade exergética".

\subsection{ESTRUTURA DA TESE}

O texto está estruturado em três partes fundamentais.

Revisão da literatura (Capítulo 2) dividida em quatro itens: análise termodinâmica, análise termodinâmica aplicada na escala celular, analise termodinâmica aplicada na escala de órgãos e sistemas, e análise termodinâmica aplicada na escala do corpo humano. Nessas, os conceitos termodinâmicos e fisiológicos para proposição do modelo foram sistematizados e organizados.

Proposição do modelo para análise exergética fundamentado no resgate dos conceitos da literatura foi proposto um modelo que integra a escala celular (metabolismo celular, síntese do ATP) com o modelo na escala do corpo humano. Nesse capítulo foram realizadas as devidas modificações no modelo para aplicação em três estudos de caso: hipotermia, atividade física e conforto térmico (Capítulo 3).

Resultados e conclusões indicados nos Capítulos 4 e 5, nos quais a viabilidade da aplicação do modelo de análise exergética do corpo humano foi testada para as diferentes condições. 


\section{REVISÃO DA LITERATURA}

\subsection{ANÁLISE TERMODINÂMICA}

\subsubsection{Primeira lei da termodinâmica}

A primeira lei da termodinâmica (balanço de energia) para um volume de controle qualquer, com várias entradas e saídas, considerando propriedades constantes na seção transversal ao escoamento, pode ser escrita da forma indicada na Equação 2.1.

$$
\frac{d E_{V C}}{d t}=\sum \dot{m}_{e}\left(h_{e}+\frac{V_{e}^{2}}{2}+g z_{e}\right)-\sum \dot{m}_{s}\left(h_{s}+\frac{V_{s}^{2}}{2}+g z_{s}\right)+\dot{Q}_{V C}-\dot{W}_{V C}
$$

Na qual, $d E_{V C} / d t$ é a variação temporal da energia no volume de controle (VC), $\dot{Q}_{V C}$ é o termo referente às taxas de transferência de calor pela fronteira do volume de controle, $\dot{W}_{V C}$, a taxa de realização de trabalho (potência) e $\sum \dot{m}_{i}\left(h_{i}+\frac{v_{i}^{2}}{2}+g z_{i}\right)$, os fluxos de entalpia, energia cinética e potencial que cruzam a fronteira do volume de controle, em que $i$ pode se referir à entrada $(e)$ ou à saída $(s)$.

\subsubsection{Segunda lei da termodinâmica}

A segunda Lei da Termodinâmica é umas das leis físicas mais significativas. Segundo Zhen (1996), ela indica que um sistema isolado evolui de forma que a entropia nunca decresça tornando-se,, portanto, cada vez mais desorganizado até que sua entropia se maximize. A Primeira Lei estabelece a conservação de energia, porém sem que haja um impedimento quanto à direção do fluxo de calor, informação trazida pela aplicação da Segunda Lei da Termodinâmica. Nota-se, também, que a entropia não é uma grandeza conservativa.

A Segunda Lei da Termodinâmica, para sistemas, é demonstrada pela Equação 2.2. 


$$
d S=\frac{\delta Q}{T}+\delta S_{g e r}
$$

Na qual, $\frac{\delta Q}{T}$ é a entropia transportada pelo fluxo de calor que atravessa a fronteira do sistema, e $\delta S_{g e r}$ é a entropia gerada.

Para um volume de controle, a Segunda Lei fica na forma indicada pela Equação 2.3.

$$
\frac{d S_{V C}}{d t}=\sum \dot{m}_{e} s_{e}-\sum \dot{m}_{s} s_{s}+\sum \frac{\dot{Q}_{V C}}{T}+\dot{S}_{g e r}
$$

Assim, $d S_{V C} / d t$ é a variação temporal da entropia no volume de controle (VC), $\dot{Q}_{V C}$ é a taxa de transferência de calor pela fronteira do volume de controle, $T$ é a temperatura da fronteira em que ocorre a troca de calor no volume de controle e $\sum \dot{m}_{i} . s_{i}$ são os fluxos de entropia que cruzam a fronteira do volume de controle.

\subsubsection{Princípio do aumento de entropia}

Como indicado em Van-Wylen, Sonntag e Borgnakke (2003), Moran e Shapiro (2009), considerando um sistema qualquer adicionado ao meio em que o sistema se situa, a variação líquida de entropia é demonstrada pela Equação 2.4.

$$
d S_{\text {liq }}=d S_{\text {sistema }}+d S_{\text {meio }}=\sum \delta S_{\text {ger }} \geq 0
$$

Portanto, a variação líquida da entropia deve ser a soma da variação da entropia do sistema $\left(d S_{\text {sistema }}\right)$ com a do meio $\left(d S_{\text {meio }}\right)$, ambas podem ser positivas ou negativas. Porém, a soma das duas $\left(d S_{l i q}\right)$ deve ser maior ou igual a zero. É possível mostrar que a variação líquida da entropia é um somatório de vários termos referentes aos fenômenos que provocam as irreversibilidades. Desse modo, a variação líquida da entropia pode ser denominada como geração total de entropia, cujo princípio é denominado de princípio do aumento da entropia. Tal princípio tem expressivo significado, qual seja, os únicos processos que podem ocorrer são aqueles nos quais a variação líquida de entropia do sistema, somada à do seu meio, é positiva (no limite permanece constante).

Para um sistema isolado, a Equação 2.4 fica na forma da Equação 2.5, que estabelece que, 
num sistema isolado, os únicos processos que podem ocorrer são aqueles que levam a um aumento de entropia. Em outras palavras, a Equação 2.4 indica que todos os processos ocorrem num único sentido.

$$
d S_{\text {sistema,isolado }}=\sum \delta S_{g e r} \geq 0
$$

\subsubsection{Análise Exergética}

A análise exergética consiste no emprego simultâneo da Primeira e da Segunda leis da Termodinâmica na avaliação de desempenho de processos de conversão de energia, que, segundo Cespedes e Oliveira (1997), permite efetiva avaliação termodinâmica de processos, uma vez que quantifica as irreversibilidades que ocorrem durante o desenvolvimento destes. Szargut, Morris e Steward (1988) definem exergia como o máximo trabalho que pode ser realizado quando um sistema evolui do estado em que se encontra até o estado de equilíbrio com os componentes do meio ambiente (equilíbrio mecânico, térmico e químico), mediante processos reversíveis, interagindo apenas com os componentes do meio ambiente.

Do emprego combinado da Primeira e Segunda leis da Termodinâmica, considerando o volume de controle da Figura 2.1, é possível escrever o balanço de exergia, conforme se demonstra na Equação 2.6. O volume de controle apresenta várias entradas e saídas, trocas de calor a diferentes temperaturas $T_{i}$, regime variável e volume de controle deformável.

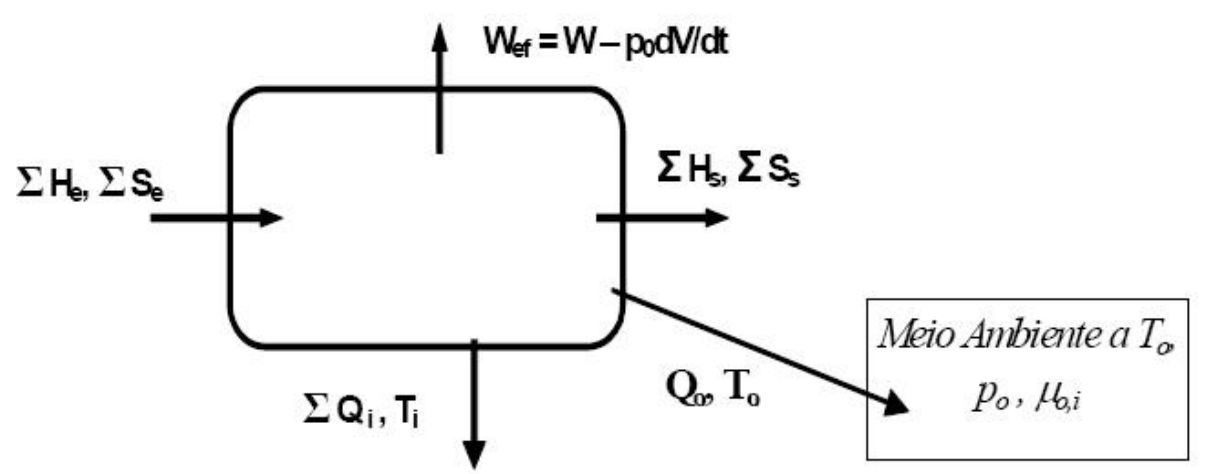

Figura 2.1: Volume de controle. Os índices e, s referem-se à entrada e à saída. Os termos $H, S$ e $\mu$ são entalpia, entropia e potencial químico, respectivamente. Obtido em Pellegrini (2009) 


$$
\begin{array}{r}
\frac{d\left(E+p_{0} V-T_{0} S\right)}{d t}=\sum_{i} \dot{Q}_{i}\left(1-\frac{T_{0}}{T_{i}}\right)-\dot{W}_{e f}-T_{0} \dot{S}_{g e r}- \\
{\left[\sum_{s} \dot{H}_{s}-\sum_{e} \dot{H}_{e}-T_{0}\left(\sum_{s} \dot{S}_{s}-\sum_{e} \dot{S}_{e}\right)\right]}
\end{array}
$$

Sendo,

- $\left(\sum_{s} \dot{H}_{s}-\sum_{e} \dot{H}_{e}-T_{0}\left(\sum_{s} \dot{S}_{s}-\sum_{e} \dot{S}_{e}\right)\right)$ : variação entre os fluxos de exergia na entrada e na saída $\left(\dot{B}_{e}\right.$ e $\left.\dot{B}_{s}\right)$;

- $\sum_{i} \dot{Q}_{i}\left(1-\frac{T_{0}}{T_{i}}\right)$ : taxa de transferência de exergia causada pela taxa de transferência de calor;

- $\dot{W}_{e f}$ : exergia pura ou potência efetiva;

- $T_{0} \dot{S}_{g e r}$ : taxa de destruição de exergia $\left(\dot{B}_{\text {dest }}\right)$;

- $d\left(E+p_{0} V-T_{0} S\right) / d t$ : variação temporal da exergia no volume de controle $(d \mathbf{B} / d t)$.

A Equação 2.6 pode ser considerada como lei da degradação da energia, visto que permite a quantificação da capacidade de realização de trabalho, por causa da ocorrência de processos irreversíveis, durante uma conversão de energia. Constata-se, assim, que a capacidade de realização de trabalho (exergia) não se conservará, mas será reduzida toda vez que houver algum processo irreversível no volume de controle analisado.

Desconsiderando-se efeitos nucleares, magnéticos, elétricos e de tensão superficial, podese dividir a exergia em quatro componentes: exergia cinética, potencial, física e química, como mostra a Figura 2.2.

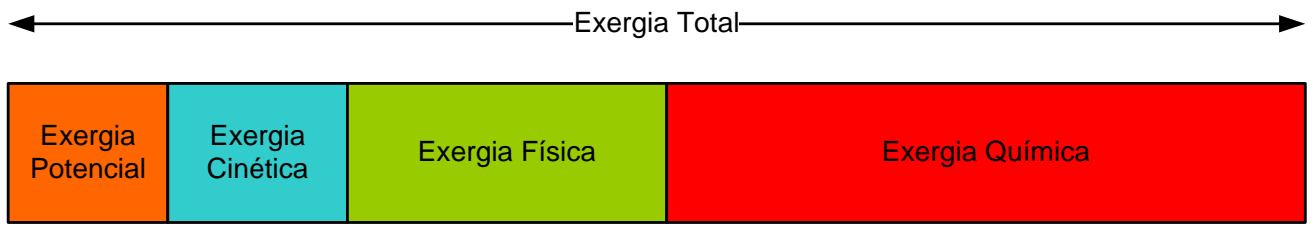

Figura 2.2: Componentes da exergia. Obtidos em Pellegrini (2009) baseado em Kotas (1985)

A exergia física equivale à máxima quantidade de trabalho que se pode obter, quando um sistema ou fluxo de uma substância passa de um estado inicial ao estado de referência restrito, caracterizado pela existência de equilíbrio térmico e mecânico com o meio ambiente. A exergia química é o máximo trabalho que é possível obter quando um sistema ou fluxo é levado do estado de referência restrito ao estado morto, caracterizado 
pela existência de equilíbrio térmico, mecânico e químico, interagindo reversivelmente com componentes do meio ambiente. Para a determinação da exergia química é necessário definir um modelo de meio ambiente padrão, conforme constatam Szargut, Morris e Steward (1988), Kotas (1985) e Oliveira (2013). Cumpre acrescentar que um dos modelos mais utilizados na literatura é o proposto por Szargut, Morris e Steward (1988).

Nesse ambiente, são definidas as seguintes substâncias de referência para um estado de equilíbrio termomecânico com $T_{0}=298,15 \mathrm{~K}$ e $p_{0}=101,325 \mathrm{kPa}$ (estado de referência restrito):

- componentes gasosos da atmosfera $\left(\mathrm{O}_{2}, \mathrm{~N}_{2}, \mathrm{CO}_{2}, \mathrm{H}_{2} \mathrm{O}\right.$, dentre outros);

- substâncias sólidas de referência na crosta terrestre;

- substâncias iônicas de referências dos mares;

- substâncias de referências em forma molecular, não ionizáveis dos mares.

De acordo com Sciubba (2001), se for definido um estado de referência da Terra, a parcela de exergia química de um minério, por exemplo, será igual a zero (se a composição do minério for igual à composição média da Terra) ou igual a um valor computado com base na composição do minério, seu estado físico e energia de Gibbs de formação de seus constituintes. A Figura 2.3 ilustra o conceito das exergias físicas e químicas para um sistema binário, em que se nota que a exergia física é o máximo trabalho que pode ser obtido para levar o sistema de $\mathrm{T}$ e $\mathrm{p}$ até $\mathrm{T}_{0}$ e $\mathrm{p}_{0}$; e a exergia química é o máximo trabalho que pode ser obtido, ao se levar cada componente até as respectivas composições de referência no ambiente.

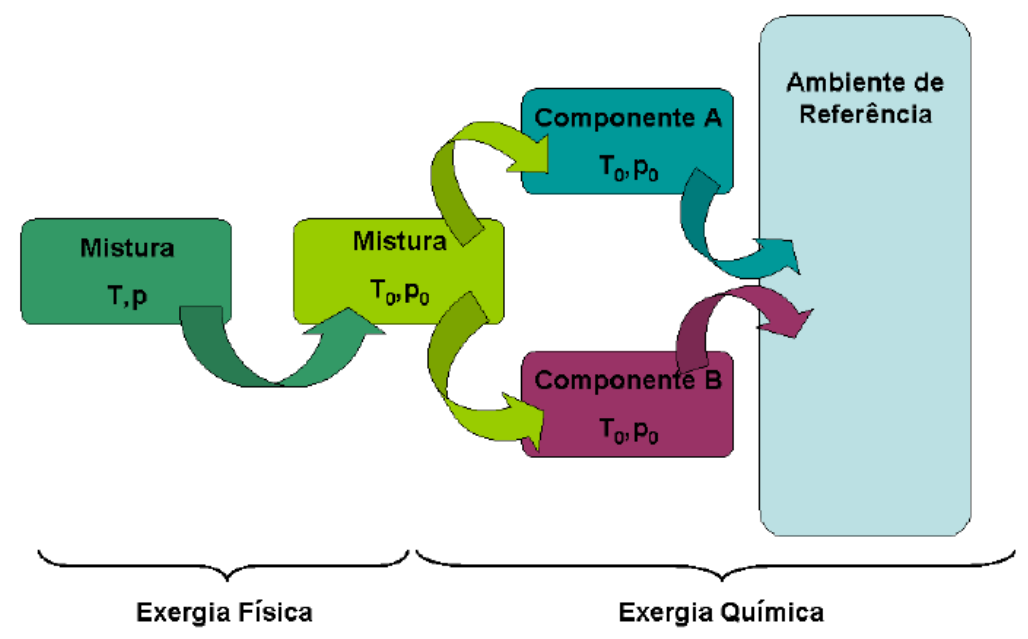

Figura 2.3: Representação das exergias físicas e químicas para uma mistura de dois componentes. Obtido em Pellegrini (2009) 
2.1.3.1 Cálculo da exergia química de um gás perfeito presente no ambiente de referência

A exergia química de um gás perfeito presente no ambiente de referência, é calculada pelo trabalho isotérmico de expansão que pode ser executado por uma turbina que troca calor com o ambiente a $T_{0}$ e leva o gás de $p_{0}$ até sua pressão parcial no ambiente de referência $p_{00}$.

A Equação 2.7 obtida em Kotas (1985), Szargut, Morris e Steward (1988) e Oliveira (2013) indica a expressão do trabalho da turbina.

$$
w_{\text {rev }}=b_{q}=R T_{0} \ln \left(\frac{p_{0}}{p_{00}}\right)
$$

\subsubsection{Cálculo da exergia química para outras substâncias}

Para calcular a exergia química de uma substância pura que não está presente no ambiente de referência, por exemplo, um hidrocarboneto, pode-se usar o método indicado na Figura 2.4, apontado por Kotas (1985), Szargut, Morris e Steward (1988) e Moran e Shapiro (2009).

Na Figura 2.4 está representada uma reação química reversível que ocorre a $T_{0}$ e $p_{0}$, na qual a substância reage com elementos trazidos do ambiente (correagentes) e gera outros elementos que já existem no ambiente (produtos). O segundo processo é uma mudança de concentração dos correagentes (do estado em que estão no ambiente até o estado em que eles se encontram puros a $T_{0}$ e $p_{0}$ ) e dos produtos (de $T_{0}$ e $p_{0}$ até o estado de equilíbrio com o ambiente).

A Equação 2.8 indica a reação de referência, em que o hidrocarboneto reage com o oxigênio para formar gás carbônico e água. Assim, o oxigênio do meio passa por uma membrana de permeabilidade seletiva seguida de uma compressão isotérmica reversível, como indicado na Figura 2.4. Depois da reação de oxidação do hidrocarboneto (Equação 2.8), os produtos (água e dióxido de carbono) sofrerão uma expansão isotérmica reversível e serão devolvidos para o ambiente com as suas respectivas concentrações de equilíbrio com o ambiente.

$$
\mathrm{C}_{a} \mathrm{H}_{b}+\left(a+\frac{b}{4}\right) \mathrm{O}_{2} \rightarrow a \mathrm{CO}_{2}+\frac{b}{2} \mathrm{H}_{2} \mathrm{O}
$$




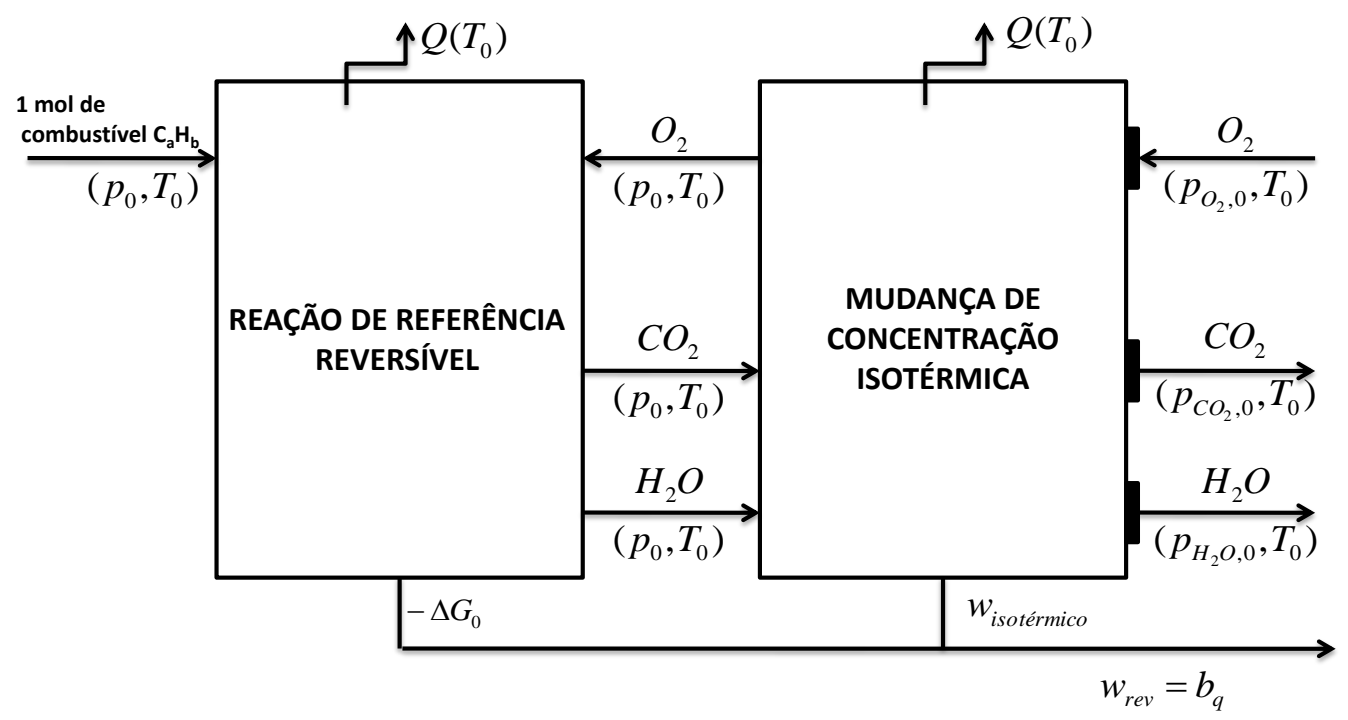

Figura 2.4: Representação do método de cálculo da exergia química padrão de um hidrocarboneto. O método é válido para qualquer substância que não esteja no ambiente de referência. Figura baseada em: Kotas (1985), Szargut, Morris e Steward (1988) e Moran e Shapiro (2009)

Desse modo, a exergia química do hidrocarboneto em questão é obtida pela Equação 2.9.

$$
w_{\text {rev }}=b_{q}=-\left(\Delta g_{0}\right)-\left[\sum x_{i} b_{q, i}\right]_{\text {co-reagentes }}+\left[\sum x_{i} b_{q, i}\right]_{\text {produtos }}
$$

Ou seja, $\Delta g_{0}$ é a variação da função de Gibbs da reação de oxidação do hidrocarboneto (com reagentes e produtos a $T_{0}$ e $P_{0}$ ), $b_{q, i}$ é a exergia química padrão do elemento i no ambiente de referência e $x_{i}$, a fração molar do elemento i na reação de referência

Para algumas substâncias ou misturas mais complexas o cálculo da exergia química não é trivial. Assim, se pode calcular a exergia química como função do poder calorífico inferior (PCI), conforme indica a Equação 2.10. O fator $\beta$ pode ser calculado usando correlações baseadas na composição do combustível, de acordo com Kotas (1985), Szargut, Morris e Steward (1988).

$$
\beta=\frac{b_{q}}{P C I}
$$




\subsubsection{Eficiência Exergética}

Segundo Szargut, Morris e Steward (1988), todos os componentes do balanço de exergia devem ser alocados dentro de três grupos: exergia útil dos produtos, perdas de exergia e exergia de alimentação. Uma das possíveis definições de rendimento de Segunda Lei se dá pela Equação 2.11, a qual será utilizada para todos os estudos de caso deste trabalho.

$$
\eta_{e x}=\frac{\text { Exergia útil dos produtos }}{\text { Exergia de alimentação }}=\frac{\text { Exergia de alimentação }- \text { Perdas de exergia }}{\text { Exergia de alimentação }}
$$

\subsubsection{Indicadores termodinâmicos}

Como explicado em Velásquez (2009), Gong e Wall (2001), vários indicadores têm sido propostos como forma de se avaliar o desempenho ambiental de processos de conversão de energia. Para que um indicador ambiental seja de qualidade, deve conter alguns requisitos: fornecer informação de qualidade ambiental, ser facilmente calculado e interpretado, mostrar uma tendência no tempo, permitir comparações e ser calculado de forma científica eliminando subjetividades.

Geralmente, a exergia é usada como um indicador ambiental, "concorrendo com a energia". No entanto, essa última estabelece que a energia se conserva, sem que exista o consumo de energia, só existe a transformação da energia em outra forma, menos nobre para execução de trabalho. Porém, a ferramenta que indica a qualidade é a análise exergética.

Nota-se que a exergia tem três relações com a poluição ambiental (Dincer (2002) apud Velásquez (2009)).

- Destruição da ordem da natureza, pela geração de entropia;

- Degradação dos recursos naturais;

- Associação das emissões à geração de resíduo que podem ter um potencial dano ambiental por estarem em desequilíbrio com o meio.

Uma análise bem detalhada dos indicadores exergéticos ambientais e seu histórico pode ser vista em Pellegrini (2009), Velásquez (2009) e Oliveira (2013). Não é do escopo deste trabalho tratar sobre esses indicadores ambientais, mas sim, mostrar sua existência para usá-los como base na proposição de um indicador relacionando ao corpo humano. 
Finalmente, para avaliar o processo de produção de bicombustíveis foi proposto por Pellegrini (2009) e Velásquez (2009) o "Índice Exergético de Renovabilidade $(\lambda)$ ”. O índice leva em conta a relação entre exergia dos produtos $\left(B_{P}\right)$, a exergia não renovável utilizada no processo $\left(B_{N R}\right)$, a exergia destruída $\left(B_{d}\right)$, a exergia de desativação $\left(B_{D E}\right)$, e a exergia das emissões ou resíduos não tratados $\left(B_{W}\right)$, como indicado na Equação 2.12 .

$$
\lambda=\frac{\sum_{i}\left(B_{P}\right)_{i}}{\sum_{j}\left(B_{N R}\right)_{j}+\sum_{k}\left(B_{D E}\right)_{k}+\sum_{l}\left(B_{W}\right)_{l}+B_{d}}
$$

A avaliação baseada nesse indicador implica em um processo:

- Ambientalmente desfavorável quando $0<\lambda<1$;

- Internamente e externamente reversíveis, com o uso de insumos não-renováveis $\lambda=$ 1

- Ambientalmente favorável $\lambda>1$;

- Internamente reversíveis, com uso de insumos renováveis, $\lambda \rightarrow \infty$.

\subsection{ANÁLISE TERMODINÂMICA NA ESCALA CELULAR}

Nesta seção será realizada uma análise da respiração celular, ou seja, como as células transformam os substratos energéticos (carboidratos, proteínas e lipídeos) em energia interna, que é armazenada sob a forma de ligações químicas, na molécula de adenosina trifosfato (ATP). Será realizada, ainda, uma revisão da aplicação da Segunda Lei da Termodinâmica em uma célula. Será dado destaque para à aplicação proposta por Luo (2009) que calcula a entropia gerada uma célula cancerígena e saudável.

\subsubsection{Respiração celular}

A análise a seguir refere-se ao processo da respiração aeróbica e fermentação, baseada nos textos elaborados por Villela, Bacila e Tastaldi (1961), Gilbert (2000), Hammes (2000), Sasson (2002), Lehninger, Nelson e Cox (2005), Haynie (2008) e Lems (2009). 
Tomando a glicose como representativa dos carboidratos, a respiração celular está dividida em: glicólise, ciclo de Krebs (ácido cítrico) e cadeia respiratória (respiração mitocondrial).

A oxidação dos carboidratos, lipídeos e proteínas ocorre aos poucos no interior das células do corpo humano, decorrente da contribuição de diversas enzimas, de forma que as energias de ativação das reações sejam reduzidas. Assim, a energia é liberada gradualmente e capturada com certo rendimento pela adição de um grupo inorgânico fosfato $\left(\mathrm{P}_{i}\right.$ ou $\mathrm{HPO}_{4}^{-2}$ ) que reage com a adenosina bifosfato (ADP) e forma a adenosina trifosfato (ATP), como indicado na Equação 2.13. A variação da energia livre de Gibbs nas condições padrões bioquímicas $\left(\Delta g^{\prime}\right)$ equivale a $30,5 \mathrm{~kJ} / \mathrm{mol}$. Nota-se que a reação reversa, ou hidrólise do ATP, é exotérmica (usada para liberar energia na célula). Deve-se destacar que o ATP funciona como uma "moeda energética" dentro das células, ou seja, a energia química dos carboidratos, lipídeos e proteínas é retida na forma de energia química na molécula de ATP. Uma parte dessa energia é eliminada na forma de calor, a outra é usada para geração de trabalho, dentre eles, trabalho mecânico de contração muscular, movimento de células, trabalho osmótico, transporte de íons, dentre outros.

Deve-se ressaltar o uso do sobrescrito ' $O$ no $\Delta g^{\prime}$, que se refere às condição padrão em sistemas bioquímicos, que são: $T_{0}=298,15 \mathrm{~K}, P_{0}=1 \mathrm{~atm}, \mathrm{pH}=7,\left[\mathrm{H}_{2} \mathrm{O}\right]=55,5 \mathrm{~mol} / \mathrm{l} \mathrm{e}$ $\left[\mathrm{Mg}^{2+}\right]=1 \mathrm{mmol} / \mathrm{L}$. Este último é usado para reações que envolvem a presença dos íons magnésio, a exemplo da hidrólise do ATP. Por convenção, quando $\mathrm{H}_{2} \mathrm{O}, \mathrm{H}^{+}$e $\mathrm{Mg}^{2+}$ estão presentes nas reações, eles são omitidos do equacionamento por estarem incorporados na constante de equilíbrio $k_{e q}^{\prime}$ e no $\Delta g^{\prime}{ }^{0}$.

$$
P_{i}+A D P \rightleftharpoons A T P+H_{2} \mathrm{O}
$$

A Figura 2.5 indica a estrutura química do ATP, na qual estão indicados os grupos adenina, ribose e fosfato. Somente o grupo trifosfato está diretamente envolvido na transferência de energia.

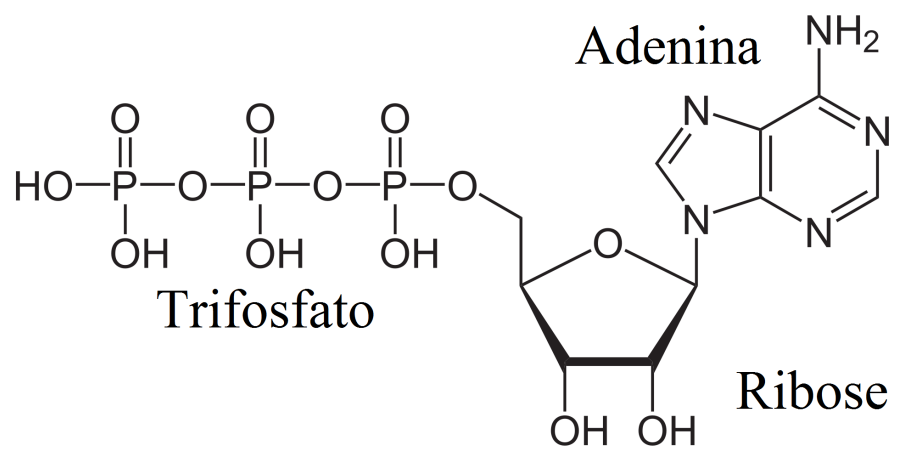

Figura 2.5: Fórmula química do ATP, com o grupo adenina, ribose e trifosfato. Obtido em Lems (2009) 
As reações de oxirreduções consistem em eventos básicos da respiração celular. Assim, cada substância que se oxida é acompanhada de uma outra que se reduz. As reações biológicas, por sua vez, ocorrem em uma das três formas: ganho de oxigênio (R.CHO $+1 / 2 \mathrm{O}_{2} \rightarrow \mathrm{R}$.COOH, em que $\mathrm{R}$ é um radical qualquer), desidrogenação ( $\mathrm{R} . \mathrm{CH}_{2} \mathrm{OH} \rightarrow$ $\mathrm{R} . \mathrm{CHO}+2 \mathrm{H})$ e por perda de elétrons $\left(\mathrm{Fe}^{++} \rightarrow \mathrm{Fe}^{+++}+\mathrm{e}^{-}\right)$.

Um processo de oxidação/redução que ocorre nas diversas etapas do ciclo de respiração é a desidrogenação dos combustíveis orgânicos. Essas moléculas de hidrogênio reagem com as moléculas transportadoras denominadas NAD (nicotinamida adenina dinucleotídeo) e FAD (flavina adenina dinucleotídeo). O NAD (ou $\mathrm{NAD}^{+}$) reage com o hidrogênio do combustível (equação de redução, ou ganho de elétrons) e converte-se em NADH (ou $\mathrm{NADH}+\mathrm{H}^{+}$, ou $\mathrm{NADH}_{2}$ ). Na cadeia respiratória, os hidrogênios do NADH reagem com o oxigênio (reação de oxidação), formam água, ocorrendo a transformação de NADH para NAD. Tais reações de oxirredução podem ser verificadas na Equação 2.14 e 2.15. Desse modo, costuma-se chamar o NAD de aceptor intermediário de hidrogênio, e o oxigênio, de aceptor final. Nota-se que a Equação 2.14 mostra apenas a redução do NAD em $\mathrm{NADH}$, de forma concomitante algum composto deve sofrer oxidação, por isso somente o potencial de redução está indicado na equação, enquanto que para Equação 2.15 o NADH está oxidando e o oxigênio reduzindo, no qual é possível calcular a variação da energia livre de Gibbs a partir do potencial de redução tabelados das duas substâncias.

$$
\begin{array}{ll}
N A D+2 H^{+}+2 e^{-} \rightarrow N A D H & \left(E^{\prime 0}=-0,320 \mathrm{~V}\right) \\
N A D H+1 / 2 \mathrm{O}_{2} \rightarrow \mathrm{NAD}+\mathrm{H}_{2} \mathrm{O} & \left(\Delta g^{\prime 0}=-219,2 \mathrm{~kJ} / \mathrm{mol}\right)
\end{array}
$$

Para a reação de oxirredução 2.15, a variação da energia livre de Gibbs é calculada pela Equação 2.16.

$$
\Delta G^{\prime 0}=-n F \Delta E^{\prime 0}
$$

Nessa Equação, $n$ representa o número de elétrons transferido, $F$, a constante de Faraday $\left(96,5 \mathrm{~kJ} /(\mathrm{V} . \mathrm{mol})\right.$ e $\Delta E^{\prime 0}$, a variação do potencial de redução da reação de oxirredução nas condições padrões bioquímicas. Esses potenciais equivalem a 0.816 e $-0.320 \mathrm{~V}$ para redução do oxigênio e NADH, respectivamente. 


\subsubsection{Metabolismo dos carboidratos}

Tomando a glicose como representativa dessa classe de substâncias, a degradação está dividida em: glicólise, ciclo de Krebs (ciclo do ácido cítrico) e cadeia respiratória (respiração mitocondrial). A degradação da glicose no interior das células do corpo humano pode ser representada pela Equação 2.17.

$$
\mathrm{C}_{6} \mathrm{H}_{12} \mathrm{O}_{6}+6 \mathrm{O}_{2} \rightarrow 6 \mathrm{CO}_{2}+6 \mathrm{H}_{2} \mathrm{O}+32 \mathrm{ATP} \quad\left(\Delta g^{\prime 0}=-1896 k J / \mathrm{mol}\right)
$$

Glicólise: A glicólise é um evento comum à respiração aeróbica e à fermentação. Consiste em uma série de reações, que ocorrem integralmente no hialoplasma, no qual a molécula de glicose é degradada em duas moléculas de ácido pirúvico. Inicialmente, a glicose é ativada para que possa haver posterior quebra pelo gasto de duas moléculas de ATP. Em seguida, são produzidas quatro moléculas de ATP (saldo de dois ATP) e duas moléculas de NADH. Assim, a reação global está indicada pela Equação 2.18 e o resultado geral pode ser visto na Figura 2.6. Portanto, nota-se que o NADH (nicotinamida adenina dinucleotídeo) é um transportador de elétrons e hidrogênio. Tanto a respiração aeróbica quanto a anaeróbica apresentam essa etapa, demonstrado na Equação $2.18\left(\Delta g^{\prime}{ }^{0}=-85 k \mathrm{~J} / \mathrm{mol}\right)$.

$$
\mathrm{C}_{6} \mathrm{H}_{12} \mathrm{O}_{6}+2 \mathrm{NAD}+2\left(\mathrm{ADP}+\mathrm{P}_{i}\right) \rightarrow 2 \mathrm{C}_{3} \mathrm{H}_{4} \mathrm{O}_{3}+2 \mathrm{NADH}+2 \mathrm{ATP}+2 \mathrm{H}_{2} \mathrm{O}
$$

Pode-se dividir a glicólise em dois processos, como indicado na Equação 2.13, multiplicada por dois, e pela Equação 2.19. Os valores de $\Delta g^{\prime 0}$ equivalem a -146 e $61 \mathrm{~kJ} / \mathrm{mol}$, respectivamente.

$$
\mathrm{C}_{6} \mathrm{H}_{12} \mathrm{O}_{6}+2 \mathrm{NAD} \rightarrow 2 \mathrm{C}_{3} \mathrm{H}_{4} \mathrm{O}_{3}+2 \mathrm{NADH}
$$

Após a glicólise, dependendo do tipo de organismo, a respiração celular segue para fermentação (ou metabolismo anaeróbico), ou para o ciclo de Krebs e cadeia respiratória, conforme indicado na Figura 2.6. Nota-se que a molécula será degradada completamente só na respiração, ou seja, processo no qual haverá a maior libração de energia.

Fermentação alcoólica e láctica: na fermentação, o ácido pirúvico produzido na glicólise é transformado em etanol ou ácido láctico. No caso da fermentação láctica (que 


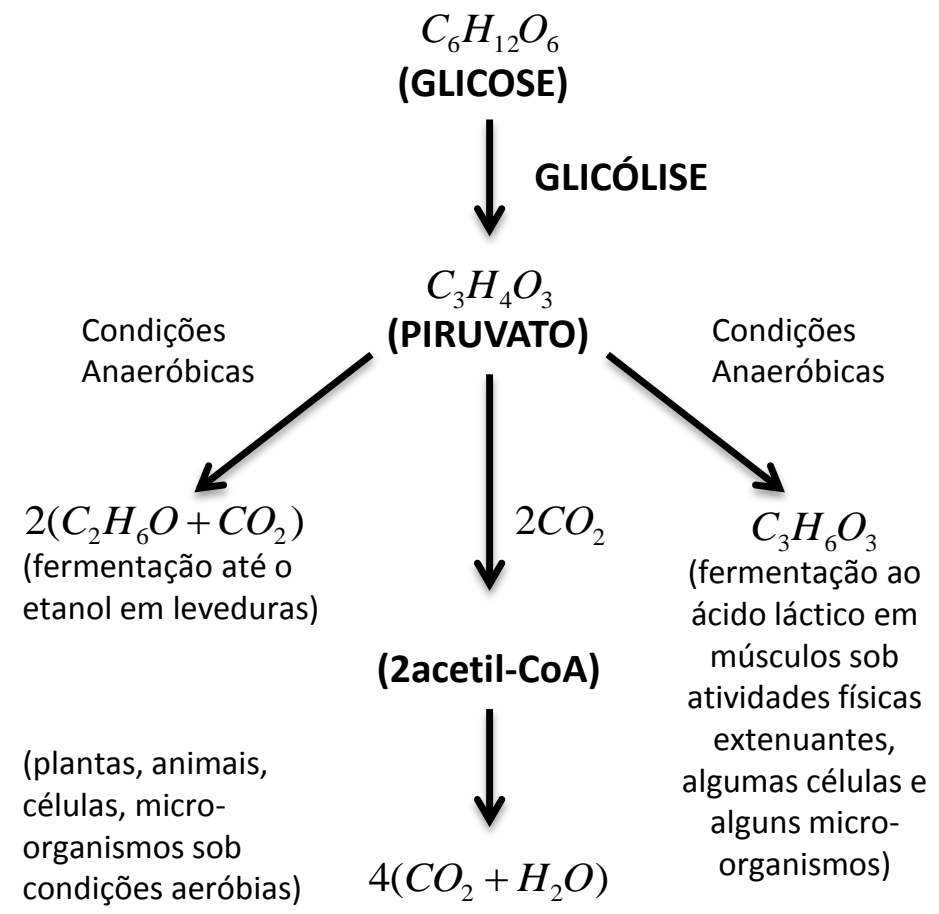

Figura 2.6: Três possíveis caminhos para o catabolismo do ácido pirúvico (piruvato).

Baseado em Lehninger, Nelson e Cox (2005)

ocorre no corpo quando em atividades extenuantes), há a formação de duas moléculas de ácido láctico $\left(\mathrm{C}_{3} \mathrm{H}_{5} \mathrm{O}_{3}\right)$ e duas moléculas de $\mathrm{ATP}$, de acordo com a Equação 2.13. Essa reação pode ser vista na Equação 2.20. Na fermentação alcoólica, o processo é similar, no entanto, há liberação de duas moléculas de gás carbônico, já que o álcool só possui dois carbonos em sua estrutura molecular.

$$
2 \mathrm{C}_{3} \mathrm{H}_{4} \mathrm{O}_{3}+2 \mathrm{NADH} \rightarrow 2 \mathrm{NAD}+2 \mathrm{C}_{3} \mathrm{H}_{5} \mathrm{O}_{3} \quad\left(\Delta g^{\prime 0}=-50,2 \mathrm{~kJ} / \mathrm{mol}\right)
$$

Ciclo de Krebs ou do ácido cítrico: A molécula de ácido pirúvico se descarboxila (perde carbono na forma de $\left.\mathrm{CO}_{2}\right)$ formando uma molécula de radical acetil $\left(\mathrm{C}_{2} \mathrm{H}_{4} \mathrm{O}\right)$. Este reage com uma enzima chamada coenzima A formando acetilcoenzima A, ou acetilCoA, que, ao reagir com a coenzima A, libera elétrons para produção de um NADH. A reação global está indicada na Equação $2.21\left(\Delta g^{\prime 0}=-66,8 \mathrm{~kJ} / \mathrm{mol}\right)$.

$$
2 \mathrm{C}_{3} \mathrm{H}_{4} \mathrm{O}_{3}+2 \mathrm{NAD} \rightarrow 2 \mathrm{NADH}+2 \mathrm{CO}_{2}+2 \text { Acetil }-\mathrm{CoA}
$$

Na mitocôndria, o acetil-CoA combina-se com o ácido oxalacético $\left(\mathrm{C}_{4} \mathrm{H}_{4} \mathrm{O}_{5}\right)$ para formar o 
ácido cítrico, que vai perdendo carbonos, oxigênio e hidrogênio, regenerando dessa forma o ácido oxalacético. Em cada ciclo, há remoção do hidrogênio por três NAD, que ficam reduzidos a três NADH, e por uma substância similar aceptora de hidrogênio, o FAD, reduzida a $\mathrm{FADH}_{2}$. Além disso, se formam duas moléculas de ATP e quatro moléculas de $\mathrm{CO}_{2}$, como demonstrado na Equação $2.22\left(\Delta g^{\prime}=-100,6 \mathrm{~kJ} / \mathrm{mol}\right)$. Logo, ao final do ciclo de Krebs, a molécula de glicose foi completamente oxidada, ou seja, as duas moléculas de ácido pirúvico formaram a gás carbônico, duas moléculas de ATP e seus elétrons capturados pelos aceptores intermediários de hidrogênio, conforme se observa na Equação 2.23 .

2 Acetil- $\mathrm{CoA}+6 \mathrm{H}_{2} \mathrm{O}+6 \mathrm{NAD}+2 \mathrm{FAD}+2\left(\mathrm{ADP}+\mathrm{P}_{i}\right) \rightarrow 6 \mathrm{NADH}+2 \mathrm{FADH} \mathrm{H}_{2}+2 \mathrm{ATP}+4 \mathrm{CO}_{2}$

$2 \mathrm{C}_{3} \mathrm{H}_{4} \mathrm{O}_{3}+6 \mathrm{H}_{2} \mathrm{O}+8 \mathrm{NAD}+2 \mathrm{FAD}+2\left(\mathrm{ADP}+\mathrm{P}_{i}\right) \rightarrow 8 \mathrm{NADH}+2 \mathrm{FADH} \mathrm{H}_{2}+2 \mathrm{ATP}+6 C \mathrm{O}_{2}$

Cadeia respiratória ou cadeia transportadora de elétrons: Na cadeia respiratória, que ocorre nas cristas mitocondriais, o NADH e o $\mathrm{FADH}_{2}$ gerados durante a degradação da glicose são convertidos para sua forma oxidada NAD e FAD. Tal processo está acoplado com a produção ATP e com o bombeamento de prótons $\left(\mathrm{H}^{+}\right)$para o espaço existente entres as membranas interna (matriz mitocondrial) e externa, conhecido como espaço intermembranar. Parte considerável da energia contida no $\mathrm{NADH}$ e $\mathrm{FADH}_{2}$ é usada e conservada no processo de bombeamento. Para cada par de elétrons transferidos para o $\mathrm{O}_{2}, 10$ prótons $\mathrm{H}^{+}$são transferidos para fora da matriz mitocondrial, desbalanço denominado de força próton-motriz (proton-motive force) que tem duas componentes: (i) potencial químico causado pela diferença de concentração das duas espécies; (ii) energia associada ao potencial elétrico causado pela separação de cargas. A Figura 2.7 indica de forma esquemática os processos que ocorrem na cadeia respiratória.

A variação da energia livre de Gibbs nesse processo é determinada pela Equação 2.24.

$$
\Delta g^{\prime 0}=R T_{0} \ln \left(\left[C_{2}\right] /\left[C_{1}\right]\right)+z F \Delta \psi
$$

Sendo, $\left[\mathrm{C}_{2}\right]$ e $\left[\mathrm{C}_{1}\right]$ as concentrações da substância (no caso o próton hidrogênio) em duas 


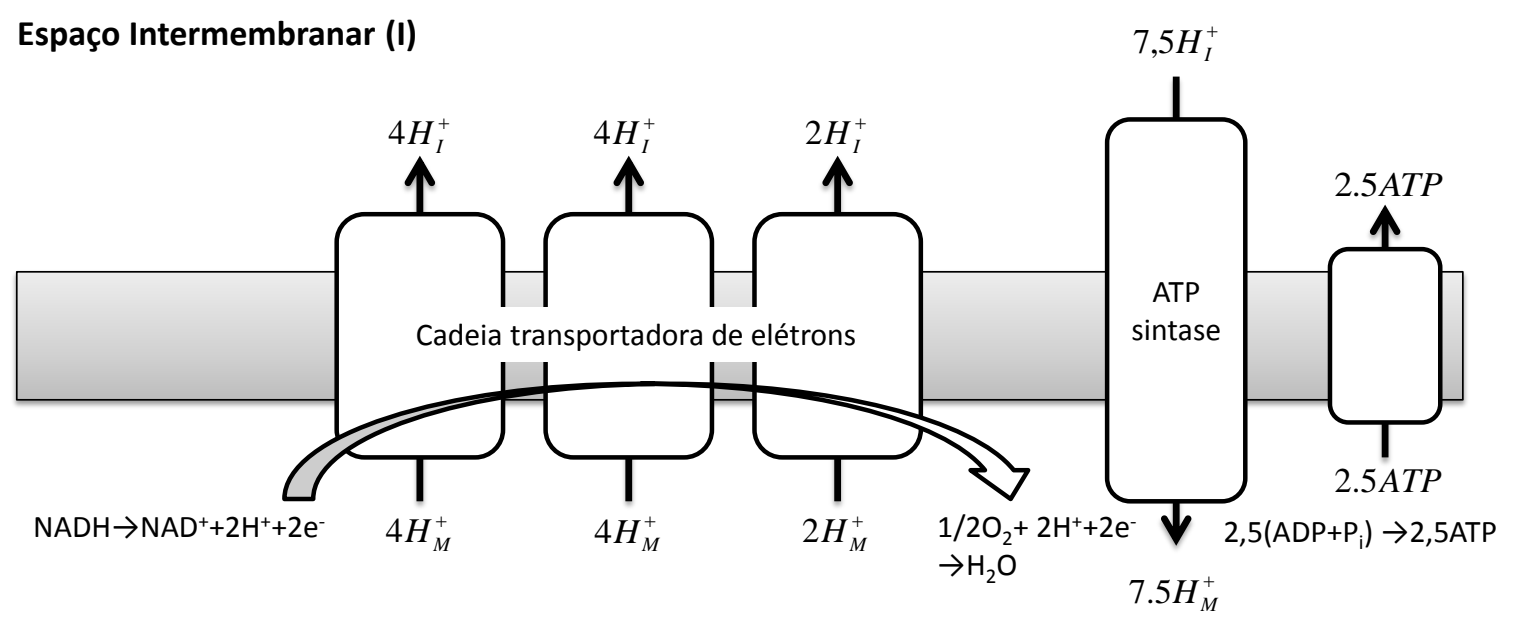

Matriz Mitocondrial (M)

Figura 2.7: Esquema da cadeia transportadora de elétrons que gera a força próton-motriz necessária para produção de ATP. Adaptado de Lems (2009)

regiões, $z$ a carga elétrica (1 para próton, por exemplo) e $\Delta \psi$ a diferença de potencial elétrico.

Assim, se pode dizer que:

$R T_{0} \ln \left(\left[C_{2}\right] /\left[C_{1}\right]\right)=R T_{0}\left[\left(\log \left[H^{+}\right]_{I}-\log \left[H^{+}\right]_{M}\right) \ln (10)\right]=\ln (10) R T_{0}\left(p H_{I}-p H_{M}\right)=$ $\ln (10) R T_{0} \Delta p h$,

sendo que $I$ refere-se ao espaço intermembranar e $M$, a matriz mitocondrial.

Portanto, a Equação 2.24 torna-se igual à Equação 2.25.

$$
\Delta g^{\prime 0}=R T_{0} \ln (10) \Delta p h+z F \Delta \psi
$$

Segundo Lehninger, Nelson e Cox (2005), a diferença de $p h$ entre o espaço inter-membranar e a matriz mitocondrial é aproximadamente 0,75 , e o valor medido de $\Delta \psi$ varia de 0.15 e $0.20 \mathrm{~V}$. Calcula-se que variação da energia livre de Gibbs no bombeamento de cada próton $\left(\left[\mathrm{H}^{+}\right]\right)$equivale a $20 \mathrm{~kJ} / \mathrm{mol}$. Como a cada 2 elétrons transferidos do NADH para o $\mathrm{O}_{2}$ são bombeados 10 prótons, ou seja, dos 220 kJ da oxirredução da Equação 2.15, 200 kJ são convertidos em gradientes de prótons.

Quando esses prótons retornam para a matriz mitocondrial, via enzima ATP sintase ocorre a formação do ATP a partir do ADP $+\mathrm{P}_{i}$. Lehninger, Nelson e Cox (2005) destacam que o valor experimental mais aceito de prótons necessários para a formação do ATP são quatro (no qual um é usado para o transporte de ADP, $\mathrm{P}_{i}$ e ATP para fora ou 
dentro da mitocôndria). Portanto, cada NADH é responsável pela produção de 2,5ATP, e cada $\mathrm{FADH}_{2}$ é responsável pela produção de 1,5ATP (dado que a oxidação do $\mathrm{FADH}_{2}$ é responsável pelo bombeamento de seis prótons para o espaço inter-membranar). Ao todo, são gerados 32 ATP por molécula de glicose. As Equações 2.26 e 2.27 indicam as reações globais de desidrogenação do $\mathrm{NADH}$ e do $\mathrm{FADH}_{2}\left(\Delta g^{\prime}{ }^{0}\right.$ equivalente a $-2192,5$ e $-399,5$ $\mathrm{kJ} / \mathrm{mol}$, respectivamente).

$$
\begin{aligned}
& 10 \mathrm{NADH}+5 \mathrm{O}_{2}+25\left(\mathrm{ADP}+\mathrm{P}_{i}\right) \rightarrow 25 \mathrm{ATP}+10 \mathrm{H}_{2} \mathrm{O}+10 \mathrm{NAD} \\
& 2 \mathrm{FADH}+\mathrm{O}_{2}+3\left(A D P+P_{i}\right) \rightarrow 3 A T P+2 \mathrm{H}_{2} \mathrm{O}+2 \mathrm{FAD}
\end{aligned}
$$

A Tabela 2.1 indica a produção de $\mathrm{NADH}$ e $\mathrm{FADH}_{2}$ durante o processo de quebra da glicose (respiração celular - glicólise e ciclo de Krebbs) e a produção de ATP pela reação de oxirredução do oxigênio com essas duas substâncias.

Tabela 2.1: Produtos formados na quebra de um mol de glicose na oxidação celular

\begin{tabular}{|c|c|c|c|}
\hline Etapa & NADH & FADH $_{2}$ & ATP \\
\hline Glicólise & 2 & 0 & 2 \\
Ciclo de Krebs & 8 & 2 & 2 \\
Cadeia Respiratória & - & - & 28 \\
\hline Total & 10 & 2 & 32 \\
\hline
\end{tabular}

\subsubsection{Metabolismo dos lipídeos}

Em uma etapa que precede a oxidação propriamente dita, os ácidos graxos são convertidos em acetil-CoA. Esta transformação passa por uma série de ciclos que, de forma global, se chama de $\beta$-oxidação (Figura 2.8). Nesta etapa, os ácidos graxos reagem com a coenzima A formando um acil-CoA (ativação que envolve um gasto de duas moléculas de ATP). Estes são oxidados no carbono- $\beta$ (ou terceiro carbono), quebrando a molécula em um ácido de dois carbonos a menos e num resíduo identificado como acetil-CoA. Como exemplo, o ácido palmítico $\left(\mathrm{C}_{16} \mathrm{H}_{32} \mathrm{O}_{2}\right)$ sofre sete sequências sucessivas de oxidação (sobra como "resíduo" uma molécula de acetil-CoA). Portanto, formam-se oito moléculas de acetil-CoA. Para cada molécula de acetil-CoA formada, são retiradas quatro moléculas de hidrogênio do ácido palmítico para formação de um NADH e um $\mathrm{FADH}_{2}$. Finalmente, de forma similar ao que ocorre com a glicose, os produtos vão para o ciclo de Krebs (degradação completa 
da molécula) e, posteriormente, para a cadeia respiratória (geração de ATP, como indicam as Equações 2.26 e 2.27).

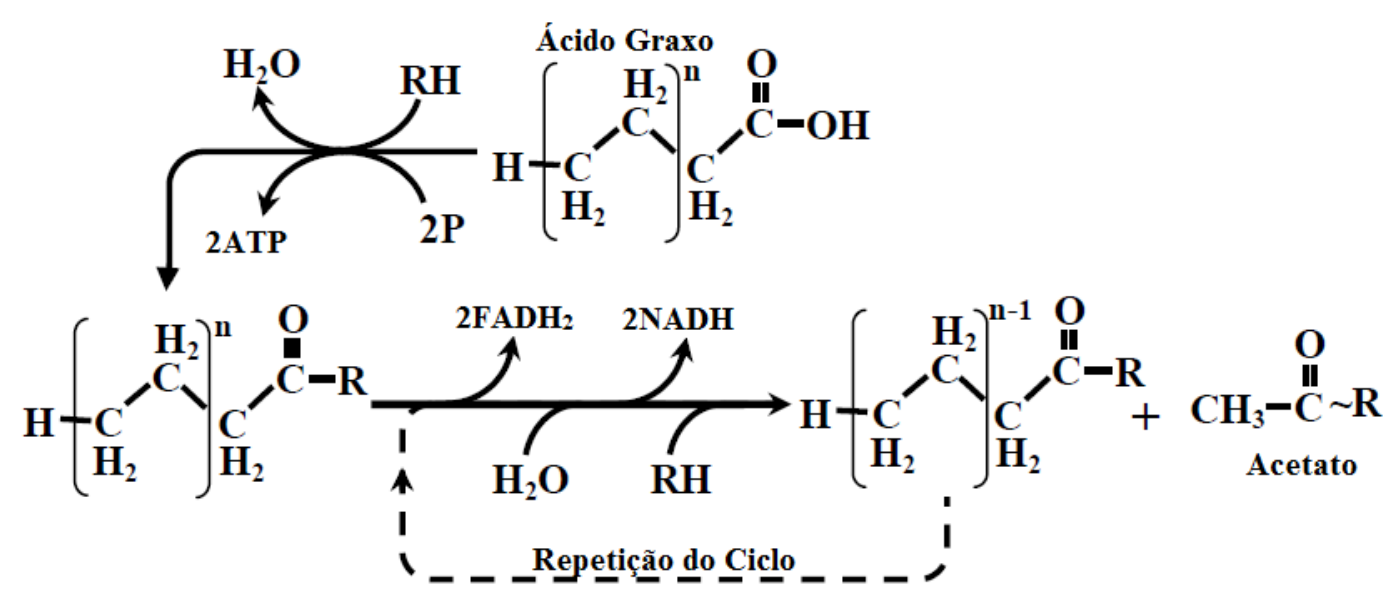

Figura 2.8: Quebra de um ácido graxo saturado com número par de carbonos. São removidos até restar somente o grupo acetil. Adaptado de Lems (2009)

Após a $\beta$-oxidação, o grupo acetil entra no ciclo de Krebs que resulta na formação de três $\mathrm{NADH}$, um $\mathrm{FADH}_{2}$, um ATP e dois $\mathrm{CO}_{2}$. Portanto, a Equação 2.28 indica a reação global até o final do ciclo de Krebs. Nesta é possível notar que já se consideram seis moléculas de ATP, ou seja, o saldo líquido.

$$
\mathrm{C}_{16} \mathrm{H}_{32} \mathrm{O}_{2}+30 \mathrm{H}_{2} \mathrm{O}+6\left(\mathrm{ADP}+\mathrm{P}_{i}\right) \rightarrow 16 \mathrm{CO}_{2}+31 \mathrm{NADH}+15 \mathrm{FADH} \mathrm{H}_{2}+6 \mathrm{ATP}
$$

Na Equação 2.29, observa-se a oxidação dos produtos do ciclo de Krebs na cadeia respiratória.

$$
31 \mathrm{NADH}^{2} 15 \mathrm{FADH}_{2}+23 \mathrm{O}_{2}+106\left(A D P+P_{i}\right) \rightarrow 46 \mathrm{H}_{2} \mathrm{O}+106 \mathrm{ATP}+31 \mathrm{NAD}+15 \mathrm{FAD}
$$

Na Tabela 2.2 constam os produtos e subprodutos formados na oxidação de um mol de ácido palmítico. 
Tabela 2.2: Produtos formados na quebra de um mol de ácido palmítico na oxidação celular, baseado em Gilbert (2000)

\begin{tabular}{|c|c|c|c|}
\hline Etapa & NADH & FADH $_{2}$ & ATP \\
\hline Ativação do ácido em acil-CoA e formação do acetil-CoA & 7 & 7 & -2 \\
Ciclo de Krebs & 24 & 8 & 8 \\
Cadeia Respiratória & - & - & 100 \\
\hline Total & 31 & 15 & 106 \\
\hline
\end{tabular}

\subsubsection{Metabolismo das proteínas}

O metabolismo das proteínas ocorre em três circunstâncias distintas: (i) quando os aminoácidos liberados da quebra de proteínas não são necessários para síntese proteica; (ii) em dieta rica em proteínas (aminoácidos não podem ser armazenados); (iii) durante fome intensa e diabetes, no qual os carboidratos não estão disponíveis, ou não são usados corretamente.

Uma distinção dos aminoácidos com relação aos outros substratos energéticos é a existência do grupo amina. Esses grupos são separados da cadeia carbônica principal ("esqueleto" carbônico), o qual é levado aos processos de degradação dos aminoácidos. Cada aminoácido sofre uma série de reações químicas oxidativas, sendo algumas delas comuns a todos, e outras, específicas.

Silva e Annamalai (2009) seguiram o ciclo metabólico de cada um dos 20 aminoácidos e a porcentagem de ocorrência destes na natureza para obter uma aminoácido médio, cuja energia liberada na oxidação é responsável pela produção de 8 moléculas de ATP.

\subsubsection{Aplicações da Segunda Lei em uma célula}

Nessa seção será realizada uma revisão da aplicação da Segunda Lei da Termodinâmica em uma célula. Será dado destaque para à aplicação proposta por Luo (2009) que calcula a entropia gerada uma célula cancerígena e saudável. Outra aplicação importante referese ao trabalho de Lems (2009) sobre a mudança das propriedades termodinâmicas das condições padrões bioquímicas para as condições reais das células. 
2.2.2.1 Geração de entropia em células saudáveis e com câncer

Conforme afirma Luo (2009), a entropia é uma grandeza física fundamental para análise de um sistema vivo, porque ela sempre aumenta para qualquer sistema real, isolado. Pode-se mostrar que a entropia gerada $\left(\dot{S}_{g e r}\right)$ é composta por cinco termos resultantes dos seguintes processos:

1. Fluxo térmico determinado pela diferença de temperatura $\left(\dot{S}_{\text {ger }}^{(1)}\right)$;

2. Difusão estabelecida pela diferença de potencial químico $\left(\dot{S}_{\text {ger }}^{(2)}\right)$;

3. Gradientes de velocidades acoplados a tensões viscosas $\left(\dot{S}_{\text {ger }}^{(3)}\right)$;

4. Taxa de reação química comandada pelo decréscimo da energia livre de Gibbs $\left(\dot{S}_{g e r}^{(4)}\right)$;

5. Variação da energia interna causada pelo trabalho realizado por uma força externa $\left(\dot{S}_{\text {ger }}^{(5)}\right)$.

A taxa de geração de entropia pode ser escrita pela Equação 2.30, ou seja, a soma de todos os termos.

$$
\begin{aligned}
& \dot{S}_{g e r}=\sum_{i=1}^{5} \dot{S}_{\text {ger }}^{(i)} \\
& \dot{S}_{\text {ger }}^{(1)}=j_{q} \cdot \nabla \frac{1}{T} \\
& \dot{S}_{g e r}^{(2)}=-j_{\gamma} \nabla \frac{\mu_{\gamma}}{T} \\
& \dot{S}_{g e r}^{(3)}=-\frac{1}{T} \sum_{i j} \partial_{i} V_{j} \prod_{j i} \\
& \dot{S}_{g e r}^{(4)}=\frac{1}{T} \sum_{\delta} j_{\delta} A_{\delta} \\
& \dot{S}_{g e r}^{(5)}=\frac{1}{T} \sum_{\gamma} j_{\gamma} F_{\gamma}
\end{aligned}
$$


No qual, $j_{q}$ é o fluxo de calor; $j_{\gamma}$ é o fluxo difusivo na componente $\gamma ; j_{\delta}$ é a reação química de número $\delta$ por unidade de tempo e volume; $A_{\delta}$ é afinidade química da reação $\delta$ ou variação da energia livre de Gibbs $\Delta G^{0} ; \prod_{i j}$ é o tensor das tensões viscosas; $F_{\gamma}$ é a força externa que age no componente $\gamma$.

Segundo Luo (2009), a geração de entropia causada pelas reações químicas (4) é de ordem de grandeza maior que os outros termos (1, 2 e 3). O autor se baseou na constatação de que a célula com câncer tem uma atividade mitocondrial reduzida, portanto, a proteólise, lipólise e glicólise tornam-se a fonte de energia fundamental para a célula com câncer, com consequente perda de músculo e tecido adiposo. Para modelar o problema, o autor estudou somente o consumo de carboidratos (no caso a glicose), não levando em conta o efeito das outras fontes energéticas.

Luo (2009) ainda concluiu que a razão entre a variação da energia livre de Gibbs da oxidação da glicose em uma célula saudável (respiração celular normal) e em uma célula com câncer (somente a glicólise) equivale a 7,67. Em contrapartida, com base em dados experimentais, o autor constatou que o consumo de glicose de uma célula com câncer é aproximadamente 20 vezes maior do que o de uma célula saudável. Esses resultados indicam que a produção de ATP em uma célula com câncer é 15,5 vezes maior do que em uma célula saudável. De acordo com Lehninger, Nelson e Cox (2005) essa razão equivale a 10 e esse aumento na taxa da glicólise ocorre tanto em condições normais como em condições anaeróbicas. Contudo, os autores afirmam que os tecidos cancerígenos geralmente sofrem de hipoxia, ou seja, fornecimento de oxigênio limitado, o que torna a metabolismo anaeróbico mais recorrente.

O balanço de entropia na forma diferencial está indicado na Equação 2.36, e o fluxo de entropia $\left(j_{s}\right)$ pode ser visto na Equação 2.37 (contém três termos: convecção de entropia, condução relacionada com o transporte de calor e condução relacionada com o transporte de massa).

$$
\begin{aligned}
& \frac{\partial(\rho S)}{\partial t}+\nabla j_{s}=\dot{S}_{g e r} \\
& j_{s}=\rho \dot{s} V+j_{q} \nabla \frac{1}{T}-\frac{1}{T} \sum_{\gamma} \mu_{\gamma} j_{\gamma}
\end{aligned}
$$

O autor usa essa modelagem para comparar uma célula com câncer com uma saudável. Para tal, ele faz uma relação com a termodinâmica estatística e expõe que com um fluxo de entropia há sempre um fluxo de informação. Assim, se o fluxo for de uma célula saudável para uma cancerígena, a informação irá da célula saudável para a cancerígena. 
Caso contrário, o fluxo irá da cancerígena para saudável.

Pela Equação 2.37 pode-se determinar o sentido do fluxo de entropia entre a célula doente e a saudável. O primeiro termo dessa equação envolve o fluxo de entropia de uma região de alta densidade para uma de baixa densidade de entropia que acompanha o fluxo convectivo. Em virtude da alta entropia gerada em uma célula com câncer, o fluxo se dá para a célula saudável. O segundo termo refere-se ao sentido do gradiente de temperatura: como a temperatura da célula com câncer é maior do que a temperatura da célula saudável, o fluxo ocorre em direção da célula sã. O transporte de massa ocorre por causa da diferença de concentrações; logo, novamente é em direção à célula saudável. Portanto, o fluxo de entropia (e o fluxo de informação) sempre será na direção da célula saudável.

\subsubsection{Rendimento metabólico}

Para sistemas reagentes que ocorrem naturalmente, observa-se que a energia de Gibbs dos produtos $\left(G_{p}\right)$ é menor que a dos reagentes $\left(G_{r}\right)$. Então, uma redução na energia de Gibbs em uma reação indica que esta acontece naturalmente, enquanto um aumento aponta a necessidade de execução de trabalho ou fornecimento de energia (em sistemas biológicos, formação do ATP). Para uma dada reação $j$, a variação da energia livre de Gibbs equivale à Equação 2.38, onde $\left[C_{i}\right]$ é a concentração dos reagentes e produtos. Nota-se que Silva e Annamalai $(2008,2009)$ consideraram em seu trabalho que o segundo termo (o das concentrações) é muito menor do que o primeiro termo.

$$
\Delta G_{j}=G_{p, j}-G_{r, j}=\Delta G^{\prime 0}(T, P)+R T \ln \left(\frac{\left[C_{p 1}\right]\left[C_{p 2}\right] \ldots}{\left[C_{r 1}\right]\left[C_{r 2}\right] \ldots}\right) \approx \Delta G^{\prime 0}(T, P)
$$

Inicialmente, Silva e Annamalai (2008, 2009) consideraram a reação de oxidação da glicose (representando os carboidratos) como indicado por 2.39, em que $\Delta g_{o x i}^{\prime 0}=-2870 \mathrm{~kJ} / \mathrm{mol}$. Já durante o metabolismo celular, a oxidação da glicose forma 32 moléculas de ATP, conforme indicado na Equação 2.17, em $\Delta g_{m e t}^{\prime 0}=-1896 \mathrm{~kJ} / \mathrm{mol}$. Por fim, o $\Delta g_{A T P}^{\prime 0}=976$ kJ/mol (variação da energia livre de Gibbs da Equação 2.13 multiplicada por 32). O resto da energia é liberada para o corpo na forma de calor.

$$
\mathrm{C}_{6} \mathrm{H}_{12} \mathrm{O}_{6}+6 \mathrm{O}_{2} \rightarrow 6 \mathrm{CO}_{2}+6 \mathrm{H}_{2} \mathrm{O}
$$


A energia química do ATP é usada pelo corpo para trabalho muscular, trabalho osmótico, síntese de novas substâncias, manutenção de gradientes de íons reversos, dentre outros. Assim, Silva e Annamalai (2008, 2009) definem a eficiência metabólica como se mostra na Equação 2.40. Para a Glicose essa eficiência equivale a aproximadamente $34 \%$.

$$
\eta_{M}=\frac{\Delta g_{A T P}^{\prime 0}}{\Delta g_{o x i}^{\prime 0}}
$$

Além disso, é pelo acúmulo de gorduras que o corpo armazena a energia. Um ser humano normal tem entre 6 e $20 \mathrm{~kg}$ de sua massa formada por essa substância. Fazendo os lipídeos serem representados pelo ácido palmítico tem-se a oxidação completa, conforme se verifica na Equação 2.41. Essa classe de substância forma 106 ATP no metabolismo celular. Desse modo, a eficiência metabólica equivale a aproximadamente $32,2 \%$.

$$
\mathrm{C}_{16} \mathrm{H}_{32} \mathrm{O}_{2}+23 \mathrm{O}_{2} \rightarrow 16 \mathrm{CO}_{2}+16 \mathrm{H}_{2} \mathrm{O}
$$

Por outro lado, as proteínas foram representadas pelos autores por um aminoácido de composição e propriedades termodinâmicas médias. Durante o metabolismo, tais moléculas geram em média 8 ATP, o que resulta em uma eficiência de 10,4\%. Nota-se que essa eficiência é $1 / 3$ das outras classes de substâncias, o que demonstra que a energia é obtida pela oxidação dos aminoácidos em pequenas quantidades.

\subsubsection{Analise exergética da quebra da glicose e ácidos-graxos}

Lems (2009) aplicou a análise exergética em uma célula. Foram calculados os valores das exergias dos compostos bioquímicos para uma condição intracelular específica, ou seja, em relação a um ambiente de referência bioquímico. Os resultados obtidos chegam a valores próximos de 60\% de eficiência metabólica (Tabelas 2.3 e 2.4). Lems (2009) ainda sugere algumas iterações dos compostos bioquímicos com a solução intracelular que influenciam no cálculo da exergia química. 
Tabela 2.3: Balanço de exergia do processo de oxidação da glicose. Proposto por Lems (2009)

\begin{tabular}{|c|c|c|c|}
\hline \multicolumn{2}{|c|}{ Exergia de Entrada $(\mathrm{kJ})$} & \multicolumn{2}{c|}{ Exergia de Saída $(\mathrm{kJ})$} \\
\hline 1 Glicose & 2955 & $30 \mathrm{ATP}$ & 1707 \\
$6 \mathrm{O}_{2}$ & 0 & $6 \mathrm{H}_{2} \mathrm{O}$ & 0 \\
$30 \mathrm{P}$ & 0 & $6 \mathrm{CO}_{2}$ & 0 \\
Total & 2955 & Total & 1707 \\
\hline- & - & Destruída & 1248 \\
\hline
\end{tabular}

Tabela 2.4: Balanço de exergia do processo de oxidação do ácido palmítico. Proposto por Lems (2009)

\begin{tabular}{|c|c|c|c|}
\hline \multicolumn{2}{|c|}{ Exergia de Entrada (kJ) } & \multicolumn{2}{|c|}{ Exergia de Saída (kJ) } \\
\hline $1 \mathrm{Ac} \mathrm{Palm.}$ & 9994 & $106 \mathrm{ATP}$ & 6030 \\
$23 \mathrm{O}_{2}$ & 0 & $16 \mathrm{H}_{2} \mathrm{O}$ & 0 \\
$106 \mathrm{P}$ & 0 & $16 \mathrm{CO}_{2}$ & 0 \\
Total & 9994 & Total & 6030 \\
\hline- & - & Destruída & 3964 \\
\hline
\end{tabular}

2.2.2.4 Mudança da referência termodinâmica para estado próximo ao real da célula

Em conformidade com Lems (2009), a exergia nas condições padrões bioquímicas pouco refletem na condição real da célula. Por exemplo, raramente o ambiente intracelular está com coeficientes de atividade unitário e ph neutro. Por essa razão, Lems (2009) adicionou correções para o cálculo da exergia química baseando-se nos seguintes efeitos: diluição de um composto, dissociação ácida ou básica, formação de íons complexos, iterações iônicas e não iônicas e potenciais elétricos. Foram obtidas propriedades de diversas fontes, porém as principais foram: Alberty e Goldberg (1992), Alberty (1998), Lehninger, Nelson e Cox (2005), dentre outros.

O procedimento indicado a seguir indica os passos usados por Lems (2009) para as correções que levam as propriedades termodinâmicas de uma substância qualquer da referência bioquímica para o estado próximo ao real de uma célula.

1 - Cálculo da exergia química dos elementos: Essa análise é realizada de acordo com o método proposto por Szargut, Morris e Steward (1988). Para o caso do ATP, por exemplo, foram analisados os elementos tirados do ambiente de referência para formação do $\mathrm{H}_{4} \mathrm{P}_{3} \mathrm{O}_{9}$ (unidade trifosfato do ATP). Para o grupo adenosina são atribuídos valores nulos para as propriedades de formação nas condições padrões bioquímicas. Essa hipótese é feita por Alberty e Goldberg (1992), pois ainda não foi possível calcular as propriedades dos elementos que formam o ATP, ADP nessas condições padrões, principalmente a adenosina. Segundo os autores, tal atribuição resulta em valores consistentes de propriedades termodinâmicas de substâncias iônicas. 
2 - Cálculo/Obtenção da energia livre de Gibbs de formação para os compostos: No caso, na forma neutra do ATP, por exemplo, obteve-se a energia livre de Gibbs do $\mathrm{H}_{4}$ ATP (forma neutra do ATP). Alguns autores como Alberty (1998), também, fornecem esses valores.

3 - Exergia associada à diluição do composto: Esta leva em conta a concentração do composto no meio intracelular, como indicado na Equação 2.42, na qual, $\left[\mathrm{C}_{0}\right]$ é a concentração de uma espécie $\mathrm{C}$ qualquer, na forma não dissociada. Para o ATP, ADP e $\mathrm{P}_{i}$, Lems (2009) e Hammes (2000) indicam nos seus textos os dados de concentrações nos glóbulos vermelhos (condições próximas ao hialoplasma das células do ser humano) obtidos por Minakami e Yoshikawa (1965).

$$
b_{\text {conc }}=R T_{0} \ln \left[C_{0}\right]
$$

4 - Efeito da dissociação ácida ou básica: Os próximos passos indicam a dissociação ácida, raciocínio que pode ser feito de modo similar para dissociação básica. Portanto, pode-se reescrever a Equação 2.42 tendo por base a Equação 2.43 .

$$
b_{\text {conc }}=R T_{0} \ln [C]-R T_{0} \ln \left(1+\sum_{i=1}^{n} \frac{\left(\prod_{j=1}^{i} k_{j}\right)}{\left[H^{+}\right]^{i}}\right)
$$

Nessa, $[\mathrm{C}]$ refere-se a concentração total da espécie (valor medido experimentalmente que leva em conta a concentração total, independente se a molécula está dissociada ou não), $k_{i}$ é a constante equilíbrio da k-ésima dissociação ácida e $\left[\mathrm{H}^{+}\right]$é a concentração de prótons hidrogênio.

Para se chegar à Equação 2.43 Lems (2009) partiu da Equação 2.44.

$$
C_{0} \stackrel{k_{1}}{\leftrightarrow} C_{1}+H^{+} \stackrel{k_{2}}{\leftrightarrow} C_{2}+2 H^{+} \ldots \stackrel{k_{n}}{\leftrightarrow} C_{n}+n H^{+}
$$

Sendo $\left[\mathrm{C}_{0}\right]$ a concentração da espécie não dissociada, $\left[\mathrm{C}_{1}\right]$ a espécie com 1 hidrogênio dissociado, e assim por diante. As constantes de equilíbrio $k_{1}$ a $k_{n}$ apresentam ordem de grandeza decrescente, indicando que as dissociações são cada vez menos favoráveis.

Assumindo que as espécies estão em equilíbrio com o meio aquoso, o potencial termodinâmico de realização de trabalho (a exergia) é o mesmo para cada nível 
de dissociação. Por consequência, todas as espécies possuem o mesmo potencial termodinâmico de $\left[\mathrm{C}_{0}\right]$; no entanto, a grandeza medida é a concentração total $[\mathrm{C}]$ (com todas as espécies dissociadas). Assim, pode-se obter uma relação entre essas duas grandezas, como indicado pela Equação 2.45, sendo possível por meio dessa relação, a Equação 2.43 resultar na Equação 2.42 .

$$
\frac{[C]}{\left[C_{0}\right]}=1+\sum_{i=1}^{n} \frac{\left(\prod_{j=1}^{i} k_{j}\right)}{\left[H^{+}\right]^{i}}
$$

$5^{o}$ - Efeito da formação de íons complexos: Esse procedimento avalia o efeito da ligação da molécula com algum metal presente no ambiente celular. Por exemplo, no caso do ATP esse efeito é dado pela ligação com o íon Magnésio e pode ser calculado pela Equação 2.46, no qual [M] é a concentração do metal.

$$
b_{\text {ions }}=R T_{0} \ln \left(1+\sum_{i=1}^{p}\left(\prod_{j=1}^{i} k_{j}\right)[M]^{i}\right)
$$

Da mesma forma que na dissociação ácida, o autor parte das reações com os íons, como indicado na Equação 2.47.

$$
C \stackrel{k_{1}}{\leftrightarrow} M C-M \stackrel{k_{2}}{\leftrightarrow} M_{2} C-2 M \ldots \stackrel{k_{n}}{\leftrightarrow} M_{p} C-p M
$$

6- Efeito da interação iônica: O autor considerou o método proposto em Szargut, Morris e Steward (1988), no qual foi usada a Equação 2.48 para cálculo da força iônica (I) e a Equação 2.49 (de Debye-Hückel) para o coeficiente de atividade $\left(\gamma_{i}\right)$.

$$
\begin{aligned}
& I=\frac{1}{2} \sum_{i} n_{i} z_{i}^{2} \\
& -\log \gamma_{i}=\frac{A z_{i}^{2} \sqrt{I}}{1+d_{i} B \sqrt{I}}
\end{aligned}
$$

No qual, $n_{i}$ é o número de mols do íon por kg de solvente, $z_{i}$ é o número de cargas elétricas 
elementares do íon, $\gamma_{i}$ é o coeficiente de atividade, $d_{i}$ é o diâmetro do íon e $A$ e $B$ são constantes que dependem do solvente no qual o íon está dissolvido.

A partir do momento em que se considera esse efeito, a solução não se comporta mais como ideal, não podendo, pois, as constantes de equilíbrio serem usadas como ideais, mas sim, deve-se usar uma constante de equilíbrio equivalente. Tabelas que consideram a interação iônica são fornecidas por Alberty (1998). O cálculo da constante de equilíbrio equivalente é realizado de acordo com a Equação 2.50, sendo os expoentes $\nu_{i}$ os coeficientes estequiométricos das reações.

$$
k^{e q}=\prod_{i}\left(\left[C_{i}\right]^{\nu_{i}} \gamma^{\nu_{i}}\right)=k \gamma_{i}^{\nu_{i}}
$$

Para ilustrar o procedimento de cálculo da exergia química, Lems (2009) analisou a molécula de ATP (Figura 2.5) e a variação da exergia na hidrólise dessa substância (Equação 2.13). Para tal, o autor considerou que o ATP se encontra em diferentes formas químicas (dissociado e ligado ao íon magnésio). A temperatura e pressão do ambiente foram consideradas as de referência $\left(P_{0}, T_{0}\right)$, ou seja, a exergia física foi negligenciada em comparação com a exergia química. Outra aproximação feita foi que o autor se concentrou no cálculo da exergia somente da cadeia inorgânica trifosfato, pelas dificuldades de se encontrar propriedades termodinâmicas da adenosina (por convenção a energia livre de Gibbs de formação para esse composto é zero). Este composto é o responsável pela transferência de energia dentro das células. A exergia química do ATP equivale a 299 $\mathrm{kJ} / \mathrm{mol}$ e a variação da exergia da formação do ATP equivale a $57 \mathrm{~kJ} / \mathrm{mol}$ (quase o dobro do valor nas condições padrões bioquímicas).

Finalmente, a Tabela 2.5 indica os valores obtidos pelo autor para exergias químicas do ATP, ADP e $\mathrm{P}_{i}$, com respectivos efeitos do meio intracelular. Nota-se que, para se chegar ao $\Delta B$ de $57 \mathrm{~kJ} / \mathrm{mol}$, deve-se atentar a exergia da água. Uma curiosidade dessa tabela é que a dissociação ácida, a ligação do íon magnésio e as iterações iônicas se anulam na hidrólise e formação do ATP.

\subsection{ANALISE TERMODINÂMICA NA ESCALA DE SISTEMAS E ÓRGÃOS}

Nesta seção serão analisados alguns dos modelos termodinâmicos de órgãos do corpo humano existentes na literatura, assim como análises via Segunda Lei da Termodinâmica de órgãos e sistemas. 


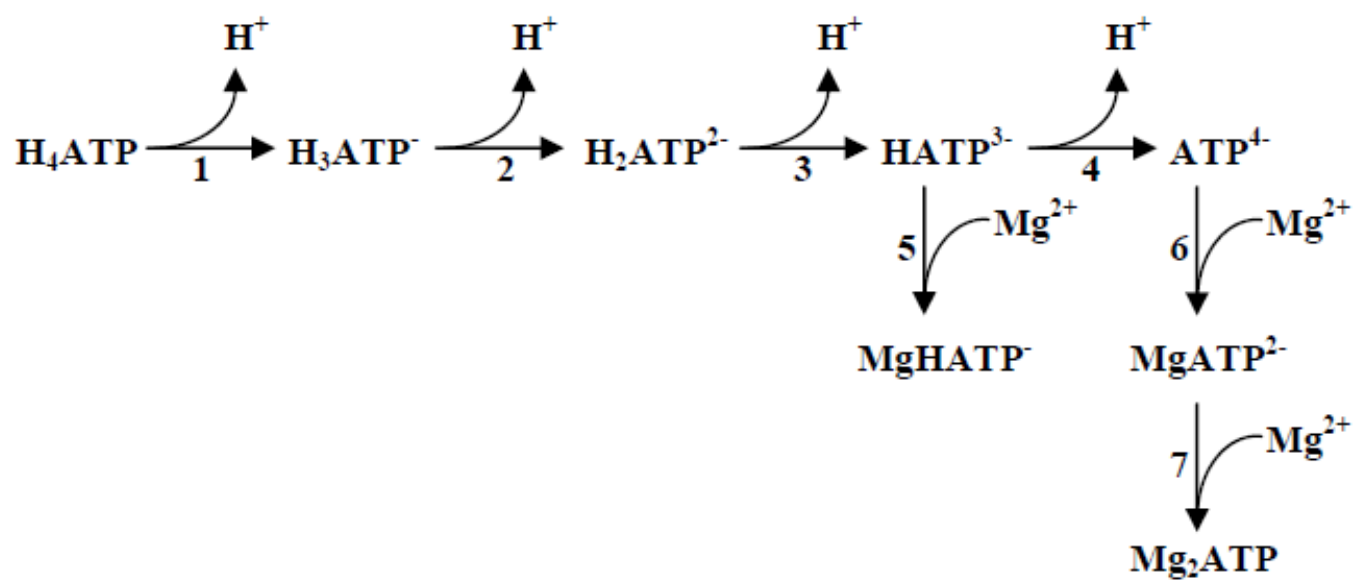

Figura 2.9: Diferentes formas do ATP consideradas por Lems (2009) nos cálculos exergéticos. O composto $\mathrm{H}_{4}$ ATP é a forma neutra. As outras possuem prótons dissociados e ligações com íons magnésio. Os números foram usados para facilitar a exposição das reações

Tabela 2.5: Exergia do ATP, ADP e $\mathrm{P}_{i}$ e respectivos efeitos do meio intracelular nos valores de exergia química, obtidos por Lems (2009)

\begin{tabular}{|c|c|c|c|c|}
\hline Efeito na exergia $(\mathrm{kJ} / \mathrm{mol})$ & $b_{A T P}$ & $b_{A D P}$ & $b_{P_{i}}$ & $\Delta b$ \\
\hline Elementos & 3074,3 & 2088,9 & 1223,5 & $-238,1$ \\
Energia de Gibbs de formação & $-2672,1$ & $-1794,5$ & $-1147,6$ & 270 \\
Concentração intracelular & $-15,6$ & -22 & $-17,1$ & 23,5 \\
Dissociação ácida & $-68,9$ & -42 & $-32,5$ & 5,6 \\
Ligação do ion Magnésio & -16 & $-7,9$ & $-0,6$ & $-7,5$ \\
Iterações iônicas & $-2,7$ & $-1,9$ & $-3,2$ & 2,4 \\
\hline Total & 299 & 220,5 & 22,5 & 56 \\
\hline
\end{tabular}




\subsubsection{Sistema Respiratório}

Albuquerque-Neto, Yanagihara e Turri (2008) propuseram um modelo compartimental do sistema respiratório do corpo humano, no qual foram levados em conta o transporte de oxigênio, dióxido de carbono e monóxido de carbono tanto no trato respiratório como no circulatório e nos tecidos do corpo. O objetivo fundamental foi analisar como é feito o transporte de monóxido de carbono para diferentes níveis de atividade física. Mais recentemente, Albulquerque-Neto (2010) integrou esse modelo com uma simplificação daquele proposto por Ferreira e Yanagihara (2009a), ou seja, a análise dos tecidos passou a ser feita via o modelo do sistema térmico do corpo e do pulmão.

\subsubsection{Aplicação da Segunda Lei em órgãos e sistemas}

Albulquerque-Neto et al. (2010) realizaram a análise exergética do corpo humano e do sistema respiratório quando em atividade física. Para tal, propuseram um modelo (Figura 2.10) com sistemas respiratório e térmico integrados. A análise envolveu a taxa de oxigênio fornecida para os pulmões e transportado pelo sangue para os tecidos e a taxa de eliminação de dióxido de carbono. Os resultados indicaram que, sob o ponto de vista da exergia destruída, os tecidos se tornam mais eficientes quando em atividade física, porém os pulmões, menos. Essas análises podem ser comprovadas na Figura 2.11, na qual a destruição de exergia dos tecidos diminui no decorrer da atividade, enquanto que a do pulmão aumenta.

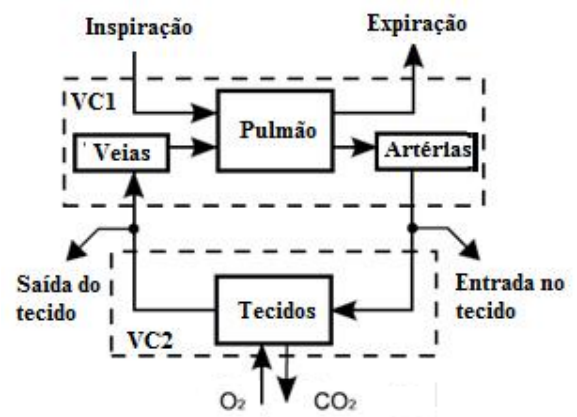

Figura 2.10: Sistema respiratório e térmico dividido em dois volumes de controle.

Obtido por Albulquerque-Neto et al. (2010)

Baseando-se nesse modelo, Henriques (2013) e Henriques et al. (2013) implementaram a análise exergética dos sistemas respiratório e térmico. No volume de controle relativo ao sistema respiratório, foram calculados os fluxos de exergia associados ao ar inspirado, ar expirado, ao sangue venoso que entra no pulmão e ao sangue arterial que sai do pulmão. 


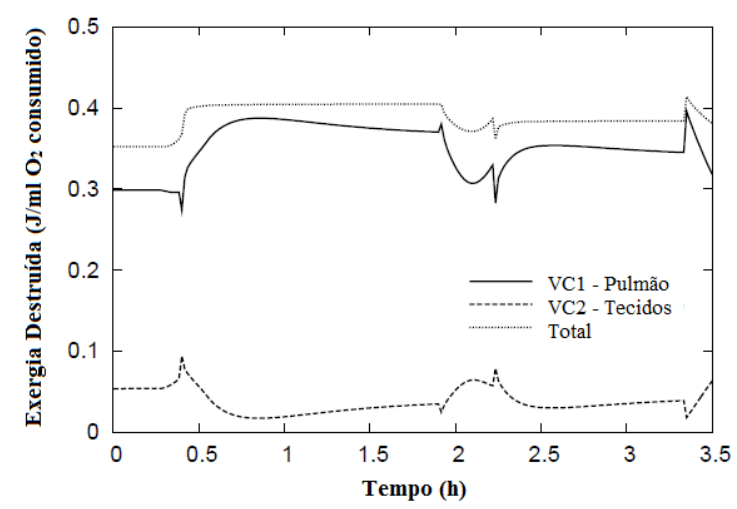

Figura 2.11: Exergia destruída no corpo quando em atividade física. Obtido por Albulquerque-Neto et al. (2010)

A transferência de exergia ocorre por meio do calor gerado pelas reações metabólicas e do trabalho dos músculos respiratórios. Há também uma variação da exergia relativa ao metabolismo exergético do pulmão. Destaca-se, ainda, que o comportamento do pulmão é bem similar ao comportamento de um trocador de massa, no qual o ar exterior é transformado para que o sangue deixe o pulmão rico em oxigênio. A Figura 2.12 indica a evolução do modelo em relação à Figura 2.10, no qual o sistema respiratório não é dividido mais em dois volumes de controle, e a referência passou a ser considerada como o próprio meio.

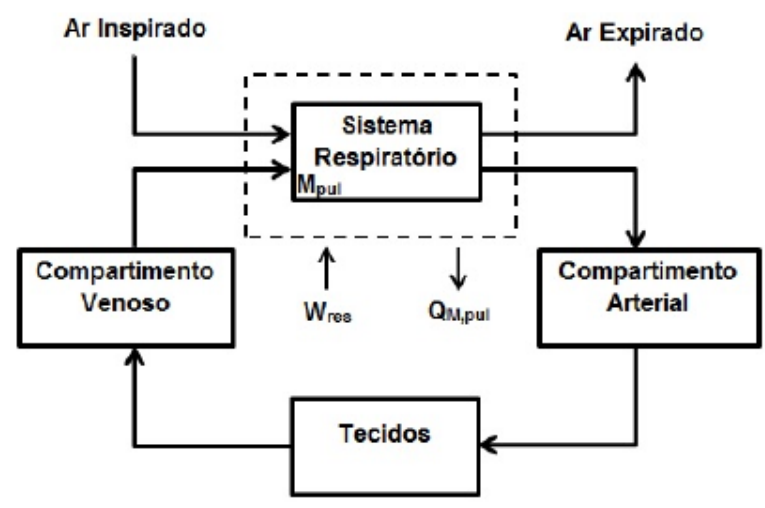

Figura 2.12: Sistema respiratório e térmico em apenas um volume de controle. Obtido em Henriques (2013)

Quanto aos resultados obtidos, calculou-se que a eficiência exergética do pulmão diminui com a altitude e atividade física, enquanto a do corpo aumenta para ambos os parâmetros. Com relação à aclimatação, o período no qual as eficiências exergéticas são máximas é a partir de vinte dias. A Figura 2.13 indica a evolução da eficiência exergética do pulmão e a do corpo em função da altitude para uma pessoa aclimatada a uma altitude de $4500 \mathrm{~m}$ e não aclimatada; tanto para o repouso como para caminhada. O que se observa é que as eficiências de uma pessoa que passou por um período de aclimatação em grandes altitudes é sempre maior (corpo e pulmão). 


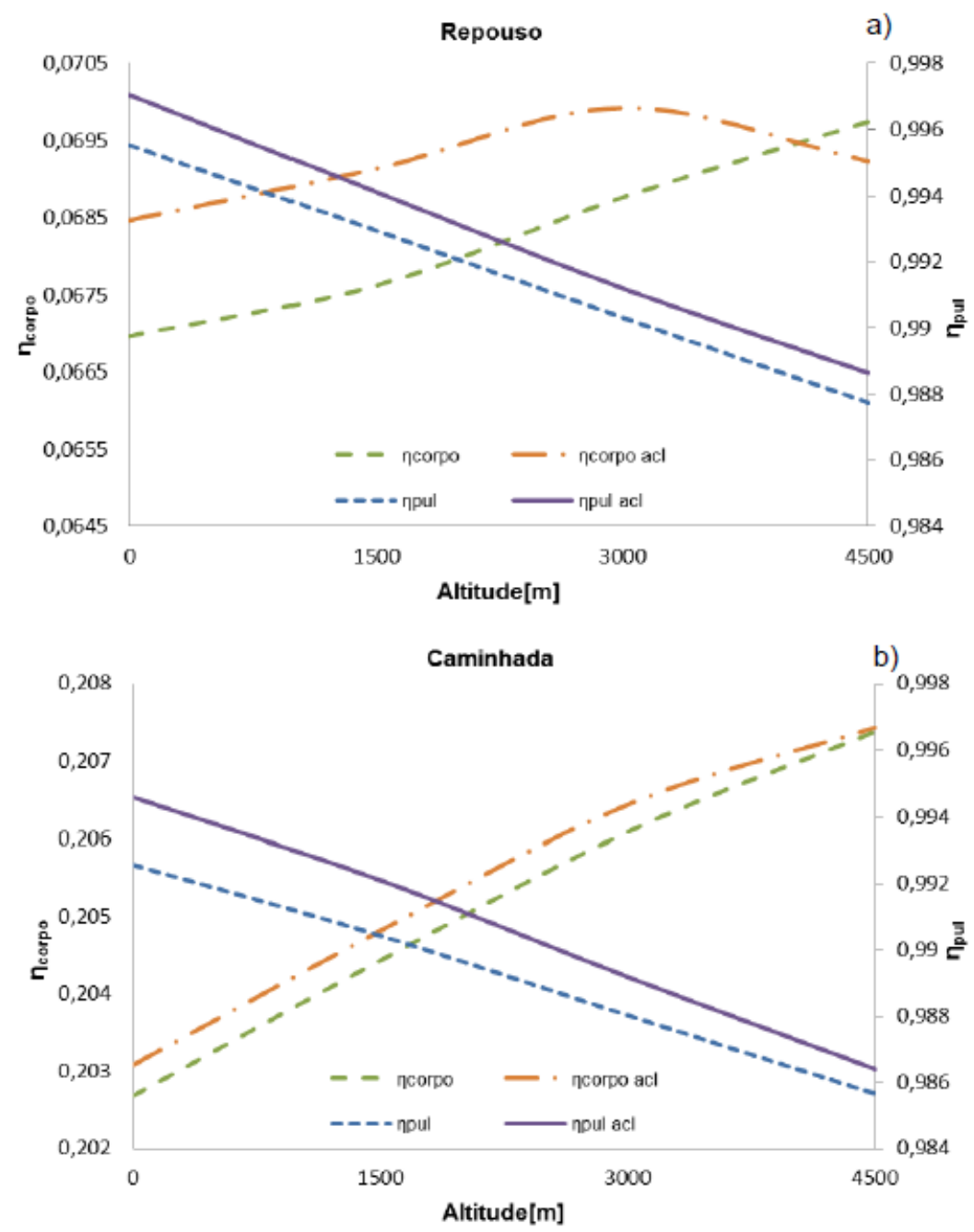

Figura 2.13: Eficiência exergética do corpo e do pulmão para diferentes níveis de altitude e aclimatação. Obtido em Henriques (2013)

Muñoz-Diosdado (2010) propôs uma análise das irreversibilidades do ciclo cardíaco e do rendimento energético do coração. O ciclo adotado pelo autor está indicado na Figura 2.14(a), na qual são considerados os fluxos de entrada (sucção) e saída (bombeamento) nos átrios e ventrículos; e também a circulação para o pulmão e para o resto dos tecidos (sistêmica). A Figura 2.14(b) indica o diagrama $p-v$ simplificado do ciclo cardíaco. O autor concluiu que a eficiência energética do coração varia no decorrer do dia e que ela é menor para uma pessoa com insuficiência cardíaca. Afirma-se que as irreversibilidades são maiores para sistemas fisiológicos saudáveis e estas decrescem com o envelhecimento e aparecimento de doenças. A segunda afirmação pode ser comprovada pelo princípio de Prigogine e Wiame (1946) (princípio de mínima geração de entropia). Já como justificativa para a primeira, Muñoz-Diosdado (2010) explica que os seres vivos possuem fluxos de massa, energia e entropia pela sua fronteira e que em condições saudáveis, o organismo opera em uma faixa distante do equilíbrio (o que aumenta a irreversibilidade) e a diminuição da irreversibilidade do sistema pode ser um indicativo de patologia (afirmação contrariada por trabalhos como o de Luo (2009)). 

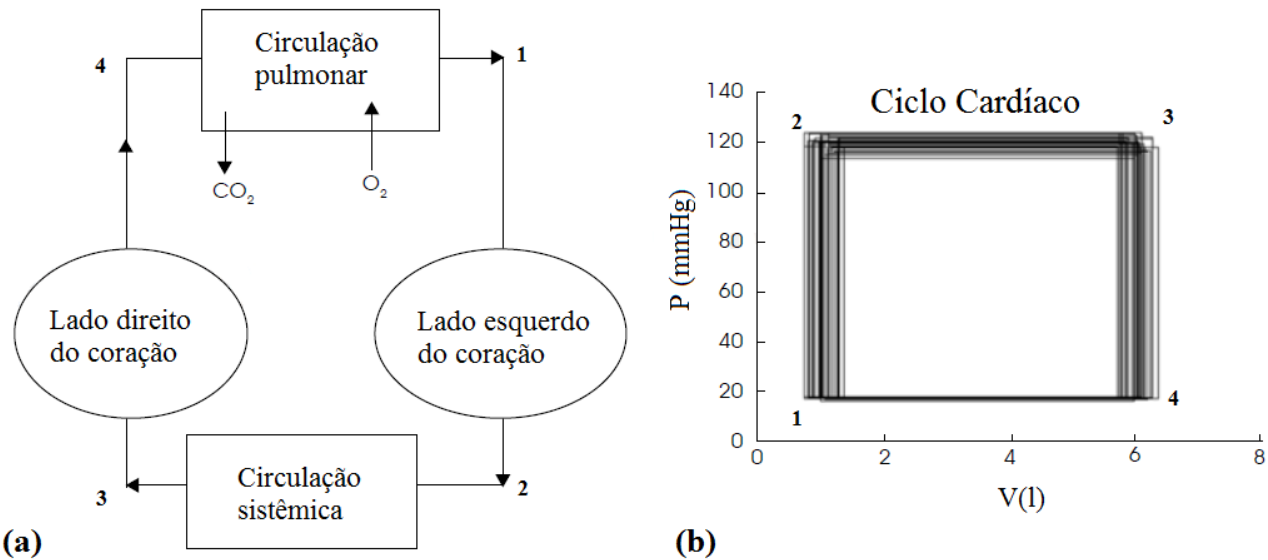

(b)

Figura 2.14: Modelo proposto por Muñoz-Diosdado (2010): (a) ciclo cardíaco; (b) gráfico da pressão em função do volume no ciclo

Finalmente, Annamalai e Silva (2012) expõem que existem inúmeros artigos que tratam o envelhecimento e a busca por uma vida mais longa para sistemas biológicos. As análises vão desde sistemas na escala microscópica até os maiores mamíferos. O autor relata que a maior parte das mortes naturais são causadas por uma ou mais das seguintes causas: reduções cardíaca, renal, hepática, cerebral (mente, visão e audição), pulmonar e imunológica. Baseando-se na teoria de que o metabolismo desenvolvido e a entropia gerada durante toda uma vida são constantes e iguais a $836 \mathrm{MJ} / \mathrm{kg}, 11,1 \mathrm{MJ} /(\mathrm{kgK})$, respectivamente (mamíferos com altas taxas metabólicas teriam uma duração de vida menor do que aqueles com baixas taxas metabólica) os autores calcularam a contribuição dos órgãos que mais levam à morte natural. Para eles o coração é o órgão que mais gera entropia durante a vida, seguido pelos rins, cérebro e fígado.

\subsection{ANALISE TERMODINÂMICA NA ESCALA DO ORGANISMO}

Serão analisados nessa seção experimentos e modelos da literatura referentes ao sistema térmico do corpo humano, assim como será efetuada uma revisão e conceituação da grandeza física conhecida como metabolismo, fundamental para análises de Segunda Lei. Cumpre lembrar que na escala celular, essa foi definida na Seção 2.2. Contudo aqui será demonstrada a sistematização de como se pode medir tal grandeza e seus efeitos para o corpo. Como principais pontos encontrados na literatura, tanto para análise de Primeira como de Segunda Leis, o conforto térmico tem sido a área com maior aplicação, seguido pela tentativa de se comprovar o princípio de mínima geração de entropia. 


\subsubsection{Metabolismo energético}

Segundo a norma ASHRAE (2005), a energia metabólica do corpo humano $(M)$ é a demanda energética requerida para atividades da pessoa $\left(M_{a t i v}\right)$, mais aquela requerida na produção de tremores $M_{\text {tremor }}$ (quando houver). Uma parte dessa energia pode acarretar uma elevação na temperatura do corpo ou se dissipa para o ambiente através da superfície da pele e pelo aparelho respiratório. Portanto, o metabolismo energético é a taxa que indica como os nutrientes são consumidos pelo corpo para produzir energia. Como destacado por Mountcastle (1974), de toda a variedade de ligações químicas encontradas em compostos orgânicos e inorgânicos apenas um tipo é significativo como fonte de energia em animais, a ligação carbono-hidrogênio existente em compostos como carboidratos, lipídeos e aminoácidos.

\subsubsection{Metabolismo e duração da vida}

A alometria é uma linha de estudo da biologia que lida com a variação de caracteres associados à variação no tamanho geral de um organismo. A partir de equações matemáticas na forma $y=a x^{b}$ descreve o processo de crescimento do corpo, área superficial, massa do cérebro, duração da vida, dentre outros. Segundo Speakman (2005), quanto maior for o animal, mais ele vive. Rubner (1908) apud Speakman (2005) concluiu que $1 \mathrm{~kg}$ de célula possui o metabolismo gerado durante uma vida independente do animal na qual essa massa está inserida (836MJ/kg de corpo). Já Speakman (2005) estudou o metabolismo gerado por uma vida por unidade de massa para diferentes espécies de mamíferos e concluiu que essa grandeza não varia significativamente se comparada à variação da massa, de espécie para espécie. Esta última varia ordens de grandeza, sendo a razão máxima do metabolismo equivalente a 5 , se for considerado o ser humano e 1,5, se este não for considerado; enquanto que a razão das massas pode chegar a 50000. Com base em uma análise do expoente da relação entre o metabolismo basal por unidade de massa e duração da vida, Speakman (2005) também concluiu que, dentre as espécies, um grama de tecido gasta aproximadamente a mesma quantidade de energia.

Hershey (2010) afirma que há uma quantidade limitada de energia liberada no metabolismo - "lifetime energy expenditure theory" - a partir da qual não é possível manter a vida (o metabolismo decresce com o envelhecimento). Pacientes com câncer e doenças cardiovasculares apresentam um metabolismo acelerado. Nos fumantes também se verifica um maior metabolismo, se comparados com não fumantes. Um aumento 
de metabolismo pode ser relacionado a uma diminuição no tempo de vida. Se for realizada uma comparação de duas pessoas com idade cronológica igual, a que tiver maior taxa metabólica pode ser considerada com idade fisiológica maior. Silva e Annamalai (2008, 2009) e Hershey (2010) afirmam que a entropia gerada em uma vida pode ser mais adequada para ser utilizada como idade fisiológica, pois quanto mais velho o indivíduo, maior o grau de desordem, ou entropia. Usando-se desse conceito, Hershey (2010) obteve que a idade máxima para homens equivale a 103 anos, enquanto para mulheres, 110 anos. O conceito de entropia e vida será exposto mais adiante neste trabalho.

\subsubsection{Equações para cálculo do metabolismo basal}

Um conceito relevante é o de metabolismo basal, definido como a velocidade de utilização da energia no organismo durante o repouso absoluto, mas estando a pessoa acordada, conforme enunciado em Ferreira (2001). Harris e Benedict (1918) propuseram as Equações 2.51 (para homens) e 2.52 (para mulheres), que hoje levam o nome dos autores, em kcal/dia, acerca do metabolismo basal em função da idade, massa e estatura. Essas duas expressões foram obtidas para massa entre 25 e $125 \mathrm{~kg}$, altura entre 151 e $200 \mathrm{~cm}$ e idade de 21 a 70 anos.

$$
\begin{aligned}
& M_{\text {homem }}(k c a l / \text { dia })=66,5+13,8 m+5,0 h-6,8 a \\
& M_{\text {mulher }}(k c a l / \text { dia })=655,1+9,6 m+1,8 h-4,7 a
\end{aligned}
$$

Nas quais, $m$ é a massa em $\mathrm{kg}, h$ é a altura em $\mathrm{cm}$ e $a$ é a idade em anos.

Para o cálculo do metabolismo de crianças e adolescentes de ambos os sexos, em função da massa, foram utilizadas as Equações 2.53 e 2.54., que são válidas de 0 a 18 anos e foram obtidas em $\mathrm{FAO} / \mathrm{WHO} / \mathrm{UNU}$ (1985).

$$
\begin{aligned}
& M_{\text {homem }}(k c a l / \text { dia })=17,5 m+651 \\
& M_{\text {mulher }}(k c a l / \text { dia })=12,2 m+746
\end{aligned}
$$




\subsubsection{Medição do metabolismo - calorimetria indireta}

Como salienta Diener (1997), as equações de Harris e Benedict (1918), muito utilizadas para obtenção do metabolismo em repouso, apresentam uma precisão de 80 a $90 \%$ para indivíduos normais. Para algumas aplicações, por exemplo, exercício físico e pacientes enfermos, pode ser mais conveniente o uso de técnicas de medição do metabolismo. No último caso, quando os pacientes estão gravemente enfermos, a precisão da Equação pode cair para $50 \%$.

Também os autores Mountcastle (1974), Batato et al. (1990) e Diener (1997) ressaltam que as principais formas para medição do metabolismo são: (i) calorimetria direta, na qual as trocas de calor e massa com o ambiente são medidas diretamente; (ii) calorimetria indireta, na qual as trocas respiratórias do indivíduo (consumo de oxigênio e produção de dióxido de carbono) são determinadas e usadas como base para o cálculo do metabolismo energético; (iii) calorimetria indireta, na qual o balanço entre a ingestão de calorias, por meio dos alimentos e das alterações medidas no depósito energético do organismo do indivíduo (gorduras e proteínas) são seguidas durante semanas. O uso da calorimetria indireta - (ii) - é o mais simples e comum para cálculo do metabolismo, pois para (i) é necessário um aparato com ambiente controlado, semelhante ao usado por Hardy e DuBois (1938) e, em (iii), deve-se ter controle e acompanhamento da ingestão de alimentos do paciente por um período longo de tempo, o que nem sempre é viável.

A calorimetria indireta baseia-se em algumas hipóteses, dentre elas: a entrada e a saída dos gases participantes do metabolismo ocorre somente pelo nariz e pela boca (as perdas pela pele são desconsideradas); nem o oxigênio nem o gás carbônico são armazenados no organismo; não ocorre a produção anaeróbica de energia; os substratos energéticos consistem de proteínas, carboidratos e gorduras (todos com uma dada composição química) e a taxa de excreção de nitrogênio na urina (medida a partir da ureia) representa a taxa de catabolismo proteico.

Antes de uma análise mais detalhada da calorimetria indireta, deve-se definir o quociente respiratório $(Q R)$ que é a razão do volume de dióxido de carbono expirado pelo volume de oxigênio consumido durante um período de tempo (essa razão é equivalente à razão em mols). Segundo a norma ASHRAE (2005), o $Q R$ de uma pessoa em condições basais equivale a 0,83 .

Os autores Mountcastle (1974) e Diener (1997) realizaram uma análise detalhada da calorimetria indireta e do cálculo do metabolismo. Para tal, definiram três classes de substâncias utilizadas no corpo como principal fonte de energia: os carboidratos, os lipídeos e as proteínas. 
Os carboidratos são representados pela fórmula geral $\left(\mathrm{CH}_{2} \mathrm{O}\right)_{n}$. Fazendo a oxidação da glicose como representativa dessa classe de substâncias, chega-se à Equação 2.39. O que se nota é que o quociente respiratório é unitário.

Os lipídeos têm um coeficiente respiratório menor que a unidade. A oxidação indicada pela Equação 2.41 refere-se ao ácido palmítico como usado por Batato et al. (1990), o que resulta em um $Q R$ de 0,696. Mountcastle (1974) usou a tripalmitina, cuja fórmula química é $C_{51} H_{98} O_{6}$ que resulta em um coeficiente respiratório de 0,703. Já Diener (1997) utilizou valores médios de propriedades e, portanto, um quociente de 0,7 (Equação 2.55).

$$
1 \mathrm{~g} \text { lipidio }+2,019 \mathrm{~L} \quad \mathrm{O}_{2} \rightarrow 1,427 \mathrm{~L} \quad \mathrm{CO}_{2}+1,09 \mathrm{~g} \quad \mathrm{H}_{2} \mathrm{O}
$$

No caso das proteínas, é mais difícil calcular o $Q R$ da reação de oxidação no organismo, pois parte do oxigênio e carbono dos aminoácidos constituintes permanecem combinados com o nitrogênio e são excretados como compostos nitrosos na urina e nas fezes. As quantidades de carbono e hidrogênio envolvidas em processos oxidativos no organismo requerem 138,18g de oxigênio para produção de 152,17g de dióxido de carbono, como expõe Mountcastle (1974). Estes, quando convertidos em volume, resultam em quociente de 0,802. Batato et al. (1990) sugeriram para a reação de oxidação um aminoácido até a ureia $\left(\mathrm{CH}_{4} \mathrm{~N}_{2} \mathrm{O}\right)$ como representativo dessa classe de substâncias, demonstrado pela Equação 2.56. De acordo com Diener (1997), cada grama de nitrogênio urinário representa a oxidação de 6,25g de proteínas. Assim, foi sugerida a Equação 2.57 para oxidação das proteínas (apesar de a ureia não estar na equação, os valores de propriedades termodinâmicas apresentados pelo autor são da oxidação da proteína até a ureia).

$$
1 \text { Aminoácido }+5,1 \mathrm{O}_{2} \rightarrow 4,1 \mathrm{CO}_{2}+0,7 \mathrm{CH}_{4} \mathrm{~N}_{2} \mathrm{O}+2,8 \mathrm{H}_{2} \mathrm{O}
$$

$$
1 g \text { proteína }+0,746 \mathrm{~L}_{2} \rightarrow 0,746 \mathrm{~L} \quad \mathrm{CO}_{2}+0,60 \mathrm{~g} \quad \mathrm{H}_{2} \mathrm{O}
$$

Diener (1997) apresenta uma equação para cálculo do metabolismo com base no consumo de oxigênio em volume $\left(\dot{V}_{\mathrm{O}_{2}}\right)$ e produção de gás carbônico em volume $\left(\dot{V}_{\mathrm{CO}_{2}}\right)$ - Equações 2.58 e 2.59 , as quais foram obtidas pela estequiometria das reações de oxidação propostas pelo autor.

$$
\dot{V}_{\mathrm{O}_{2}}=0,746 \dot{m}_{\text {carb }}+2,019 \dot{m}_{\text {lip }}+0.966 \dot{m}_{a m i n}
$$




$$
\dot{V}_{\mathrm{CO}_{2}}=0,746 \dot{m}_{c a r b}+1,427 \dot{m}_{\text {lip }}+0,774 \dot{m}_{\text {amin }}
$$

Isolando-se a massa de glicose, lipídeos e proteínas nas Equações 2.58 e 2.59, chega-se ao sistema de Equações 2.60 a 2.62 para uma dada pressão e temperatura. Esse sistema indica o consumo de glicose, lipídeos e proteína em decorrência das vazões volumétricas de oxigênio consumido, gás carbônico produzido e nitrogênio excretado. Na equação já é feita a substituição em que cada grama de nitrogênio urinário representa a oxidação de $6,25 \mathrm{~g}$ de proteínas.

$$
\begin{array}{r}
\dot{m}_{\text {carb }}=-3,23 \dot{V}_{\mathrm{O}_{2}}+4,57 \dot{V}_{\mathrm{CO}_{2}}-2,6 \dot{m}_{N} \\
\dot{m}_{\text {lip }}=1,69 \dot{V}_{\mathrm{O}_{2}}-1,69 \dot{V}_{\mathrm{CO}_{2}}-2,03 \dot{m}_{N} \\
\dot{m}_{\text {amin }}=6,25 \dot{m}_{N}
\end{array}
$$

Torna-se possível calcular o metabolismo baseado nas taxas de consumo das Equações 2.60 a 2.62 e pelo balanço de energia, como mostra a Equação 2.63.

$$
M=3,91 \dot{V}_{O_{2}}+1,10 \dot{V}_{C O_{2}}-1,93 \dot{m}_{N}
$$

\subsubsection{Análise da capacidade funcional durante atividades físicas}

Deve-se destacar que, segundo Mountcastle (1974), a energia gasta para executar um trabalho muscular durante o exercício físico resulta da oxidação de combustíveis, predominantemente das gorduras e carboidratos. A maior parte dos trabalhos executados pelo homem é em nível moderado, em que a energia necessária é fornecida ao músculo por mecanismos oxidativos. Mesmo em trabalhos extenuantes, porém de curta duração, em que a liberação de energia pode exceder em muito a capacidade do individuo em suprir e utilizar oxigênio, a fonte de todas as energias gastas é a oxidação do combustível. Neste último caso, o trabalho é executado predominantemente com a energia advinda das reações químicas anaeróbicas nos músculos, e a fim de repor a energia do sistema, são efetuadas oxidações adicionais.

A ergoespirometria, ou teste cardiopulmonar, é reconhecida como um dos melhores meios de se avaliar a capacidade funcional física de indivíduos com graus variados de aptidão física. O método se baseia no cálculo da energia liberada pela oxidação dos nutrientes, a 
partir das trocas gasosas pulmonar, especificamente por medidas de consumo de oxigênio e produção de dióxido de carbono, ou calorimetria indireta.

Além disso, como destacado em Fernandes et al. (2012), a identificação do consumo máximo de oxigênio possibilita verificar momentos de transição metabólica que avaliam a relação entre a disponibilidade e a utilização oxigênio. A análise desses parâmetros pode ser utilizada para proposição e classificação de índices funcionais, verificação do efeito de treinamento, gasto energético e prescrição de exercícios. Portanto, segundo os autores, a ergoespirometria é um método dinâmico que leva vantagem sobre muitas técnicas, pois é quantitativa, reprodutível em qualquer ambiente, de fácil manuseio, não invasiva e pode ser repetida diversas vezes no mesmo indivíduo. Pela análise dos gases expirados, é possível compreender melhor os fatores que relacionam a respiração celular e externa durante o exercício físico.

\subsubsection{Indicadores na ergoespirometria}

O máximo consumo de oxigênio, ou $V O_{2, \max }$ é definido por Mountcastle (1974) como a máxima taxa de energia liberada pelo metabolismo para obtenção de trabalho. Ela é alcançada após 2 ou 3 minutos de atividade exaustiva, na qual a necessidade de trabalho ultrapassa a sua capacidade de oxidação de nutrientes. Para obter essa variável em um teste ergoespirométrico, aumenta-se a intensidade de atividade física até o instante em que o consumo de oxigênio não se altera, independentemente da velocidade, representada por $V O_{2, \max }$. A Figura 2.15 indica o procedimento para cálculo dessa variável fisiológica a fim de fazer uma comparação entre corredores com níveis de capacidade funcional distintos.

Durante o exercício em ritmo estável de baixa intensidade, a concentração sanguínea do lactato não aumenta além da variação biológica normal que é observada em repouso. À medida que a intensidade do exercício aumenta os níveis sanguíneos de lactato vão ultrapassando a concentração usual. Em determinado estágio da atividade, a concentração sanguínea dessa substância aumenta exponencialmente. Esse ponto de inflexão é definido como virada do lactato (VL) ou limiar de lactato (LL). Além disso, o limiar de lactato pode ser utilizado como base para elaboração de treinos de aperfeiçoamento do desempenho de corredores de longa distância e triatletas.

O primeiro indicador definido é um dos mais utilizados na análise de resultados da ergoespirometria; já o segundo tem sido aplicado em estudos e mostrado um bom indicador como demonstrado em Fernandes et al. (2012). 


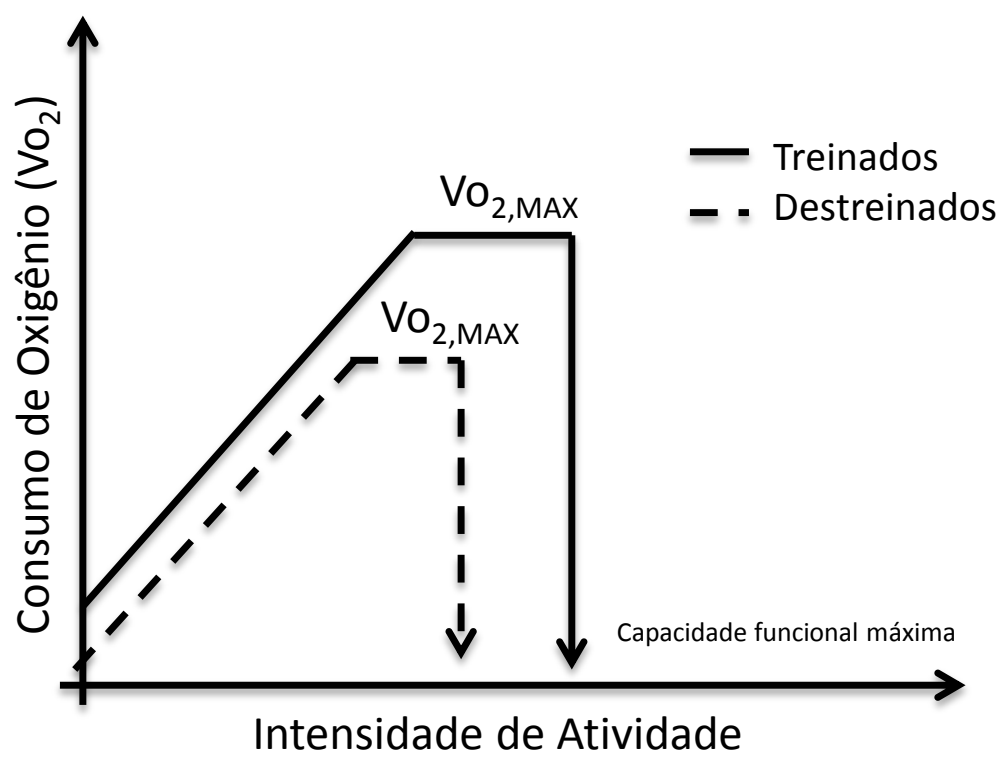

Figura 2.15: Representação do consumo de oxigênio decorrente do nível de atividades, para cálculo do máximo consumo de oxigênio. Baseado em Silva e Santos (2004)

\subsubsection{Experimentos e modelos do sistema térmico do corpo humano}

Os autores Hardy e DuBois (1938), Hardy et al. (1938), Hardy e DuBois (1940), Hardy et al. (1941), DuBois et al. (1952) fizeram um estudo intensivo de como ocorrem as trocas de calor e entalpia no corpo humano. Eles desenvolveram técnicas de medição de troca de calor por radiação e convecção; e verificaram transferência de massa via respiração e evaporação sob várias condições de temperatura; mediram metabolismo basal; calcularam os efeitos de corrente de ar e roupas na troca de calor; estudaram os efeitos de exercícios físicos e calafrios; e ainda observaram diferenças nas trocas de calor do homem e da mulher.

Os autores obtiveram como resultado a Tabela 2.6, para um dos indivíduos estudados, denominado E.F.D.B., com respectivos consumo de $\mathrm{O}_{2}\left(\dot{m}_{O_{2, M}}\right)$, produção de $\mathrm{CO}_{2}\left(\dot{m}_{O_{2, M}}\right)$ e produção de $\mathrm{H}_{2} \mathrm{O}\left(\dot{m}_{H_{2} O, M}\right)$. O metabolismo energético $(M)$ equivale a $79,7 \mathrm{~W}$, calculado a partir desta tabela.

Tabela 2.6: Consumo de ar obtido por Hardy e DuBois (1938)

\begin{tabular}{|c|c|c|}
\hline- & Massa produzida/consumida $(\mathrm{g} / \mathrm{h})$ & Base molar $(\mathrm{gmol} / \mathrm{s})$ \\
\hline$\dot{m}_{C O_{2, M}}$ & 23,16 & $1,4610^{-4}$ \\
$\dot{m}_{O_{2, M}}$ & 20,67 & $1,7910^{-4}$ \\
$\dot{m}_{\mathrm{H}_{2} O, M}$ & 35,42 & $5,4710^{-4}$ \\
\hline
\end{tabular}

As trocas de calor e entalpia pela superfície do corpo por causa da radiação, da vaporização e da convecção estão indicadas na Tabela 2.7. Para a radiação térmica foi descontada a energia transferida pelo meio decorrente desse fenômeno. Assim, a perda de calor total 
equivale a $89,9 \mathrm{~W}$. Para todos os valores das Tabelas 2.6 e 2.7 , a temperatura do calorímetro (do ambiente) foi de $27,4^{\circ} \mathrm{C}$.

Tabela 2.7: Fluxos entálpicos e trocas de calor pela pele obtidos por Hardy e DuBois

(1938)

\begin{tabular}{|c|c|c|}
\hline & $(\mathrm{W})$ & \% do total \\
\hline Radiação & 53,1 & 59 \\
Convecção & 12,8 & 14 \\
Vaporização & 24 & 27 \\
\hline
\end{tabular}

Mais recentemente surgiram modelos para as trocas térmicas e distribuição da temperatura do corpo (sistema passivo do corpo) compostos por um único cilindro representando o corpo humano, como os apresentados por Fanger (1967), Gagge, Stolwijk e Nishi (1972), Wyndham (1965), Ferreira (1997). Já Wissler (1961), Gordon, Roemer e Horvath (1976) propuseram modelos mais complexos que são formados por várias esferas e cilindros que representam o corpo humano. Ferreira (2001), Ferreira e Yanagihara (2001) e Ferreira e Yanagihara (2009a) sugeriram um modelo que trata o corpo humano como diversas elipses excêntricas, representando cada parte do corpo humanoe afirmaram que as elipses resultam em dimensões mais realistas do que nos outros casos.

Para a condição de neutralidade térmica, ou seja, temperatura ambiente entre 29 e $31^{\circ} \mathrm{C}$, Ferreira (2001) obteve os resultados da Tabela 2.8 para as trocas de calor causadas pela radiação e convecção, e os fluxos de entalpia decorrentes da evaporação pela pele e respiração. O metabolismo adotado pelo autor foi de $79,1 \mathrm{~W}$, para o qual a condição de neutralidade térmica é de $30^{\circ} \mathrm{C}$.

Tabela 2.8: Fluxos de entalpia e trocas de calor pela pele obtidos por Ferreira (2001)

\begin{tabular}{|c|c|c|}
\hline Modo de troca de calor/massa & $(\mathrm{W})$ & \% do total \\
\hline Radiação & 29,7 & 37,5 \\
Convecção & 23,7 & 30,0 \\
Evaporação & 19,9 & 25,2 \\
Respiração & 5,8 & 7,3 \\
\hline
\end{tabular}

\subsubsection{Hipotermia}

Como mencionado anteriormente, o ser humano é um animal homeotermo, ou seja, apresenta uma temperatura corpórea dentro de uma faixa bem restrita. Dessa forma, o corpo pode ser entendido como uma máquina térmica cujo funcionamento ótimo se dá a uma temperatura interna entre 36 e $37^{\circ} \mathrm{C}$. Um aumento da temperatura interna pode levar à desnaturação de proteínas, e uma diminuição de temperatura pode levar a um redução 
na atividade enzimática. Macroscopicamente, esses efeitos são vistos pela hipotermia e hipertermia.

O centro controlador da temperatura corporea é o hipotálamo que recebe a informação dos diversos receptores espalhados pelo corpo. Segundo Tsuei e Kearney (2004) e Ferreira (2001) esses receptores (que, sob o ponto de vista da engenharia, são medidores de sinal) estão situados em diversas partes do corpo e são sensíveis à variação de temperatura do núcleo, da pele e do cérebro. Esses diversos receptores estão situados nos grandes vasos (por exemplo, artéria carótida), na pele, nas regiões centrais do cérebro, no hipotálamo pré-óptico e no hipotálamo posterior. Segundo os autores, os mecanismos de termorregulação, ou seja, de controle do corpo, estão ligados à geração de tremores, sudorese, regulação de vazão de sangue para a pele, dentre outros.

Para Peng e Bongard (1999) hipotermia é uma condição comum e bem conhecida em pacientes sob trauma, e pode ser definida como a temperatura interna corpórea menor ou igual a $35^{\circ} \mathrm{C}$. Nota-se que, para temperaturas inferiores a $28^{\circ} \mathrm{C}$, a hipotermia vem associada a riscos de fibrilação cardíaca, ou seja, ocorre um movimento irregular dos átrios cujas fibras musculares agem de forma independente, não viabilizando a contração muscular. Sua classificação é tradicionalmente feita de acordo com distúrbios observados na condução cardíaca. Existem duas formas tradicionalmente tratadas na literatura para que ocorra a hipotermia: quando acontece um acidente, ou seja, em virtude de um trauma e quando é estudada para aplicações terapêuticas.

Peng e Bongard (1999) afirmam que não existe uma única causa para hipotermia em pacientes sob trauma. Do momento da lesão até a chegada à emergência, ou até a chegada à sala de operação, vários fatores contribuem para hipotermia. A lesão por si só já altera a termorregulação do corpo bloqueando os calafrios, estes que ocorrem somente sob temperaturas ainda menores do que a normal. Em choque hipovolêmico, por exemplo, a oxigenação dos tecidos cai, o corpo tende a preferenciar o coração e o cérebro, como destacado por Magno (2010).

Quando a hipotermia é induzida, pode ser classificada, de acordo com Peng e Bongard (1999), Tsuei e Kearney (2004):

- Hipotermia leve: temperaturas do núcleo entre $35-32^{\circ} \mathrm{C}$.

- Hipotermia moderada: temperaturas do núcleo entre $32-28^{\circ} \mathrm{C}$.

- Hipotermia severa: temperatura do núcleo entre $28-20^{\circ} \mathrm{C}$.

- Hipotermia profunda: temperaturas do núcleo entre $20-14^{\circ} \mathrm{C}$.

- Hipotermia grave: temperaturas do núcleo do inferior a $14^{\circ} \mathrm{C}$. 
A taxa de mortalidade de pacientes sujeitos a trauma é muito maior do que em pacientes expostos ao frio como terapia, como foi destacado por Peng e Bongard (1999), Tsuei e Kearney (2004). Estudos em ratos indicam que tremores se iniciam em temperaturas inferiores, quando os ratos foram submetidos a algum tipo de trauma, ou seja, a algum tipo de ferimento grave causado por acidente. Enquanto que a taxa de mortalidade em pacientes sujeitos à temperatura do núcleo inferior a $32^{\circ} \mathrm{C}$ foi de quase $100 \%$, valor que cai para $21 \%$ para um grupo de controle que usaram a hipotermia como terapia. Portanto, devido o prognóstico da vítima de trauma ser tão fraco, deve-se ter uma outra classificação que não a tradicional. A hipotermia, pois, pode ser classificada da seguinte forma, quando em pacientes sob trauma:

- Hipotermia leve: temperaturas do núcleo entre $34-36^{\circ} \mathrm{C}$.

- Hipotermia moderada: temperaturas do núcleo entre $32-34^{\circ} \mathrm{C}$.

- Hipotermia severa: temperaturas do núcleo do inferior a $32^{\circ} \mathrm{C}$.

Diller e Zhu (2009) afirmam que a isquemia cerebral é o resultado de derrame, de desordens cardiovasculares ou respiratórias e de um trauma físico externo. Se o trauma inicial for limitado, o cérebro pode se recuperar, no entanto, se for extensivo danos secundários podem ocorrer, incluindo hipertensão intracraniana, hemorragia, hipoxia e edema. Segundo Dine e Abella (2009), o mecanismo protetor exato da hipotermia ainda não é muito bem descrito e conhecido; provavelmente, múltiplos mecanismos estão envolvidos. Por outro lado, sabe-se que o mecanismo está associado à redução de neurônios perdidos tanto imediatamente após como algum tempo depois da isquemia. Por exemplo, Diller e Zhu (2009) explicaram que a hipotermia tem efeitos neuroprotetores, dentre eles destacam que o consumo de oxigênio cerebral pode reduzir de 5 a $7 \%$ para cada grau Celsius de diminuição na temperatura do núcleo. Destaca-se ainda que essa mesma taxa de reducão $\left(\% /{ }^{\circ} \mathrm{C}\right)$ ocorre para o restante do corpo.

Diller e Zhu (2009) fizeram uma revisão da hipotermia e seus efeitos protetores para o cérebro, após uma parada cardíaca. Já é bem documentado que a inconsciência ocorre depois 15s de oclusão (bloqueio da passagem de sangue) da artéria cerebral e que o tecido do cérebro não pode se recuperar depois de $5 \mathrm{~min}$ fora da temperatura normal. Hipotermia induzida vem sendo estudada como forma de se proteger o cérebro da isquemia desde a década de 40.

A hipotermia cerebral foi introduzida em uma parada cardíaca pela primeira vez na década de 1950. Entre as décadas de 1950 e 1960 estudos mostraram os benefícios da hipotermia para tolerância no tempo do cérebro em paradas cardíacas. O uso desse tratamento possibilitou que cirurgias ocorressem em tempo suficiente para que se obtivesse o mínimo dano possível. Muitos estudos foram realizados em animais, porém os resultados com seres 
humanos ainda são limitados. No entanto, existem evidências clínicas de que terapia de hipotermia parece ser mais bem sucedida em cirurgias cardíacas e na região do pescoço do que em cirurgias de lesões cerebrais.

A Figura 2.16 indica um fluxograma esquemático proposto por Dine e Abella (2009) sobre as áreas de estudo do uso da hipotermia como terapia. Destacam-se: forma de aplicação, momento da aplicação, o quão profunda deve ser e por quanto tempo deve ser mantida. Existem estudos que também tratam a taxa de retorno, porém o foco nessa área parece ser um pouco menor, apesar da necessidade de controle desse item.

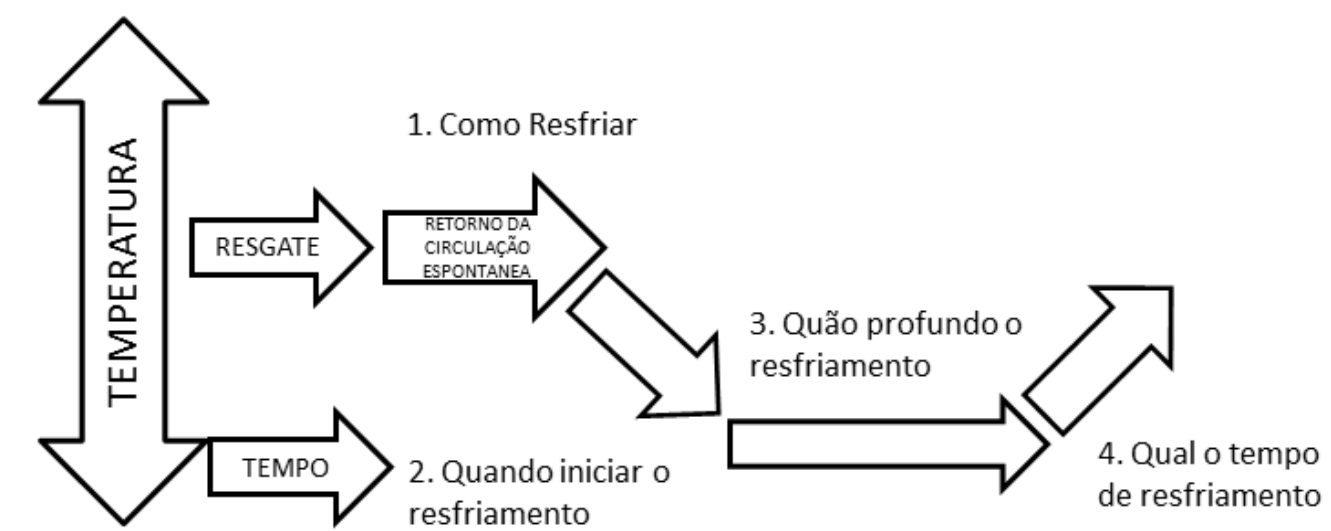

Figura 2.16: Áreas de interesse no estudo da hipotermia, baseado em Dine e Abella (2009)

\subsubsection{Técnicas de resfriamento do corpo}

Diller e Zhu (2009), Dine e Abella (2009) fizeram um estudo das diferentes formas de obtenção de hipotermia. Dentre as técnicas destacam-se:

- Resfriamento da superfície da pele: esse é o método mais estudado em hipotermia. Técnicas que abrangem o uso da convecção de ar, jaquetas e cobertores de resfriamentos, colchão de água, sacos de gelo, banho de álcool e água, dentre outros.

- Inserção intravenosa com solução salina: trata-se de uma forma barata para obtenção de hipotermia, a qual todo hospital possui capacidade de execução, pois é usada como fluido de hidratação. Essa técnica é bastante eficiente, no entanto, não se sabe até que ponto o paciente pode tolerar uma alta infusão.

- Resfriamento de sangue intravascular usando um cateter: consiste no uso de equipamentos para trocar calor com sangue sem que haja troca de fluidos. Essa 
técnica independe das resistências térmicas dos tecidos e conecta-se diretamente ao sistema circulatório (remoção de energia do sangue venoso a uma taxa de até 150W). Uma outra vantagem foi a não observação de calafrios, pois eles são associados à superfície da pele. A Figura 2.17 (a) indica o dispositivo para esse tipo de técnica. Nota-se que o cateter é inserido pela veia femoral e levado até a veia cava inferior. O diâmetro desse cateter não ultrapassa $10 \%$ do da veia na qual foi inserido, assim, não obstrui o escoamento. Dae et al. (2003) estudaram esse procedimento em porcos e Dixon et al. (2002), em seres humanos. Os resultados do último podem ser vistos na Figura 2.18.

- Resfriamento extracorpóreo de sangue: técnica aplicada por Behringer et al. (2002) em cães, cujo resultado pode ser visto na Figura 2.19, indicando que esse tipo é 4 vezes mais rápido do que o resfriamento da pele. O dispositivo é semelhante ao anterior, entretanto o sangue é removido do corpo. Nessa técnica há a inserção de dois cateteres na veia femoral, um $5 \mathrm{~cm}$ da veia cava inferior para entrada do sangue venoso e outro a $25 \mathrm{~cm}$ para saída de sangue venoso. A vazão de sangue retirada foi de $200 \mathrm{ml} / \mathrm{min}$ (aproximadamente $10 \%$ do débito cardíaco).

- Bypass cardiopulmonar: como destacado por Cooley, DeBakey e MorrisJr (1957), o procedimento do bypass cardiopulmonar é muito usado para tratamento de aneurisma da aorta. Ele é bastante eficaz para obtenção da hipotermia, mas, é bastante invasivo e complexo, como pode ser visto na Figura 2.17(b).

\subsubsection{Parâmetros de resfriamento do corpo}

Quando iniciar o resfriamento do corpo: Estudos em animais mostram que a hipotermia imediata é sempre melhor do que a aplicada depois de se esperar um intervalo de tempo. Assim, sugere-se que quanto mais próxima da parada cardíaca, melhor para o paciente. Diller e Zhu (2009) afirmam que, mesmo ocorrendo um atraso de 6 horas para o tratamento, ainda é possível observar efeitos neuroprotetores. Essa técnica mesmo que aplicada com atraso, permite a redução de danos secundários no cérebro, porém estudos em animais indicam que depois de 1 a 2 horas os efeitos benéficos se reduzem drasticamente.

Profundidade do resfriamento: A visão tradicional de que quanto mais frio melhor, segundo Diller e Zhu (2009), vem sendo questionada nas últimas décadas. As mais usadas são as hipotermias leves $\left(35-32^{\circ} \mathrm{C}\right)$ e moderadas $\left(32-28^{\circ} \mathrm{C}\right)$. Alguns modelos em animais sugerem que a hipotermia leve e moderada provocam menos efeitos adversos após o retorno 


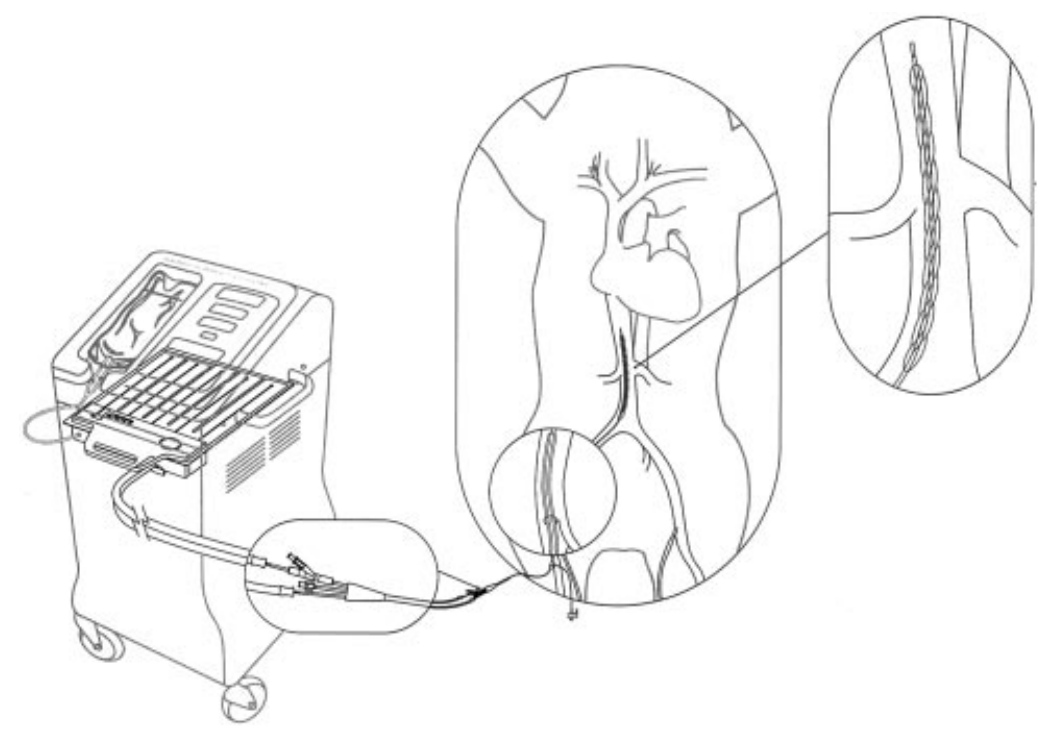

(a)

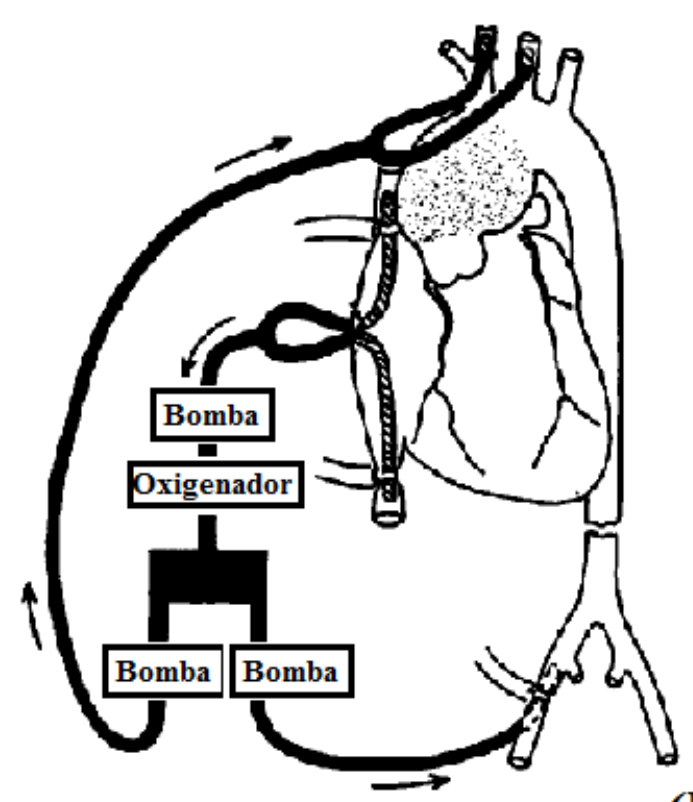

(b)

Figura 2.17: Tipos de dispositivo para resfriamento do sangue: (a) circulação extracorpórea ou cateter resfriado com solução salina obtido em Dae et al. (2003), (b) desenho esquemático de um bypass cardiopulmonar obtido em Cooley, DeBakey e MorrisJr (1957) 


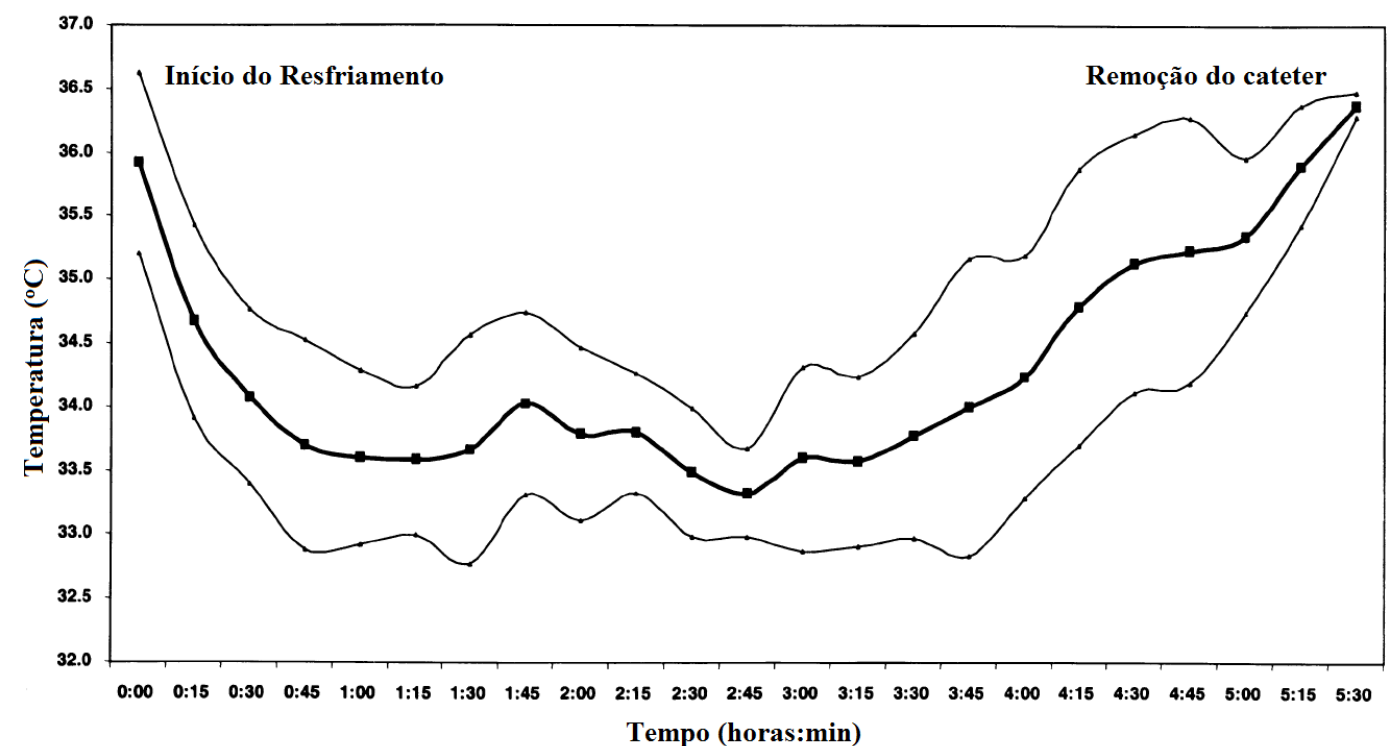

Figura 2.18: Resultados do resfriamento de sangue intravascular em seres humanos. As curvas limites representam os desvios padrões e a curva central os valores médios obtidos por Dixon et al. (2002)

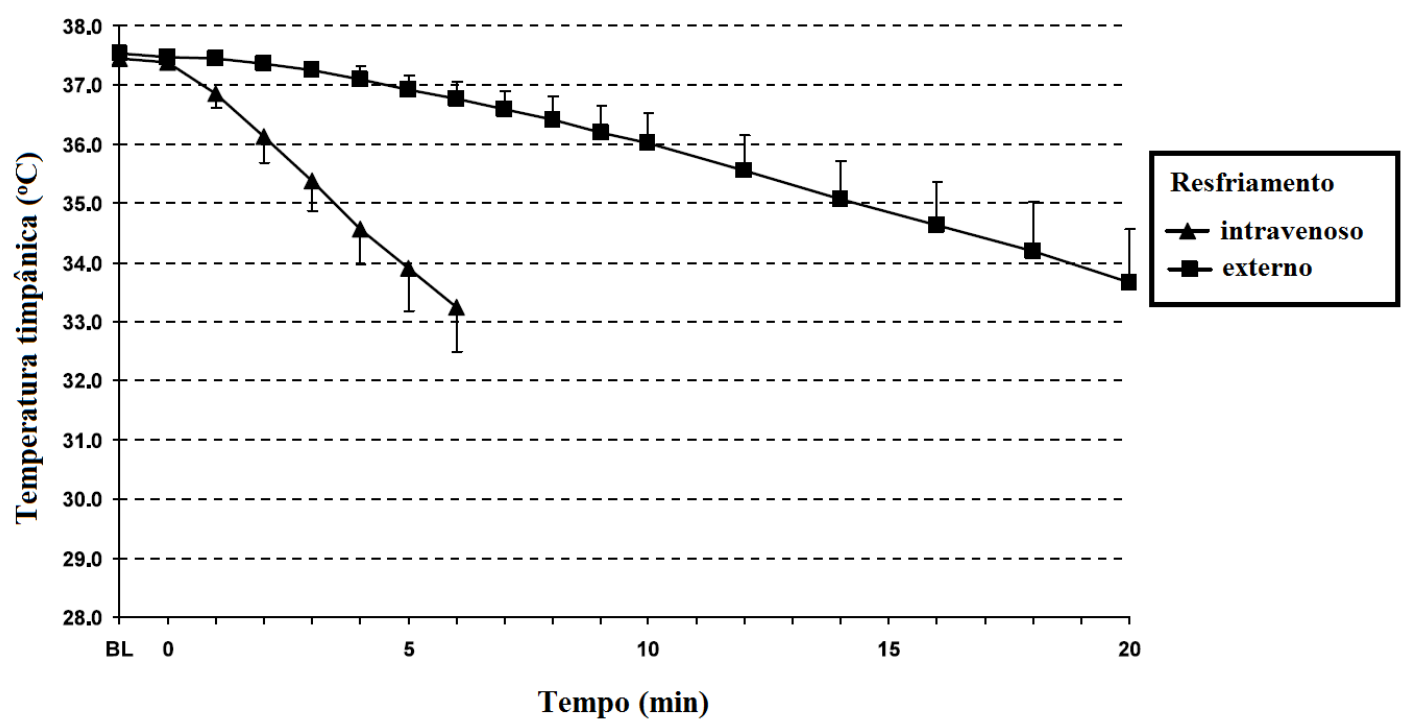

Figura 2.19: Resultados da circulação de sangue extracorpórea de sangue em cães, comparado com resfriamento externo do corpo, obtido em Behringer et al. (2002) 
da circulação. Tipicamente, esses estudos são realizados quando a hipotermia é aplicada em todo o corpo.

Tempo de resfriamento: Resfriamentos com intervalos menores que 1 hora não provocaram efeitos neuroprotetores em ratos, como afirmaram Diller e Zhu (2009). Hipotermias curtas têm efeitos transientes, recomendando-se que seja feita entre 6 e 48 horas; no entanto, estudos chave indicam que a hipotermia leve deve ser aplicada por 12 a 24 horas. A profundidade e duração da hipotermia não devem ser tratadas como variáveis independentes. Deve-se tomar cuidado com a profundidade da hipotermia, pois, apesar de períodos longos poderem trazer efeitos benéficos, existem diversas implicações clínicas relacionadas ao resfriamento excessivo.

Tempo para retorno da hipotermia: Segundo Diller e Zhu (2009) um retorno rápido pode trazer problemas relacionados à volta da pressão, aumento da perfusão de sangue. Os autores destacam duas taxas, $3^{\circ} \mathrm{C} / \mathrm{h}$ e $0,5^{\circ} \mathrm{C} / \mathrm{h}$, mas afirmam que o reaquecimento deve ser lento.

\subsubsection{Aplicação da Segunda Lei em organismos}

Um dos primeiros autores que tentou descrever a vida usando a grandeza física entropia foi Schrödinger (1944). O autor relata que o corpo extrai negentropia do ambiente para compensar a produção contínua de entropia. Ele usou conceitos da mecânica estatística que relacionam o grau de desordem do sistema com a entropia; assim, afirmou que o organismo absorve continuamente ordem do ambiente.

Considerando-se que tanto o tempo quanto a Segunda Lei da Termodinâmica (a partir do conceito de entropia gerada) progridem em uma única direção, cujo crescimento sempre vai na mesma direção que a idade cronológica, torna-se natural a tentativa de se descreverem fenômenos biológicos não só dependentes do tempo, mas também da entropia, como pode ser visto em Balmer (1982), Aoki (1991). Assim, a Segunda Lei passa a ser chamada de flecha do tempo ("arrow of time"). Prigogine e Wiame (1946) estão entre os primeiros autores que propuseram o princípio de que um organismo vivo tende a progredir para um estado de mínima geração de entropia (princípio da mínima geração de entropia). Esse princípio está baseado na hipótese de que a maior parte da entropia gerada no corpo se deve ao metabolismo.

Por sua vez, Stoward (1962) estudou a entropia gerada em culturas de bactérias na tentativa de comprovar o princípio de Prigogine e Wiame. Todavia, Forrest e Walker (1962) questionaram a validade de alguns experimentos do autor. 
Os autores Zotin e Zotina (1967) examinaram de forma experimental e teórica a validade do princípio de aumento de entropia. Eles alegaram que essa teoria não só abrangeria um considerável número de fenômenos na biologia (incluindo processo de crescimento, envelhecimento, morte, cicatrização de feridas, regeneração de tecidos, crescimento de tumores, etc), como também poderia resolver um grande número de fenômenos biológicos. Partindo do princípio de que a taxa de geração de entropia é proporcional ao metabolismo, eles estudaram desde o período embrionário até o envelhecimento de diferentes organismos (desde ovos de truta até o ser humano). Os autores concluíram que: (i) durante o crescimento e envelhecimento, organismos estão continuamente aproximando-se de uma condição de regime permanente (da produção de entropia à uma taxa constante), ou seja, diminuindo a entropia gerada; (ii) o desvio da condição de regime dá-se na oogênese (momento em que o organismo ainda forma parte do organismo materno), no período inicial de regeneração e cicatrização de feridas e quando um tumor aparece (tecidos com câncer tem uma taxa de geração de entropia maior do que tecidos saudáveis e não passam para a fase em que a geração de entropia diminui).

Pode-se ainda mencionar Balmer (1982) que realizou um estudo de entropia e envelhecimento em sistemas biológicos. Para tal, escolheu estudar os peixes da espécie africana Nothobranchius guentheri cujo ciclo de vida é de aproximadamente 12 meses, porque se originam em rios intermitentes. Constatou-se que o peixe adulto morre durante a época de secas, porém os ovos sobrevivem. Portanto, essa espécie possui todas as características de uma vida durante esse período. A taxa metabólica de um grupo desses peixes foi medida pela calorimetria indireta e por resultados fornecidos por Brett (1972). Balmer (1982) confirmou o postulado de Prigogine e Wiame (1946) de que sistemas vivos tendem a um estado de mínima geração de entropia, como indicado na Figura 2.20. Balmer (1982) afirma que a entropia gerada pelo metabolismo é uma função da temperatura, conforme indica a Figura 2.21, e explica que esse resultado, no entanto, é restrito a animais de "sangue frio" (ectotérmicos).

Aoki (1987, 1989, 1990, 1991), baseando-se nos diversos trabalhos de Hardy e Du Bois calculou a entropia do corpo humano sob diferentes temperaturas, correntes de ar ao redor do corpo, níveis de exercícios físicos, além de ter calculado a entropia em decorrência da idade, para a população japonesa. Aoki (1987) estudou a geração de entropia em um veado branco, no qual sugeriu pela primeira vez a rota de cálculo dos fluxos de entropia. Aoki (1991) verificou, ainda, o efeito do crescimento e envelhecimento no corpo humano, demonstrando a partir de resultados experimentais de metabolismo da sociedade japonesa que o princípio da mínima geração de entropia é válido para humanos.

A Figura 2.22 confirma o princípio de mínima geração de entropia para os humanos. Fundamentando-se nesses resultados, o autor propôs que a entropia produzida passaria por três estágios no decorrer da vida, ou seja, até o nascimento tem-se um aumento da 


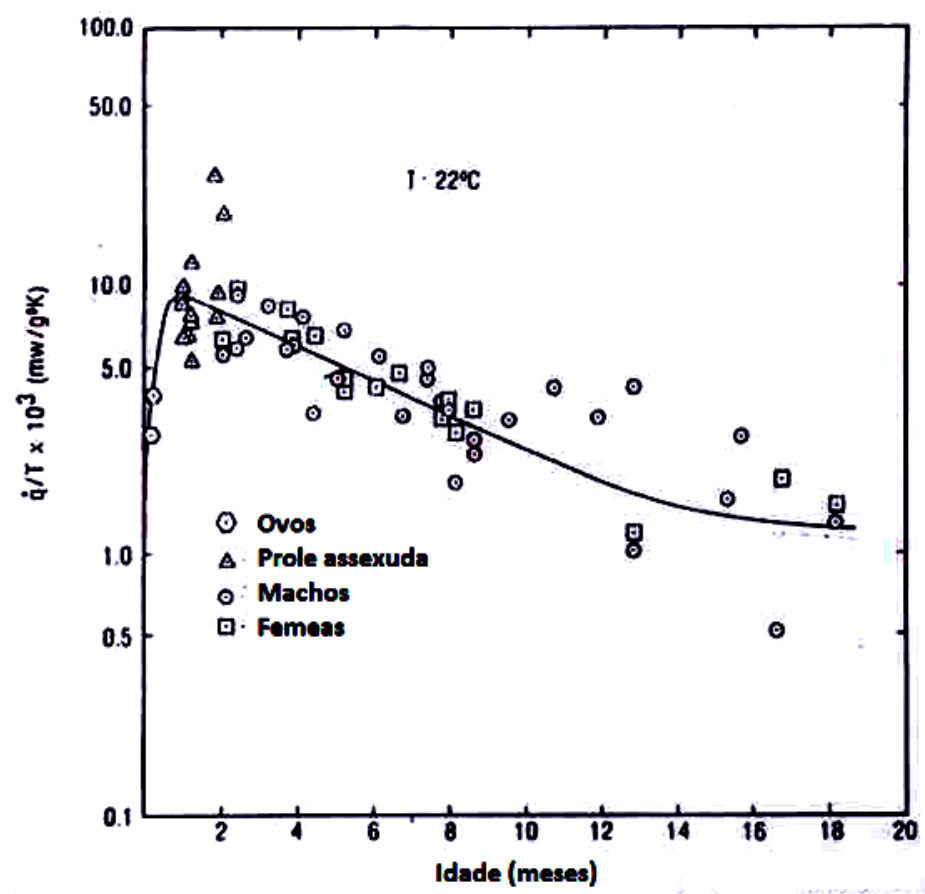

Figura 2.20: Taxa de entropia gerada pelo metabolismo decorrente do tempo de vida do peixe Nothobranchius guentheri. Resultado obtido por Balmer (1982)

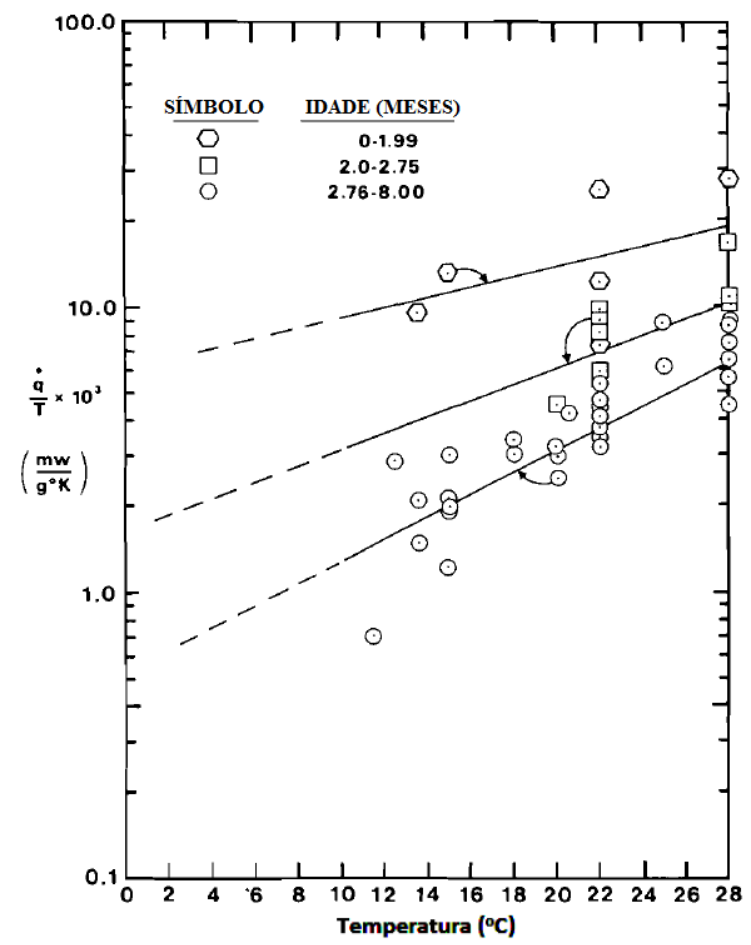

Figura 2.21: Taxa de entropia gerada pelo metabolismo em função da temperatura ambiente obtida por Balmer (1982)

entropia gerada, seguida do crescimento em que há um aumento da produção de entropia até o instante em que se atinge um máximo e, por fim, o envelhecimento em que a entropia gerada decresce continuamente no decorrer da vida.

A Figura 2.23 indica os resultados de Aoki (1991) da geração de entropia em função da 


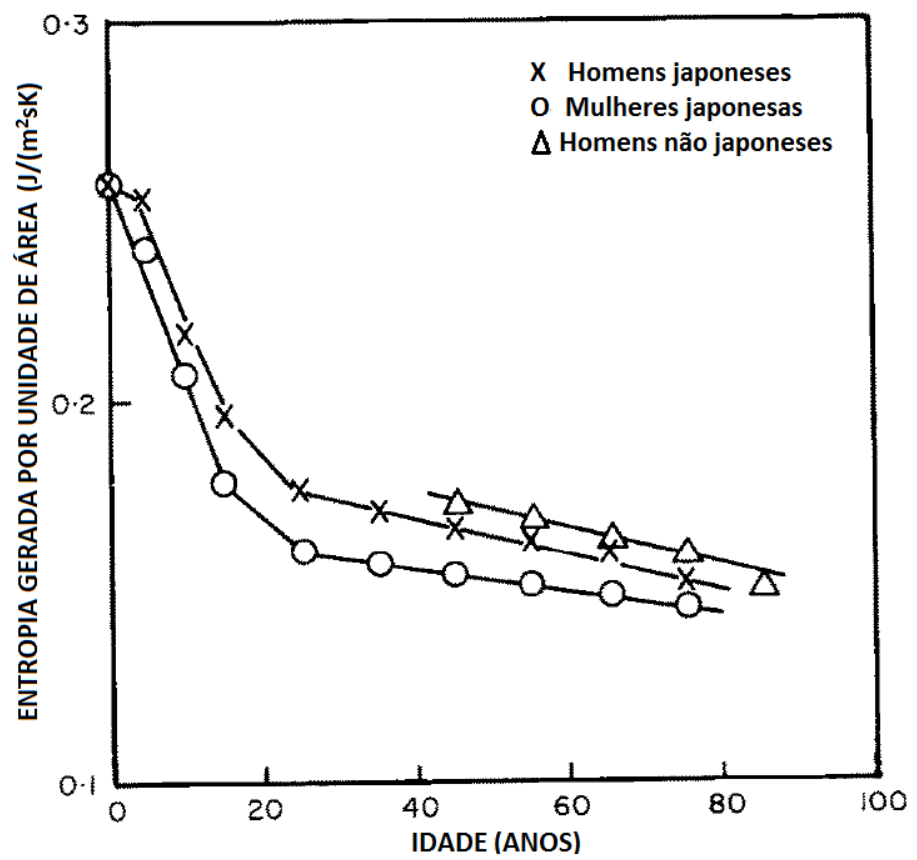

Figura 2.22: Variação da entropia gerada por unidade de área em função da idade, obtida por Aoki (1991)

temperatura ambiente. Nota-se que a temperatura não influenciou de forma significativa na entropia produzida. Esse resultado é explicado pela próprio cálculo da entropia gerada, calculada pelo autor como a razão entre o metabolismo e a temperatura do corpo. Como ele não dispunha de modelos computacionais, provavelmente não levou em conta a resposta do sistema ativo do corpo, ou seja, sudorese, tremores e perfusão sanguínea. Mais adiante esse resultado será contraposto a outros da literatura.

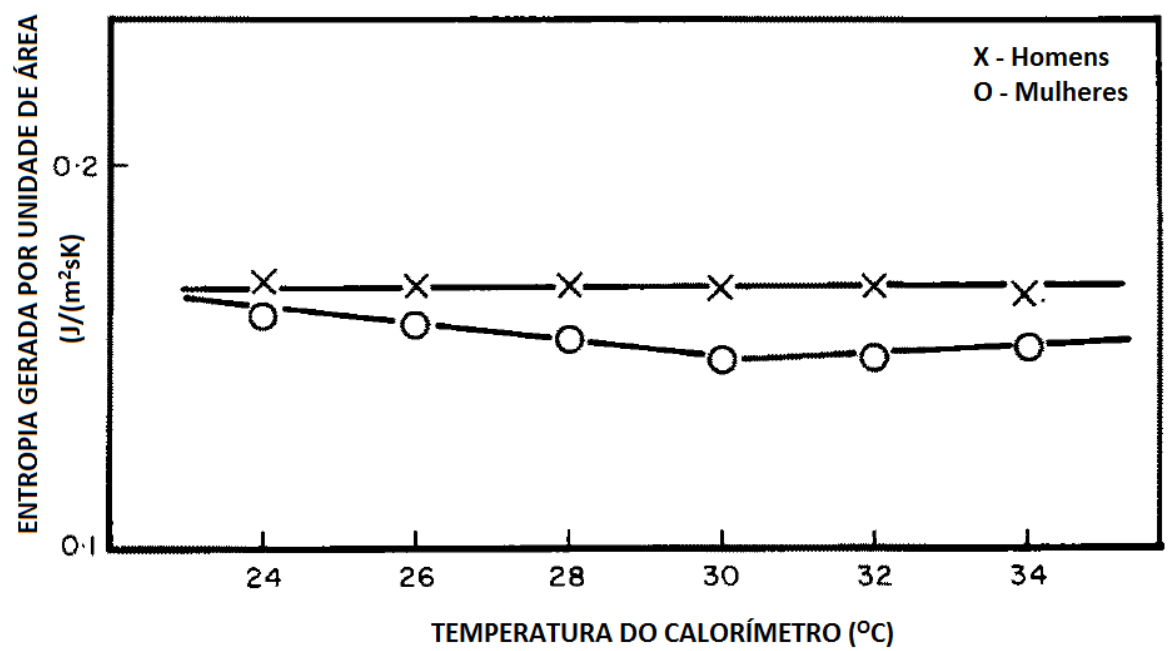

Figura 2.23: Variação da entropia gerada por unidade de área em consequência da temperatura ambiente, obtida por Aoki (1991)

De forma pioneira, Batato et al. (1990) realizaram a análise exergética do corpo. Os resultados experimentais foram obtidos com utilização da ressonância magnética (medição da composição do corpo), da calorimetria direta e indireta. Os autores concluíram que, apesar de as contribuições energéticas dos fluxos de calor e massa serem altas, 
a contribuição exergética desses fluxos é muito baixa. Os autores também deduziram que o metabolismo energético é muito próximo do metabolismo exergético e a eficiência exergética é próxima de zero.

Rahman (2007) baseou-se e estendeu o modelo proposto por Aoki, ao qual adicionou complementos numéricos, diminuindo a dependência de dados experimentais. Para o cálculo da troca de calor e massa com o meio por convecção e vaporização, o autor estimou os coeficientes de troca de calor e massa (tanto por convecção como por vaporização) com base nos resultados obtidos por Kandjov (1999). Ademais adotou os valores de fluxos mássicos como indicado na Figura 2.24 e para cálculo do metabolismo foram usadas as Equações 2.51 e 2.52. Nota-se, também, que ao balanço de entropia devido aos fluxos mássicos, o autor adicionou a entrada de alimentos e saída de resíduos.

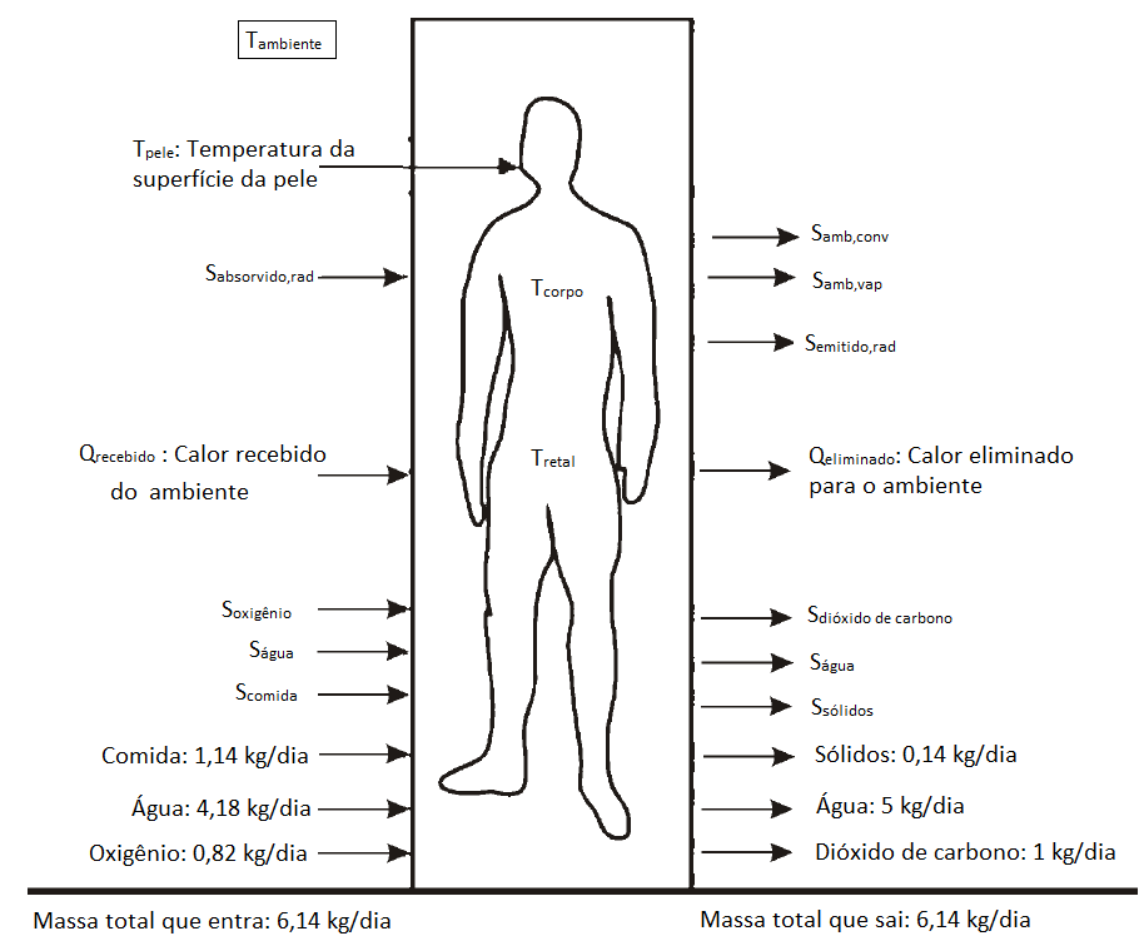

Figura 2.24: Modelo do corpo humano com respectivos fluxos de massa, de calor e de entropia com o meio ambiente. Proposto por Rahman (2007)

A Figura 2.25 indica os resultados obtidos por Rahman (2007), em que é possível verificar que os valores obtidos são maiores do que os dos outros autores, e a idade em que há a máxima geração de entropia não é a mesma.

Silva e Annamalai (2008, 2009) aplicaram a Primeira e Segunda leis para análise de reações bioquímicas que são típicas do metabolismo humano. Eles analisaram a geração de entropia ao longo da vida de um ser humano e os resultados confirmaram o princípio da mínima geração de entropia. Levando em conta a geração de entropia durante toda uma vida $(11404 \mathrm{~kJ} / \mathrm{kgK})$, previram a expectativa de vida de um cidadão médio americano (chegando a valores próximos dos obtidos a partir de bases estatísticas da sociedade norte- 


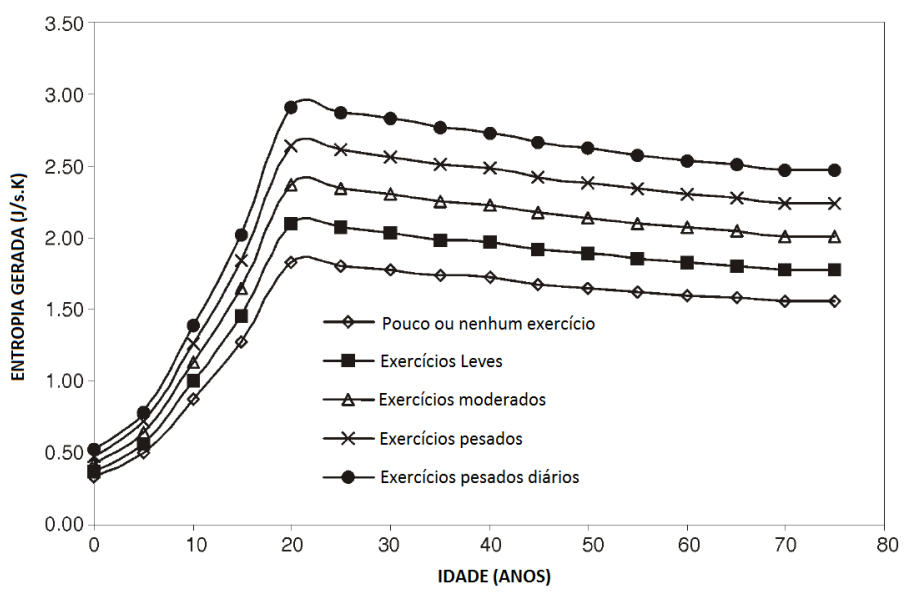

Figura 2.25: Resultados da entropia gerada em decorrência da atividade física da pessoa. Obtido por Rahman (2007)

americana). Também obtiveram, sob o ponto de vista da Segunda Lei, que o exercício físico aumenta a produção de entropia, devendo ser mantido em um mínimo saudável, além de mostrarem que uma redução na dieta de proteínas e no teor calórico da ingestão pode induzir a um aumento percentual na vida. Segundo os autores, o resultado do aumento de entropia em decorrência das atividades físicas parece contrariar a literatura médica, que afirma justamente o contrário: atividades físicas aumentam a duração da vida. Na verdade, nenhum dos resultados estaria errado ou inválido, apenas que a atividade física ajuda a manter o funcionamento do corpo e a evitar doenças (que podem levar a uma morte prematura), mas se praticada em excesso pode levar a um envelhecimento precoce. Deve-se ainda destacar que os modelos existentes na literatura não levam em conta na análise os benefícios da prática de atividade física.

Hershey (2010) faz uma análise de como os sistemas biológicos se mantém a uma condição fora do equilíbrio com o meio ambiente. Há uma entrada de energia no sistema na forma de ligações químicas dos alimentos, no qual os resultados são fenômenos "ordenados" como formação de proteínas, crescimento, locomoção, dentre outros. A ordem biológica é alcançada pelas reações químicas que trazem o sistema para uma condição distante daquela que estaria em equilíbrio com o meio. Os seres vivos são produtores de entropia e a dissipam na forma de radiação, convecção, vaporização e respiração para o meio. Pode-se afirmar que a entropia é um parâmetro mais condizente para o cálculo da duração da vida se comparada com o metabolismo (discussão realizada na Seção 2.4.1.1), pois a entropia do corpo aumenta com o envelhecimento (enquanto que a entropia gerada diminui) e tende a um máximo antes da morte. Hershey (2010) chegou a propor uma escala diferente para a idade, ou seja, "idade entrópica" (ou entropia acumulada) e obteve que a entropia gerada durante a vida equivale a $10025 \mathrm{~kJ} / \mathrm{kgK}$ e $10678 \mathrm{~kJ} / \mathrm{kgK}$ para homens e mulheres, respectivamente.

Deve-se ainda ressaltar que Hershey (2010) faz uma comparação do processo de 
envelhecimento com o processo de rompimento e desgaste (tear and wear), da mesma forma que uma máquina envelhece o ser humano passa por processos semelhantes. Segundo o autor, a vida é caracterizada por uma série de reações químicas aceleradas ou moderadas, moduladas pelas enzimas, e como os seres vivos são compostos por subsistemas, órgãos, tecidos, células, são necessários gastos de energia e trabalho constantes para manter o sistema na ordem adequada. Porém, algumas imperfeições sempre existem. No início essas imperfeições são sutis e perceptíveis somente em nível microscópico; com o decorrer do tempo, cada vez menos células são levadas para sua condição ou configuração inicial aumentando as imperfeições até que um ponto mais frágil apareça em um órgão vital, levando, em últimas instâncias, ao colapso do sistema. Esses erros induzidos são geralmente atribuídos à entropia.

Uma abordagem numérica foi proposta por Prek (2004, 2006), Prek e Butala (2010), na qual se apresenta um modelo térmico com dois nós (núcleo e pele) para simular condições de conforto térmico, utilizando os conceitos da análise exergética para diferentes condições ambientais. Por esse modelo consideram-se as trocas de calor e massa com o ambiente, e condução de calor entre os compartimentos interno e externo. A Figura 2.26 indica um dos resultados com relação da exergia destruída em função da temperatura do ar. Tal resultado contradiz o da Figura 2.23, provavelmente devido ao uso de um sistema termorregulador, que faz com que o metabolismo energético, os fluxos de exergia e a exergia destruída se tornem dependentes das condições ambientais. A partir de um modelo mais elaborado Ferreira e Yanagihara (2009b) fizeram a análise exergética do corpo humano, no qual foram obtidos resultados semelhantes aos de Batato et al. (1990).

Por sua vez, Simone et al. (2011) escreveram um artigo de revisão da literatura, em que relacionaram a exergia destruída (calculada de forma similar a Prek e Butala (2010)) com a sensação de conforto térmico. Os autores ainda constataram que existem estudos que afirmam que temperaturas radiantes médias altas e temperaturas ambientais baixas do ar levam a uma sensação de conforto térmico maior (o que ainda não está comprovado), no entanto é um padrão que pode ser observado nas Figuras 2.26 e 2.27, apesar de a mínima destruição de exergia ser em outro ponto.

Além de comparar o ponto de mínima destruição de exergia com condições de conforto, Wu et al. (2012) a compararam com a performance das pessoas no trabalho. Os autores mostraram que, embora o ponto de mínima destruição não coincida com a máxima performance, existe um ponto em que as grandezas se cruzam, como indicado na Figura 2.28. Esse ponto é classificado como levemente frio, porém é próximo da condição de conforto térmico.

Baseando-se em conclusões de modelos e resultados experimentais, Rabi, Silva e Oliveira (2012) afirmam que um estudo geral do comportamento do corpo humano (aplicando a Segunda Lei da Termodinâmica) pode levar a um melhor entendimento das condições 


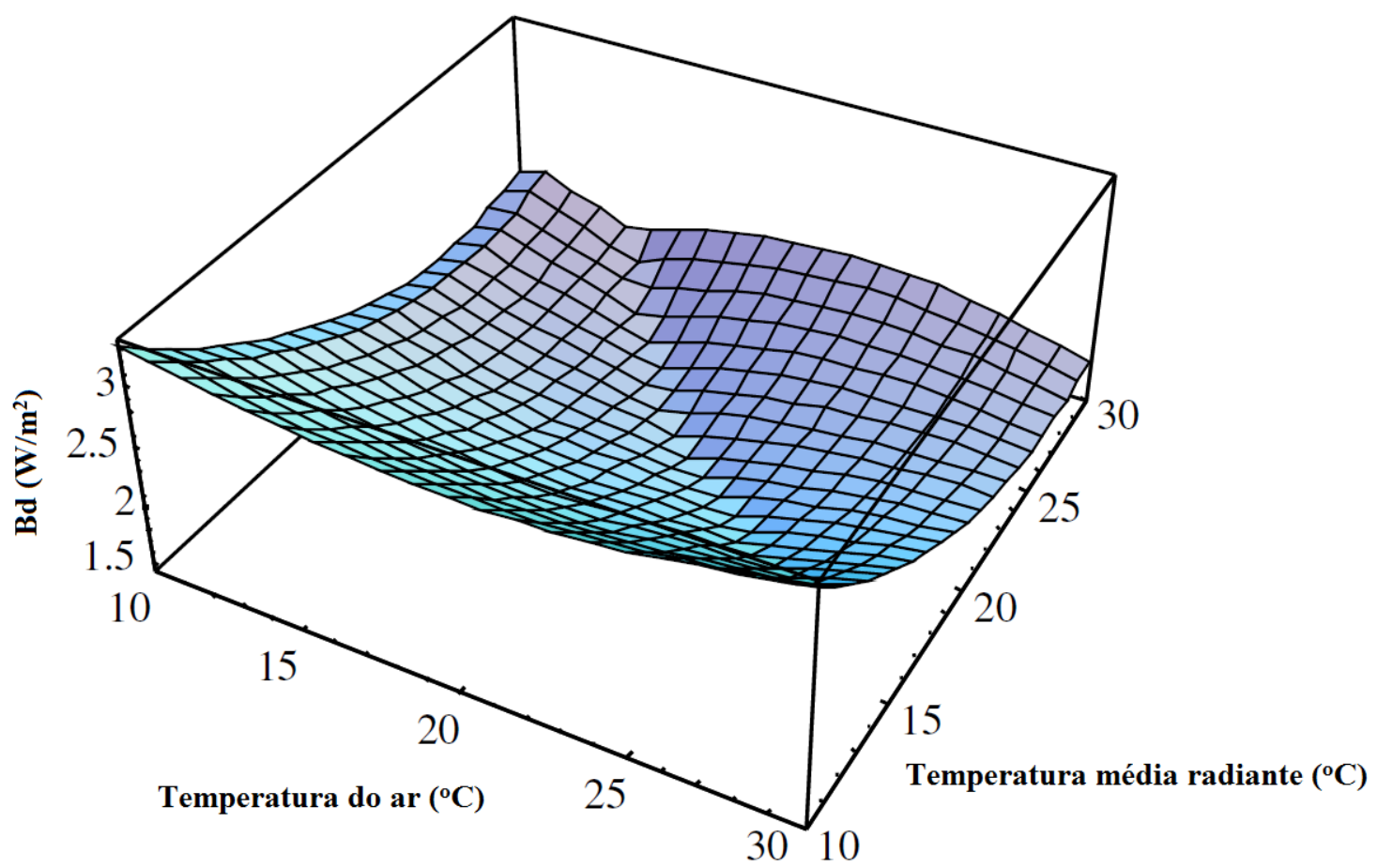

Figura 2.26: Resultado da exergia destruída pelas condições ambientais. Obtido em Prek (2004)

de conforto térmico do corpo. Para os autores, os resultados publicados pelos diversos pesquisadores deve encorajar a criação de um indicador de conforto térmico fundamentado na Segunda Lei da Termodinâmica.

\subsubsection{Indicadores termodinâmicos existentes}

Grande parte dos indicadores aplicados ao corpo são baseados na Primeira Lei da Termodinâmica. Esses indicadores, na maioria, são aplicados para análise de conforto térmico. Uma das poucas exceções são os indicadores de níveis de esforços durante atividades físicas, porém eles se baseiam no consumo máximo de oxigênio do corpo, ou seja, no máximo metabolismo e na concentração de lactato no sangue.

ASHRAE (2005) possui uma escala que varia de -3 (frio) a +3 (calor) para descrever a sensação térmica de acordo com o ambiente em que a pessoa está inserida. Fanger (1970) define o Índice de Atividade Térmica, IAT, baseado no nível de atuação do sistema termorregulador (para um dado metabolismo), ou seja, aquele que mostra o grau de afastamento das condições de conforto térmico. Como mostrado na Equação 2.64 esse índice nada mais é do que a diferença entre o metabolismo para uma determinada atividade e os fluxos de energia para o ambiente real, mas para uma pessoa que está 


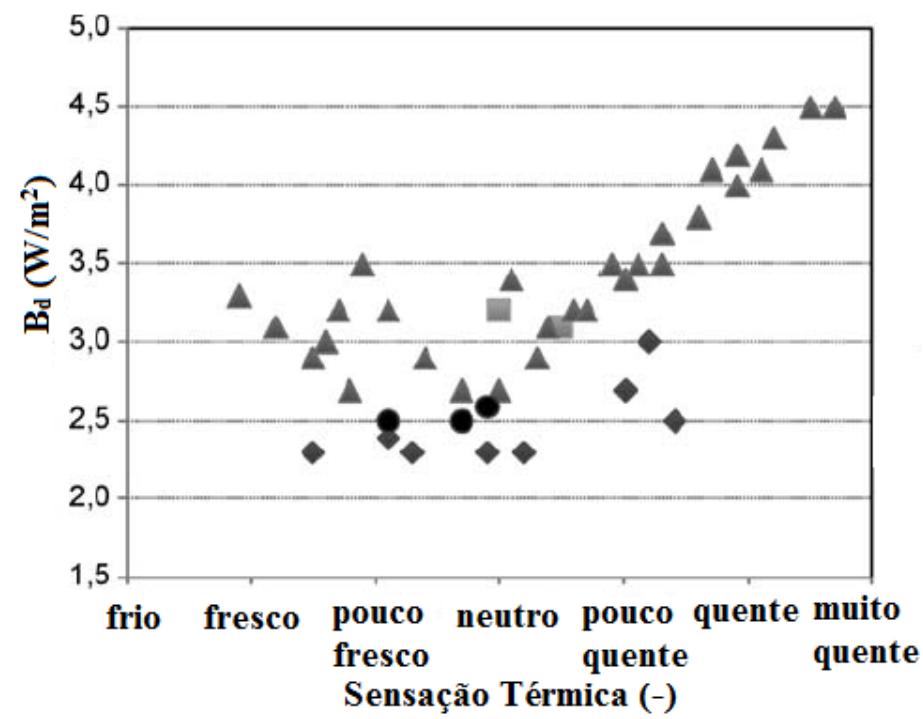

Figura 2.27: Resultados da exergia destruída em função da sensação térmica. Obtidos em Simone et al. (2011)

na condição de neutralidade térmica para o nível de atividades (temperatura da pele, sudorese, dentre outros). Nota-se que esse índice é nulo para condições de conforto térmico

$$
I A T=(M-W)-\left(Q_{c}+Q_{r}+H_{e}+\Delta H_{\text {res }}\right)
$$

Fanger (1970) relacionou esse índice com o voto médio estimado (PMV - predicted mean vote), obtido a partir de resultados experimentais, como indicado na Equação 2.65. Uma vez que o cálculo do voto médio estimado é um pouco trabalhoso, Fanger (1970) apresenta os resultados em forma de tabelas e gráficos. A norma ISO7730 (2005) apresenta essas tabelas e uma rotina para utilização em computador, que permitem determinar o PMV para diferentes atividades, tipos de vestimenta e condições ambientais. A região de validade para o cálculo do PMV deve se restringir a faixa de $-2<P M V<2$.

$$
P M V=\left(0,352 e^{-0,042\left(M / A_{D}\right)}+0,032\right) I A T
$$

Fanger (1970) propôs a Equação 2.66 para o cálculo da percentagem estimada de insatisfeitos (PPD - predicted percentage of dissatisfied) em função do voto médio estimado, o qual estima o percentual de pessoas termicamente insatisfeitas obtido a partir de resultados experimentais. 


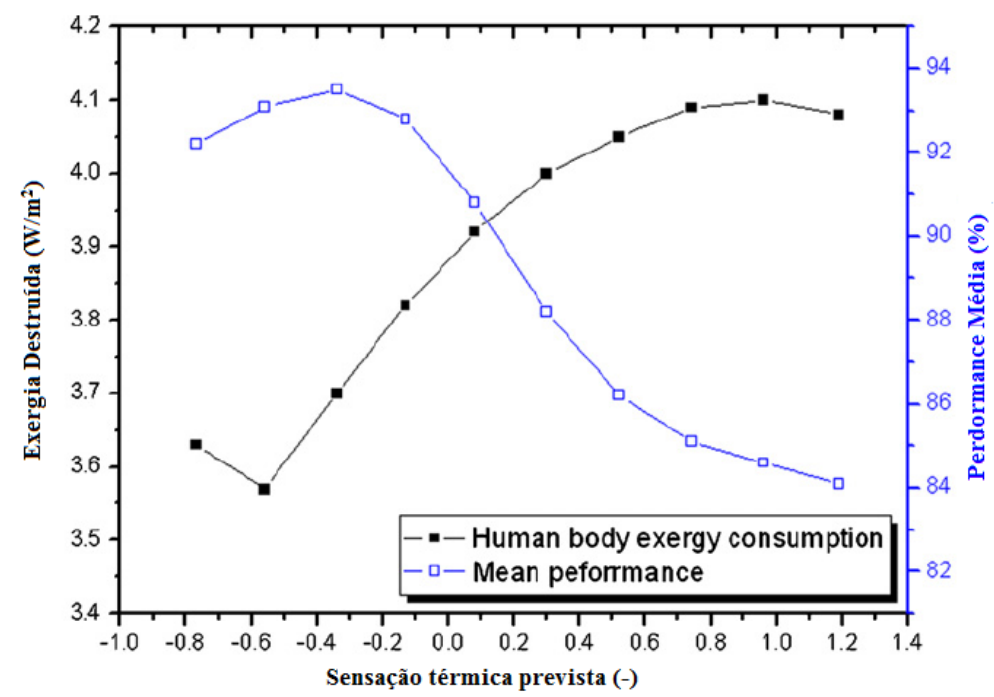

Figura 2.28: Resultados da exergia destruída e performance em decorrência sensação térmica. Obtidos em Wu et al. (2012)

$$
P P D=100-95 e^{-\left(0,03353 P M V^{4}+0,2179 P M V^{2}\right)}
$$

A Figura 2.29 demonstra uma correlação entre o voto médio estimado (PMV) e a percentagem de insatisfeitos. Evidencia-se que quando PMV equivale a 0 a porcentagem de insatisfeitos torna-se mínima. Como destacado na Seção 2.4.5, a análise de exergética tem sido aplicada ao corpo humano na tentativa de se achar alguma correlação com condições de conforto térmico. O que diferencia a análise exergética da análise de Primeira Lei (sob condições basais) são os fluxos de exergia para o meio ambiente, que levam em conta a qualidade no processo de convenção de energia, diferente dos fluxos de energia que, em regime permanente, devem ser iguais ao metabolismo para uma dada atividade. Desse modo, condições de conforto térmico seriam obtidas por um método analítico e não por dados experimentais apenas. As Figuras 2.26 a 2.28 indicam essas análises, em que a condição de mínima destruição de exergia ocorre em pontos semelhantes ao de mínimo da Figura 2.29, sem a necessidade de resultados experimentais. 


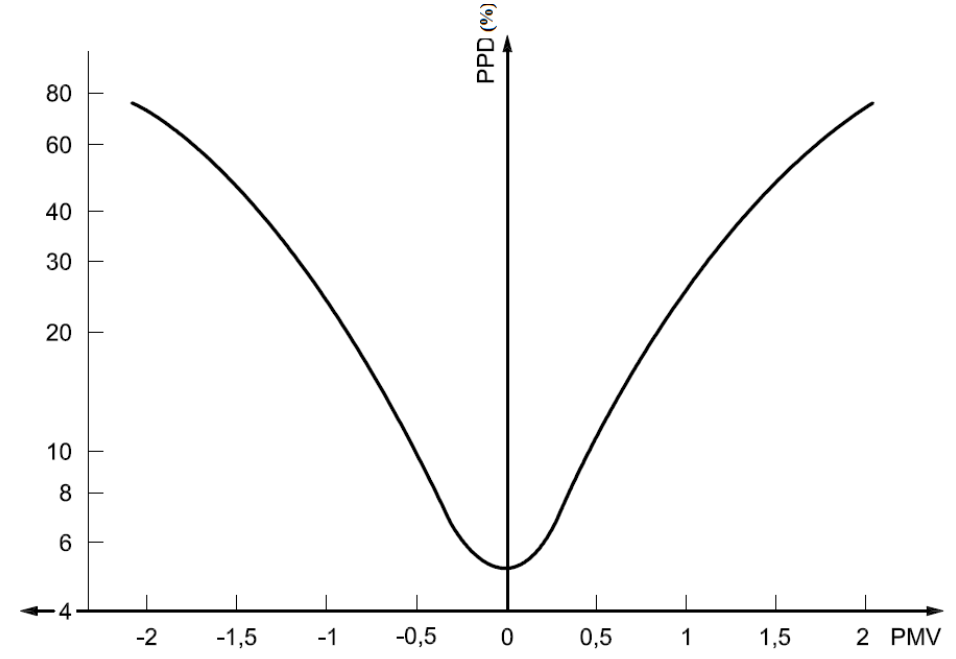

Figura 2.29: Correlação entre PMV e PPD. Retirado de ISO7730 (2005) 


\section{DESCRIÇÃO DO MODELO}

A Figura 3.1 indica uma representação do modelo de corpo humano com respectivos fluxos de calor e entalpia para o meio ambiente, ingestão de alimentos e de água, e saída de urina e fezes. Observa-se que o corpo humano está dividido em dois volumes de controle: VC1 e VC2. O primeiro volume de controle (VC1) é composto pelos sistemas térmico, respiratório e circulatório, no qual se consideram os fluxos de calor e entalpia para o ambiente associados à radiação $\left(\dot{Q}_{r}\right)$, convecção $\left(\dot{Q}_{c}\right)$, vaporização $\left(\dot{H}_{e}\right)$ e respiração $\left(\Delta \dot{H}_{r e s}=\dot{H}_{e x}-\dot{H}_{a}\right)$ e o calor liberado devido ao metabolismo $\left(\dot{Q}_{M}\right)$. O segundo volume de controle (VC2) representa o metabolismo celular em que foram considerados os fluxos de entrada de nutrientes (glicose, lipídeos e aminoácidos) e oxigênio; e saída de água, ureia, gás carbônico e o calor liberado pelas reações $\dot{Q}_{M}$ para o VC1. Ressalta-se que a divisão em VC1 e VC2 é uma idealização para fins didáticos e tem como objetivo facilitar a modelagem e possibilitar dividir o corpo em dois processos de conversão de energia: o térmico e o químico. Dessa forma, foi possível comparar as alterações feitas no modelo em relação à literatura que só considera a parcela térmica, assim como uma análise detalhada do metabolismo.

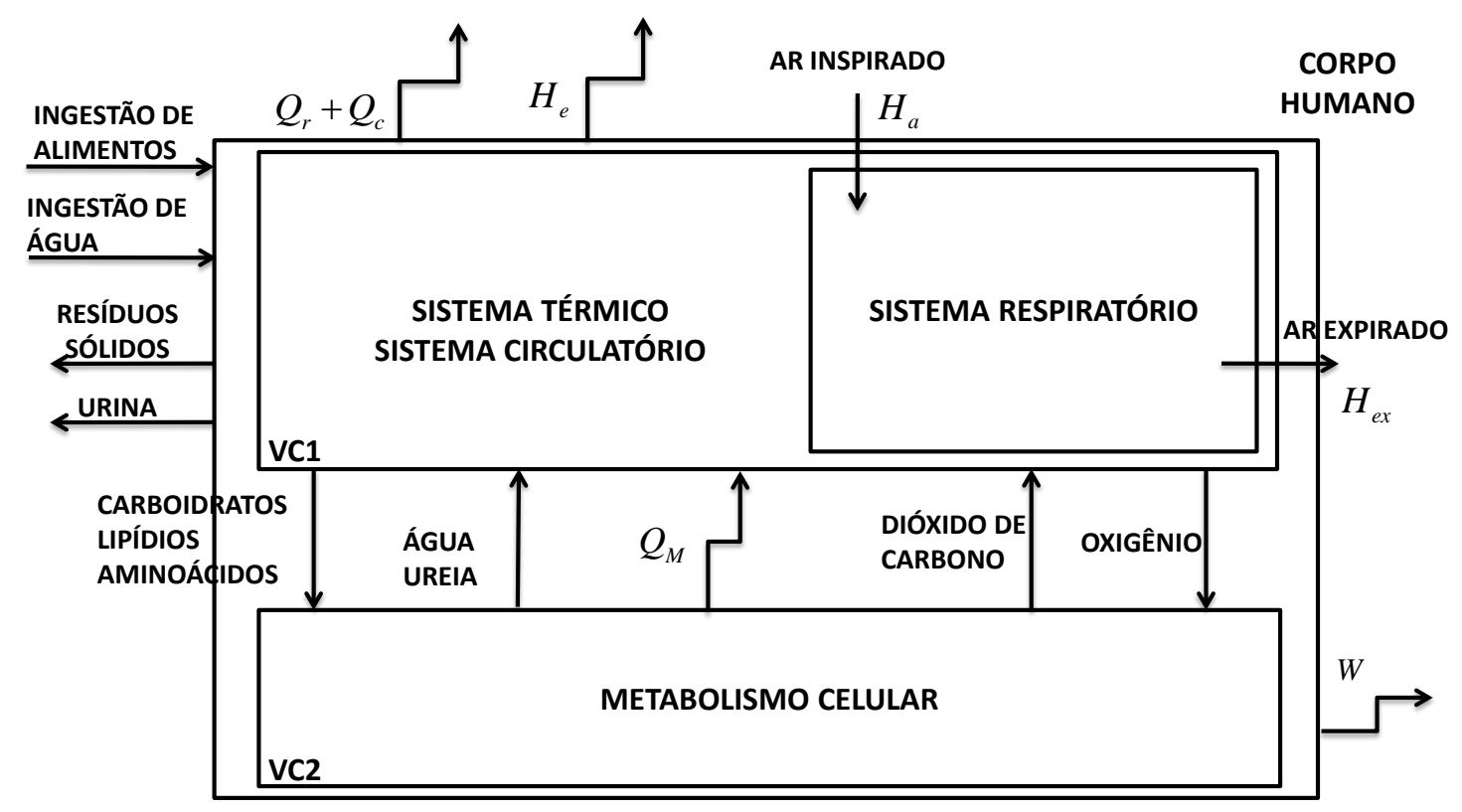

Figura 3.1: Modelo esquemático do corpo humano com respectivos subsistemas

Segundo Rahman (2007), no período de um dia, a entrada de massa (comida, líquidos e ar inspirado) equivale à saída de massa (fezes, urina, ar expirado e vaporização pela pele). Em períodos mais curtos, esse pressuposto não é sempre válido. Neste texto, por simplicidade, a variação de massa do corpo causada pela entrada, pela saída e pelo 
acúmulo de substâncias é negligenciada.

A Primeira Lei da Termodinâmica e a Análise Exergética estão indicadas nas Equações 3.1 e 3.2 (Equações retomadas da Seção 2.1), já com as devidas simplificações, para um volume de controle. Nessas, foi considerado que o ambiente de referência é o próprio ambiente em que o corpo está inserido, ou seja, a temperatura $T_{0}$, a pressão $P_{0}$ e a umidade relativa $\phi_{0}$.

$$
\begin{aligned}
& \frac{d U_{V C}}{d t}=\sum \dot{m}_{e} h_{e}-\sum \dot{m}_{s} h_{s}+\dot{Q}_{V C}-\dot{W}_{V C} \\
& \frac{d B_{V C}}{d t}=\sum_{i} \dot{Q}_{i}\left(1-\frac{T_{0}}{T_{i}}\right)-\dot{W}_{V C}+\sum \dot{m}_{e} b_{e}-\sum \dot{m}_{s} b_{s}-\dot{B}_{d}
\end{aligned}
$$

Na Equação 3.3 está indicada a variação total da energia interna do corpo que é uma soma da variação de energia interna metabólica $(M)$ com a variação de energia interna do corpo por variações de temperatura $\left(d U_{\Delta T} / d t\right)$. O mesmo pode ser feito para a variação temporal da exergia, como indicado na Equação 3.4, no qual B é a exergia do corpo e $\dot{B}_{M}$ é o metabolismo em base exergética.

$$
\begin{aligned}
& \frac{d U}{d t}=-\dot{M}+\left.\frac{d U}{d t}\right|_{\Delta T} \\
& \frac{d \mathbf{B}}{d t}=-\dot{B}_{M}+\left.\frac{d \mathbf{B}}{d t}\right|_{\Delta T}=-\dot{B}_{M}+\left(\left.\frac{d U}{d t}\right|_{\Delta T}-\left.T_{0} \frac{d S}{d t}\right|_{\Delta T}\right)
\end{aligned}
$$

A Equação 3.5 indica o balanço de energia aplicado ao VC1, em que $\dot{Q}_{M}$ representa o calor liberado ao corpo pelo metabolismo. Nota-se que é feita a hipótese de que a variação temporal da energia interna devido a gradientes de temperatura do corpo ocorre apenas no VC1 (o mesmo será feito para variação temporal da exergia do VC1). Os termos $\dot{Q}_{r}$, $\dot{Q}_{c}, \dot{H}_{e}$ e $\Delta \dot{H}_{r e s}\left(\Delta \dot{H}_{r e s}=\dot{H}_{e x}-\dot{H}_{a}\right)$ representam a taxa de calor e entalpia transferidas para o ambiente, em virtude da radiação, da convecção, da vaporização e da respiração.

$$
\left.\frac{d U_{V C 1}}{d t}\right|_{\Delta T}=\left.\frac{d U}{d t}\right|_{\Delta T}=\dot{Q}_{M}-\left(\dot{Q}_{c}+\dot{Q}_{r}+\Delta \dot{H}_{r e s}+\dot{H}_{e}\right)
$$


O metabolismo celular pode ser descrito pela Equação 3.6. Nessa equação, $\dot{H}_{\text {reag }}$ é a entalpia dos reagentes (oxigênio, carboidratos, lipídeos e aminoácidos) e $\dot{H}_{\text {prod }}$, a entalpia dos produtos das reações celulares (dióxido de carbono, água líquida e ureia). Fazendo o termo $\left.\frac{d U_{V C 2}}{d t}\right|_{\Delta T}=0$, pois toda variação de temperatura do corpo é considerada no VC1, chega-se à Equação 3.7 (o mesmo tratamento será realizado para o balanço de exergia). Verifica-se que se subtraiu a parcela relacionada ao trabalho, pois parte da energia do metabolismo é transformada em ATP, podendo ser convertida em trabalho. Se a pessoa está em repouso, $W=0$, o calor liberado para o corpo equivale ao metabolismo.

$$
\begin{aligned}
& \left.\frac{d U_{V C 2}}{d t}\right|_{\Delta T}=\dot{H}_{\text {reag }}-\dot{H}_{\text {prod }}-\dot{Q}_{M}-W \\
& \dot{Q}_{M}=\dot{H}_{\text {reag }}-\dot{H}_{\text {prod }}-W
\end{aligned}
$$

Define-se metabolismo pela Equação 3.8. Percebe-se que $\dot{Q}_{M}=\dot{M}$ somente para condições basais (sem realização de trabalho) e, nesse caso, sob o ponto de vista da Primeira Lei, é numericamente indiferente considerar o metabolismo como uma forma de transferência de calor para o corpo ou como uma variação de entalpia.

$$
\dot{M}=\dot{H}_{\text {reag }}-\dot{H}_{\text {prod }}
$$

Somando-se as Equações 3.5 com a 3.7, é possível obter a Primeira Lei aplicada ao corpo, como mostra a Equação 3.9. A partir da Figura 3.1 e das Equações 3.3 a 3.8 foi possível realizar o balanço de energia, no qual os efeitos térmico e químico do metabolismo estão separados. A soma dos dois efeitos resulta na análise global para o corpo, como indica a Equação 3.9. Um processo semelhante será realizado para a análise exergética, conforme pode ser visto adiante, nas Equações 3.10 a 3.13 .

$$
\left.\frac{d U}{d t}\right|_{\Delta T}=\dot{M}-\left(\dot{Q}_{c}+\dot{Q}_{r}+\Delta \dot{H}_{r e s}+\dot{H}_{e}\right)-\dot{W}
$$

Aplicando-se a análise exergética ao VC1, pode-se chegar à Equação 3.10, na qual o termo $\dot{B}_{Q_{M}}$ (definido na Equação 3.11) representa a exergia liberada para o corpo associada a $\dot{Q}_{M}$. Os termos $\dot{B}_{r}, \dot{B}_{c}, \dot{B}_{e}$ e $\Delta \dot{B}_{r e s}\left(\Delta \dot{B}_{r e s}=\dot{B}_{e x}-\dot{B}_{a}\right)$ representam a taxa com que o corpo perde exergia para o ambiente, em virtude da radiação, da convecção, da 
vaporização e da respiração.

$$
\dot{B}_{\text {dest }}^{V C 1}=\dot{B}_{Q_{M}}-\left.\frac{d \mathbf{B}}{d t}\right|_{\Delta T}-\left(\dot{B}_{r}+\dot{B}_{c}+\Delta \dot{B}_{r e s}+\dot{B}_{e}\right)
$$

A Equação 3.11 demonstra a definição de $\dot{B}_{Q_{M}}$, ou seja, da exergia liberada para o VC1 decorrente das reações do metabolismo celular. Nessa equação, $T_{0}$ é a temperatura do ambiente de referência e $T_{m}$ é a temperatura média do corpo.

$$
\dot{B}_{Q_{M}}=\dot{Q}_{M}\left(1-\frac{T_{0}}{T_{m}}\right)
$$

Aplicando-se a análise exergética ao VC2, chega-se à Equação 3.12 , em que $\dot{B}_{\text {reag }}$ e $\dot{B}_{\text {prod }}$ representam a exergia dos reagentes e produtos das reações celulares de oxidação.

$$
\dot{B}_{\text {dest }}^{V C 2}=\dot{B}_{\text {reag }}-\dot{B}_{\text {prod }}-\dot{B}_{Q_{M}}-\dot{W}
$$

Portanto, o metabolismo exergético $\dot{B}_{M}$ é definido de acordo com a Equação 3.13.

$$
\dot{B}_{M}=\dot{B}_{\text {reag }}-\dot{B}_{\text {prod }}
$$

A partir da análise das Equações 3.11 a 3.13, fica evidente que o metabolismo não deve ser tratado como uma fonte de calor, pois $\dot{B}_{Q_{M}}$ tem uma magnitude diferente de $\dot{B}_{M}$. Ele deve ser tratado como um processo de conversão de energia, por meio do qual entram no corpo os nutrientes que são degradados de forma que o corpo seja capaz de realizar trabalho como produto principal (atividades físicas e manutenção das funções vitais) e dissipar uma parte dessa exergia na forma de calor. Prek (2004, 2006), Prek e Butala (2010) e Simone et al. (2011) usaram como metabolismo exergético apenas a parcela térmica $\dot{B}_{Q_{M}}$. Portanto, toda a exergia dos nutrientes disponível no VC2, da Figura 3.1, seria negligenciada, se tal abordagem fosse utilizada. Como os autores estudaram o modelo em repouso, a análise não teve contradições. Se fosse feita uma análise que leva em conta a realização de trabalho, seria possível obter incoerências no resultados, como a exergia de alimentação ser menor do que o trabalho executado, dado que a energia desse último vem de $\dot{B}_{M}$ e não de $\dot{B}_{Q_{M}}$. 
Somando-se as Equações 3.10 e 3.13, obtém-se o balanço de exergia para o corpo (Equação $3.14)$.

$$
\dot{B}_{\text {dest }}^{\text {corpo }}=\dot{B}_{\text {dest }}=\dot{B}_{M}-\left.\frac{d \mathbf{B}_{\text {corpo }}}{d t}\right|_{\Delta T}-\left(\dot{B}_{r}+\dot{B}_{c}+\Delta \dot{B}_{r e s}+\dot{B}_{e}\right)-\dot{W}
$$

Calcula-se o rendimento exergético de acordo com a Equação 3.15, que, em regime permanente (sem variações da temperatura do corpo com o tempo), equivale à Equação 3.16 .

$$
\begin{aligned}
& \eta_{b}=\frac{\left|\frac{d \mathbf{B}}{d t}\right|-\dot{B}_{\text {dest }}}{\left|\frac{d \mathbf{B}}{d t}\right|} \\
& \eta_{b}=\frac{\dot{B}_{M}-\dot{B}_{\text {dest }}}{\dot{B}_{M}}
\end{aligned}
$$

\subsection{ANÁLISE ENERGÉTICA E EXERGÉTICA}

\subsubsection{Cálculo do metabolismo em base energética e exergética}

Para o cálculo dos metabolismos energético e exergético, foram utilizadas as reações de oxidação da glicose (Equação 2.39), ácido palmítico (Equação 2.41) e um aminoácido com propriedades termodinâmicas médias (Equação 3.17). Tanto em Diener (1997) como em Batato et al. (1990) apresentam-se reações de oxidação para aminoácidos. Porém, o primeiro usa de valores médios para os coeficientes estequiométricos, e o segundo adota um aminoácido representativo, mas não há clareza quanto aos valores de propriedades obtidos. Lehninger, Nelson e Cox (2005) atribuem a taxa de ocorrência dos aminoácidos em mais de 1150 proteínas encontradas na natureza, sendo possível obter um aminoácido com composição média $\left(\mathrm{C}_{4,98} \mathrm{H}_{9,8} \mathrm{~N}_{1,4} \mathrm{O}_{2,5}\right)$. A reação 3.17 indica a oxidação desse aminoácido médio até atingir a formação de gás carbônico, água líquida e ureia. Mais adiante se mostrará a análise de como foram obtidas a reação e a molécula média. 


$$
\mathrm{C}_{4,98} \mathrm{H}_{9,8} \mathrm{~N}_{1,4} \mathrm{O}_{2,5}+5,135 \mathrm{O}_{2} \rightarrow 4,28 \mathrm{CO}_{2}+3,5 \mathrm{H}_{2} \mathrm{O}+0,7 \mathrm{CH}_{4} \mathrm{~N}_{2} \mathrm{O}
$$

\subsubsection{Cálculo da taxa de consumo de nutrientes}

Usando-se as Equações de oxidação da glicose, do ácido palmítico e do aminoácido com composição média, pode-se proceder de modo semelhante ao das Equações 2.58 e 2.59, porém em base mássica. Assim, chega-se ao sistema de Equações 3.18 a 3.20. Nota-se que foi utilizada a seguinte convenção: cada grama de nitrogênio excretado pela urina representa a oxidação de 6,25g de aminoácidos, como em Diener (1997).

$$
\begin{array}{r}
\dot{m}_{\text {carb }}=-2,14 \dot{m}_{\mathrm{O}_{2}}+2,24 \dot{m}_{\mathrm{CO}_{2}}-3,39 \dot{m}_{N} \\
\dot{m}_{l i p}=1,14 \dot{m}_{\mathrm{O}_{2}}-0,83 \dot{m}_{\mathrm{CO}_{2}}-1,5 \dot{m}_{N} \\
\dot{m}_{a m i}=6,25 \dot{m}_{N}
\end{array}
$$

\subsubsection{Cálculo do metabolismo energético}

Tomando por base os valores de variação de entalpia específica da glicose, do ácido palmítico e do aminoácido médio (substâncias representativas das classes carboidratos, lipídeos e aminoácidos) e do sistema de Equações 3.18 a 3.20, é possível calcular a variação da entalpia das reações de oxidação como função do consumo de oxigênio e produção de dióxido de carbono. De forma mais específica, como função da taxa de consumo de carboidratos, lipídeos e aminoácidos, como indicado na Equação 3.21. A massa consumida de aminoácidos é calculada usando-se a consideração feita por Diener (1997) de que diariamente são excretados $12 \mathrm{~g}$ de nitrogênio na ureia vindos da oxidação das proteínas.

$$
\Delta \dot{H}_{M}=\dot{m}_{c a r b} \Delta h_{c a r b}+\dot{m}_{l i p} \Delta h_{l i p}+\dot{m}_{a m i} \Delta h_{a m i}
$$

Neste texto, o metabolismo energético é definido pela forma indicada na Equação 3.22 (também na Equação 3.8). 


$$
\dot{M}=-\Delta \dot{H}_{M}
$$

\subsubsection{Cálculo do metabolismo exergético}

Com base nos valores de variação de exergia específica da glicose, do ácido palmítico e do aminoácido médio, e do sistema de Equações 3.18 a 3.20, é possível calcular a variação da exergia das reações de oxidação $\left(\Delta \dot{B}_{M}\right)$ como função da taxa de consumo de glicose, lipídeos e aminoácidos, conforme indica a Equação 3.23.

$$
\Delta \dot{B}_{M}=\dot{m}_{c a r b} \Delta b_{c a r b}+\dot{m}_{l i p} \Delta b_{g l i c}+\dot{m}_{a m i} \Delta b_{a m i}
$$

Assim, define-se o metabolismo exergético $\left(\dot{B}_{M}\right)$ pela Equação 3.24.

$$
\dot{B}_{M}=-\Delta \dot{B}_{M}
$$

\subsubsection{Propriedades Termodinâmicas}

Para o cálculo do metabolismo energético e exergético, torna-se necessário conhecer a variação de entalpia e da energia livre de Gibbs no que se refere às reações de oxidação dos substratos energéticos. Esses valores estão indicados nas Tabelas 3.1 e 3.2. Os dados foram obtidos em: Diener (1997), Haynie (2008) e Cortassa et al. (2002) . Nota-se que, na terceira coluna dessas tabelas, a variação de entalpia e da energia de livre Gibbs das proteínas não está indicada, pois Cortassa et al. (2002) forneceram os valores da variação de entalpia e energia livre de Gibbs para oxidação completa (e não até a formação de água líquida, dióxido de carbono e ureia) de diversos aminoácidos, conforme a Tabela 3.3.

Tabela 3.1: Variação da entalpia das reações de oxidação da glicose, ácido palmítico e proteínas $(\mathrm{kJ} / \mathrm{kg})$ na forma como ocorrem no corpo

\begin{tabular}{|c|c|c|c|}
\hline- & \multicolumn{3}{|c|}{$\Delta h(\mathrm{~kJ} / \mathrm{kg})$} \\
\hline Referências & Glicose & Ácido Palmítico & Aminoácido \\
\hline Diener (1997) & -15648 & -39581 & -18075 \\
Haynie (2008) & -15600 & -39200 & -19000 \\
Cortassa et al. (2002) & -15594 & -39020 & - \\
\hline
\end{tabular}


Tabela 3.2: Variação da energia de livre Gibbs quanto às reações de oxidação da glicose, ácido palmítico e proteínas $(\mathrm{kJ} / \mathrm{kg})$ na forma como ocorrem no corpo

\begin{tabular}{|c|c|c|c|}
\hline- & \multicolumn{3}{|c|}{$\Delta g(\mathrm{~kJ} / \mathrm{kg})$} \\
\hline Referências & Glicose & Ácido Palmítico & Aminoácido \\
\hline Diener (1997) & - & - & - \\
Haynie (2008) & -15946 & -38212 & - \\
Cortassa et al. (2002) & -15956 & -38281 & - \\
\hline
\end{tabular}

A Tabela 3.3 aponta os valores de propriedades termodinâmicas para $96 \%$ dos aminoácidos presentes na natureza, exceção à metionina e cisteína. Esses valores são usados para o cálculo da composição média e propriedades termodinâmicas médias dessas substâncias, similar ao proposto por Silva e Annamalai (2008, 2009).

Tabela 3.3: Propriedades termodinâmicas da oxidação completa (formação de dióxido de carbono, água líquida e nitrogênio) de 95,8\% dos aminoácidos . Dados obtidos em

Cortassa et al. (2002), Szargut, Morris e Steward (1988) e ocorrência média de cada aminoácido na natureza, obtidos em Lehninger, Nelson e Cox (2005)

\begin{tabular}{|c|c|c|c|c|c|}
\hline Aminoácido & Fórmula & $\%$ Natureza & $\Delta h(\mathrm{~kJ} / \mathrm{kg})$ & $\Delta g(\mathrm{~kJ} / \mathrm{kg})$ & $b_{c h}^{*}(\mathrm{~kJ} / \mathrm{kg})$ \\
\hline Glicina & $\mathrm{C}_{2} \mathrm{H}_{5} \mathrm{NO}_{2}$ & 7,2 & -12987 & -13480 & 14150 \\
\hline Alanina & $\mathrm{C}_{3} \mathrm{H}_{7} \mathrm{NO}_{2}$ & 7,8 & -19180 & -18449 & 18991 \\
\hline Serina & $\mathrm{C}_{3} \mathrm{H}_{7} \mathrm{NO}_{3}$ & 6,8 & -13857 & -14305 & 14783 \\
\hline Ácido Aspártico & $\mathrm{C}_{4} \mathrm{H}_{7} \mathrm{NO}_{3}$ & 5,3 & -12090 & -12667 & 13189 \\
\hline Aspargina & $\mathrm{C}_{4} \mathrm{H}_{8} \mathrm{~N}_{2} \mathrm{O}_{3}$ & 4,3 & -14667 & -15144 & 15643 \\
\hline Treonina & $\mathrm{C}_{4} \mathrm{H}_{9} \mathrm{NO}_{3}$ & 5,9 & -17681 & -17899 & 18446 \\
\hline Prolina & $\mathrm{C}_{5} \mathrm{H}_{9} \mathrm{NO}_{2}$ & 5,2 & -23783 & $-24205^{* * *}$ & $24856^{* *}$ \\
\hline Ácido Glutâmico & $\mathrm{C}_{5} \mathrm{H}_{9} \mathrm{NO}_{4}$ & 6,3 & -15306 & -15748 & 16312 \\
\hline Glutamina & $\mathrm{C}_{5} \mathrm{H}_{10} \mathrm{~N}_{2} \mathrm{O}_{3}$ & 4,2 & -17603 & -18000 & 18553 \\
\hline Valina & $\mathrm{C}_{5} \mathrm{H}_{11} \mathrm{NO}_{2}$ & 6,6 & -24957 & -24957 & 25623 \\
\hline Histidina & $\mathrm{C}_{6} \mathrm{H}_{9} \mathrm{~N}_{3} \mathrm{O}_{2}$ & 2,3 & -22103 & $-22039^{* * *}$ & $22629^{* *}$ \\
\hline Leucina & $\mathrm{C}_{6} \mathrm{H}_{13} \mathrm{NO}_{2}$ & 9,1 & -27389 & -27214 & 27921 \\
\hline Lisina & $\mathrm{C}_{6} \mathrm{H}_{14} \mathrm{~N}_{2} \mathrm{O}_{2}$ & 5,9 & -25233 & $-25951^{* * *}$ & $26541^{* *}$ \\
\hline Arginina & $\mathrm{C}_{6} \mathrm{H}_{14} \mathrm{~N}_{4} \mathrm{O}_{2}$ & 5,1 & -21517 & -21759 & 22294 \\
\hline Fenilalanina & $\mathrm{C}_{9} \mathrm{H}_{11} \mathrm{NO}_{2}$ & 3,9 & -28200 & -28164 & 29021 \\
\hline Tirosina & $\mathrm{C}_{9} \mathrm{H}_{11} \mathrm{NO}_{3}$ & 3,2 & -24514 & -24768 & 25560 \\
\hline Triptofano & $\mathrm{C}_{11} \mathrm{H}_{12} \mathrm{~N}_{2} \mathrm{O}_{2}$ & 1,4 & -27608 & -27691 & 28540 \\
\hline Valor Médio & $\mathrm{C}_{4.98} \mathrm{H}_{9.8} \mathrm{~N}_{1.4} \mathrm{O}_{2.5}$ & - & -20965 & -21164 & 21784 \\
\hline
\end{tabular}

Considerando-se os valores da Tabela 3.3, da variação de entalpia da oxidação da ureia Doran (1995) (10527 kJ/kg) e da exergia química fornecida por Szargut, Morris e Steward (1988) (11483 kJ/kg), é possível calcular a variação de entalpia e da exergia para oxidação dos aminoácidos da maneira como ocorrem no corpo, ou seja, até a formação de água líquida, dióxido de carbono e ureia. Para tal, é realizada uma combinação linear das propriedades termodinâmicas da ureia com cada um dos aminoácidos. Tomando como exemplo o aminoácido tirosina $\left(\mathrm{C}_{9} \mathrm{H}_{11} \mathrm{NO}_{3}\right)$, as Equações 3.25 e a 3.26 representam a 
oxidação da tirosina e da ureia necessárias para o cálculo da variação de entalpia e da exergia química das duas substâncias (reações de referência).

$$
\begin{aligned}
& \mathrm{C}_{9} \mathrm{H}_{11} \mathrm{NO}_{3}+10,25 \mathrm{O}_{2} \rightarrow 9 \mathrm{CO}_{2}+5,5 \mathrm{H}_{2} \mathrm{O}+0,5 \mathrm{~N}_{2} \\
& \mathrm{CH}_{4} \mathrm{~N}_{2} \mathrm{O}+1,5 \mathrm{O}_{2} \rightarrow \mathrm{CO}_{2}+2 \mathrm{H}_{2} \mathrm{O}+\mathrm{N}_{2}
\end{aligned}
$$

A Equação 3.27 representa a oxidação da tirosina até a ureia. Nota-se que o processo é basicamente subtrair da Reação 3.27 a Reação em sentido inverso à 3.26 multiplicada por um coeficiente (no caso 0,5). O mesmo pode ser feito para as propriedades termodinâmicas. A variação da entalpia na oxidação parcial pode ser escrita como função da variação da entalpia da reação de oxidação completa dos compostos tirosina e ureia, assim como indicado na Equação 3.28. Um processo semelhante pode ser aplicado para obter a Equação 3.29. Esses valores, se usados em base mássica, podem ser representativos da classe de aminoácidos dentro do corpo.

$$
\begin{aligned}
& \mathrm{C}_{9} \mathrm{H}_{11} \mathrm{NO}_{3}+9,5 \mathrm{O}_{2} \rightarrow 8,5 \mathrm{CO}_{2}+4,5 \mathrm{H}_{2} \mathrm{O}+0,5 \mathrm{CH}_{4} \mathrm{~N}_{2} \mathrm{O} \\
& \Delta h=\Delta h_{C_{9} \mathrm{H}_{11} \mathrm{NO}_{3}}-0,5 \Delta h_{\mathrm{CH}_{4} \mathrm{~N}_{2} \mathrm{O}} \\
& \Delta b_{q}=b_{q, C_{9} \mathrm{H}_{11} \mathrm{NO}_{3}}-0,5 b_{q, \mathrm{CH}_{4} \mathrm{~N}_{2} \mathrm{O}}
\end{aligned}
$$

Como destacado anteriormente, o método usado para obter as Equações 3.28 e 3.29 é uma forma simplificada de se obter as propriedades termodinâmicas $\left(\Delta H, \Delta B\right.$ e $\left.\Delta B_{q}\right)$ da oxidação dos aminoácidos conforme essas reações ocorrem no corpo (formação de água líquida, dióxido de carbono e ureia) sem a necessidade de se usar propriedades de formação. Portanto, $\Delta h_{C_{9} H_{11} N_{3}}$ e $b_{q, C_{9} H_{11} N O_{3}}$ referem-se à variação da entalpia e exergia química da Equação 3.25, enquanto que $\Delta h_{\mathrm{CH}_{4} \mathrm{~N}_{2} \mathrm{O}}$ e $b_{q, \mathrm{CH}_{4} \mathrm{~N}_{2} \mathrm{O}}$, a variação da entalpia e exergia química da Equação 3.26 


\subsubsection{Metabolismo celular e máximo trabalho}

\subsubsection{Hidrólise ou formação do ATP}

Neste texto, não houve a pretensão de calcular a exergia química das moléculas do ATP e ADP, pois estas misturam cadeias orgânicas (adenosina) com elementos inorgânicos (trifosfato). Para o cálculo da exergia química, Lems (2009) partiu da constatação de que a energia de Gibbs de formação do grupo adenosina é considerada nula nas condições padrões bioquímicas e concentrou os cálculos no grupo fosfato. Entretanto, nada foi dito quanto à energia de ligação do grupo fosfato com o grupo adenosina

Tendo em vista que para o cálculo da exergia as condições de temperatura e pressão dos compostos bioquímicos são as mesmas do ambiente de referência (ou seja, a exergia física nas reações de oxidação são negligenciadas), a variação da energia livre de Gibbs das reações é a própria variação da exergia. É importante destacar que, como esses compostos ou estão na forma apresentada ao lado esquerdo da Reação 2.13 ou do lado direito, esse é o máximo trabalho que pode ser obtido dessa reação (no caso, a hidrólise do ATP).

Para o tratamento do metabolismo na escala celular, deve-se levar em conta a hidrólise ou formação da molécula do ATP, mostrado na Seção 2.2. A Reação $2.13\left(A D P+P_{i} \rightleftharpoons\right.$ $\left.A T P+H_{2} \mathrm{O}\right)$ é a fonte de energia para todas as atividades do corpo, sendo o ATP denominado na literatura bioquímica de "moeda energética". Lehninger, Nelson e Cox (2005), Hammes (2000) e Lems (2009) mostram que as condições padrões bioquímicas e as reais da célula nem sempre são as mesmas. Na Tabela 2.5, percebe-se que a variação da exergia nas condições reais $(-56 \mathrm{~kJ} / \mathrm{mol})$ é quase o dobro das condições bioquímicas $(30,5 \mathrm{~kJ} / \mathrm{mol})$ para hidrólise do ATP.

Para se levar em conta o efeito da dissociação ácida deve-se encontrar as constantes de equilíbrio $\mathrm{k}_{i}$. Lems (2009) encontrou os valores de $p k_{i}\left(p k_{i}=-\log \left(k_{i}\right)\right)$ para as sete constantes. O autor recalculou as constantes de equilíbrio levando em conta as Equações 2.48 e 2.49 para obter o efeito das iterações iônicas. Os resultados estão indicados na Tabela 2.5. No entanto, neste texto, serão usados os resultados propostos por Alberty e Goldberg (1992), Alberty (1998). Os autores calcularam a energia de Gibbs de formação e a entalpia de formação para diversos compostos bioquímicos em condições "próximas das condições fisiológicas", que são: 298,15 K, 1 atm, $p H=7, p M g=3$ e 0,25 mol/L de força iônica. Assim, obtiveram, para essas condições, que a variação da energia livre de Gibbs para hidrólise do ATP equivale a $-32,48 \mathrm{~kJ} / \mathrm{mol}$, faltando apenas corrigir as concentrações dos reagentes e produtos. Nesse caso, assim como para Lems (2009), os efeitos citados 
anteriormente são pequenos se comparados ao valor absoluto de variação de energia de Gibbs na reação de hidrólise do ATP (afeta aproximadamente 1 a $2 \mathrm{~kJ} / \mathrm{mol}$ a variação da energia livre de Gibbs). Já no caso das propriedades de formação, ele passa a ser relevante.

Por fim, deve-se mudar as concentrações dos ATP, ADP e $\mathrm{P}_{i}$ da referência bioquímica para o estado real da célula, como indicado na Equação 3.30 para hidrólise do ATP, as quais equivalem a 1,85, 0,14 e 1,0 mmol/L, respectivamente. Esses valores estão indicados em Lems (2009) e Hammes (2000) para glóbulos vermelhos (condições próximas ao hialoplasma das células do ser humano) e foram obtidos por Minakami e Yoshikawa (1965). Apesar de Lehninger, Nelson e Cox (2005) mostrarem uma concentração de ADP maior que $0,25 \mathrm{mmol} / \mathrm{L}$ eles afirmam que esse valor pode ser bem menor. Portanto, a variação na energia livre de Gibbs passa a ser $-56,1 \mathrm{~kJ} / \mathrm{mol}$ (o efeito das concentrações equivale a $-23,51 \mathrm{~kJ} / \mathrm{mol})$.

$$
\Delta g=\Delta g^{\prime 0}+R T_{0} \ln \left(\frac{[A D P]\left[P_{i}\right]}{[A T P]}\right)=-56,1 k J / m o l
$$

\subsubsection{Máximo trabalho disponível para o corpo}

Apoiando-se no conceito de rendimento do metabolismo celular, indicado na Equação 2.40, pode-se escrever qual é o máximo trabalho que o corpo pode realizar a partir da energia contida nas moléculas de ATP, como na Equação 3.31. Nota-se que essa pode ser escrita avaliando o número de mols de ATP que sofrem hidrólise $\left(\dot{n}_{A T P}\right)$ ou pelo consumo de nutrientes (glicose, lipídeos e carboidratos).

$$
\dot{W}_{\text {max }}=\dot{n}_{A T P}\left|\Delta g_{A T P}\right|=\sum_{i=1}^{3} \eta_{M, i}\left|\Delta G_{i}\right|
$$

No qual, $W_{\max }$ é o máximo trabalho que pode ser executado a partir da energia química contida nas moléculas de ATP, $\dot{n}_{A T P}$ números de mols de ATP que sofreram hidrólise, $\Delta g_{A T P}$ variação da energia livre de Gibbs na hidrólise do $\operatorname{ATP}, \Delta G_{i}$ é a variação da energia livre de Gibbs da reação de oxidação do nutriente $i$ ( $i$ refere-se à glicose, lipídeos e aminoácidos) e $\eta_{M, i}$ é o rendimento metabólico da reação de oxidação.

Para o cálculo do número de mols de ATP que sofreram hidrólise, deve-se usar os 
resultados propostos em Lehninger, Nelson e Cox (2005), Silva e Annamalai (2008) e Silva e Annamalai (2009), ou seja, de que $1 \mathrm{~mol}$ de glicose consumido na respiração aeróbica forma 32 mols de ATP, 1 mol de ácido palmítico forma 106 mols de ATP e 1 mol de aminoácido forma 8 mols de ATP. Sabendo-se o consumo de carboidratos $\left(\dot{m}_{\text {carb }}\right)$, lipídeos $\left(\dot{m}_{l i p}\right)$ e aminoácidos $\left(\dot{m}_{\text {amin }}\right)$, consegue-se calcular a taxa de hidrólise do ATP de acordo com a Equação 3.32. No caso da oxidação anaeróbica da glicose, há a formação de 2 mols de ATP.

$$
\dot{n}_{A T P}=32 \frac{\dot{m}_{\text {carb }}}{M_{\text {carb }}}+106 \frac{\dot{m}_{\text {lip }}}{M_{\text {lip }}}+8 \frac{\dot{m}_{\text {amin }}}{M_{\text {amin }}}
$$

\subsubsection{Metabolismo celular e o ATP}

Pelos conceitos apresentados, pode-se dividir o metabolismo celular (indicado como VC2 na Figura 3.1) em duas etapas principais, ou em duas reações, como realçado na Figura 3.2. A primeira é a oxidação completa dos nutrientes (carboidratos, lipídeos e proteínas), seguida da hidrólise ou formação do ATP. Esta última é a fonte real de energia do corpo para realização de trabalho e funções vitais (fenômenos organizados). Simultaneamente à ocorrência da oxidação dos nutrientes, tem-se a hidrólise e a formação do ATP.

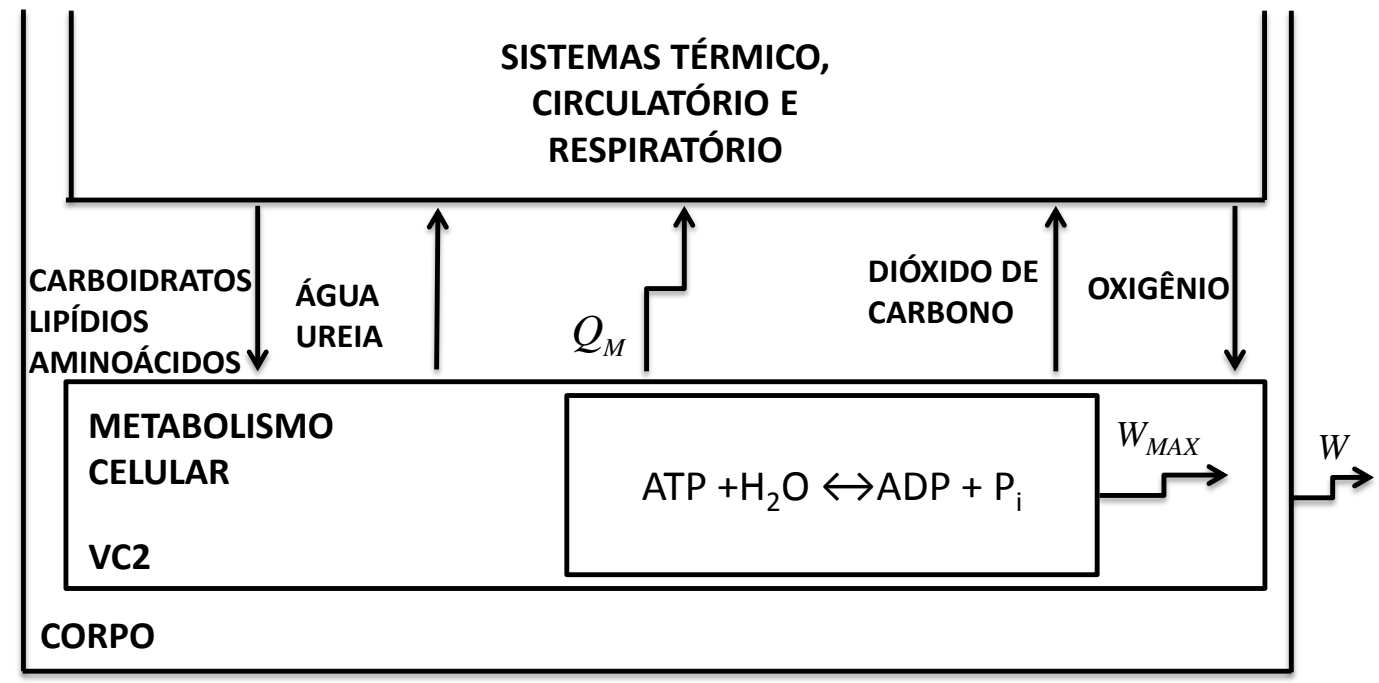

Figura 3.2: Representação do metabolismo celular com a hidrólise e formação do ATP

A Equação 3.33 descreve a quantidade de exergia destruída pelo metabolismo para gerar certa quantidade de ATP, por meio dos macronutrientes $\left(\dot{B}_{d, A T P}\right)$. Por exemplo, um mol de glicose gera $32 \mathrm{~mol}$ de ATP. O termo $\dot{B}_{d, A T P}$ significa o quanto da exergia liberada na oxidação dos nutrientes o corpo deixa de aproveitar ao transformar o ATP em "moeda energética e exergética" (grupo responsável pela liberação de exergia dentro do corpo para 
qualquer atividade).

$$
\dot{B}_{d, A T P}=B_{M}-B_{Q_{M, A T P}}-\Delta G_{A T P}=\sum_{i=1}^{3} \Delta G_{i}-\Delta G_{A T P}=\sum_{i=1}^{3} \Delta G_{i}\left(1-\eta_{m e t, i}\right)
$$

O restante da exergia destruída no metabolismo celular $\left(\dot{B}_{d, r e s t}\right)$ pode ser visto na Equação 3.34. Observa-se que a soma das duas equações equivale à Equação 3.12, ou seja, a exergia destruída no metabolismo celular $\dot{B}_{d, A T P}+\dot{B}_{d, \text { rest }}=\dot{B}_{d}^{V C 2}$. Vale ressaltar que, segundo a literatura da área, a hidrólise do ATP libera energia para as funções vitais do corpo de forma reversível, afirmação que será utilizada como hipótese simplificadora neste texto.

$$
\dot{B}_{d, r}=\Delta G_{A T P}-W-B_{Q_{M, r}}
$$

Baseando-se nas Equações 3.33 e 3.34, é possível propor um diagrama que representa o metabolismo celular, considerando-se a atividade física, como um processo de três etapas principais (Figura 3.3): oxidação dos nutrientes, formação do ATP e uso do ATP:

- Oxidação dos nutrientes: representa a variação da exergia da oxidação completa dos nutrientes no corpo (que equivale à variação da energia livre de Gibss dessa reação), ou metabolismo exergético. Essa grandeza, $B_{M}$, representa o máximo trabalho que o corpo poderia extrair dos nutrientes consumidos.

- Formação do ATP: o corpo é capaz apenas de extrair energia para atividades por meio das moléculas de ATP; entretanto, parte da exergia contida nos nutrientes (glicose, lipídeos e aminoácidos) é destruída e transferida para o corpo na forma de calor. Portanto, $W_{\text {MAX }}$ representa o limite superior para realização de trabalho.

- Uso do ATP: Parte de $W_{M A X}$ não é convertida em trabalho, logo, $W$ representa o que é realmente convertido em trabalho, sendo o restante destruído (atrito e ineficiências do corpo em transformar a exergia do ATP em trabalho) ou transferido para o corpo na forma de calor.

Embora a exergia associada ao metabolismo $\left(\dot{B}_{Q_{M}}\right)$ seja um resíduo do processo de degradação dos nutrientes, ela deve ser considerada um produto do metabolismo, pois animais homeotermos conseguem manter a temperatura do corpo constante devido a essa transferência de energia $\dot{B}_{M}$. Propõe-se, então, um índice que leva em conta a contribuição percentual de $\dot{B}_{Q_{M}}$ no $\dot{B}_{M}$, como indicado na Equação 3.35. Caso o indivíduo esteja em repouso, o indicador fica bem próximo do valor do fator de Carnot (como obtido por 


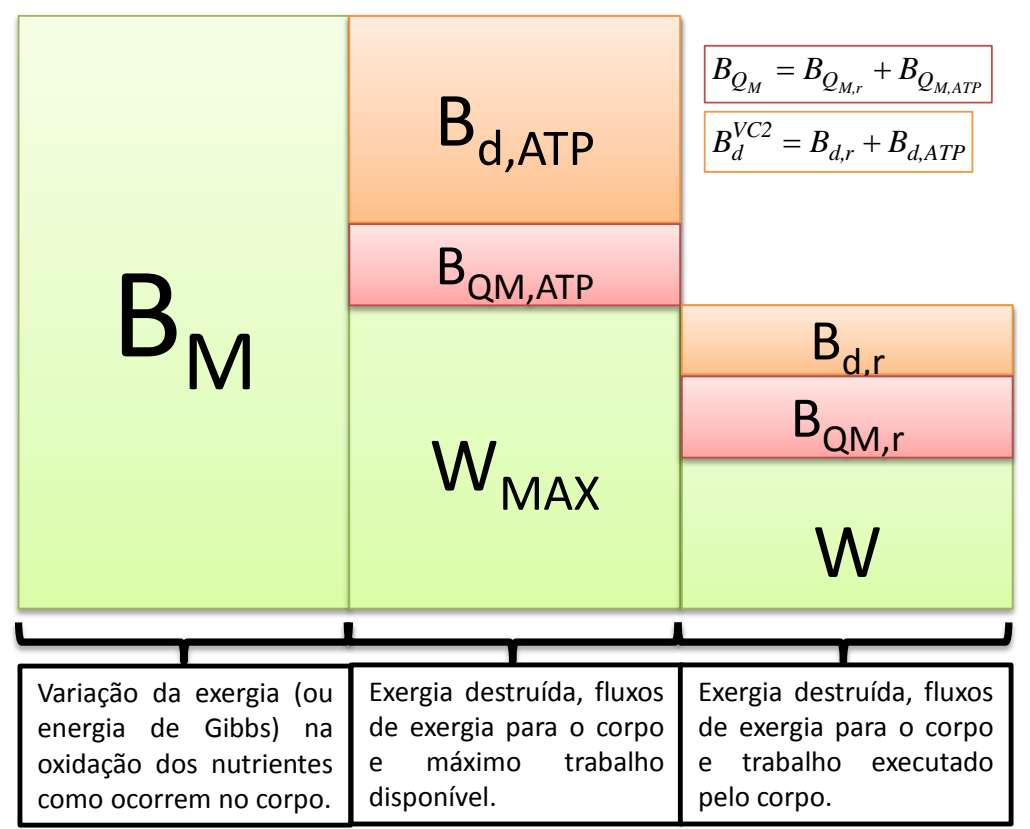

Figura 3.3: Degradação dos nutrientes do corpo divididos em três etapas fundamentais: oxidação dos nutrientes, formação do ATP e uso do ATP

Batato et al. (1990): $M / B_{M} \rightarrow 1$ ). No entanto, como $\dot{B}_{M}=M-W$, caso o individuo esteja praticando alguma atividade física, percentualmente, a contribuição do calor do metabolismo diminui em relação à contribuição do trabalho.

$$
r=\frac{B_{Q_{M}}}{B_{M}}=\frac{(M-W)\left(1-\frac{T_{0}}{T_{m}}\right)}{B_{M}}
$$

\subsubsection{Taxas de transferência de calor e fluxos de entalpia para o ambiente}

Para aplicar o balanço de energia, devem ser levadas em conta as trocas de calor e entalpia por meio da convecção, da radiação, da evaporação e da respiração. Na análise dos fluxos, considera-se uma resistência adicional à superfície da pele, sendo a roupa representada conforme indica a norma ASHRAE (2005). O cálculo dos fluxos de calor e entalpia são baseados em ASHRAE (2005) e Ferreira (2001).

O calor transferido por convecção pode ser calculado pela Equação 3.36.

$$
\dot{Q}_{c}=f_{c l} h_{c} A_{d}\left(T_{c l}-T_{a r}\right)
$$


Sendo $\dot{Q}_{c}$ a taxa de troca de calor por convecção $(\mathrm{W}) ; f_{c l}$ a razão entre a área do corpo vestido e nu; $h_{c}$ o coeficiente de transferência de calor por convecção $\left(\mathrm{W} / \mathrm{m}^{2} .{ }^{o} \mathrm{C}\right)$ (obtido em Dear et al. (1997)); $T_{c l}$ a temperatura da superfície da roupa $\left({ }^{\circ} \mathrm{C}\right) ; T_{a}$ a temperatura do ar ambiente $\left({ }^{\circ} \mathrm{C}\right)$; e $A_{d}$ a área da superfície do corpo $\left(\mathrm{m}^{2}\right)$ (calculada a partir da equação de DuBois e DuBois (1916)).

O calor transferido por radiação é calculado pela Equação 3.37 .

$$
\dot{Q}_{r}=f_{c l} h_{r} A_{d}\left(T_{c l}-T_{r m}\right)
$$

Sendo $\dot{Q}_{\text {rad }}$ a taxa de troca de calor por radiação $(\mathrm{W}) ; h_{r}$ o coeficiente de transferência de calor por radiação $\left(\mathrm{W} / \mathrm{m}^{2} .{ }^{\circ} \mathrm{C}\right)$ (obtido em Dear et al. (1997)); e $T_{r m}$ a temperatura radiante média $\left({ }^{\circ} \mathrm{C}\right)$.

O coeficiente de transferência de calor pode ser calculado pela Equação 3.38. Nota-se que as temperaturas estão incorporadas no coeficiente para aplicação da Equação 3.39.

$$
h_{r}=\sigma f_{r} \epsilon A_{d}\left(T_{c l}+T_{r m}\right)\left(T_{c l}^{2}+T_{r m}^{2}\right)
$$

Sendo $\epsilon$ a emissividade da pele; $\sigma$ a constante de Stefan - Boltzamnn $\left(\mathrm{W} / \mathrm{m}^{2} \mathrm{~K}^{4}\right)$; e $f_{r}$ a razão entre área efetiva radiante e externa do corpo.

Nas Equações 3.36 e 3.37, a roupa pode ser considerada uma resistência adicional ao fluxo de calor (facilitando a modelagem da transferência de calor entre pele e roupa). Assim, aplicando-se o balanço de energia em torno da roupa, chega-se à Equação 3.39.

$$
\dot{Q}_{r}+\dot{Q}_{c}=\frac{T_{s}-T_{o}}{R_{c l}+\frac{1}{f_{c l} . h}}
$$

No qual, $R_{c l}$ é a resistência térmica da roupa à condução; $T_{s}$, a temperatura da superfície da pele; $T_{o}$, a temperatura operativa (Equação 3.40 ); $h$, o coeficiente combinado de transferência de calor $\left(\mathrm{W} /\left(\mathrm{m}^{2 o} \mathrm{C}\right)\right)$ (Equação 3.41).

$$
T_{o}=\frac{h_{c} T_{a r}+h_{r} T_{r m}}{h_{c}+h_{r}}
$$


Verifica-se que, se for considerado um ambiente com temperatura das paredes com valor igual à do ar ambiente, a temperatura operativa se tonará igual à temperatura do ar ambiente. Os coeficientes de transferência de calor por radiação e convecção foram obtidos a partir de trabalhos experimentais em um manequim feminino, como indicam Dear et al. (1997), sendo o valor do coeficiente combinado a soma dos coeficientes radiativo e convectivo (Equação 3.41).

$$
h=h_{c}+h_{r}
$$

Os fluxos de entalpia em consequência da evaporação pela pele podem ser divididos em duas parcelas: uma por causa da perda natural de água pela superfície da pele, e outra, sujeita ao sistema de controle do corpo, causado pela evaporação do suor. Os fluxos de energia relacionados ao efeito da evaporação e perdidos na superfície da pele podem ser calculados pela vazão de água multiplicada pela energia necessária para mudança de fase (Equação 3.42), ou utilizando o coeficiente de transferência de massa por difusão (Equação $3.43)$.

$$
\begin{aligned}
& \dot{H}_{e}=\left(\dot{N}_{e} M_{v a p}\right) h_{l v}\left(T_{s}\right) \\
& \dot{H}_{e}=h_{e} A_{d} \Delta p_{v a p}
\end{aligned}
$$

Nessas equações, $\dot{H}_{e}$ é o fluxo de entalpia causado pelo suor evaporado pela pele (W); $\dot{N}_{e}$ é o número de mols de água que evaporam da superfície da pele $(\mathrm{kmol} / \mathrm{s}) ; M_{v a p}$ é a massa molecular da água $(\mathrm{kg} / \mathrm{kmol}) ; h_{l v}\left(T_{s}\right)$ é a entalpia de evaporação da água na temperatura da superfície da pele; $h_{e}$ é o coeficiente de transferência de massa por evaporação $\left(\mathrm{W} / \mathrm{m}^{2 o} \mathrm{C}\right) ; \Delta p_{\text {vap }}$ é a diferença da pressão de saturação entre o vapor no ar e na pele $(\mathrm{Pa})$.

A evaporação pela pele pode ser calculada pela Equação 3.44. Nesta, o fator multiplicador $w$, chamado de fração de superfície molhada, equivale a 0,06 , quando só houver difusão (suor não está presente), e equivale a 1, quando a pele estiver completamente molhada por suor.

$$
\dot{H}_{e}=w A \frac{p_{v a p, s}-\phi_{a} p_{v a p, a}}{R_{e, c l}+\frac{1}{f_{c l} h_{e}}}
$$


Na qual, $\omega$ é a fração da superfície molhada; $p_{v a p, s}$ é a pressão parcial do vapor de água na superfície da pele $(\mathrm{Pa})$, normalmente assumida como a pressão de saturação; $p_{v a p, a}$ é a pressão parcial de saturação do vapor de água no ar $(\mathrm{Pa}) ; \phi_{a}$ é a umidade relativa do ar; $R_{e, c l}$ é a resistência à evaporação imposta pela roupa $\left(\mathrm{Pam}^{2} / \mathrm{W}\right)$.

Considerando-se que não há simultaneamente difusão de água e suor na mesma área superficial, o cálculo da fração molhada na Equação 3.44 está indicado na Equação 3.45, sendo $\dot{H}_{e, \max }$ a máxima variação de entalpia, em virtude da evaporação pela pele.

$$
w=0,06+0,94 \frac{\dot{H}_{e, s w}}{\dot{H}_{e, \max }}
$$

O fluxo de entalpia provocado pela respiração pode ser dividida em duas parcelas: uma se deve ao aumento de umidade do ar expirado em relação ao inspirado, e outra, proveniente da diferença de temperaturas entre o ar inspirado e o expirado (Equação 3.46). Nota-se que não se apresenta a hipótese de que o ar saia saturado, porém ele é expelido saturado do pulmão, deixando o corpo com uma umidade relativa diferente. A energia associada aos fluxos de entalpia é dividida em: $45 \%$ para os músculos da cabeça, $25 \%$ para os músculos do pescoço e $30 \%$ para os pulmões.

$$
\Delta \dot{H}_{r e s}=\dot{m}_{r e s} c_{p, a r}\left(T_{e x}-T_{a r}\right)+\dot{m}_{r e s}\left(\omega_{e x} h_{v a p, e x}-\omega_{a r} h_{v a p, a r}\right)
$$

Sendo $\Delta \dot{H}_{\text {res }}$ o fluxo de entalpia provocado pela respiração $(\mathrm{W}) ; \dot{m}_{\text {res }}$ a ventilação pulmonar $(\mathrm{kg} / \mathrm{s}) ; \omega_{e x}$ a umidade absoluta do ar expirado; $\omega_{\text {ar }}$ a umidade absoluta do ar inspirado do ambiente; $c_{p, a r}$ o calor específico à pressão constante do $\operatorname{ar}(\mathrm{J} /(\mathrm{kgK})) ; T_{e x} \mathrm{a}$ temperatura do ar expirado $\left({ }^{\circ} \mathrm{C}\right) ; T_{a r}$ a temperatura do ar inspirado do ambiente $\left({ }^{\circ} \mathrm{C}\right)$; $h_{v a p, e x}$ a entalpia específica do vapor na temperatura do ar expirado $(\mathrm{J} / \mathrm{kg}) ; h_{\text {vap,ar }}$ a entalpia específica do vapor na temperatura do ar inspirado $(\mathrm{J} / \mathrm{kg})$.

A ventilação pulmonar está diretamente relacionada ao metabolismo, ou seja, quanto maior for este, maior será o consumo de oxigênio e, portanto, maior será a ventilação, como indicado na Equação 3.47 obtida em Fanger (apud ASHRAE, 2005).

$$
\dot{m}_{\text {res }}=1,43310^{-6} A_{d} \dot{M}
$$

Para condições ambientais típicas é possível obter a temperatura e a umidade absoluta 
do ar expirado como uma função da temperatura expirada $\left({ }^{\circ} C\right)$ e umidade absoluta $(\mathrm{kg}$ de vapor por $\mathrm{kg}$ de ar seco). Assim, o estado termodinâmico do ar expirado pode ser determinado pelas Equações 3.48 e 3.49.

$$
\begin{aligned}
& T_{e x}=32,6+0,066 T_{a r}+32 w_{a r} \\
& w_{e x}=0,0277+0,00065 T_{a r}+0,2 w_{a r}
\end{aligned}
$$

\subsubsection{Transferência de exergia para o ambiente}

Para a aplicação da análise exergética no corpo humano, deve-se definir as condições do ambiente em estudo, cuja temperatura equivale a $T_{0}$, a pressão $P_{0}$ e a umidade relativa $\phi_{0}$.

Calcula-se a exergia associada com a radiação pela Equação 3.50.

$$
\dot{B}_{r}=\left(1-\frac{T_{m r}}{T_{s}}\right) \dot{Q}_{r}
$$

A exergia proveniente do calor trocado por convecção pode ser calculada de acordo com a Equação 3.51.

$$
\dot{B}_{c}=\left(1-\frac{T_{0}}{T_{s}}\right) \dot{Q}_{c}
$$

Caso o ambiente de referência seja adotado como o próprio ambiente em que o corpo se encontra, o fluxo de exergia associado à evaporação permanece do modo indicado pela Equação 3.52, na qual fica evidente a exergia associada com a evaporação (primeiro termo) e a exergia associada com a mudança de concentração de vapor saturado na superfície da pele até a concentração do vapor de água no ambiente, referente ao segundo termo da equação. 


$$
\dot{B}_{e}=\dot{m}_{e}\left[h_{l v}-T_{0} s_{l v}+R_{v a p} T_{0} \ln \left(\frac{p_{v a p, s}}{p_{v a p, a}}\right)\right]
$$

A variação da exergia advinda da respiração deve-se ao fluxo de ar inspirado e expirado que atravessa a fronteira do volume de controle, como indica a Equação 3.53. O índice i refere-se aos gases presentes na atmosfera, por exemplo, $\mathrm{O}_{2}, \mathrm{~N}_{2}, \mathrm{CO}_{2}$ e $\mathrm{H}_{2} \mathrm{O}$

$$
\Delta \dot{B}_{r e s}=\left(\sum \dot{m}_{s} b_{s}-\sum \dot{m}_{e} b_{e}\right)_{r e s}=-\sum_{i}\left(B_{i, e x}-B_{i, a}\right)
$$

A exergia dos gases na inspiração é a própria exergia do ar que equivale a zero, caso o ambiente seja a referência. Então, a exergia associada à respiração está indicada pela Equação 3.54, somente para o ar expirado. Nesta, o termo $y_{i, e x}$ é a fração mássica de cada elemento na expiração.

$$
\Delta \dot{B}_{r e s}=\dot{m}_{r e s} \sum_{i}\left[y_{i, e x} c_{p, i}\left(T_{e x}-T_{0}-T_{0} \ln \left(\frac{T_{e x}}{T_{0}}\right)\right)+y_{i, e x} T_{0} R_{i} \ln \left(\frac{P_{e x, i}}{P_{0, i}}\right)\right]
$$

\subsection{ENTROPIA E ENVELHECIMENTO}

Como foi discutido anteriormente, alguns autores como Silva e Annamalai (2008, 2009), Annamalai e Silva (2012) e Hershey (2010) afirmaram que a entropia gerada durante toda uma vida é constante. Para tal, basearam-se no conceito de que o metabolismo celular por unidade de massa pouco varia entre as espécies de mamíferos. Assim como a duração da vida para cada espécie tende a um valor máximo, a entropia gerada tende a um valor limite. Silva e Annamalai (2008, 2009), Annamalai e Silva (2012) utilizaram-se da Equação 3.55 para cálcular a entropia gerada por unidade de massa no corpo humano, na qual foram negligenciadas as transferências de entropia para o ambiente associadas à radiação, convecção, vaporização e respiração. Ressalta-se que para cálculo do $\Delta G_{i}$ os autores se basearam no consumo de macronutrientes recomendados por agências norte-americanas. Porém, ao se aplicar os valores de $\Delta G_{i}$ encontrados na literatura, ao consumo de glicose, lipídeos e proteínas fornecidos pelos autores (130, 60, $56 \mathrm{~g} /$ dia, respectivamente), o resultado é um metabolismo de $62 \mathrm{~W}$, o que é relativamente baixo até para condições basais. 


$$
S_{g} \approx \frac{\left(\sum_{i=1}^{3} \eta_{\text {met }, i} \Delta G_{i}\right)}{T_{\text {corpo }}}
$$

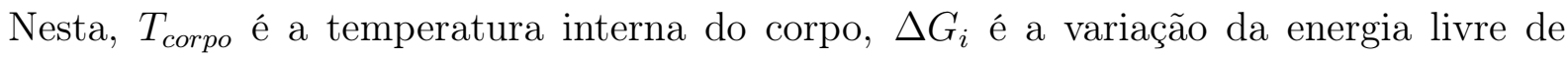
Gibbs da reação de oxidação do nutriente $i$ (glicose, lipídeos e aminoácidos) e $\eta_{m e t, i}$ é o rendimento metabólico da reação de oxidação do nutriente $i$.

Já Hershey (2010) calculou a entropia gerada a partir do metabolismo energético, indicado na Equação 3.56. Essa equação é a mesma utilizada por Aoki (1991). Ressalta-se que como $\Delta G_{i} \approx \Delta H_{i}$, as Equações 3.55 e 3.56 resultam em valores próximos.

$$
S_{g} \approx \frac{M}{T_{\text {corpo }}}
$$

É necessário observar que, nas duas equações, o metabolismo é tratado como se fosse uma transferência de calor para o corpo. Esse termo representa apenas uma parcela do metabolismo (Capítulo 3).

Considerando-se os valores de taxa de geração de entropia decorrentes da idade, é possível obter a entropia gerada durante uma vida, como indica a Equação 3.57. É possível inferir que tanto a entropia gerada quanto a idade são dependentes do tempo. A entropia do corpo aumenta com o passar da vida e, concomitantemente a geração de entropia diminui. Como destacado por Hershey (2010), quando a primeira chega a um valor máximo, "o estado de desordem é tão alto que não se pode sustentar a vida".

$$
s_{g, v i d a}=\int_{v i d a} \frac{S_{g}(t)}{m(t)} d t
$$

Neste estudo, o modelo de cálculo de exergia destruída será utilizado (Equação 3.14) e a exergia destruída será integrada como função do envelhecimento. A criação do conceito de idade entrópica pode se tornar um indicador. Sob essa ótica, se forem comparadas duas pessoas de mesma idade cronológica, aquela que tiver maior geração de entropia será a que está envelhecendo mais rapidamente. Esse conceito pode proporcionar a comparação de uma pessoa saudável a pessoa doente, um indivíduo que pratica esportes com outro sedentário e até fumantes aos não fumantes, como exposto em Hershey (2010). 


\subsection{BALANÇOS DIÁRIOS DE MASSA, ENERGIA E EXERGIA}

Segundo Rahman (2007), no período de um dia, a entrada de massa (alimentos, líquidos e ar inspirado) equivale à saída de massa (fezes, urina, ar expirado e vaporização pela pele). Se o indivíduo não estiver engordando ou emagrecendo, ou seja, se não houver acúmulos, a massa do corpo não deve se alterar com o passar de um dia.

Para conseguir aplicar o balanço de massa no corpo humano, é preciso obter o consumo diário de água, nutrientes, oxigênio e produção diária de urina, gás carbônico e fezes. A Figura 2.24 indica os valores obtidos por Rahman (2007). No entanto, foram realizadas algumas alterações nos seguintes termos:

- Consumo de nutrientes: o consumo de carboidratos, lipídeos e proteínas foram obtidos por meio do sistema de Equações 3.20 , do consumo de $\mathrm{O}_{2}(0,82 \mathrm{~kg} / \mathrm{dia})$ e produção de $\mathrm{CO}_{2}(1 \mathrm{~kg} /$ dia);

- Produção de resíduos sólidos: existe uma convenção na literatura médica de que $75 \%$ das fezes se compõem de água, portanto dos 0,14kg produzidos por dia, 0,035kg/dia são formados por sólidos e $0,105 \mathrm{~kg} /$ dia por água.

- Ingestão de alimentos: foram levados em conta a soma do consumo de nutrientes (carboidratos, lipídeos e proteínas) e a produção de resíduos sólidos (já descontada a parcela de água). A água nos alimentos é considerada como a diferença entre o valor fornecido por Rahman (2007) e o resultado da soma da massa dos nutrientes com a massa de resíduos produzidos. Isso se deve ao fato de cada alimento possuir um percentual de água, sendo para alguns legumes 95\% (alface e tomate) e 12\% para o arroz. É, portanto, mais objetivo o tratamento da água nos alimentos em geral.;

- Produção de água e ureia pelo metabolismo: essas grandezas foram calculadas pela estequiometria das reações de oxidação, sendo a massa de ureia proporcional à massa de proteínas oxidadas (convenção na literatura médica - Diener (1997)). As Equações 3.58 e 3.59 indicam de que modo essas grandezas foram calculadas.

$$
\begin{aligned}
& \dot{m}_{a ́ g u a, M}=0,6 \dot{m}_{g l i c}+1,125 \dot{m}_{\text {lip }}+0,488 \dot{m}_{a m i n} \\
& \dot{m}_{\text {ureia }}=0,325 \dot{m}_{\text {amin }}
\end{aligned}
$$


- Ingestão de água: Em média um adulto consome 2,5L de água por dia, incluindo à água presente nos alimentos.

- Urina: É excretado aproximadamente 1,5L de água pela urina por dia.

Levando-se em conta a massa de alimento ingerida $\left(\dot{m}_{\text {ing,ali }}\right)$, a massa eliminada de fezes $\left(\dot{m}_{\text {fezes }}\right)$, o consumo de água $\left(\dot{m}_{\text {ing,água }}\right)$, a excreção de água e ureia $\left(\dot{m}_{\text {urina }}\right)$, a vazão de carboidratos, lipídeos e aminoácidos que vão para o metabolismo celular $\left(\dot{m}_{c a r b}, \dot{m}_{l i p}\right.$, $\left.\dot{m}_{a m i}\right)$, as vazões de vapor de água expirado e inspirado $\left(\dot{m}_{v a p, e x}\right.$ e $\left.\dot{m}_{v a p, i n}\right)$, a vazão de água que evapora pela pele $\left(\dot{m}_{e}\right)$, as vazões de ar seco inspirado e expirado $\dot{m}_{a r, e x}$ e $\dot{m}_{a r, i n}$, a produção de água e de gás carbônico no metabolismo $\left(\dot{m}_{H_{2} O, M}, \dot{m}_{C O_{2}, M}\right)$ e o consumo de oxigênio $\left(\dot{m}_{\mathrm{O}_{2}, M}\right)$, tem-se que:

- $d m_{n u t r} / d t=\dot{m}_{\text {ing,ali }}-\dot{m}_{\text {fezes }}=\dot{m}_{\text {carb }}+\dot{m}_{\text {lip }}+\dot{m}_{\text {ami }}$;

- $d m_{l i q} / d t=\dot{m}_{\text {ing,água }}-\dot{m}_{e}-\dot{m}_{\text {urina }}=\dot{m}_{H_{2} O, M}$;

- $d m_{g a s} / d t=\dot{m}_{O_{2}, \text { in }}+\dot{m}_{C O_{2}, \text { in }}+\dot{m}_{N_{2}, \text { in }}+\dot{m}_{v a p, i n}-\dot{m}_{O_{2}, e x}-\dot{m}_{C O_{2}, e x}-\dot{m}_{N_{2}, e x}-\dot{m}_{v a p, e x}$ $=\dot{m}_{O_{2}, M}+\dot{m}_{C O_{2}, M}$;

- $d m_{\text {corpo }} / d t=d m_{\text {nutr }} / d t+d m_{\text {liq }} / d t+d m_{\text {gas }} / d t=\dot{m}_{\text {carb }}+\dot{m}_{\text {lip }}+\dot{m}_{\text {ami }}+\dot{m}_{\mathrm{O}_{2}, M}+$ $\dot{m}_{C O_{2}, M}+\dot{m}_{H_{2} O, M}=0$;

\subsection{MODELO DO SISTEMA TÉRMICO DO CORPO HUMANO}

O modelo do sistema térmico do corpo humano proposto por Ferreira (2001), Ferreira e Yanagihara (2001, 2009a) será usado para aplicação da análise exergética. A Figura 3.4 expõe uma visão geral do modelo de sistema térmico.

O sistema térmico do corpo humano é composto pelo sistema termorregulatório e pelo sistema passivo. O primeiro é relacionado com respostas fisiológicas, mudanças no ambiente térmico ou no nível de atividades físicas, por exemplo: vaso dilatação ou constrição, tremor e suor. O segundo inclui a condução de calor dentro do corpo, transferência de calor por convecção devido ao fluxo de sangue e à transferência de calor entre o corpo e o ambiente.

Os parâmetros usados no modelo são: altura $1,76 \mathrm{~m}$, massa $67 \mathrm{~kg}$, área do corpo $1,8 \mathrm{~m}^{2}$ e volume de $0,00627 \mathrm{~m}^{3}$. Para modelagem, o corpo foi dividido em membros inferiores (coxas, pernas e pés), membros superiores (braços, antebraços e mãos), cabeça, tronco 


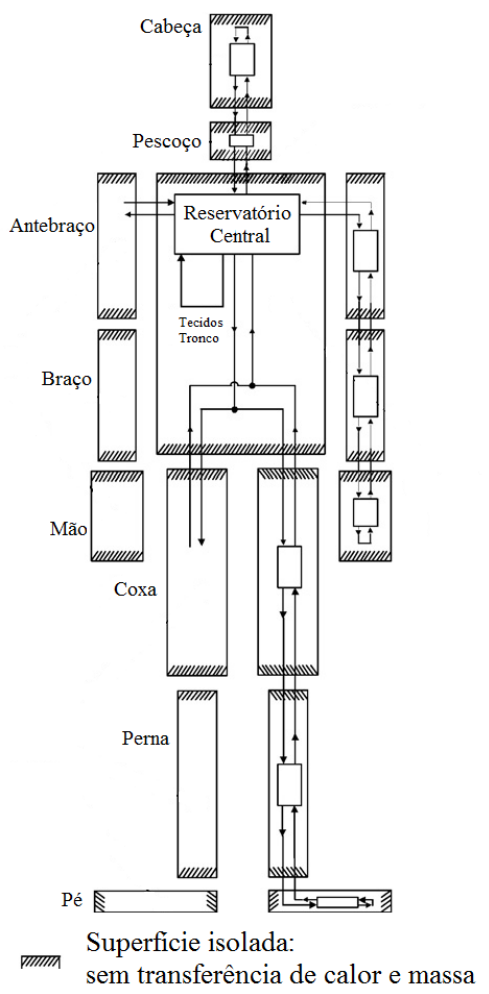

Figura 3.4: Representação do modelo de sistema térmico do corpo. Adaptado de Ferreira (2001)

(divididos em três seções) e pescoço. Ao todo, o corpo é representado por 15 cilindros de seção elíptica.

Cada parte do corpo teve uma combinação dos tecidos: pele, gordura, músculo, osso, cérebro, víscera, pulmão e coração. A escolha dos tecidos não foi arbitrária. Assim, a pele foi escolhida graças ao fluxo de sangue variável dependente do sistema termorregulatório; a gordura, pela baixa condutibilidade térmica; os músculos, pelo metabolismo variável de acordo com a atividade física e tremores; coração e cérebro, por suas altas taxas metabólicas, dentre outros.

A Figura 3.5 demonstra de que maneira foram modelados os membros superiores e o tronco, diferenciando um cilindro com seção bidimensional (membros superiores) e um cilindro com composição dependente da seção transversal (tronco).

O balanço de energia é resolvido para cada tecido com respectivos metabolismo, propriedades termofísicas e perfusão sanguínea. A troca de calor entre sangue e tecido foi incluída no balanço de energia de cada elemento. Os vasos foram divididos em dois tipos: os grandes e os pequenos. Os pequenos foram tratados como parte de um contínuo, de acordo com o modelo de Pennes (1948). No entanto, a temperatura é dependente da posição do modelo (e não uma representativa do corpo). Os vasos grandes foram tratados em conformidade com o modelo de Wissler (1985). Cada elemento tem dois reservatórios de sangue (exceção ao tronco que tem apenas um), sendo um de sangue arterial e outro, 

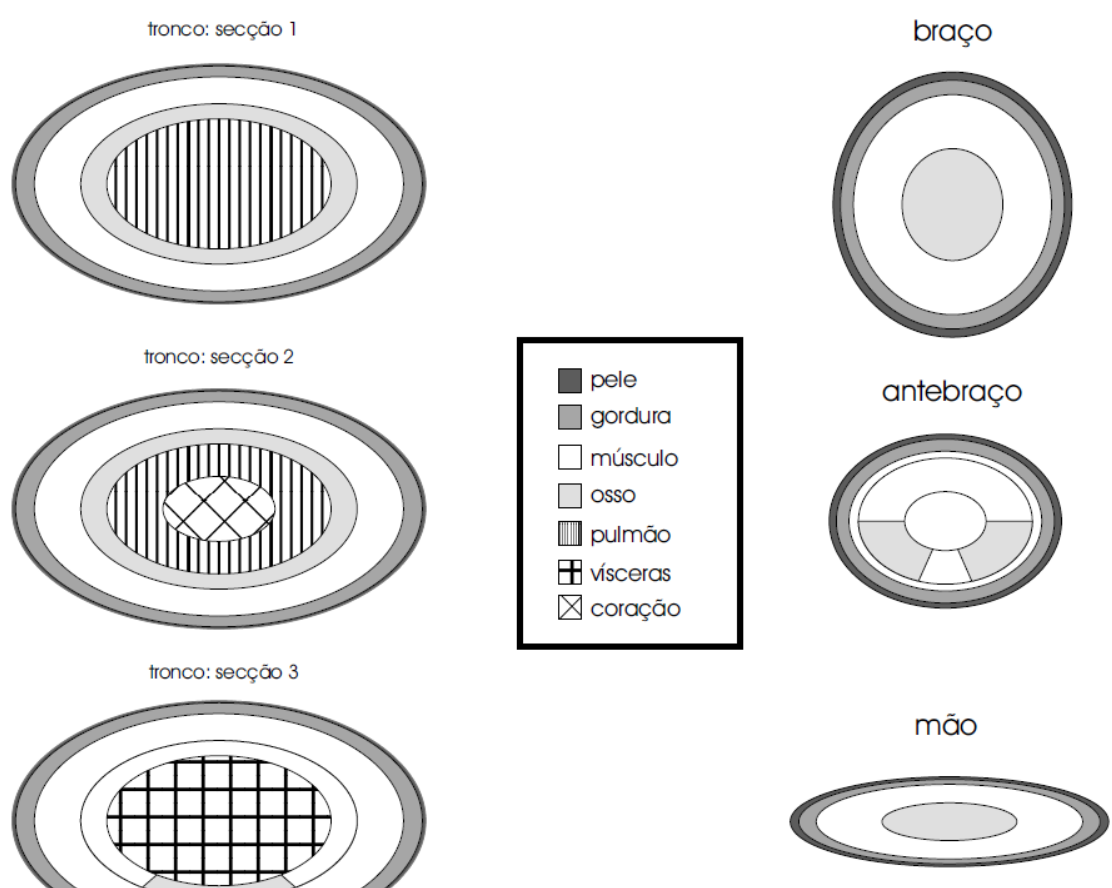

Figura 3.5: Divisão em seções e camadas do tronco (em escala) e membros superiores. Retirado e adaptado de Ferreira (2001)

de sangue venoso, os quais trocam calor entre si, e sangue com os tecidos e elementos vizinhos. A Figura 3.6 indica a representação do sistema circulatório.

Assim, o balanço de energia para o sangue pode ser descrito por três Equações: 3.60 e 3.61 para todos os compartimentos com dois reservatórios; e 3.62 para o tronco. Os primeiros termos do segundo membro das Equações 3.60 e 3.61 referem-se à entalpia que entra no volume de controle devido ao sangue proveniente de outros elementos. Nas mãos e nos pés, elementos na extremidade, não há vazão de sangue venoso entrando nesses elementos, logo, o primeiro termo do segundo membro da equação 3.61 anula-se. A integral que aparece na Equação 3.61 refere-se à entalpia que entra no reservatório venoso proveniente do sangue dos pequenos vasos, o qual deixa os tecidos com temperatura $T_{t}$ (sendo $t$ pele, gordura, músculo, dentre outros), ou seja, em equilíbrio térmico. No tronco considerou-se apenas um reservatório de sangue. Desse modo, não há transferência de calor entre artérias e veias, restando apenas os termos referentes às entalpias que entram e saem do reservatório. O primeiro termo da Equação 3.62 se refere a entalpia de sangue venoso proveniente dos diferentes compartimentos $i$ do corpo.

$$
m_{a r, i} c_{s} \frac{d T_{a r, i}}{d t}=\rho_{s} c_{s} \dot{V}_{a r, i}\left(T_{a r, i}^{e}-T_{a r, i}\right)+h_{a v}\left(T_{v e, i}-T_{a r, i}\right)
$$




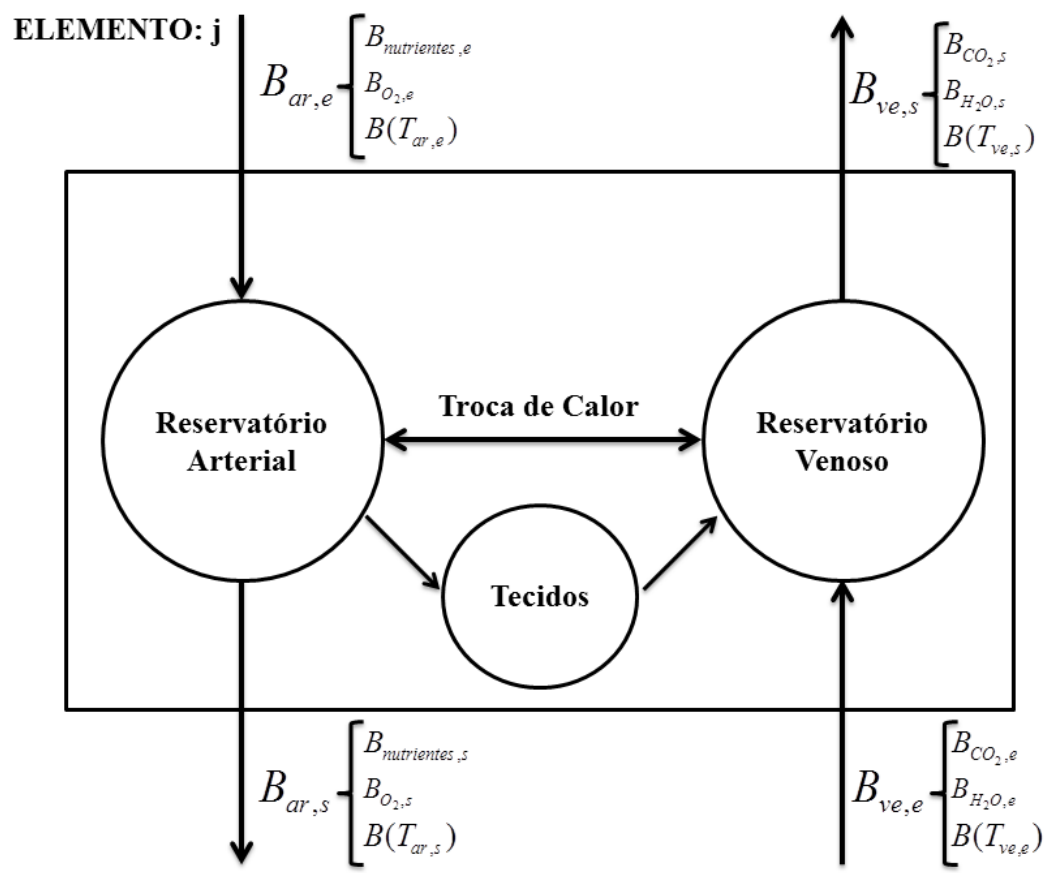

Figura 3.6: Representação do sistema circulatório com entrada e saída de sangues arterial e venoso

$$
m_{v e, i} c_{s} \frac{d T_{v e, i}}{d t}=\rho_{s} c_{s} \dot{V}_{v e, i}\left(T_{v e, i}^{e}-T_{v e, i}\right)+h_{a v}\left(T_{a r, i}-T_{v e, i}\right)+\int_{V} \rho_{s} c_{s} \dot{\omega}_{s}\left(T_{t}-T_{v e, i}\right) d V
$$

$$
m_{s} c_{s} \frac{d T_{s, i}}{d t}=\sum_{i} \rho_{s} c_{s} \dot{V}_{v e, i}\left(T_{v e, i}-T_{s}\right)+\int_{V} \rho_{s} c_{s} \dot{\omega}_{s}\left(T_{t}-T_{s}\right) d V
$$

Sendo:

- $m_{a r, i}, m_{v e, i}$, e $m_{s}$ : as massas dos reservatórios arterial, venoso e do tronco;

- $c_{s}$ : o calor específico do sangue;

- $\rho_{s}$ : a massa específica do sangue;

- $\dot{V}$ : a vazão de sangue arterial (subíndice ar) ou venoso (subíndice ve);

- $T_{a r, i}^{e}, T_{v e, i}^{e}$ : as temperaturas de sangue arterial e venoso que entram no volume de controle;

- $T_{a r, i}, T_{v e, i}, T_{s}$ : as temperaturas dos reservatórios arterial, venoso e central;

- $h_{a v}$ : o coeficiente de transferência de calor entre as grandes artérias e veias;

- $T_{t}$ : a temperatura do sangue proveniente tecidos; 
- $\dot{\omega}_{s}$ : vazão de sangue nos tecidos.

De acordo com Ferreira (2001), deve-se ter uma condição inicial para resolução das equações diferenciais das simulações transientes. Para tal, deve-se determinar a condição de neutralidade térmica para que as temperaturas dos tecidos e sangue dos diferentes compartimentos dessa condição sejam usadas como condição inicial das simulações transientes. Segundo ASHRAE (2005), temperaturas operativas entre 29 e $31^{\circ} \mathrm{C}$ acarretam a situação de neutralidade térmica do corpo. Essa condição é aquela em que todos os mecanismos de controle termorregulador do corpo como sudorese e tremores não estão ativos.

Para se realizarem simulações do comportamento exergético do corpo, considerando o uso de roupas, é necessário obter dados da resistência térmica e da resistência à evaporação de uma pessoa vestida. As tabelas da ASHRAE (2005) fornecem esses valores para diferentes vestimentas, desde uso de bermudas com camiseta até o uso de calças com casacos de lã. Neste trabalho se considerou o uso de roupas para inverno, ou seja, $R_{\text {clo }}$ equivalente a $0,155^{\circ} \mathrm{Cm}^{2} / W(1 \mathrm{CLO})$. A razão entre a área do roupa e a área do corpo nu $\left(f_{c l}\right)$ equivale a 1,28 . A resistência à evaporação é igual a $0,0527^{\circ} \mathrm{Cm}^{2} / W(0,34 \mathrm{CLO})$. Esse condição acarreta uma temperatura de neutralidade térmica de aproximadamente $25^{\circ} \mathrm{C}$.

\subsubsection{Efeito $Q_{10}$}

Mountcastle (1974) e Albulquerque-Neto (2010) descreveram que as reações metabólicas tem sua velocidade alterada quando ocorre variação na temperatura dos tecidos. A razão entre duas taxas de metabolismo com diferenças de temperatura de $10^{\circ} \mathrm{C}$ é denominada de "efeito Q $Q_{10}$ ". Esse incremento na taxa metabólica é uma função da temperatura média dos músculos $\left(T_{m}\right)$, temperatura média dos músculos na condição basal $\left(T_{m, 0}\right)$ e do metabolismo basal $\left(M_{0}\right)$, demonstrado na Equação 3.63.

$$
\dot{M}_{Q_{10}}=M_{0} 2^{\left(T_{m}-T_{m, 0}\right) / 10}
$$




\subsubsection{Sistema de controle}

Os autores Ferreira (2001), Ferreira e Yanagihara (2009a) consideraram em seus estudos os sinais de temperatura provenientes do hipotálamo (no modelo cérebro) e da pele. O modelo empregado baseia-se em pesquisas experimentais (determinação das constantes e equações), cujos sistemas de controle são considerados como os mecanismos de vasomotor, sudorese e calafrios.

A Equação 3.64 foi proposta por Savage e Brengelmann (1996), cujos coeficientes foram obtidos a partir de simulações que fornecem respostas semelhantes aos dados experimentais.

$$
\Delta \dot{\omega}_{b l}=k_{1}\left(T_{h y}-T_{h y, 0}\right)+k_{2}\left(\bar{T}_{s}-\bar{T}_{s, 0}\right)
$$

Em que, $\Delta \dot{\omega}_{s}$ é a taxa de variação da vazão de sangue na pele do elemento $\left(814.10^{-6} \leq\right.$ $\left.\Delta \omega_{s} \leq 3345 \mathrm{~m}^{3} /\left(\mathrm{m}^{3} . \mathrm{s}\right)\right) ; T_{h y}$ é a temperatura do hipotálamo; $T_{h y, 0}$ é a temperatura do hipotálamo de referência; $\bar{T}_{s}$ é a temperatura média da superfície da pele; $\bar{T}_{s, 0}$ é a temperatura média de referência da pele; $k_{1}$ é a constante igual a $1810.10^{-6} \mathrm{~m}^{3} /\left(\mathrm{m}^{3} . \mathrm{s}\right)$; $k_{2}$ é a constante igual a $181 \cdot 10^{-6} \mathrm{~m}^{3} /\left(\mathrm{m}^{3} \cdot \mathrm{s}\right)$.

Para o cálculo do mecanismo de sudorese foi utilizado o modelo de Nadel, Bullard e Stolwijk (1971), como indicado na Equação 3.65. Levaram-se em consideração nesse modelo tanto os efeitos locais como os médios.

$$
\dot{H}_{e, s w}=A \cdot\left[k_{3}\left(T_{h y}-T_{h y, 0}\right)+k_{4}\left(\bar{T}_{s}-\bar{T}_{s, 0}\right)\right] \exp \left(\frac{\bar{T}_{s, i}-\bar{T}_{s, 0}}{10}\right)
$$

Na qual, $\dot{H}_{e, s w}$ é a taxa de evaporação de suor pela pele $(\mathrm{W}) ; \bar{T}_{s, i}$ é a temperatura média da superfície da pele no elemento $i ; k_{3}$ é a constante igual a $197 \mathrm{~W} /\left(\mathrm{m}^{2} . \mathrm{K}\right)$; e $k_{4}$ é a constante igual a $23 \mathrm{~W} /\left(\mathrm{m}^{2} \cdot \mathrm{K}\right)$.

O modelo escolhido para o incremento do metabolismo causado pelos calafrios foi proposto por Gordon, Roemer e Horvath (1976). Considerou-se a temperatura do tímpano como representada pela do hipotálamo (no modelo, o cérebro), chegando-se à Equação 3.66.

$$
\Delta \dot{M}_{s h}=k_{5}\left(T_{t y}-T_{t y, 0}\right)+K_{6}\left(\bar{T}_{s}-\bar{T}_{s, 0}\right)+k_{7} \Delta Q
$$


Na qual, $\Delta \dot{M}_{s h}$ é a taxa de variação do metabolismo causado pelos calafrios (W); $k_{5}$ é a constante igual a $250 \mathrm{~W} / \mathrm{K} ; k_{6}$ é a constante igual a $40 \mathrm{~W} / \mathrm{K}$; e $k_{7}$ é a constante igual a 0,06 .

\subsubsection{Análise exergética aplicada ao modelo}

\subsubsection{Análises transientes}

Para aplicar a análise exergética no corpo humano em situações transientes, deve-se ter o valor de temperatura a cada instante ou o valor da variação da energia interna para um dado intervalo de tempo (tendo-se uma das duas grandezas, a outra pode ser calculada). Desse modo, é necessário calcular os fluxos de calor, entalpia e exergia para o ambiente, como indicado nos Itens 3.1.3 e 3.1.4, faltando somente determinar a variação temporal da energia interna e da entropia. Assim, a partir da variação dessas grandezas, pode-se aplicar a Equação 3.4. A variação da energia interna pode ser determinada diretamente pelo balanço de energia, ou pelo procedimento indicado a seguir. Para o cálculo da variação temporal da energia interna e da entropia do corpo podem ser utilizadas as Equações 3.67 e 3.68 .

$$
\begin{aligned}
& \left.\frac{d U}{d t}\right|_{\Delta T}=\left.\sum_{j} \frac{d U_{\text {elem,j }}}{d t}\right|_{\Delta T}=\sum_{j}\left(\left.\frac{d U_{b l, j}}{d t}\right|_{\Delta T}+\left.\frac{d U_{t, j}}{d t}\right|_{\Delta T}\right) \\
& \left.\frac{d S}{d t}\right|_{\Delta T}=\left.\sum_{j} \frac{d S_{\text {elem }, j}}{d t}\right|_{\Delta T}=\sum_{j}\left(\left.\frac{d S_{b l, j}}{d t}\right|_{\Delta T}+\left.\frac{d S_{t, j}}{d t}\right|_{\Delta T}\right)_{j}
\end{aligned}
$$

Sendo:

- $d U /\left.d t\right|_{\Delta T}$ : variação temporal da energia interna do corpo;

- $d S /\left.d t\right|_{\Delta T}$ : variação temporal da entropia do corpo devido a uma variação temporal da energia interna;

- $d U_{\text {elem,j }} /\left.d t\right|_{\Delta T}$ : variação temporal da energia interna do elemento $j$ (cabeça, pescoço, tronco, braços, dentre outros); 
- $d S_{\text {elem,j }} /\left.d t\right|_{\Delta T}$ : variação temporal da entropia do elemento $j$ (cabeça, pescoço, tronco, braços, dentre outros);

- $d U_{b l, j} / d t$ : contribuição da variação temporal da energia interna do sangue no compartimento $j$;

- $d S_{b l, j} / d t$ : contribuição da variação temporal da entropia do sangue no compartimento $j$;

- $d U_{t} / d t$ : contribuição da variação temporal da energia interna dos tecidos no compartimento (pele, gordura, músculo, osso, pulmão, vísceras e coração).

- $d S_{t} / d t$ : contribuição da variação temporal da entropia dos tecidos no compartimento (pele, gordura, músculo, osso, pulmão, vísceras e coração).

A variação temporal da energia interna e a da entropia do sangue no elemento j estão representadas nas Equação 3.69 e 3.70, sendo esta uma soma entre a variação temporal da entropia do sangue no compartimento arterial com a do sangue no compartimento venoso, com exceção do tronco que tem apenas um compartimento de sangue. Deve-se ressaltar que a Equação 3.69 é resultado da aplicação do método de Euler explícito, proposto no trabalho do Ferreira e Yanagihara (2009a) para calcular a temperatura de cada nó do modelo, portanto o método foi previamente validado.

$$
\begin{aligned}
& \left.\left.\frac{d U_{b l, j}}{d t}\right|_{\Delta T} \approx \frac{\Delta U_{b l, j}}{\Delta t}\right|_{\Delta T}=\frac{m_{a r, j} c_{b l}}{\Delta t}\left(T_{a r, k+1}-T_{a r, k}\right)+\frac{m_{v e, j} c_{b l}}{\Delta t}\left(T_{v e, k+1}-T_{v e, k}\right) \\
& \left.\left.\frac{d S_{b l, j}}{d t}\right|_{\Delta T} \approx \frac{\Delta S_{b l, j}}{\Delta t}\right|_{\Delta T}=\frac{m_{a r, j} c_{b l}}{\Delta t} \ln \left(\frac{T_{a r, k+1}}{T_{a r, k}}\right)+\frac{m_{v e, j} c_{b l}}{\Delta t} \ln \left(\frac{T_{v e, k+1}}{T_{v e, k}}\right)
\end{aligned}
$$

Sendo $m_{a r, j}$ a massa de sangue no reservatório arterial do elemento j (constante); $m_{v e, j}$ a massa de sangue no reservatório venoso do elemento j (constante); $T_{a r, k}$ a temperatura do reservatório arterial no instante $\mathrm{k} ; T_{v e, k}$ a temperatura do reservatório venoso no instante $\mathrm{k}$; e $c_{b l}$ o calor específico do sangue.

A variação temporal da energia interna e a da entropia causada pela variação de temperatura nos tecidos é determinada pelas Equações 3.71 e 3.72.

$$
\left.\left.\frac{d U_{t, j}}{d t}\right|_{\Delta T} \approx \frac{\Delta U_{t, j}}{\Delta t}\right|_{\Delta T}=\frac{1}{\Delta t}\left[\sum_{i} m_{t_{i}} c_{t_{i}}\left(T_{t_{i}, k+1}-T_{t_{i}, k}\right)\right]
$$




$$
\left.\left.\frac{d S_{t, j}}{d t}\right|_{\Delta T} \approx \frac{\Delta S_{t, j}}{\Delta t}\right|_{\Delta T}=\frac{1}{\Delta t}\left[\sum_{i} m_{t_{i}} c_{t_{i}}\left(\frac{T_{t_{i}, k+1}}{T_{t_{i}, k}}\right)\right]
$$

Sendo $T_{t_{i}, k}$ a temperatura do tecido $i$ no instante $k ; m_{t_{i}}$ a massa do tecido $\mathrm{i} ; c_{t_{i}}$ o calor específico do tecido i.

\subsubsection{Análise exergética de cada elemento}

A análise exergética de cada compartimento é baseada na Figura 3.6, na qual se pode notar que em todos os elementos (exceção ao tronco) há uma entrada de sangue arterial $\left(B_{a r, e}\right)$ e venoso $\left(B_{v e, e}\right)$, proveniente de outros elementos, e saída de sangue arterial $\left(B_{a r, s}\right)$ e venoso $\left(B_{v e, s}\right)$, para outros elementos. A exergia térmica de cada fluxo pode ser calculada de acordo com a equação 3.73. A exergia dos nutrientes, oxigênio, gás carbônico, dentre outros, está computada no metabolismo exergético. Ou seja, o metabolismo exergético é, simplesmente, o balanço de exergia dessas substâncias.

$$
\dot{B}_{b l}=\dot{m}_{b l} c_{b l}\left[T_{b l}-T_{0}-T_{0} \ln \left(\frac{T_{b l}}{T_{0}}\right)\right]
$$

A variação entre a exergia térmica na entrada $\left(B_{b l, e}\right)$ e na saída $\left(B_{b l, s}\right)$ do sangue, para cada membro, é dada pela Equação 3.74 (a variação das substâncias está computada no metabolismo exergético de cada nutriente). No caso do tronco, tem-se como entrada fluxos de sangue venoso provenientes de diversas partes do corpo e saídas de sangue arterial para as diversas partes, como indicado na Equação 3.75

$$
\begin{aligned}
& \left(\dot{B}_{b l, e}-\dot{B}_{b l, s}\right)_{j}=\dot{B}_{a r, e}+\dot{B}_{v e, e}-\dot{B}_{a r, s}-\dot{B}_{v e, s} \\
& \left(\dot{B}_{b l, e}-\dot{B}_{b l, s}\right)_{\text {tronco }}=\sum \dot{B}_{v e, e}-\sum \dot{B}_{a r, s}
\end{aligned}
$$

Assim, para cada elemento (j) é possível calcular a exergia destruída (Equação 3.76). Nota-se que o termo referente à respiração estará presente apenas no tronco, na cabeça e no pescoço. 


$$
\dot{B}_{\text {dest }}^{j}=\left(\dot{B}_{M}-\left.\frac{d \mathbf{B}}{d t}\right|_{\Delta T}\right)_{j}-\left(\dot{B}_{r}+\dot{B}_{c}+\Delta \dot{B}_{r e s}+\dot{B}_{e}\right)_{j}+\left(\dot{B}_{b l, \text { in }}-\dot{B}_{b l, o u t}\right)_{j}-\dot{W}_{j}
$$

\subsubsection{Indução da hipotermia ao modelo}

Como visto na Seção 2.4.4, há uma dificuldade de análise dos parâmetros da hipotermia (porque essas análises devem ser realizadas em seres vivos) e do comportamento do corpo para esses diferentes parâmetros (poucos estudos numéricos na área). A indução de hipotermia no modelo proposto por Ferreira e Yanagihara (2009a) pode contribuir para compreender as técnicas de hipotermia e os melhores parâmetros (tempo, profundidade, taxa de resfriamento e taxa de retorno) e, portanto, obter respostas que dificilmente são viáveis apenas com experimentos. Assim, optou-se por induzir o modelo do sistema térmico proposto por Ferreira e Yanagihara (2009a) à hipotermia utilizando-se de três cenários:

1. Indução de hipotermia via dispositivo extracorpóreo.

2. Indução de hipotermia via inserção de cateter intravenoso.

3. Indução de hipotermia via resfriamento da superfície da pele.

O objetivo dessa análise é a comparação das diferentes técnicas e parâmetros de resfriamento, sob a perspectiva da análise exergética. Para as simulações foram usados como base os estudos experimentais e numéricos apresentados por Volpe e Jain (1982), Dixon et al. (2002), Behringer et al. (2002) e Dae et al. (2003). Optou-se o uso da hipotermia como terapia, no entanto, com os devidos ajustes no modelo é viável a indução da hipotermia associada à choques, por exemplo, hipovolêmicos (perda de sangue).

\subsubsection{Indução de hipotermia via dispositivo de circulação extracorpórea}

Induziu-se o modelo à hipotermia via um dispositivo de circulação extracorpórea. A Figura 3.7 indica como foi possível induzir esse tipo de hipotermia ao modelo e as modificações feitas no balanço de energia para tal adaptação. Nessa figura, o subscrito $s$ foi usado para o sangue do reservatório central, a fim de diferenciar do subscrito $b l$ usado na 
descrição do sangue de forma mais geral neste texto. Realizou-se um balanço de energia em torno do reservatório central de sangue como indicado na Equação 3.77 (dado que o cateter ou dispositivo de circulação são inseridos na região da veia femoral até a veia cava inferior, independente da técnica). Nesse balanço foi feita retirada de um fluxo mássico $\dot{m}_{\text {hip }}$ que é resfriado da temperatura do reservatório $\left(T_{s}\right)$ até a temperatura de hipotermia $\left(T_{h i p}\right)$ e, então, retornado ao reservatório, observa-se que esse tipo de dispositivo pode ser usado para indução de hipertermia. Em todos os trabalhos experimentais os autores tentaram inibir os tremores, ou seja, a elevação do metabolismo associada a esse mecanismo, por isso desligou-se o sistema passivo durante as simulações (como se o paciente estivesse anestesiado ou com esse mecanismo inibido pelo uso de medicamentos).

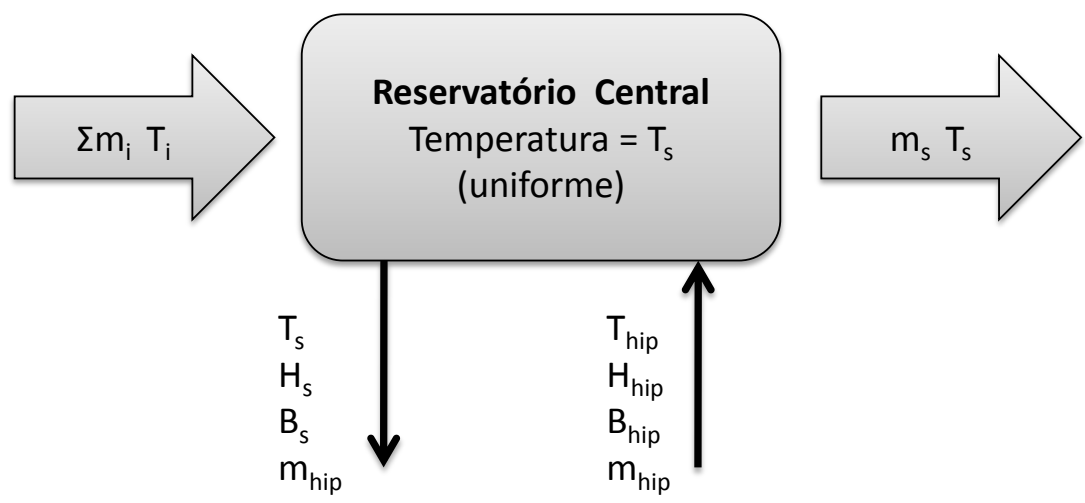

Figura 3.7: Esquema representativo da indução da hipotermia, usando-se o sistema de circulação extracorpórea

$m_{s} c_{b l} \frac{d T_{s, i}}{d t}=\sum_{i} \rho_{b l} c_{b l} \dot{V}_{v e, i}\left(T_{v e, i}-T_{s}\right)+\int_{V} \rho_{b l} c_{b l} \dot{\omega}_{b l}\left(T_{t}-T_{s}\right) d V+\dot{m}_{h i p} c_{s}\left(T_{h i p}-T_{s}\right)$

Para efeito da análise exergética do corpo, deve-se adicionar um fluxo de exergia de entrada e outro de saída referentes ao sangue removido (a uma temperatura $T_{h i p}$ ) e ao seu retorno (na temperatura do reservatório central, $T_{s}$ ). Esse equacionamento é baseado na Figura 3.7 e pode ser visto na Equação 3.78. O cálculo da eficiência exergética possui o mesmo princípio da Equação 3.15, porém considera-se a exergia do sangue de retorno como alimentação no volume de controle, assim como $B_{M}$. Portanto o rendimento exergético, com as devidas substituições, resulta na Equação 3.79. Vale destacar que, no processo de hipotermia, não foi considerada a eficiência do processo, mas sim, a eficiência do corpo decorrente de uma variação de exergia do sangue $\Delta \dot{B}_{b l}$, ou seja resultante do processo. 


$$
\begin{aligned}
& \dot{B}_{h i p}-\dot{B}_{s}=\dot{m}_{h i p} c_{b l}\left[T_{h i p}-T_{s}-T_{0}\left(\ln \frac{T_{h i p}}{T_{s}}\right)\right] \\
& \eta_{b}=\frac{\left|\frac{d \mathbf{B}}{d t}\right|+\dot{B}_{h i p}-\dot{B}_{d e s t}}{\left|\frac{d \mathbf{B}}{d t}\right|+\dot{B}_{h i p}}=\frac{\dot{B}_{a m b}+\dot{B}_{s}}{\left|-\dot{B}_{M}+\frac{d \mathbf{B}}{d t}\right|_{\Delta T} \mid+\dot{B}_{h i p}}
\end{aligned}
$$

As condições simuladas foram:

- hipotermia com temperatura de resfriamento de $32^{\circ} \mathrm{C}$ (limitou-se em hipotermia leve) durante 6 horas, pois, com exceção do efeito térmico, o modelo não pode levar em conta os benefícios ou consequências negativas do parâmetro duração;

- a taxa de vazão de sangue resfriada (em $\mathrm{kg} / \mathrm{s}$ ) foi 20, 10, 5 e 2,5\% da massa do reservatório central do modelo proposto por Ferreira (2001), cuja massa de sangue equivale a $2,04 \mathrm{~kg}$;

- o retorno , segundo Diller e Zhu (2009) deve ser lento e, pelo exposto nos trabalhos de Dae et al. (2003), Dixon et al. (2002), o modelo deve ser tirado da hipotermia até uma temperatura próxima dos $36,5^{\circ} \mathrm{C}$, durante 3 horas, via o reaquecimento do sangue a uma taxa de 20, 10, 5 e 2,5\% da vazão de sangue para resfriamento. Depois dessa temperatura que pode ser considerada como além das gerações de tremores, o próprio sistema termorregulador consegue voltar às condições normais, evitando-se uma hipertermia transiente.

- durante a hipotermia, desligou-se o sistema de controle no período 10 a 12 horas de procedimento, dependendo dos parâmetros de resfriamento adotados, pois os processos intravenosos não causam tremores, embora em alguns casos sejam inibidos com o uso de drogas.

\subsubsection{Resfriamento com inserção de cateter intravenoso}

Outra forma de hipotermia simulada foi o resfriamento com inserção de cateter intravenoso, que pode ser usado tanto para hipotermia como para hipertermia. A modelagem foi realizada considerando que o cateter forma um duto cilíndrico anular de seção concêntrica com a veia cava inferior. Conforme relatado por Dae et al. (2003) o diâmetro do cateter não equivale a mais do que $10 \%$ do diâmetro da veia (segundo os 
autores, o cateter possui $8,25 \mathrm{~mm}$ de diâmetro e admitiu-se $25 \mathrm{~cm}$ de comprimento). No entanto, como pode ser visto na Figura 2.17, a geometria do catéter não é simples, pois tem uma seção helicoidal tripla, que dificulta o cálculo do coeficiente de transferência de calor por convecção. Porém, por essa técnica já estar bem estabelecida, pode-se, mediante resultados experimentais (Figura 2.18) calcular a variação da energia interna do corpo do paciente durante todo o processo e o coeficiente de transferência de calor multiplicado pela área do dispositivo $(h A)$, conforme demonstado nas Equações 3.80 e 3.81, respectivamente. Nessa Equação $c_{\text {corpo }}$ é o calor específico médio do corpo.

$$
\begin{aligned}
& \frac{\Delta U}{\Delta t}=m c_{\text {corpo }} \frac{\Delta T_{b l}}{\Delta t} \\
& h A=\frac{\frac{\Delta U}{\Delta t}}{\left(T_{s}-T_{h i p}\right)}
\end{aligned}
$$

Para o equacionamento, adotou-se que a superfície do cilindro está a $32^{\circ} \mathrm{C}\left(T_{\text {hip }}\right)$ e o sangue sai em equilíbrio térmico com o mesmo. Nota-se que ao se usar a Equação 3.81 para análise da transferência de calor, não são necessárias hipóteses do tipo de escoamento, velocidade, geometria da veia, dentre outros. Uma vez que o aparelho oferece apenas uma geometria, o uso dessa Equação torna-se suficiente para descrever o fenômeno, portanto calculou-se o produto $h A$ e chegou-se a, aproximadamente, $62 \mathrm{~W} / \mathrm{K}$ (foi realizada uma simulação para o caso de aumento da área de contato, ou seja, $\mathrm{hA}=110 \mathrm{~W} / \mathrm{K})$. Para efeito da análise energética, deve-se considerar o ajuste da Equação 3.82 na Equação 3.78. Como o cateter não é considerado parte do volume de controle do corpo, chega-se ao termo adicional da análise exergética da Equação 3.83. O rendimento exergético pode ser calculado pela Equação 3.84, no qual o único fluxo acrescentado é relacionado à transferência de calor para o cateter. Durante o reaquecimento esse fluxo deixa de ser produto e passa a ser exergia de alimentação, passando para o denominador da Equação 3.84.

$$
\begin{gathered}
\dot{m}_{h i p}\left(T_{s}-T_{h i p}\right) \rightarrow h A\left(T_{s}-T_{h i p}\right) \\
\dot{B}_{Q_{h i p}}=h A\left(T_{s}-T_{h i p}\right)\left(1-\frac{T_{0}}{T_{h i p}}\right)
\end{gathered}
$$




$$
\eta_{b}=\frac{\left|\frac{d \mathbf{B}}{d t}\right|-\dot{B}_{d e s t}}{\left|\frac{d \mathbf{B}}{d t}\right|}=\frac{\dot{B}_{a m b}+\dot{B}_{Q_{h i p}}}{\left|-\dot{B}_{M}+\frac{d \mathbf{B}}{d t}\right|_{\Delta T} \mid}
$$

\subsubsection{Resfriamento da superfície da pele}

Finalmente, simulou-se o resfriamento da superfície da pele com o sistema de controle ligado e desligado, este último equivalente a uma pessoa sob efeito de medicamentos. Em razão do fluido de resfriamento ser a água, inibe-se a radiação e evaporação, ou seja, tudo se passa como se a pessoa estivesse imersa em água a uma dada temperatura. O coeficiente de transferência de calor por convecção para água em torno dos diferentes membros teve de ser adaptado. Foram usadas correlações relatadas em Dewitt e Incropera (2003) para escoamento em torno dos diferentes membros a uma velocidade de $0,15 \mathrm{~m} / \mathrm{s}$. As propriedades da água adotada foram: viscosidade dinâmica de $7055.10^{-} 6 \mathrm{Ns} / \mathrm{m}$, massa específica de $993,7 \mathrm{~kg} / \mathrm{m}^{3}$, condutibilidade térmica de $0,6121 \mathrm{~W} / \mathrm{mK}$ e número de Prandtl equivalente a 4,821. Não há nenhuma mudança nos termos das análises energética e exergética, pois não há nenhum fluxo de energia/exergia adicional.

Para esse cenário simulou-se apenas o resfriamento, por causa da dificuldade de mudar os coeficientes de transferência de calor e condições ambiente do modelo para uma mesma simulação e por essa técnica ser tradicionalmente tratada na literatura como menos eficaz que as demais (sujeita a restrições do próprio sistema passivo do corpo), sendo usada com a finalidade de complementar as outras formas de indução.

\subsubsection{Proposição do índice exergético}

O cálculo do rendimento exergético, conforme a Equação 2.11, pode resultar em distorções de interpretação quando aplicado em pacientes sob hipotermia. Ao se compararem, por exemplo, as Equações 3.79 e 3.84, considera-se, na primeira Equação, que o fluxo de exergia de sangue retorna para o corpo como exergia de fornecimento, o que acarreta o fluxo de exergia de saída ser considerada como uma exergia útil. O mesmo não ocorre quando se usa o cateter intravenoso, como indicado na Equação 3.84, pois o único efeito que se encontra é o fluxo de exergia saindo do corpo associado ao calor que é considerado um efeito útil. Portanto, definiu-se um índice baseado na razão entre o efeito

que se espera da hipotermia, ou seja, variação da exergia do corpo $\left(\left|\frac{d \mathbf{B}}{d t}\right|_{\Delta T} \mid\right)$ com a 
exergia removida do corpo. Para o resfriamento de sangue extracorpóreo, esse é o termo $\left|\Delta B_{b l}\right|=\left|B_{s}-B_{h i p}\right|$ indicado na Equação 3.85, enquanto que para o resfriamento usando um cateter intravenoso esse termo é o $\left|B_{Q_{h i p}}\right|$ indicado na Equação 3.86.

$$
\begin{aligned}
& r_{\text {hip }}=\frac{\left|\frac{d \mathbf{B}}{d t}\right|_{\Delta T} \mid}{\left|\Delta B_{b l}\right|} \\
& r_{\text {hip }}=\frac{\left|\frac{d \mathbf{B}}{d t}\right|_{\Delta T} \mid}{\left|B_{Q_{h i p}}\right|}
\end{aligned}
$$

\subsubsection{Simplificação do modelo do sistema térmico}

Para que sejam realizadas análises cuja geometria do modelo varia (crianças, adolescentes, gordos, magros, dentre outros), torna-se muito complexo o uso do modelo proposto por Ferreira e Yanagihara (2009a). Como solução, foi proposta uma simplificação do sistema térmico do corpo humano (termorregulador e passivo), no qual foi tomado como base os trabalhos sugeridos por Ferreira (1997, 2001), Ferreira e Yanagihara (2009a). Devese especificar que, embora as dimensões do corpo para as crianças estarem corretas, foi utilizada uma distribuição de músculo e gordura equivalentes a um adulto. Esse resultado é, portanto, uma aproximação, principalmente no caso de um recém-nascido, no entanto, o metabolismo basal deve ser coerente com os calculados via equações da literatura. Contudo o uso dessa solução, nos primeiros estágios da vida, é mais adequado do que usar o modelo original, cuja geometria é fixa.

A Figura 3.8 indica o modelo adotado para as simulações. Nota-se que se trata de apenas um cilindro com quatro camadas representando os seguintes tecidos: pele, gordura, músculo, núcleo.

As características fisiológicas do modelo foram obtidas em Ferreira (1997), porém, como o modelo é simplificado, elas são facilmente modificáveis. Adotou-se, então, a massa, área superficial, volume, altura e metabolismo basal como $67 \mathrm{~kg}, 1,8 \mathrm{~m}^{2}, 0,067 \mathrm{~m}^{3}, 1,76 \mathrm{~m}$ e $79,1 \mathrm{~W}$, respectivamente.

Para obter o metabolismo basal, massa específica, calor específico e condutibilidade térmica do núcleo, foi necessário fazer uma ponderação das propriedades termofísicas dos diferentes órgãos, ossos, que vão representar o núcleo, como descrito por Ferreira (1997). 


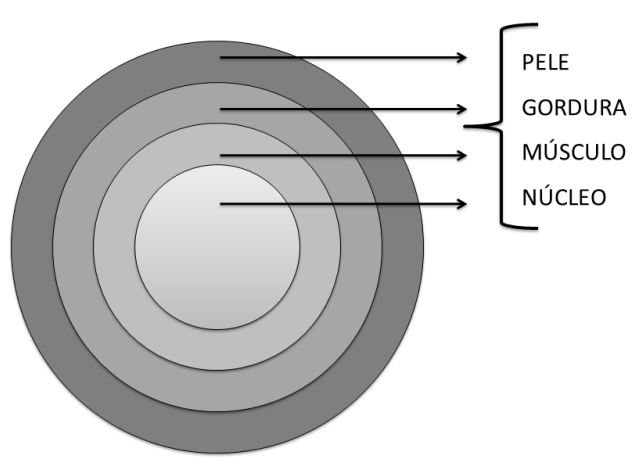

Figura 3.8: Modelo de apenas um cilindro representando as camadas do corpo

Os dois primeiros são ponderados pelo volume, enquanto o calor específico foi ponderado pela massa e o último pela raiz cúbica do volume. Assim, pode-se chegar à Tabela 3.4, em que $\rho$ é a massa específica, $k$ é a condutibilidade térmica, $c$ é o calor específico, $M^{\prime \prime \prime}$ é o metabolismo por unidade de volume e $w b_{t}$ é a perfusão de sangue. A massa específica e o calor específico do sangue são respectivamente: $1059 \mathrm{~kg} / \mathrm{m}^{3}$ e $3850 \mathrm{~J} /(\mathrm{kg} . \mathrm{K})$.

Tabela 3.4: Propriedades termofísicas das camadas.

\begin{tabular}{|c|c|c|c|c|c|}
\hline Camada & $\rho\left(\mathrm{kg} / \mathrm{m}^{3}\right)$ & $k(\mathrm{~W} /(\mathrm{m} . \mathrm{K}))$ & $c(\mathrm{~J} /(\mathrm{kg} . \mathrm{K}))$ & $M^{\prime \prime \prime}\left(\mathrm{W} / \mathrm{m}^{3}\right)$ & $w b_{t}\left(\mathrm{~m}_{s}^{3} /\left(\mathrm{m}_{t}^{3} \mathrm{~s}\right)\right)$ \\
\hline Pele & 1085 & 0,43 & 3680 & 368,1 & 361,7 \\
Gordura & 920 & 0,21 & 2300 & 368,4 & 76,7 \\
Músculo & 1085 & 0,51 & 3800 & 684,2 & 542 \\
Núcleo & 1119 & 0,5038 & 2679 & 2653 & 4155 \\
\hline
\end{tabular}

O volume e a altura do modelo anatômico foram mantidos. Dessa forma, foi possível obter os valores do raio externo subtraindo sucessivamente o volume de cada camada. Para mudar as condições anatômicas do modelo em função do metabolismo, da massa e da altura, foi necessário calcular a área superficial e obter o volume do corpo a partir do raio externo.

Tabela 3.5: Dimensões e volumes de cada camada, baseado em Ferreira (1997)

\begin{tabular}{|c|c|c|c|}
\hline Camada & $m(\mathrm{~kg})$ & $V\left(\mathrm{~cm}^{3}\right)$ & Raio externo $(\mathrm{cm})$ \\
\hline Pele (p) & 3,3246 & 3287 & 10,54 \\
Gordura (g) & 8,508 & 10153 & 10,26 \\
Músculo (m) & 27,36 & 27688 & 9,326 \\
Núcleo (n) & 20,78 & 20426 & 6,078 \\
sangue (s) & 5,825 & 5500 & - \\
\hline
\end{tabular}

Para se conseguir a distribuição de temperaturas dentro do corpo, deve-se resolver o balanço de energia, como indicado na Equação 3.87. O metabolismo e perfusão sanguínea, apesar de não serem geração de calor, são colocados nesse termo somente para resolução das equações diferenciais. Para perfusão de sangue foi usado o modelo de Pennes (1948). O subscrito $t$ refere-se ao tecido (pele, gordura, músculo e núcleo) e $s$ refere-se ao sangue. 


$$
\rho_{t} c_{t} V_{t} \frac{\partial T_{t}}{\partial t}=\frac{\partial}{\partial r}\left(k_{t} A_{t} \frac{\partial T_{t}}{\partial r}\right)+\left(\rho_{t} V_{t}\right)\left(\rho_{s} c_{s}\right) w b_{t}\left(T_{s}-T_{i}\right)+M^{\prime \prime \prime} V_{t}
$$

As principais hipóteses simplificadoras do modelo são: cada camada apresenta propriedades uniformemente distribuídas pelo volume; a temperatura da camada é considerada constante, ou seja, é usado o método da capacitância concentrada; na direção axial do cilindro se considera condução de calor; sangue arterial possui uma mesma temperatura (dependente do tempo); sangue deixa os tecidos em equilíbrio térmico com os mesmos; não é levada em conta a existência de roupa (apesar de ser facilmente implementada) e o modelo está na posição anatômica. Baseando-se em Chen e Holmes (1980), a principal troca de calor entre sangue e tecido ocorre nos capilares.

Nota-se que na pele as condições de contorno são as trocas de energia com o ambiente. A variação de entalpia associada à respiração é considerada apenas no núcleo (interação entre o núcleo e o ambiente). A partir da hipótese de capacitância concentrada, o termo $\frac{\partial}{\partial r}\left(k_{t} A_{t} \frac{\partial T_{t}}{\partial r}\right)$ passa a ser apenas uma diferença entre o calor recebido por condução do tecido anterior subtraído do calor perdido por condução para o tecido seguinte. A única exceção é a pele que troca energia diretamente com o ambiente.

Comparando-se os resultados do modelo simplificado (Figura 3.9(b)) com os resultados do modelo semelhante proposto por Ferreira (1997) (Figura 3.9(a)), verifica-se que, apesar de as temperaturas terem permanecido próximas nas diferentes camadas, o perfil é constante no presente modelo. Essa é uma hipóteses bastante forte para a gordura e pele, mas para o músculo e núcleo não é uma má aproximação, mesmo que haja uma pequena variação de temperatura ao longo do raio, como indicado na Figura 3.9(a). Contudo, ainda é possível inferir que a distribuição de temperatura é semelhante e adequada para as condições de utilização do modelo simplificado (obter fluxos de energia para o ambiente e temperatura interna do corpo para diferentes anatomias). Os fluxos de energia para o ambiente são muito próximos daqueles mostrados na Tabela 2.8 .
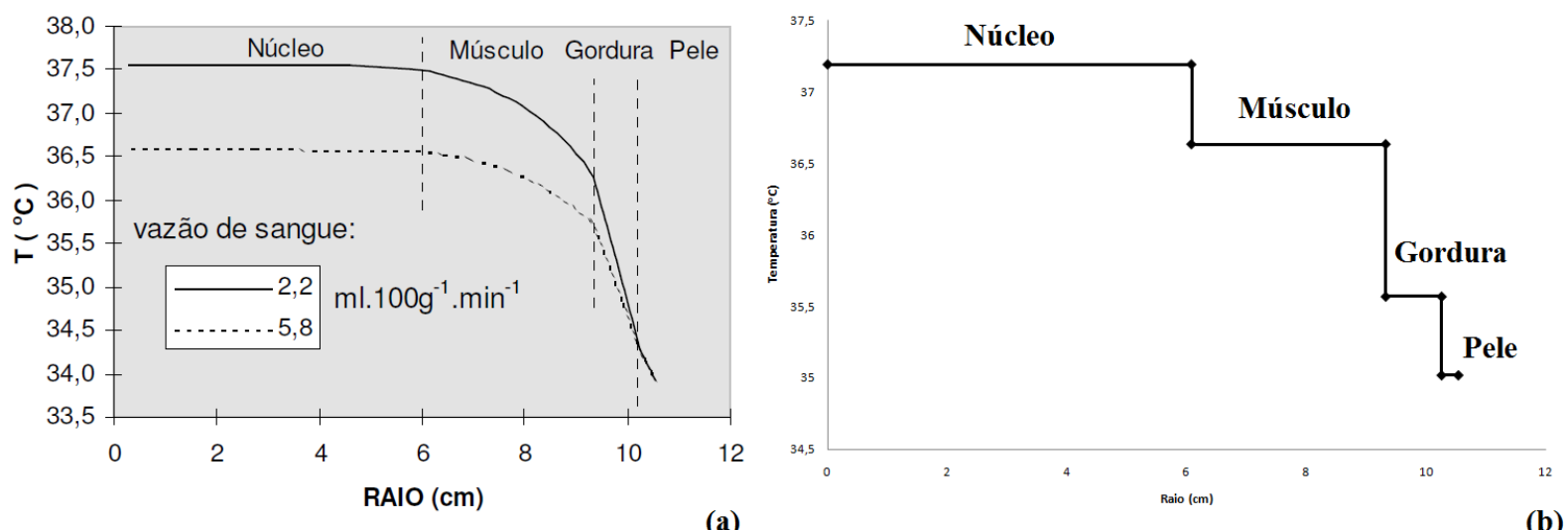

(a)

(b)

Figura 3.9: Temperatura das camadas no modelo de: (a) Ferreira (1997) para duas taxas de perfusão sanguíneas, (b) presente modelo 
Esse modelo será aplicado a situações em que se deseje calcular a entropia gerada durante uma vida, na qual serão necessárias simulações para diferentes faixas de idades e geometria: crianças, adultos e idosos.

\subsection{TESTE CARDIOPULMONAR (ERGOESPIROMÉTRICO)}

Como discutido em Fernandes et al. (2012), a ergoespirometria, ou teste cardiopulmonar, é um dos métodos mais simples para se avaliar a capacidade funcional de um indivíduo. Utilizado em larga escala, o teste é aplicado a atletas profissionais e amadores, possibilitando a obtenção de variáveis respiratórias, metabólicas e cardiovasculares pela medição das trocas gasosas pulmonares com o ambiente (consumo de oxigênio, produção de gás carbônico). Por meio desse teste torna-se possível obter índices de avaliação funcional como, por exemplo, o $\mathrm{VO}_{2, \max }$.

Por meio de dados experimentais fornecidos pelo Laboratório de Estudo do Movimento da Faculdade de Medicina da USP, foram obtidos dados fisiológicos de corredores, originalmente para o projeto FAPESP 2010/19631-2 cujo título é "Estudo comparativo dos limiares ventilatórios mensurados pelos protocolos de variabilidade da frequência cardíaca, limiar do lactato e ergoespirometria em corredores de capacidade aeróbia progressiva". O estudo baseia-se na constatação de que o limiar do lactato (LL) é dos indicadores mais confiáveis de capacidade funcional do corpo, indica o momento em que a concentração de lactato no sangue aumenta exponencialmente (o metabolismo anaeróbico começa a prevalecer sobre o aeróbico). Esse ponto é caracterizado pelo abrupto aumento da concentração de lactato no sangue.

Ao todo, participaram do estudo 11 corredores. A idade média foi de 31,4 $\pm 10,1$ anos, a massa média foi de $73,3 \pm 7,8 \mathrm{~kg}$, a altura média foi de $1,76 \pm 0,07 \mathrm{~m}$ e a área média do corpo foi de $1,89 \pm 0,11 \mathrm{~m}^{2}$. Todos eram treinados, no entanto, 7 treinavam mais de 4 vezes por semana e 4 treinavam menos de 4 vezes por semana.

Depois de terem sido conectados aos equipamentos, os corredores foram deixados em pé por 5 minutos para coleta de dados como espirometria, frequência cardíaca, dentre outros e foram submetidos a correrem por 3 minutos a $30 \%$ de sua velocidade máxima de treino de longa distância; em seguida, essa velocidade foi aumentada para $70 \%$ da velocidade máxima de treino por 4 minutos. A partir desse nível, a velocidade foi novamente aumentada em $1 \mathrm{~km} / \mathrm{h}$ a cada 4 minutos até o corredor se sentir exausto. Durante todo o experimento, a esteira permaneceu com uma inclinação de $1 \%$, para que o gasto energético fosse equivalente ao de uma corrida de rua, como destacado por Jones 
e Doust (1996). Foi escolhido o intervalo de 4 minutos porque é tempo suficiente para as funções vitais se estabilizarem. A Figura 3.10 indica a evolução das velocidades durante o teste, para um corredor, assim como o consumo de oxigênio e produção de gás carbônico medidos durante o periodo de atividade.

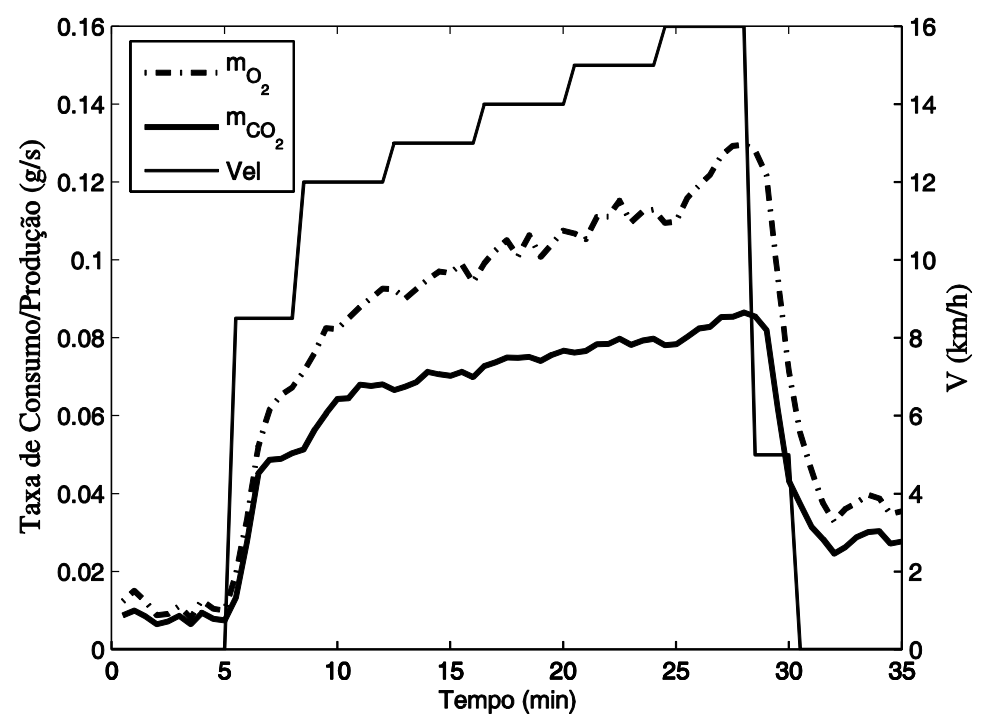

Figura 3.10: Consumo de oxigênio, produção de gás carbônico e velocidade da esteira obtidos no teste ergoespirométrico do corredor 10

Para medições de calorimetria indireta foi utilizado um respirômetro da marca TruMax 2400 Metabolic Measurement System, Consentius Technologies. Assim, foi possível a obtenção do consumo de $\mathrm{O}_{2}$ e produção de $\mathrm{CO}_{2}$ para o cálculo de metabolismo.

A temperatura da pele foi medida com o uso de uma radiômetro infravermelho (MX2, Raytek) em três lugares distintos: centro das costas, parte posterior da perna direita e braço direito. Essas medidas foram feitas nos dois minutos finais de cada velocidade. A temperatura timpânica (representativa do corpo) foi medida no final e no começo de cada exercício.

Para o cálculo do limiar do lactato (ou virada do lactado) no sangue, foram coletadas amostras da ponta do dedo a cada 3,5 minutos de cada nível de velocidade. O equipamento usado para obtenção dos dados foi o Accutrend@ Lactate (Roche, type 3012522). Três procedimentos foram usados para o cálculo do limiar do lactato, e a média deles foi considerada como a virada do lactato: (i) diferença entre a concentração de lactato das últimas duas medidas foi menor do que $1 \mathrm{mmol} / \mathrm{L}$; (ii) valor absoluto da concentração de lactato foi de $4 \mathrm{mmol} / \mathrm{L}$; e (iii) análise gráfica em escala logarítmica da concentração de lactato no tempo.

Para análises, os corredores foram divididos em três grupos, de acordo com o instante em que ocorreram limiares de lactato (LL). O primeiro grupo, LL baixo, inclui 4 indivíduos cuja virada ocorreu a velocidades inferiores a $3,1 \mathrm{~m} / \mathrm{s}$. O segundo grupo, LL médio inclui 
3 indivíduos cuja velocidade de limiar ficou 3,1 e $3,5 \mathrm{~m} / \mathrm{s}$. O último grupo, LL alto inclui corredores cuja velocidade foi maior do que $3,5 \mathrm{~m} / \mathrm{s}$. A velocidade média no qual ocorreu o LL para esses grupos foi: $2,8 \pm 0,3,3,3 \pm 0,1$, and $3,8 \pm 0,4 \mathrm{~m} / \mathrm{s}$.

Realizaram-se medidas em três dias distintos. Desse modo, as condições ambientes médias são: temperatura ambiente igual a $23,6 \pm 1.5^{\circ} C$; temperatura média radiante igual a 22,8 $\pm 1.5{ }^{\circ} \mathrm{C}$, umidade relativa igual a $56,6 \pm 8,5 \%$; e pressão barométrica de $688 \mathrm{mmHg}$.

\subsubsection{Análise energética e exergética aplicada ao teste ergoespirométrico}

Novamente, para aplicação da análise exergética, tornou-se necessária a obtenção das variações temporais da energia interna e da entropia do corpo. Para calcular os fluxos de calor, entalpia e exergia para o ambiente foi utilizado o procedimento dos Itens 3.1.3 e 3.1 .4

A variação da energia interna foi obtida pelo o balanço de energia. Como foi descrito anteriormente, a temperatura interna foi medida no começo e no fim de cada ciclo de atividades. Portanto, mediante esse valor, é possível aplicar o método de Euler para conseguir o valor de temperatura interna durante toda atividade física. O intervalo de tempo usado foi o próprio intervalo de medição. Utilizou-se, portanto, a Equação 3.88 para cálculo da temperatura para cada instante de tempo a partir dos valores de variação de energia interna e constantes médias do corpo.

$$
T_{i n t}^{k+1}=T_{i n t}^{k}+\left.\frac{\Delta t}{m c_{\text {corpo }}} \frac{\Delta U}{\Delta t}\right|_{\Delta T}
$$

Sendo:

- $T_{i n t}^{k}$ : temperatura interna do corpo no instante $\mathrm{k}$;

- $c_{\text {corpo }}$ : calor específico médio do corpo.

Com base na distribuição de temperaturas, foi possível calcular a variação temporal da entropia, indicada na Equação 3.89. Assim, a partir da variação temporal da energia interna e da entropia, pode-se aplicar a Equação 3.4.

$$
\left.\frac{\Delta S}{\Delta t}\right|_{\Delta T}=\frac{m c_{\text {corpo }}}{\Delta t} \ln \left(\frac{T_{i n t}^{k+1}}{T_{i n t}^{k}}\right)
$$


É importante mencionar que o coeficiente de transferência de calor por convecção foi correlacionado com a velocidade, de acordo com relações encontradas em Incropera e Dewitt (2002). Houve, também, um ajuste dos coeficientes de troca de calor por convecção e vaporização para que a temperatura interna calculada e a água perdida estivessem de acordo com os valores medidos.

A potência realizada pelo corredor (em W) foi calculada de acordo com o trabalho externo definido por Cavagna e Kaneko (1977) (função da massa e da velocidade). A Equação 3.90 indica a potencia calculada segundo esta definição, no qual $V$ é a velocidade do corredor em $\mathrm{m} / \mathrm{s}$ e $m_{\text {corpo }}$ é a massa do corpo em $\mathrm{kg}$. A escolha baseia-se na discussão proposta por Ward-Smith (1984) sobre trocas energéticas durante atividade física. Além do mais, essas relações forneceram resultados que ficam de acordo com a temperatura interna medida.

$$
W=\frac{4,184}{60} m_{\text {corpo }}(9,42+4,73 V)
$$

A definição de eficiência líquida está indicada na Equação 3.91 definida por Kaneko (1990) como a razão entre o trabalho líquido e a diferença entre o metabolismo total $(M)$ e basal $\left(M_{0}\right)$.

$$
\eta_{l i q}=\frac{W}{M-M_{0}}
$$

Para Kaneko (1990), a eficiência líquida da corrida diminui com o aumento de velocidade, de aproximadamente 60 para $15 \%$ entre 3,9 e 9,4 m/s. Ito et al. (1983) evidenciaram que a eficiência líquida permanece constante $(55 \pm 12,7)$. Williams e Cavanagh (1983) determinaram uma eficiência de $44 \%$ para corredores a $3,6 \mathrm{~m} / \mathrm{s}$; e Bijeker, Groot e Hollander (2001) encontraram uma eficiência de $44 \%$ para uma velocidade de $2,2 \mathrm{~m} / \mathrm{s}$ para uma corrida em uma esteira inclinada. Tal dispersão de dados se deve ao cálculo do trabalho que pode ser impreciso quando este for anaeróbico (Kaneko (1990)) e pelo método usado para calcular a potência que variou de 343 a $1650 \mathrm{~W}$ para velocidades entre 3,6 e 3,9 m/s, como relatado por Williams e Cavanagh (1983). 


\subsubsection{Fluxograma para aplicação da analise exergética no corpo humano}

A Figura 3.11 indica de forma esquemática e simplificada os passos que devem ser realizados para aplicação da análise exergética no corpo humano. São destacados desde parâmetros de entrada (em azul), com respectivos cálculos (laranja) e aplicações aos modelos (verde). Note que para o modelo do sistema térmico, os cálculos dos fluxos de energia para o ambiente e do balanço de energia são iterativos, pois os primeiros são condições de contorno do modelo durante a resolução das equações diferenciais (troca de energia entre ambiente e corpo). 


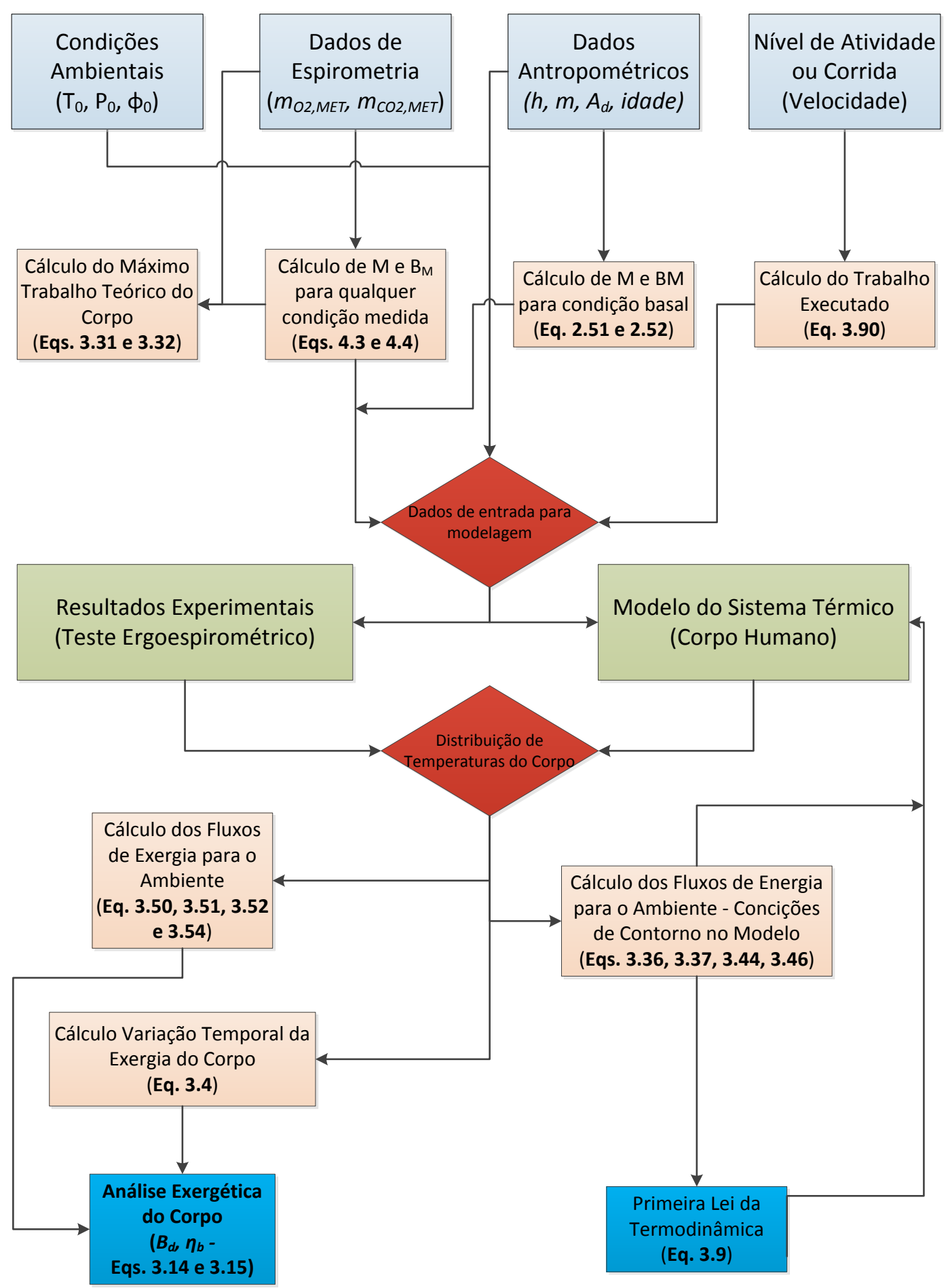

Figura 3.11: Representação esquemática para análise exergética dos corpo, com respectivos parâmetros de entrada, equações principais, para aplicações numéricas e experimentais 


\section{RESULTADOS E DISCUSSÕES}

\subsection{METABOLISMO ENERGÉTICO E EXERGÉTICO}

\subsubsection{Propriedades termodinâmicas e equação do metabolismo}

Cumpre destacar que, nesta análise, tanto os carboidratos quanto os lipídeos são representados por uma substância (glicose e ácido palmítico, respectivamente), mas os aminoácidos são reproduzidos por uma substância de propriedades médias. Sorguven e Özilgen (2010) calcularam a exergia química de três ácidos graxos com 18, 20 e 22 carbonos na cadeia. A diferença da exergia química por unidade de massa não é maior do que 1\%. A Tabela 3.3 indica que a diferença de valor de propriedades termodinâmicas dos aminácidos chega a 50\%, pois cada aminoácido tem um tipo de cadeia, com diversas ramificações, o que justifica essa diferença.

Tomando por base os valores de propriedades termodinâmicas das reações de oxidação completa dos diversos aminoácidos, apontados na Tabela 3.3, é possível obter as mesmas grandezas para as reações de oxidação, tal qual ocorrem no corpo. A Tabela 4.1 exibe os valores de variação de entalpia, variação de energia livre de Gibbs e variação de exergia dos diversos aminoácidos.

Na Tabela 3.2, o único valor de propriedade termodinâmica que Haynie (2008) não fornece é para os aminoácidos. Aplicando o resultado da Tabela 4.1, pode-se chegar a $\Delta h / \Delta b_{q}=$ 1,04. Assim, se determina a variação da exergia química para os dados desse autor como sendo $19777 \mathrm{~kJ} / \mathrm{kg}$.

Na Tabela 4.2, estão indicados os valores de exergia química $\left(b_{q}\right)$ e valores de variação de exergia química $\left(\Delta b_{q}\right)$. Este último valor se refere ao aminoácido cuja oxidação ocorre até a formação de ureia. Esses valores são usados como base para calcular da variação da exergia no corpo. Nota-se que, como a temperatura em que a reação de oxidação acontece é a mesma, a variação da energia livre de Gibbs é igual à variação da exergia.

Já na Tabela 4.3, estão indicadas as variações de exergia dos nutrientes na forma como ocorrem no corpo humano (a reação é completa no caso da glicose e do ácido palmítico e parcial se se tratar dos aminoácidos). Com base nos valores de $\Delta h$ e $\Delta b$ (das reações de oxidação na forma como ocorrem no corpo) e do procedimento indicado na Secção 3.1.1, pode-se calcular o metabolismo em base energética e exergética. 
Tabela 4.1: Variação da entalpia, energia livre de Gibbs e exergia das reações de oxidação dos 95,8\% dos aminácidos até a formação de dióxido de carbono, água líquida e ureia

\begin{tabular}{|c|c|c|c|c|}
\hline Aminoácido & $\mathrm{Fórmula}$ & $\Delta h(\mathrm{~kJ} / \mathrm{kg})$ & $\Delta g(\mathrm{~kJ} / \mathrm{kg})$ & $\Delta b_{q}(\mathrm{~kJ} / \mathrm{kg})$ \\
\hline Glicina & $\mathrm{C}_{2} \mathrm{H}_{5} \mathrm{NO}_{2}$ & -8776 & -8996 & 9556 \\
Alanina & $\mathrm{C}_{3} \mathrm{H}_{7} \mathrm{NO}_{2}$ & -15631 & -14671 & 15121 \\
Serina & $\mathrm{C}_{3} \mathrm{H}_{7} \mathrm{NO}_{3}$ & -10850 & -11102 & 11502 \\
Ácido Aspártico & $\mathrm{C}_{4} \mathrm{H}_{7} \mathrm{NO}_{3}$ & -9716 & -10148 & 10599 \\
Aspargina & $\mathrm{C}_{4} \mathrm{H}_{8} \mathrm{~N}_{2} \mathrm{O}_{3}$ & -9882 & -10049 & 10424 \\
Treonina & $\mathrm{C}_{4} \mathrm{H}_{9} \mathrm{NO}_{3}$ & -15027 & -15073 & 15551 \\
Prolina & $\mathrm{C}_{5} \mathrm{H}_{9} \mathrm{NO}_{2}$ & -21037 & -21280 & 22110 \\
Ácido Glutâmico & $\mathrm{C}_{5} \mathrm{H}_{9} \mathrm{NO}_{4}$ & -13158 & -13461 & 13969 \\
Glutamina & $\mathrm{C}_{5} \mathrm{H}_{10} \mathrm{~N}_{2} \mathrm{O}_{3}$ & -13277 & -13393 & 13834 \\
Valina & $\mathrm{C}_{5} \mathrm{H}_{11} \mathrm{NO}_{2}$ & -22258 & -22083 & 22678 \\
Histidina & $\mathrm{C}_{6} \mathrm{H}_{9} \mathrm{~N}_{3} \mathrm{O}_{2}$ & -15991 & -15530 & 16517 \\
Leucina & $\mathrm{C}_{6} \mathrm{H}_{13} \mathrm{NO}_{2}$ & -24979 & -24647 & 25291 \\
Lisina & $\mathrm{C}_{6} \mathrm{H}_{14} \mathrm{~N}_{2} \mathrm{O}_{2}$ & -20907 & -21344 & 24378 \\
Arginina & $\mathrm{C}_{6} \mathrm{H}_{14} \mathrm{~N}_{4} \mathrm{O}_{2}$ & -14257 & -14028 & 14375 \\
Fenilalanina & $\mathrm{C}_{9} \mathrm{H}_{11} \mathrm{NO}_{2}$ & -26286 & -26126 & 26933 \\
Tirosina & $\mathrm{C}_{9} \mathrm{H}_{11} \mathrm{NO}_{3}$ & -22769 & -22910 & 23657 \\
Triptofano & $\mathrm{C}_{11} \mathrm{H}_{12} \mathrm{~N}_{2} \mathrm{O}_{2}$ & -24512 & -24394 & 25162 \\
\hline Valor Médio & $\mathrm{C}_{4.98} \mathrm{H}_{9.8} \mathrm{~N}_{1.4} \mathrm{O}_{2.5}$ & -17598 & -17578 & 18317 \\
\hline
\end{tabular}

Tabela 4.2: Exergia química da glicose, ácido palmítico e composição entre a exergia química das proteínas e da ureia $(\mathrm{kJ} / \mathrm{kg})$

\begin{tabular}{|c|c|c|c|}
\hline- & \multicolumn{3}{|c|}{$b_{q}$ ou $\Delta b_{q}(\mathrm{~kJ} / \mathrm{kg})$} \\
\hline Referências & Glicose & Ac. Palmitic & Amino Ac. \\
\hline Haynie (2008) & 16506 & 39141 & 19777 \\
Cortassa et al. (2002) & 16516 & 39223 & 18317 \\
\hline
\end{tabular}

Tabela 4.3: Variação da exergia das reações de oxidação da glicose, ácido palmítico e proteínas $(\mathrm{kJ} / \mathrm{kg})$ na forma como ocorrem no corpo

\begin{tabular}{|c|c|c|c|}
\hline- & \multicolumn{3}{|c|}{$\Delta b(\mathrm{~kJ} / \mathrm{kg})$} \\
\hline Referências & Glicose & Ac. Palmitic & Amino Ac. \\
\hline Haynie (2008) & -15946 & -38212 & -18964 \\
Cortassa et al. (2002) & -15956 & -38281 & -17578 \\
\hline
\end{tabular}

Finalmente, as Equações 4.1 e 4.2 definem o metabolismo em base energética e exergética calculados via propriedades termodinâmicas obtidas por Haynie (2008). Já as Equações 4.3 e 4.4 mostram os valores dos metabolismos via propriedades fornecidas por Cortassa et al. (2002). Os valores resultantes das equações para $\dot{M}$ e $\dot{B}_{M}$ é dado em W e o consumo/produção de gases é dado em $\mathrm{kg} / \mathrm{s}$. Se a oxidação das proteínas for desprezada, ou seja, $\dot{m}_{N}=0$, as duas equações devem fornecer valores similares, porque a diferença dos coeficientes é maior para esse termo (até o sinal do coeficiente é outro). Nessas equações, o metabolismo é decorrente do consumo de oxigênio e produção de gás carbônico, apropriados para calorimetria indireta. Caso seja conhecido o consumo de 
nutrientes, basta saber a massa de cada nutriente para se obter o metabolismo; não é preciso, pois, obrigatoriamente usar tais equações.

$$
\begin{aligned}
& \dot{M}_{\text {Haynie }}=11371 \dot{m}_{O_{2}}+2366 \dot{m}_{C_{2}}+6891 \dot{m}_{N} \\
& \dot{B}_{M_{\text {Haynie }}}=9363 \dot{m}_{O_{2}}+4444 \dot{m}_{C_{2}}+8764 \dot{m}_{N} \\
& \dot{M}_{\text {Cortassa }}=11179 \dot{m}_{O_{2}}+2502 \dot{m}_{C_{2}}-1580 \dot{m}_{N} \\
& \dot{B}_{M_{\text {Cortassa }}}=9435 m_{O_{2}}+4399 m_{\mathrm{CO}_{2}}-1823 m_{N}
\end{aligned}
$$

\subsubsection{Cálculo do metabolismo energético e exergético}

Analisando-se a Tabela 2.6, pode-se calcular o metabolismo energético e exergético para condição basal medida por Hardy e DuBois (1938). Observa-se nessa tabela que o QR equivale a 0,82 (próximo aos 0,83 propostos pela ASHRAE (2005)). Nessa condição, o metabolismo obtido pelos autores foi de 79,8 W. Aplicando as Equações 4.1 a 4.4, chega-se à Tabela 4.4, na qual estão os valores do metabolismo energético e exergético, considerando-se a oxidação de proteínas $\left(M, B_{M}\right)$ e sem se levar em conta a oxidação de proteínas $\left(M_{p}, B_{M_{p}}\right)$ - deve-se tomar cuidado com a influência dos aminoácidos no cálculo do metabolismo, pois, dependendo das propriedades usadas, sua contribuição pode ser maior ou menor. Em todos os casos, a diferença entre os valores da Tabela 4.4 e o obtido por Hardy e DuBois (1938) não foi maior do que 2\%. A razão entre os metabolismos, considerando ou não a presença das proteínas não foi maior do que 1.01. Finalmente, a razão entre o metabolismo energético e exergético, não foi maior do que 1,01 , demonstrando que a aproximação $M \approx B_{M}$ é válida para condição basal, o que confirma o resultado de Batato et al. (1990).

Por intermédio dos resultados experimentais obtidos no Laboratório de Estudo do Movimento da Faculdade de Medicina da USP (Seção 3.5), o metabolismo foi calculado em base energética e exergética, usando-se os valores de Cortassa et al. (2002) (Equações 4.3 e 4.3). Na Figura 4.1(a) estão evidenciados os valores de $\dot{M}, \dot{B}_{M}$ e $\dot{B}_{Q_{M}}$ em função do 
Tabela 4.4: Metabolismo energético e exergético calculados com base nos dados obtidos por Hardy e DuBois (1938) para dois casos: com a oxidação de proteínas $\left(M, B_{M}\right)$ e sem a oxidação de proteínas $\left(M_{p}, B_{M_{p}}\right)$

\begin{tabular}{|c|c|c|}
\hline & Haynie (2008) $(\mathrm{W})$ & Cortassa et al. (2002) (W) \\
\hline$\dot{M}$ & 81,3 & 79,9 \\
$\dot{M}_{p}$ & 80,3 & 80,1 \\
$\dot{B}_{M}$ & 80,8 & 79,7 \\
$\dot{B}_{M_{p}}$ & 79,9 & 80,0 \\
\hline
\end{tabular}

tempo para o corredor 10 (lembrando que $\dot{Q}_{M}=\dot{M}-\dot{W}$ ). Apesar de $B_{M}$ e $B_{Q_{M}}$ terem o mesmo comportamento para o caso basal (primeiros 5 minutos), o mesmo não ocorre durante atividades físicas. Fica evidente que, ao se considerar o metabolismo exergético como $\dot{B}_{Q_{M}}$, estão sendo desprezados mais de $95 \%$ da exergia do corpo (valores de $\dot{B}_{Q_{M}}$ no eixo vertical secundário). Na Figura 4.1(b), nota-se que para esse corredor a razão entre o metabolismo energético e exergético teve como valor máximo, aproximadamente 1,05. Este último foi só para o ponto em que a velocidade do corredor diminuiu abruptamente. Logo, os picos de razão máxima ocorrem nos pontos em que a derivada da velocidade é alta (taxas de aceleração e desaceleração altas).

(a)

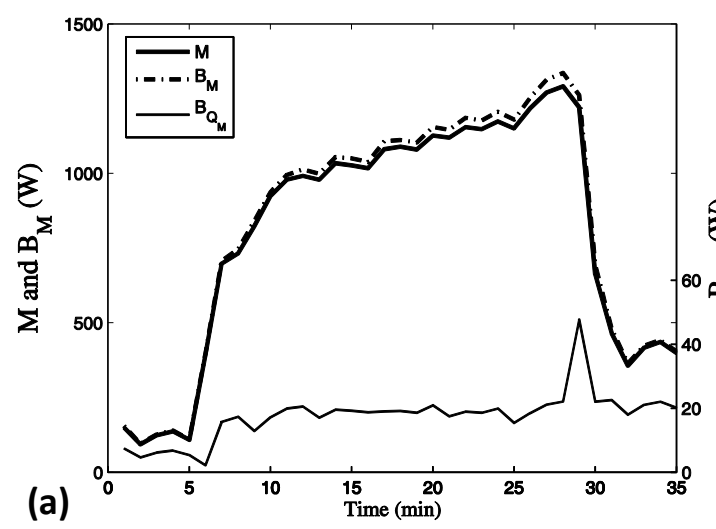

Figura 4.1: (a): Cálculo de $\dot{M}, \dot{B}_{M}$ e $\dot{B}_{Q_{M}}$; (b) relação entre o metabolismo energético e exergético. Ambas as figuras são para o corredor 10

Já a Figura 4.2 indica a razão no cálculo do metabolismo energético, ao se considerar $(M)$ ou não $\left(M_{p}\right)$ a oxidação das proteínas durante a atividade física. Verifica-se que as menores razões se deram durante os primeiros minutos, instantes nos quais o corredor estava se acostumando com o equipamento de respiração (controle da respiração)e nos quais o corredor estava em repouso, momento em que o consumo de aminoácidos é proporcionalmente maior, como ressalta Mountcastle (1974).

A Tabela 4.5 indica os valores de metabolismo energético e exergético e a exergia liberada pelo corpo por causa do metabolismo integrado ao longo do teste ergo-espirométrico (tempo de atividade somado ao início em que o corredor manteve-se parado para adaptar-se aos instrumentos). É possível notar que a parcela térmica do metabolismo 


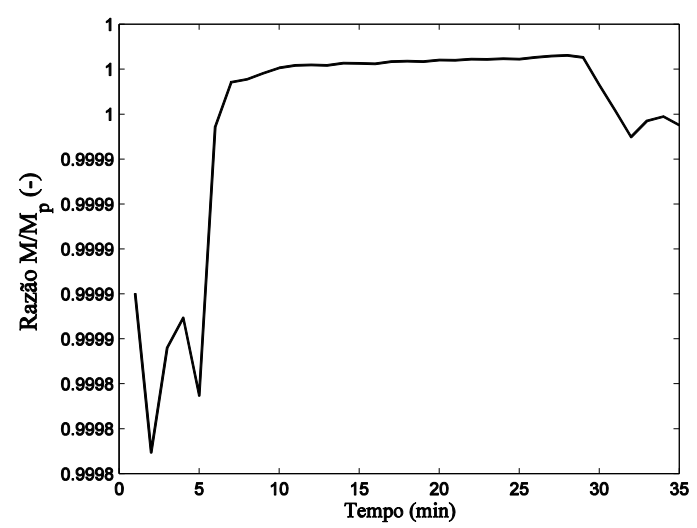

Figura 4.2: Razão entre o metabolismo calculado, considerando-se a oxidação das proteínas $(M)$ e sem se considerar a oxidação das proteínas $\left(M_{p}\right)$ para o corredor 10

exergético $\left(B_{Q_{M}}\right)$ equivale a $5 \%$ do metabolismo exergético (variação da exergia das reações). Portanto, apesar de a Figura 4.1 apresentar a mesma tendência do metabolismo exergético, quando se considera essa parcela apenas, mais de 95\% da exergia liberada da oxidação dos nutrientes está sendo desprezada. Nesta tabela, também se destaca a razão entre o metabolismo em base exergética e energética, em que é possível notar que a razão ficou entre 1.01 e 1.03. Novamente, no caso da atividade física, a aproximação $M \approx B_{M}$ é válida.

Tabela 4.5: Duração do teste, metabolismo energético, exergético, fluxo de exergia liberado para corpo devido ao metabolismo e razão entre o metabolismo exergético e energético. Valores integrados por todo o período de atividade física para cada corredor (1 a 11$)$

\begin{tabular}{|c|c|c|c|c|c|}
\hline Sub. & Test Dur. (min) & $M(\mathrm{~J} / \mathrm{kg})$ & $B_{M}(\mathrm{~J} / \mathrm{kg})$ & $B_{Q_{M}}(\mathrm{~J} / \mathrm{kg})$ & $B_{M} / M$ \\
\hline 1 & 29,5 & 16851 & 17307 & 439 & 1,03 \\
2 & 34,0 & 17617 & 17897 & 457 & 1,02 \\
3 & 29,0 & 15729 & 16150 & 383 & 1,03 \\
4 & 36,0 & 17026 & 17308 & 437 & 1,02 \\
5 & 43,5 & 27088 & 27712 & 843 & 1,02 \\
6 & 42,5 & 30434 & 30951 & 880 & 1,02 \\
7 & 41,5 & 25312 & 26019 & 617 & 1,03 \\
8 & 42,5 & 29907 & 30351 & 625 & 1,01 \\
9 & 37,0 & 22699 & 23037 & 796 & 1,01 \\
10 & 35,0 & 20826 & 21343 & 702 & 1,02 \\
11 & 52,5 & 42545 & 43504 & 1174 & 1,02 \\
\hline
\end{tabular}




\subsubsection{Rendimento metabólico}

Com base no conceito de rendimento metabólico (Equação 2.40) definido pela razão das energias livre de Gibbs da hidrólise do ATP pela oxidação completa do nutriente, foi possível obter essa grandeza física para os processos de conversão de energia no corpo humano, para oxidação aeróbica e anaeróbica da glicose, oxidação do ácido palmítico e oxidação do aminoácido. Na Tabela 4.6, estão indicados o número de mols de ATP produzidos na oxidação de cada nutriente, a variação na energia livre de Gibbs na hidrólise do ATP, a variação da energia livre de Gibbs na oxidação completa do nutriente e o rendimento metabólico. Observa-se que, conforme calculado por Lems (2009), quando se levam as propriedades termodinâmicas das condições padrões bioquimicas para condições mais próximas das reais, o rendimento praticamente dobra. Nota-se, ainda, que o rendimento metabólico dos aminoácidos é $1 / 3$ do rendimento dos outros nutrientes, resultado também demonstrado em Silva e Annamalai (2008) e Silva e Annamalai (2009).

Tabela 4.6: Número de mols de ATP produzido para oxidação das diferentes substâncias, variação da energia livre de Gibbs, das reações por mol de nutriente e rendimento metabólico de cada nutriente

\begin{tabular}{|c|c|c|c|c|}
\hline Nutriente & $n_{A T P}(\mathrm{~mol})$ & $\Delta g_{A T P}(\mathrm{~kJ} / \mathrm{mol})$ & $\Delta g_{\text {ox, compl }}(\mathrm{kJ} / \mathrm{mol})$ & $\eta_{M}(\%)$ \\
\hline Resp. Anaeróbica Glicose & 2 & -112 & -292 & 38.4 \\
Glicose & 32 & -1792 & -2872 & 62.4 \\
Ácido Palmítico & 106 & -5936 & -9800 & 60.6 \\
Aminoácidos & 8 & -448 & -2268 & 19.8 \\
\hline
\end{tabular}

\subsubsection{Metabolismo e envelhecimento}

O metabolismo, calculado pela Equação 2.51, está relacionado com a idade para indivíduos do sexo masculino, indicado na Tabela 4.7 (altura e massa adotados do modelo de Ferreira e Yanagihara (2009a)). A idade em que ocorre o maior metabolismo é 18 anos, decrescendo com o passar do tempo. Então não foram usados valores inferiores a esta idade no modelo de Ferreira e Yanagihara (2009a), pois este tem a limitação, qual seja, a de se tratar de um indivíduo adulto. Para calcular o metabolismo para outras idades seria necessário mudar a altura, raios dos compartimentos, área superficial, massa muscular, dentre outros. O metabolismo energético adotado para o restante das simulações foi o de 79,1W, (adulto de meia idade), valor estabelecido por Ferreira e Yanagihara (2009a).

Para evitar problemas com a restrição de anatomia do modelo de Ferreira e Yanagihara 
Tabela 4.7: Valor do metabolismo como função da idade da pessoa em anos

\begin{tabular}{|c|c||c|c|}
\hline Idade (anos) & $M(\mathrm{~W})$ & Idade (anos) & $M(\mathrm{~W})$ \\
\hline 18 & 84,3 & 40 & 77,0 \\
20 & 83,6 & 50 & 73,7 \\
25 & 82,0 & 60 & 70,4 \\
30 & 80,3 & 70 & 67,1 \\
\hline
\end{tabular}

(2009a), foi proposta uma simplificação em que o corpo humano é aproximado por um cilindro de seção circular. Assim, foi possível fazer novas simulações utilizando o metabolismo basal e condições anatômicas como entrada das diferentes simulações. O primeiro foi calculado como função da idade, massa, altura para o sexo masculino, pelas Equações 2.53 (até 16 anos) e 2.51 (a partir de 16 anos) para condição basal. A Tabela 4.8 indica os resultados dos valores antropométricos de brasileiros, entre 2008 e 2009, a partir dos quais se calculou o metabolismo. Nota-se que, na última coluna, estão indicados os valores em $\left(\mathrm{W} / \mathrm{m}^{2}\right)$, pois com a variação da anatomia do individuo, torna-se necessário padronizar essa grandeza física por unidade de área superficial ou por unidade de massa.

Tabela 4.8: Idade, altura , massa, em função da idade para brasileiros, obtidos em IBGE (2010). Metabolismo basal, área superficial e metabolismo por unidade de área calculados

\begin{tabular}{|c|c|c|c|c|c|}
\hline Idade (anos) & $h(\mathrm{~cm})$ & $w(\mathrm{~kg})$ & $M(\mathrm{~W})$ & $A_{d}\left(\mathrm{~m}^{2}\right)$ & $M\left(\mathrm{~W} / \mathrm{m}^{2}\right)$ \\
\hline 0 & 67 & 8 & 29,1 & 0,4 & 79,1 \\
2 & 92 & 14 & 37,0 & 0,6 & 63,6 \\
4 & 106 & 18 & 41,8 & 0,7 & 58,0 \\
6 & 118 & 22 & 46,1 & 0,9 & 54,1 \\
8 & 130 & 28 & 50,7 & 1,0 & 50,7 \\
10 & 139 & 33 & 56,0 & 1,1 & 49,1 \\
12 & 151 & 42 & 63,9 & 1,3 & 47,9 \\
14 & 164 & 52 & 73,3 & 1,6 & 47,1 \\
16 & 170 & 60 & 79,2 & 1,7 & 46,8 \\
17 & 172 & 63 & 81,4 & 1,7 & 46,7 \\
18 & 173 & 65 & 82,7 & 1,8 & 46,7 \\
20 & 173 & 69 & 84,9 & 1,8 & 46,6 \\
25 & 173 & 73 & 85,4 & 1,9 & 46,0 \\
30 & 172 & 74 & 84,5 & 1,9 & 45,3 \\
40 & 171 & 75 & 81,3 & 1,9 & 43,6 \\
50 & 170 & 75 & 77,8 & 1,9 & 41,9 \\
60 & 168 & 73 & 73,1 & 1,8 & 40,0 \\
70 & 167 & 70 & 67,6 & 1,8 & 37,9 \\
80 & 166 & 67 & 61,7 & 1,7 & 35,5 \\
\hline
\end{tabular}

Silva e Annamalai (2008, 2009), Annamalai e Silva (2012) afirmam que o uso do metabolismo basal para o cálculo da idade entrópica e entropia gerada durante uma vida, deve resultar em valores subestimados dessas grandezas. Pelos dados obtidos em Pinheiro (2013) foi possível obter tabelas com o valor do metabolismo "sedentário" ( $\left.M_{\text {sedentário }}\right)$ em 
função dos dados antropométricos. Esse valor é aquele necessário para que uma pessoa na condição sedentária mantenha o peso. A Figura 4.3 indica a razão $M_{\text {sedentário }} / M_{\text {basal }}$, na qual é possível observar que, tanto para crianças, quanto para adultos a razão equivale à aproximadamente 1,25; enquanto que para recém-nascidos a razão foi considerada como equivalente à 1 . Tal consideração deve-se aos maiores erros do modelo serem nessa faixa etária.

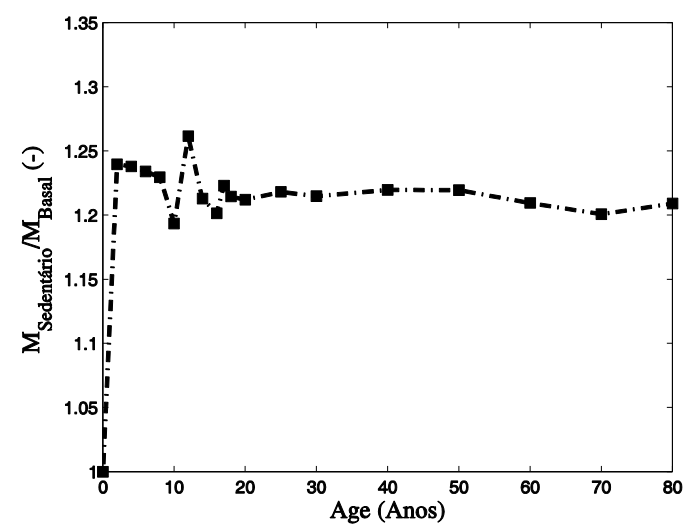

Figura 4.3: Razão entre o metabolismo "sedentário" e o metabolismo basal para idades de 0 a 80 anos

\subsection{BALANÇOS DIÁRIOS DE MASSA, ENERGIA E EXERGIA}

Nesta seção, serão demonstrados o balanço de massa, energia e exergia do corpo durante um período de 24 horas. O modelo adotado está indicado na Figura 3.1. Os dados foram obtidos da Figura 2.24 e detalhados na Seção 3.3.

Inicialmente, foi calculado pelo sistema de Equações 3.20 o consumo de nutrientes (carboidratos, lipídeos e proteínas) a partir do consumo de oxigênio e produção de gás carbônico indicados na Seção 3.3 e Figura 2.24. A massa de alimentos consumida e a de resíduos sólidos não precisam ter suas entalpias e exergias calculadas, pois se considera: $m_{\text {alim }}-m_{\text {fezes }}=m_{\text {nut }}, H_{\text {alim }}-H_{\text {fezes }}=H_{\text {nut }}$ e $B_{\text {alim }}-B_{\text {fezes }}=B_{\text {nut }}$. Esta última igualdade é uma hipótese simplificadora, porque se espera que a complexa transformação do alimento em fezes aconteça com certa irreversibilidade, porém para o escopo deste texto tal hipótese é satisfatória. A Tabela 4.9 indica os valores dessas grandezas físicas para os macronutrientes e a soma desses valores (nutrientes) ao longo de 24 horas.

Na respiração, há uma mudança na composição do ar que influi no balanço de massa, de energia e de exergia diário. Para o balanço de energia, por exemplo, os termos relacionados com o consumo de oxigênio e produção de gás carbônico $\left(\left(m_{O_{2, \text { in }}}-m_{O_{2, \text { ex }}}\right) h_{f}^{O_{2}}\right.$ e $\left.\left(m_{C O_{2, \text { in }}}-m_{C O_{2, e x}}\right) h_{f}^{C O_{2}}\right)$ são os únicos termos relacionados à mudança de composição do 
Tabela 4.9: Massa, entalpia e exergia dos fluxos relacionados à alimentação

\begin{tabular}{|c|c|c|c|}
\hline fluxo & $\dot{m}(\mathrm{~kg} /$ dia $)$ & $\dot{H}(\mathrm{~kJ} /$ dia $)$ & $\dot{B}(\mathrm{~kJ} /$ dia $)$ \\
\hline Carboidratos & 0,44 & -3120 & 7303 \\
Lipídeos & 0,088 & -302 & 3442 \\
Amino Ácido & 0,075 & -374 & 1593 \\
\hline Nutrientes & 0,605 & -3796 & 12338 \\
\hline
\end{tabular}

ar. Portanto, pode-se considerar esse termo no metabolismo e levar em conta nos balanços apenas os termos relativos à variação de temperatura e umidade relativa de uma massa de ar (mistura de ar e vapor de água) na respiração, cujo valor está indicado na Tabela 4.13 - variação de entalpia associada à respiração. Para o balanço de exergia, no entanto, devem ser levados em conta os termos de mudança de composição e concentração dos gases atmosféricos (ar expirado), como apresentado na Tabela 4.10. A exergia térmica do ar expirado equivale a $2,7 \mathrm{~kJ} /$ dia, o que significa que a mudança de composição e concentração do ar expirado em relação ao atmosférico é o termo dominante na variação da exergia relacionada com a respiração. Os gases inspirados foram considerados nos estados em que se encontram no ambiente de referência, portanto seus valores de exergia são nulos. Já para o oxigênio consumido no metabolismo $\left(O_{2, M}\right)$ e o dióxido de carbono produzido $\left(\mathrm{CO}_{2, M}\right)$, foram consideradas as respectivas entalpias de formação e as exergias químicas, como mostrado na Tabela 4.10. Nota-se, ainda, que apesar do vapor ser um termo referente aos fluxos de ar, ele é contabilizado no balanço de água, sendo apenas mostrado nesta tabela.

Tabela 4.10: Massa, entalpia e exergia de cada fluxo do ar

\begin{tabular}{|c|c|c|c|}
\hline fluxo & $\dot{m}(\mathrm{~kg} /$ dia $)$ & $\dot{H}(\mathrm{~kJ} /$ dia $)$ & $\dot{B}(\mathrm{~kJ} /$ dia $)$ \\
\hline $\mathrm{O}_{2, i n}$ & 3,827 & - & 0 \\
$\mathrm{CO}_{2, i n}$ & 0,009 & - & 0 \\
$\mathrm{~N}_{2, i n}$ & 12,6 & - & 0 \\
$\mathrm{Vap}_{\text {in }}$ & 0,013 & - & 0 \\
$\mathrm{O}_{2, e x}$ & 3,007 & - & $-65,5$ \\
$\mathrm{CO}_{2, e x}$ & 1,009 & - & 272,1 \\
$\mathrm{~N}_{2, e x}$ & 12,6 & - & 1,09 \\
Vap $_{e x}$ & 0,329 & - & 22,4 \\
$\mathrm{O}_{2, M}$ & 0,82 & 0 & 451,6 \\
$\mathrm{CO}_{2, M}$ & 1,00 & -8941 & 101,7 \\
\hline Gases Expirados & 1,00 & -8941 & 207,7 \\
\hline Gases Metabolismo & 0.18 & -8941 & 563,3 \\
\hline
\end{tabular}

Por hipótese, a sudorese e o aumento da umidade na respiração não se dão a partir da água produzida no metabolismo. Assim, é possível analisar os valores de entalpia absoluta apenas para a água produzida no metabolismo e excretada via urina, estando os outros termos em balanço de massa. Diariamente a ingestão de água se faz via líquidos e alimentos (há, também, uma entrada de umidade referente ao ar inspirado). A água é 
eliminada do corpo via urina, suor, fezes e aumento da umidade do ar expirado. Tomando por base as Equações 3.58 e 3.59, foram calculadas as massas de água e ureia produzidas no metabolismo. A massa de água ingerida nos alimentos é aproximadamente $0,5 \mathrm{~kg} / \mathrm{dia}$ e a eliminada nas fezes é de $0,105 \mathrm{~kg} /$ dia. A Tabela 4.11 expõe os valores dos balanços. $\mathrm{O}$ aumento de entalpia e exergia referente ao aumento de temperatura da água e dos alimentos (cujo calor específico foi considerado próximo ao da água líquida) equivalem a aproximadamente $170 \mathrm{~kJ} /$ dia e $4 \mathrm{~kJ} /$ dia, respectivamente. Cumpre lembrar que o estudo desse termo está fora do escopo desse trabalho pois suas variações são uma ordem de grandeza menor que todos os outros termos considerados. É importante ressaltar que apesar da massa de água evaporada ser muito pequena se comparada à massa do corpo, caso seja considerada como uma taxa de evaporação, $1.19 \mathrm{~kg} / \mathrm{dia}=1,4.10^{-5} \mathrm{~kg} / \mathrm{s}$, o fluxo de entalpia dessa quantidade de suor equivale a aproximadamente 33,5W. Portanto, não é necessário considerar a perda de massa por vaporização no balanço de massa em $\mathrm{kg} / \mathrm{s}$, porém a entalpia dessa quantidade é aproximadamente $1 / 3$ do metabolismo. A hipótese de que a massa de suor evaporada não é significativa frente à massa do corpo é, portanto, aceitável.

Tabela 4.11: Massa, entalpia e exergia de cada fluxo mássico

\begin{tabular}{|c|c|c|c|}
\hline fluxo & $\dot{m}(\mathrm{~kg} /$ dia $)$ & $\dot{H}(\mathrm{~kJ} /$ dia $)$ & $\dot{B}(\mathrm{~kJ} /$ dia $)$ \\
\hline Água ingerida & 2,5 & - & 0 \\
Água alimentos & 0,50 & - & 0 \\
Vapor Inspirado & 0,013 & - & 0 \\
Água fezes & 0,11 & - & 0 \\
Água metabolismo & 0,40 & -6352 & 20.2 \\
Urina & 1,78 & - & 0 \\
Vapor expirado & 0,329 & - & - \\
Água evaporada & 1,19 & - & - \\
\hline Total ingerido & 3.013 & -49179 & 150.7 \\
\hline Total expelido & 3.409 & -55531 & 170.5 \\
\hline
\end{tabular}

A massa, entalpia e exergia de ureia produzida no metabolismo equivalem a $0,024 \mathrm{~kg} / \mathrm{dia}$, -136 kJ/dia e $280 \mathrm{~kJ} /$ dia, respectivamente Na Tabela 4.12, a ureia está inserida no termo $d m_{\text {nutr }} / d t$. Como indicado na Seção 3.3, o balanço de massa no corpo deve ser satisfeito. Assim se calculou $d m_{n u t r} / d t=-0,61 \mathrm{~kg} / \mathrm{dia}, d m_{\text {liq }} / d t=0,43 \mathrm{~kg} / \mathrm{dia}$ e $d m_{\text {gas }} / d t=0,18 \mathrm{~kg} /$ dia. Ou seja, no período de um dia $d m_{\text {corpo }} / d t=0 \mathrm{~kg} / \mathrm{dia}$. Um processo semelhante foi realizado com os valores de entalpia $\left(d H_{\text {nutr }} / d t, d H_{\text {liq }} / d t\right.$ e $\left.d H_{\text {gas }} / d t\right)$ no qual a soma deve ser o metabolismo celular $\left(d H_{\text {corpo }} / d t=11616 \mathrm{~kJ} /\right.$ dia $)$. Como o balanço de energia deve ser satisfeito, a soma dos fluxos de energia para o ambiente é igual ao metabolismo. Por fim, os fluxos de energia e exergia para o ambiente foram calculados de acordo com o método proposto na Seção 3.1.4, no qual é possível notar que o balanço de energia é satisfeito. As Tabelas 4.12 e 4.13 indicam esses valores calculados por um período de $24 \mathrm{~h}$. O rendimento exergético do corpo durante um dia 
equivale a $5,7 \%$.

Tabela 4.12: Variação da Massa, entalpia e exergia de cada fluxo de líquidos

\begin{tabular}{|c|c|c|c|}
\hline fluxo & $d m / d t(\mathrm{~kg} / \mathrm{dia})$ & $d H / d t(\mathrm{~kJ} / \mathrm{dia})$ & $d B / d t(\mathrm{~kJ} / \mathrm{dia})$ \\
\hline Nutrientes-Ureia & 0,58 & -3660 & 12058 \\
Liquido & $-0,40$ & 6336 & -20 \\
Gas & $-0,18$ & 8941 & -350 \\
\hline Corpo & 0 & 11616 & 11688 \\
\hline
\end{tabular}

Tabela 4.13: Fluxos de Energia e exergia para o ambiente

\begin{tabular}{|c|c|c||c|c|}
\hline & Energia (kJ/dia) & $\%$ & Exergia (kJ/dia) & $\%$ \\
\hline Respiração & 983 & 8.5 & 233 & 2,0 \\
Evaporação & 2902 & 25.0 & 227 & 2,0 \\
Radiação e Convecção & 7689 & 66.2 & 212 & 1,8 \\
Metabolismo & 11623 & - & 11687 & - \\
\hline Destruição & - & - & 11017 & 94,2 \\
\hline
\end{tabular}

Nota-se que essa abordagem foi usada neste trabalho apenas para validar que durante um dia o corpo pode estar em regime permanente, caso não esteja nem engordando nem emagrecendo. Outra hipótese validada nesta seção é a que a entalpia da água evaporada no suor é significativa, enquanto que a massa dessa quantidade pode ser desprezada (principalmente se usada como taxa). Todavia, deve-se salientar que esse procedimento é o mesmo do indicado na Seção 3, apenas com cada fluxo sendo transformado em uma taxa diária.

\subsection{COMPORTAMENTO EXERGÉTICO E ENVELHECIMENETO}

A Figura 4.4 se refere à temperatura de neutralidade térmica calculada para as diferentes idades (metabolismos). Para o cálculo dessa temperatura, foram realizadas diversas simulações com diferentes temperaturas ambientes. Dado um valor de metabolismo, a temperatura cujo sistema de controle permaneceu inativo foi a de neutralidade térmica. Para a Figura 4.4(a) (simulações para uma dada anatomia do modelo de Ferreira e Yanagihara (2009a)), a menor temperatura foi para uma pessoa de 18 anos (maior metabolismo). Todos os valores permaneceram nos limites estipulados pela ASHRAE (2005) (temperaturas entre 29 e $31^{\circ} \mathrm{C}$ ). Já, aumentando-se os resultados para o modelo simplificado, foram simuladas condições entre 0 e 80 anos, apresentado na Figura 4.4(b). Nessa figura é possível notar que a máxima temperatura não se dá aos 18 anos, pois o metabolismo máximo ocorre entre 20 e 25 anos (Tabela 4.8), estimado para as condições anatômicas da sociedade brasileira. Entretanto, uma análise da Figura 4.4 indica que os resultados do modelo simplificado são próximos aos obtidos via Ferreira e Yanagihara 
(2009a). Outro resultado a se destacar é que no recém-nascido a temperatura de neutralidade térmica é menor do que os limites estipulados pela ASHRAE (2005).
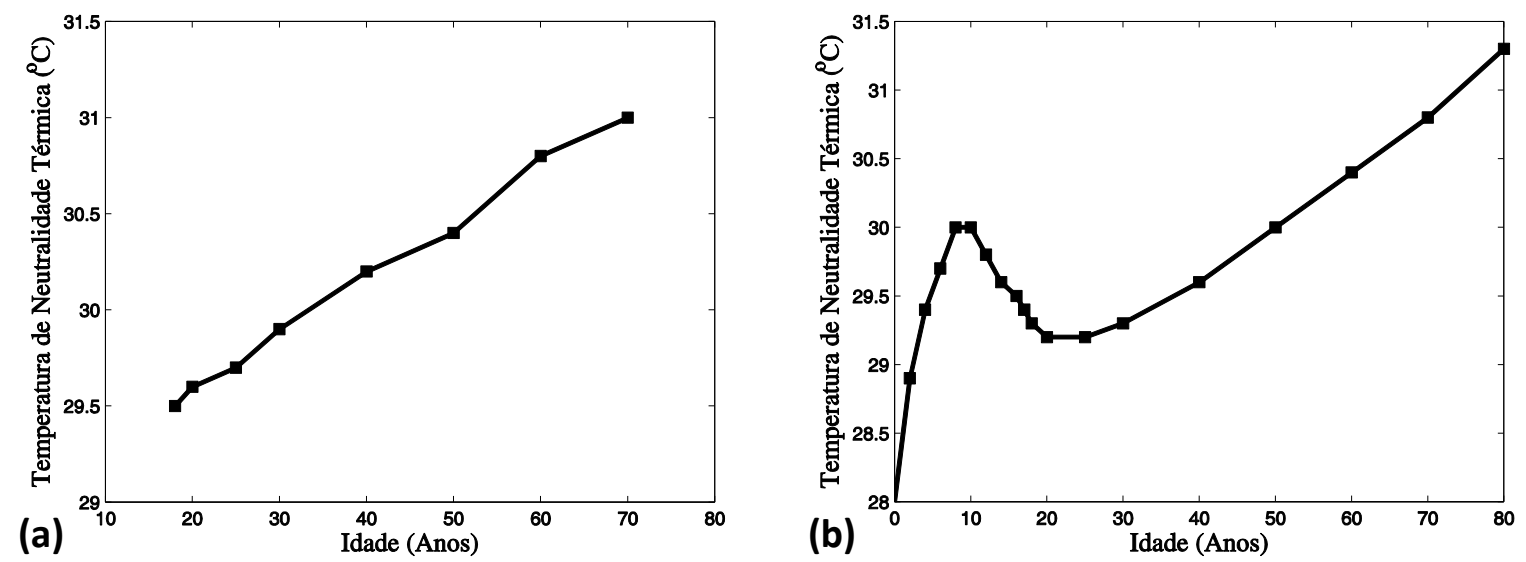

Figura 4.4: Temperatura de neutralidade térmica em função da idade (a) para um adulto de 18 a 80 anos; (b) para os dados antropométricos da sociedade brasileira entre 0 e 80 anos

A Figura 4.5(a) assinala os resultados da exergia destruída e do rendimento exergético em função da idade para o modelo de Ferreira e Yanagihara (2009a). Nota-se que não só a exergia destruída diminuiu com o passar da vida (confirmando o princípio de mínima geração de entropia), mas também o rendimento exergético diminui. A condição ambiente escolhida para formular essa figura foi a de Natal-RN durante o verão $\left(32^{\circ} \mathrm{C}\right.$ e $70 \%$ de umidade relativa). Para o modelo simplificado, a Figura 4.5(b) mostra que em valores absolutos a exergia destruída tende a um valor máximo na mesma idade que o metabolismo torna-se máximo, enquanto que o rendimento exergético tende a diminuir indefinidamente. Porém, uma análise da exergia destruída e fluxos de exergia para o ambiente por unidade de área (Figura 4.6) indica que quando essas grandezas são normatizadas pela área, a tendência é que elas diminuam continuamente com o envelhecimento e cheguem ao máximo para um recém-nascido. Novamente, deve-se salientar que a normatização pela área superficial do corpo humano se torna necessária quando se quer comparar diferentes anatomias; a divisão também pode ser pela massa, sendo a primeira mais usual na literatura de conforto térmico.

\subsubsection{Exergia e duração da vida}

Assim como Silva e Annamalai (2008, 2009), Annamalai e Silva (2012) e Hershey (2010) calcularam a entropia gerada por unidade de massa durante a duração da vida, a Tabela 4.14 mostra o valor da exergia destruída em função do envelhecimento. No entanto, como o modelo discutido na Seção 3 leva em conta a exergia metabólica e os fluxos de exergia 

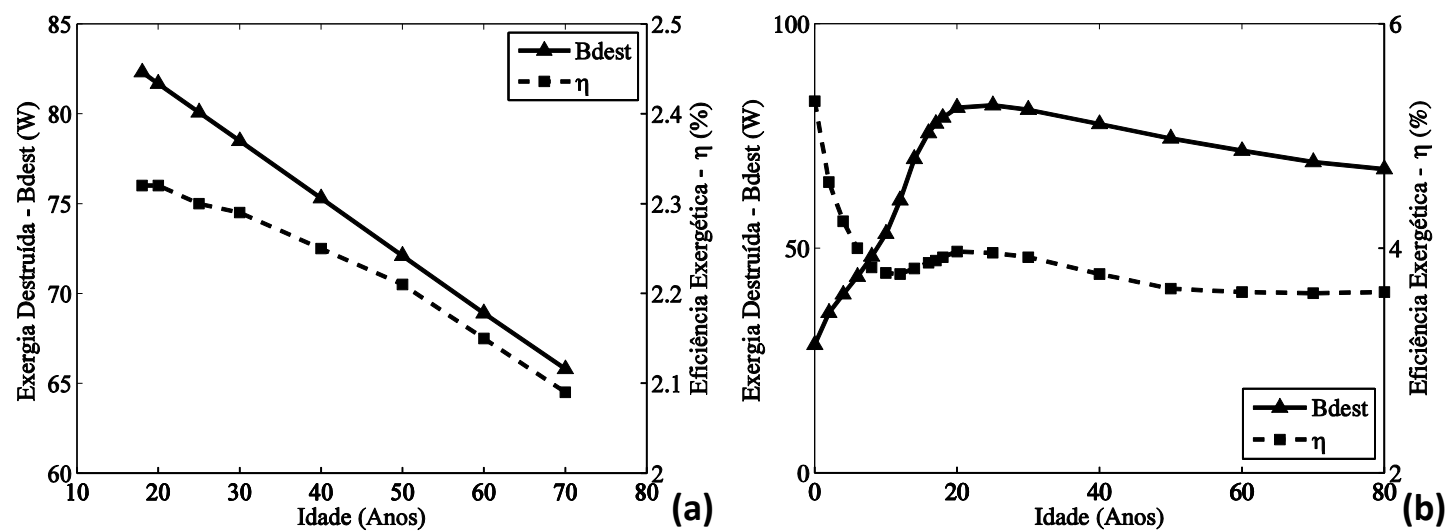

Figura 4.5: Exergia destruída e rendimento exergético do corpo em função da idade da pessoa para o modelo de Ferreira e Yanagihara (2009a) (a) e para o modelo simplificado (b)
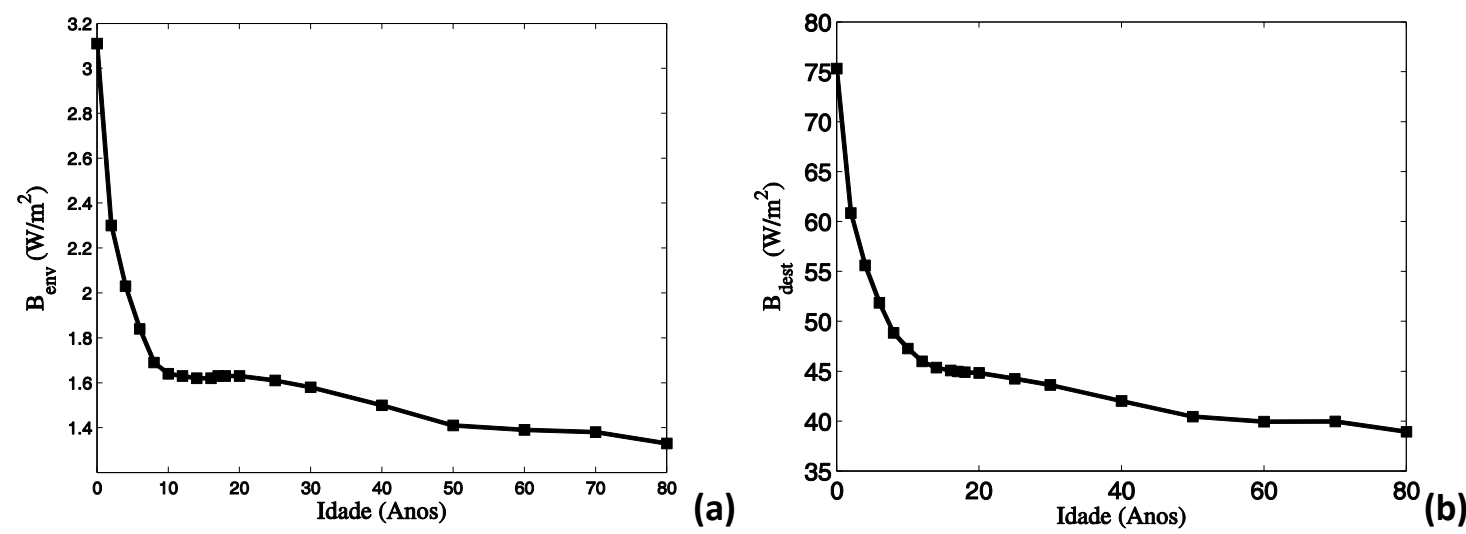

Figura 4.6: (a) Exergia destruída por unidade de área; (b) fluxos de exergia para o ambiente por unidade de área em decorrência da idade da pessoa para o modelo simplificado 
para o ambiente, essas grandezas também foram calculadas em função da duração da vida (Figura 4.6). Para integração numérica de tais valores, foi utilizado o método dos trapézios. A exergia destruída e o rendimento exergético da vida, para condições basais, equivalem a 3091MJ e 3,5\%, respectivamente. Já para o caso em que se considerou o metabolismo sedentário (metabolismo para uma pessoa sedentária não engordar nem emagrecer), a exergia destruída por uma vida equivale a $3599 \mathrm{MJ} / \mathrm{kg}$ e o rendimento exergético a $4,3 \%$. Como a temperatura utilizada foi de $30^{\circ} \mathrm{C}$, o valor de entropia gerada por unidade de massa equivale a $10196 \mathrm{~kJ} / \mathrm{KgK}$ e $11871 \mathrm{~kJ} / \mathrm{kgK}$, para condições basais e sedentárias, respectivamente.

Tabela 4.14: Termos da análise exergética integrados durante uma vida de 0 a 80 anos

\begin{tabular}{|c|c|c||c|c|}
\hline- & \multicolumn{2}{|c||}{ Condições Basais } & \multicolumn{2}{c|}{ Condições Sedentárias } \\
\hline- & $\mathrm{MJ} / \mathrm{kg}$ & $\%$ & $\mathrm{MJ} / \mathrm{kg}$ & $\%$ \\
\hline $\mathrm{B}_{M}$ & 3202 & 100 & 3752 & 100 \\
$\mathrm{~B}_{d}$ & 3091 & 96,5 & 3599 & 95,8 \\
$\mathrm{~B}_{a m b}$ & 110 & 3,5 & 155 & 4,3 \\
\hline
\end{tabular}

Finalmente, a exergia destruída "acumulada" por unidade de massa (denominação dada por Silva e Annamalai (2008, 2009), Annamalai e Silva (2012)) ou idade entrópica (denominação dada por Hershey (2010)) foi calculada para cada idade, ou seja, ao final dos 80 anos esse valor equivale a 3091MJ/ $\mathrm{kg}$ para condições basais e 3599MJ/kg para condições sedentárias, como indicado na Figura 4.7.

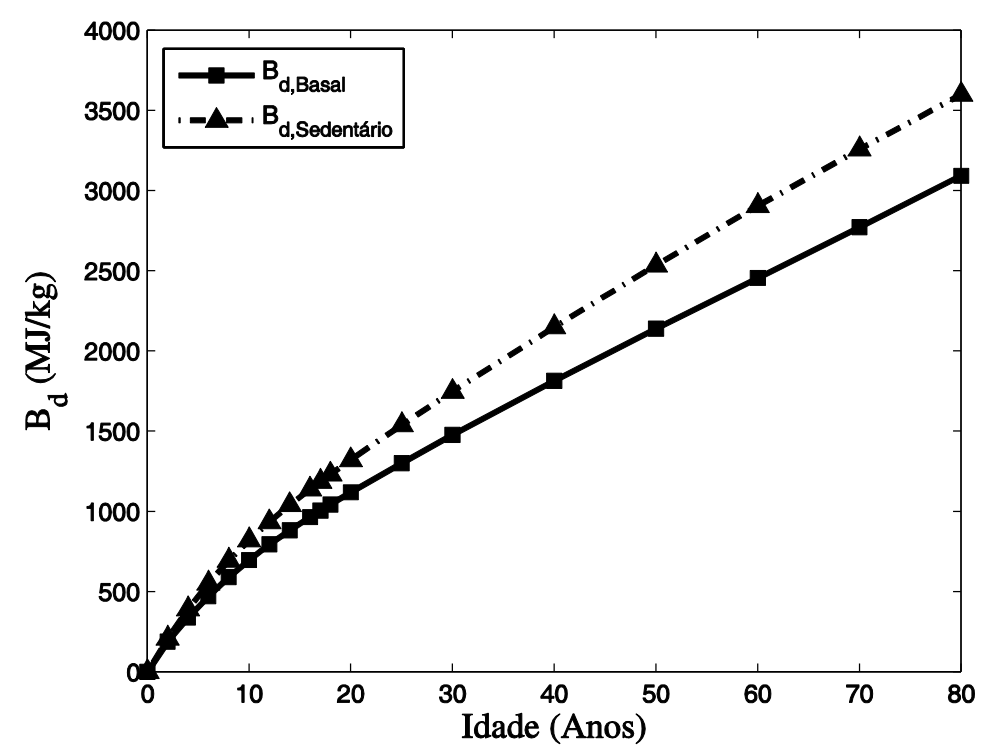

Figura 4.7: Exergia destruída por unidade de massa "acumulada" durante uma vida para condições basais e para condições sedentárias 


\subsubsection{Limitações da análise}

Para o modelo simplificado proposto neste estudo, foram integradas as taxas de exergia destruída e do fluxo de exergia para o corpo em função do envelhecimento para diferentes razões $W / W_{M A X}$. Sabe-se, como visto anteriormente, que, ao realizar trabalho, o corpo tem uma série de respostas fisiológicas à atividade física, dentre elas, elevação do metabolismo, sudorese, etc; o ato de praticar atividades físicas faz com que o metabolismo aumente e, portanto, leve a um aumento da exergia destruída. Contudo, como para se chegar na Figura 4.8, o objetivo foi comparar a existência de fenômenos organizados que usam ATP para funções corpo (diferentes níveis de atividade física, produção de proteínas, bomba sódio potássio, crescimento, dentre outros) para um mesmo metabolismo (ou uma mesma condição) e seu peso na "idade entrópica", a análise é apropriada. Quanto maior for a razão $W / W_{M A X}$, menor é a exergia destruída acumulada na vida, tendência que pode fazer com que a pessoa chegue a uma idade cronológica maior (Figura 4.8 (a)). Por outro lado, considerando-se que o aproveitamento da energia do metabolismo é maior, a diferença $Q_{M}=M-W$ será menor; espera-se, então, que a exergia dissipada na forma de calor seja menor, já que restará uma menor parcela da exergia (afirmação comprovada pela Figura 4.8(b)).
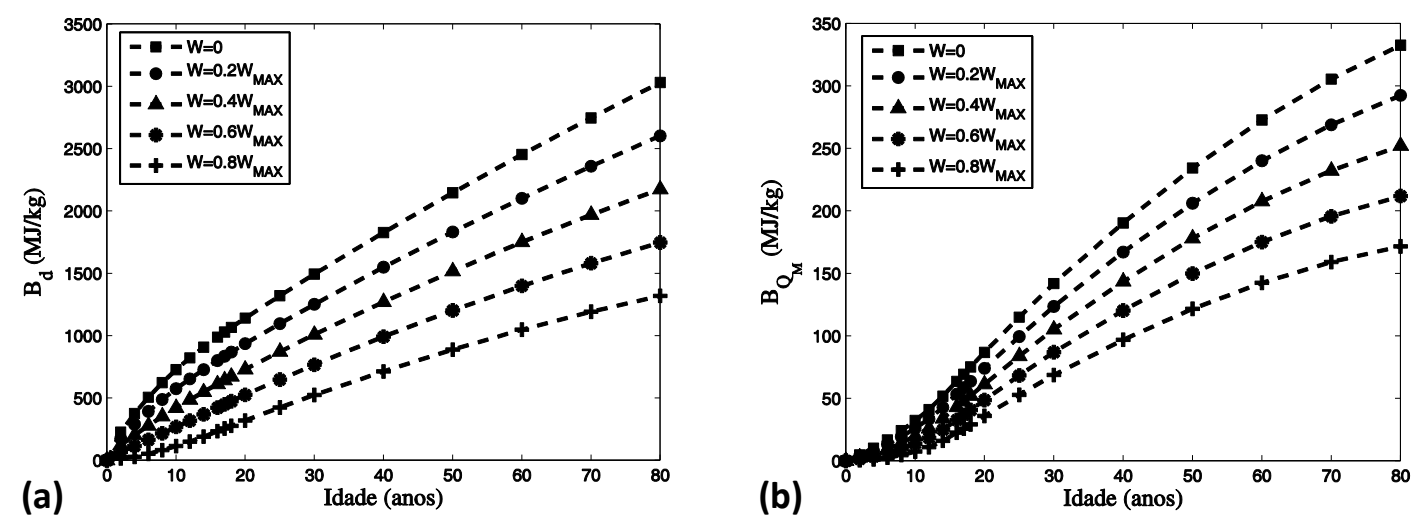

Figura 4.8: (a) Exergia destruída e (b) fluxo de exergia associado ao metabolismo integrados em função do envelhecimento

Vale discutir que os valores obtidos da exergia destruída e duração da vida para condição basal e sedentária levam a inferir que atividade física pode acarretar em um aumento do metabolismo e da destruição de exergia, ou seja, uma redução na expectativa de vida. No entanto, a Figura 4.8 indica justamente o oposto, qual seja, fenômenos organizados levam a um aumento na expectativa de vida associada a uma redução na destruição de exergia. Silva e Annamalai $(2008,2009)$ afirmaram que deve existir um ponto ótimo entre os benefícios fisiológicos da prática de atividades físicas (maior qualidade de utilização de ATP, por exemplo) e pelos malefícios acarretados pelas irreversibilidades (ou entropia 
gerada), causados por essas atividades. Outro ponto importante a se ressaltar é que os modelos não levam em conta as alterações fisiológicas positivas da prática de exercícios. Portanto, em futuras análises deverão ser realizadas as devidas modificações no modelo para levar em conta tais benefícios. Uma analise dos modelos da literatura indica que tais modificações ainda não foram realizadas.

\subsection{SEGUNDA LEI APLICADA AO CORPO SOB DIFERENTES CONDIÇÕES AMBIENTAIS}

A análise exergética foi aplicada para um adulto de meia idade - metabolismo de 79,1 W. A Tabela 4.15 foi obtida para a condição de neutralidade térmica $\left(T_{o}=30^{\circ} \mathrm{C}\right)$ na qual estão demonstrados a exergia destruída, o metabolismo exergético e o rendimento exergético para as diferentes partes do corpo. Constata-se que as partes que apresentam maior exergia destruída são a cabeça e o tronco, tendo o tronco o menor rendimento exergético (distribui exergia para as diferentes partes do corpo). Tal resultado pode ser justificado pelo fato de que essas são as regiões do corpo em que a maior parte das reações metabólicas ocorrem. O tronco, em especial, distribui sangue para o resto do corpo com uma exergia térmica maior e com nutrientes. Averigua-se, também, que as extremidades dos membros superiores e inferiores têm um rendimento exergético menor do que as partes centrais. Por exemplo, a mão apresenta um rendimento exergético menor que o do braço, que, por sua vez, apresenta um rendimento exergético menor que o do antebraço.

Tabela 4.15: Metabolismo exergético e exergia destruída das diferentes partes do corpo na condição de neutralidade térmica $\left(30^{\circ} \mathrm{C}\right)$

\begin{tabular}{|c|c|c|c|}
\hline Parte do Corpo & $B_{\text {dest }}(\mathrm{W})$ & $B_{M}(\mathrm{~W})$ & $\eta_{b}(\%)$ \\
\hline Mão & 0,25 & 0,26 & 17,2 \\
Braço & 0,50 & 0,52 & 24,3 \\
Antebraço & 0,90 & 0,94 & 30,9 \\
Pé & 0,50 & 0,54 & 17,6 \\
Perna & 1,21 & 1,26 & 23,7 \\
Coxa & 2,74 & 2,85 & 29,0 \\
Cabeça & 14,93 & 15,21 & 21,8 \\
Pescoço & 0,51 & 0,49 & 94,0 \\
Tronco & 49,55 & 50,64 & 12,1 \\
\hline Total & 77,19 & 79,08 & - \\
\hline
\end{tabular}

A Tabela 4.16 indica os fluxos de exergia de sangue que entram $\left(B_{b l, i n}\right)$ e saem $\left(B_{b l, \text { out }}\right)$ de cada elemento no volume de controle. Esta Tabela complementa a Tabela 4.15, pois, a partir dela, pode-se notar que, considerando-se os membros periféricos, como a mão e o pé, o fluxo de exergia que deixa o elemento detém menos exergia do que o fluxo que 
entra, se comparados, por exemplo, com o braço. Tal fato justifica o rendimento das extremidades do corpo ser menor do que o de membros mais "centrais". O pescoço é a parte do corpo com maior rendimento exergético, o que se explica pela baixa perda de exergia térmica do sangue (apenas 0,5\%). Finalmente, a cabeça e o tronco distribuem o sangue para o resto do corpo com uma maior exergia térmica, provocada pelas altas taxas metabólicas, do que o sangue que retorna para esses elementos (explicado pela alta taxa metabólica). Portanto, esses elementos do corpo apresentam rendimento exergético mais baixo.

Tabela 4.16: Fluxos de exergia do sangue das diferentes partes do corpo na condição de neutralidade térmica $\left(30^{\circ} \mathrm{C}\right)$ e razão entre o fluxo de saída pelo fluxo de entrada

\begin{tabular}{|c|c|c|c|}
\hline Parte do Corpo & $B_{b l, \text { in }}(\mathrm{W})$ & $B_{b l, \text { out }}(\mathrm{W})$ & $B_{b l, \text { out }} / B_{b l, \text { in }}(\%)$ \\
\hline Mão & 0,032 & 0,016 & 50.0 \\
Braço & 0,13 & 0,10 & 76.9 \\
Antebraço & 0,37 & 0,32 & 86,5 \\
Pé & 0,070 & 0,040 & 57,1 \\
Perna & 0,33 & 0,26 & 78,8 \\
Coxa & 1,01 & 0,91 & 90,1 \\
Cabeça & 3,89 & 4,06 & 104,4 \\
Pescoço & 8,03 & 7,99 & 99,5 \\
Tronco & 5,73 & 6,21 & 108,4 \\
\hline
\end{tabular}

A Tabela 4.17 mostra os valores dos diferentes termos da análise exergética para a condição de neutralidade térmica $\left(30^{\circ} \mathrm{C}\right)$. Como foi exposto anteriormente por Batato et al. (1990), as contribuições exergéticas dos fluxos de calor e entalpia são uma ordem de grandeza menor que as contribuições energéticas (comparação da segunda com a quinta coluna da Tabela 4.17). Comparando-se os valores percentuais dos fluxos de exergia com o valor da exergia destruída nota-se que os fluxos representam menos de $5 \%$ do total da exergia metabólica.

Tabela 4.17: Termos das análises energética e exergética na condição de neutralidade térmica $\left(30^{\circ} \mathrm{C}\right)$ e umidade relativa de $50 \%$. Na primeira coluna, é dado o valor absoluto, na segunda, o valor percentual para $M=79,1 \mathrm{~W}$

\begin{tabular}{|ccc||ccc|}
\hline- & $(\mathrm{W})$ & $(\%)$ & - & $(\mathrm{W})$ & $(\%)$ \\
\hline$Q_{r}$ & 29,0 & 36,7 & $B_{r}$ & 0,35 & 0,44 \\
$Q_{c}$ & 23,2 & 29,3 & $B_{c}$ & 0,27 & 0,35 \\
$H_{e}$ & 19,7 & 24,9 & $B_{e}$ & 1,26 & 1,60 \\
$\Delta H_{\text {res }}$ & 7,2 & 9,1 & $\Delta B_{\text {res }}$ & 0,40 & 0,51 \\
- & - & - & $B_{\text {dest }}$ & 76,6 & 97,1 \\
$M$ & 79,1 & 100 & $B_{M}$ & 78,9 & - \\
\hline
\end{tabular}

A Figura 4.9 expõe dois casos transientes para um adulto de meia idade (metabolismo de $79,1 \mathrm{~W}$ ). No primeiro caso (Figura 4.9 (a)), pode-se notar que, quando o corpo sofre um degrau para uma temperatura menor do que a de neutralidade térmica, a exergia destruída aumenta, enquanto o rendimento diminui. Observa-se, também, que a exergia destruída 
fica maior do que o metabolismo inicial, o que se deve a um aumento do metabolismo quando o corpo está em condições ambientais cuja temperatura operativa é menor que a de neutralidade térmica causada pela produção de tremores. No outro caso (Figura 4.9 (b)), em que o degrau de temperatura operativa é maior que a de neutralidade térmica, ocorre justamente o contrário, isto é, a exergia destruída diminui enquanto o rendimento aumenta.
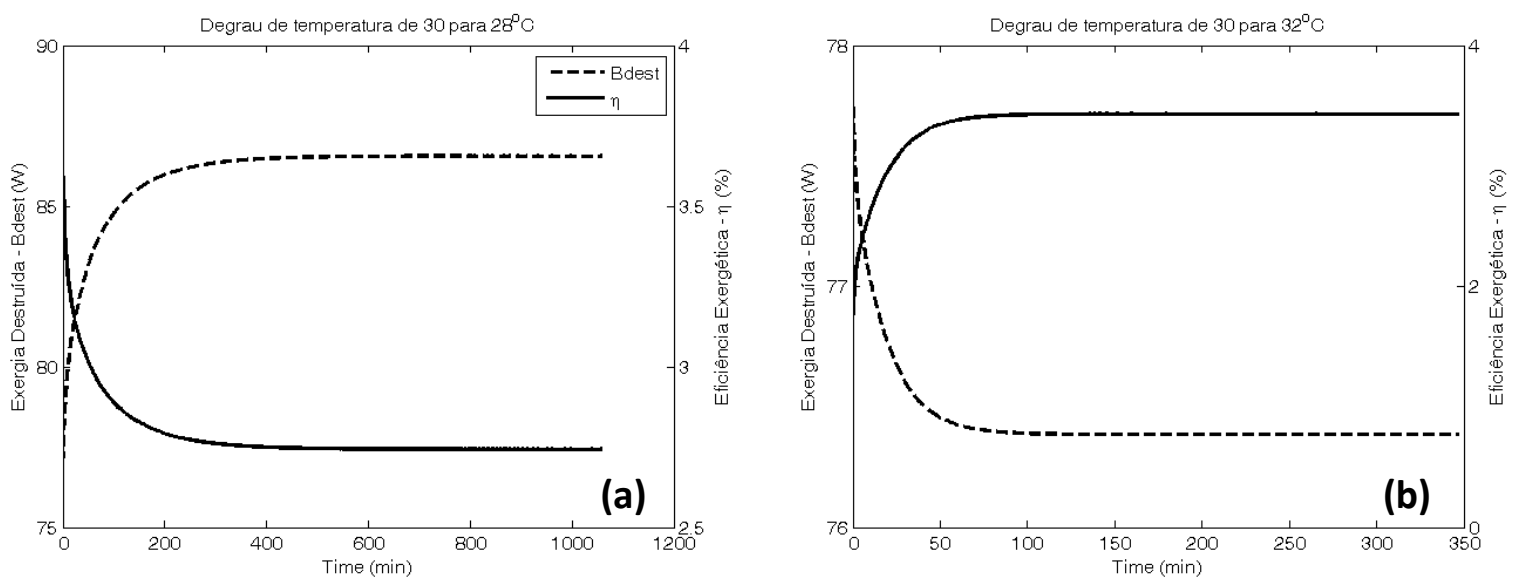

Figura 4.9: Exergia destruída e rendimento exergético em função do tempo para um degrau de temperatura para: (a) temperatura operativa menor do que a de neutralidade térmica; (b) temperatura operativa maior do que a de neutralidade térmica

Inicialmente foi realizado um estudo das temperaturas do hipotálamo e da pele, considerando-se as condições ambientais (temperatura operativa e umidade relativa), como indicado na Figura 4.10. Nota-se que a temperatura interna, representada pela temperatura do hipotálamo, na Figura 4.10(a), é praticamente constante, variando apenas 3,2\% (razão entre os valores máximo e mínimo, levando-se em conta o abrupto aumento em altas temperaturas e umidades relativas, o que diminui a capacidade de troca de energia com o ambiente). Já a temperatura da pele demonstra uma maior variação, diminuindo com a redução de temperatura ambiente, como indicado na Figura 4.10. A variação da temperatura da pele foi de 15,2\% (razão entre os valores máximo e mínimo).

Tomando-se como base a Figura 4.9, é possível obter o comportamento exergético do corpo para diferentes condições. As Figuras 4.11 e 4.12 indicam os fluxos de energia e exergia para o ambiente. No caso da Figura 4.11, os fluxos equivalem numericamente ao metabolismo (balanço de energia deve ser satisfeito), percebendo-se que para altas temperaturas há um aumento do fluxo de energia para o ambiente, causado pelo aumento de metabolismo. Isso ocorre devido à dificuldade de transferência de energia para um ambiente úmido e com temperaturas maiores que a da pele. Apesar de, percentualmente, corresponderem a uma pequena parcela da exergia metabólica, os termos da exergia associados à radiação, à convecção, à vaporização e à respiração são funções das condições ambientais. As Figuras 4.12(a) e (b) mostram a soma dos fluxos de exergia para o ambiente 
(a)

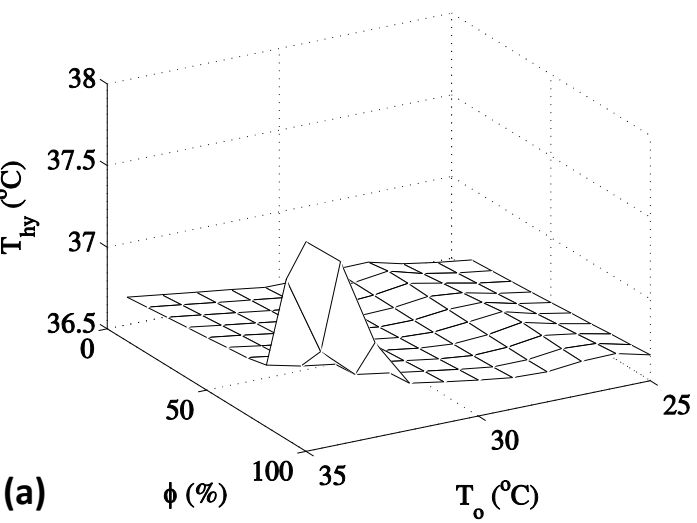

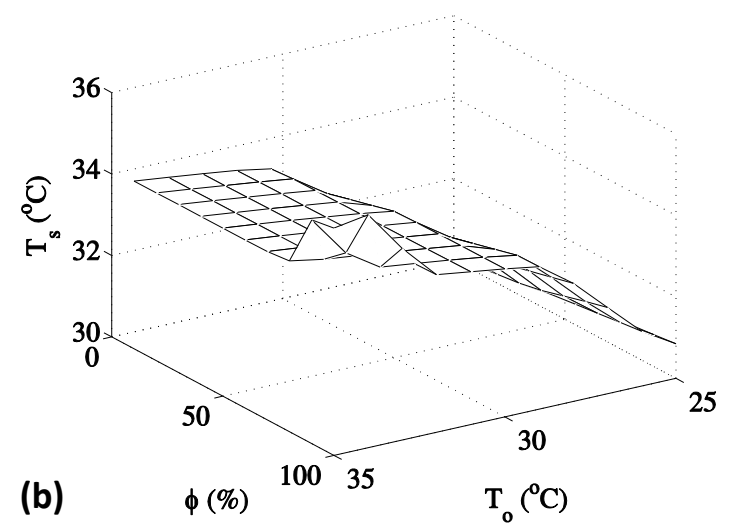

Figura 4.10: (a) Temperatura do hipotálamo; e (b) da pele em função da temperatura operativa e umidade relativa

em decorrência: da temperatura operativa e da umidade relativa (Figura 4.12(a)); da temperatura radiante média e da temperatura do ar (Figura 4.12(b)). Nota-se que a tendência dos fluxos de exergia já mostram um comportamento diferente dos fluxos de energia para o ambiente, pois os últimos equivalem numericamente ao metabolismo, o que não acontece com os primeiros, ou seja, a análise exergética leva em conta a qualidade do processo de conversão de energia. Verifica-se, ainda, que como o modelo está em repouso, o rendimento exergético $\left(\left(B_{M}-B_{d}\right) / B_{M}\right)$ passa a ser a transferência de exergia para o meio dividido pela exergia metabólica $\left(B_{a m b} / B_{M}\right)$, sendo os fluxos responsáveis pela tendência do rendimento exergético.
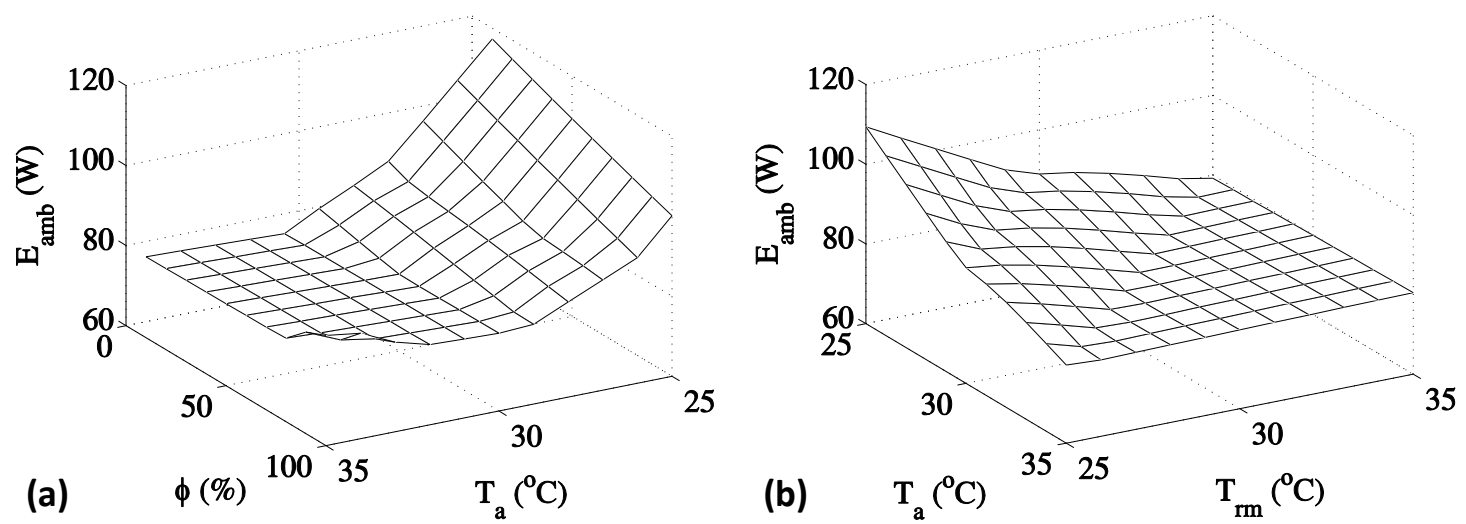

Figura 4.11: Fluxo de energia para o ambiente, como função da: (a) temperatura operativa e umidade relativa; (b) temperatura radiante média e temperatura do ar

As Figuras 4.13 e 4.14 relacionam a exergia destruída e o rendimento exergético em função de parâmetros ambientais (umidade, temperatura operativa, temperatura radiante média e temperatura do ar). Na Figura 4.13(a), existe uma clara diferença no comportamento da exergia destruída $\left(B_{\text {dest }}\right)$ entre as faixas de 25 a $30^{\circ} \mathrm{C}$ e 30 a $35^{\circ} \mathrm{C}$. No primeiro intervalo, a exergia destruída decresce com a temperatura operativa, enquanto, no segundo intervalo, tende a aumentar com o incremento da temperatura operativa. A umidade relativa não interfere de forma tão significativa quanto a temperatura na exergia destruída. 


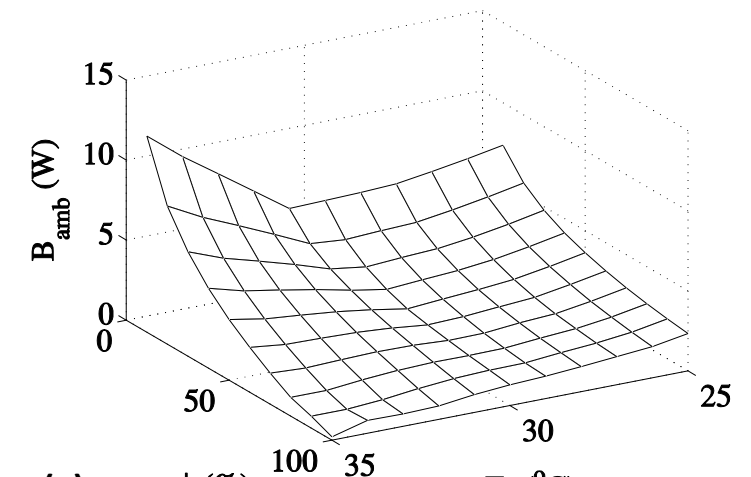

(a) $\phi(\%)$ $\mathrm{T}_{\mathrm{a}}\left({ }^{\mathrm{O}} \mathrm{C}\right)$

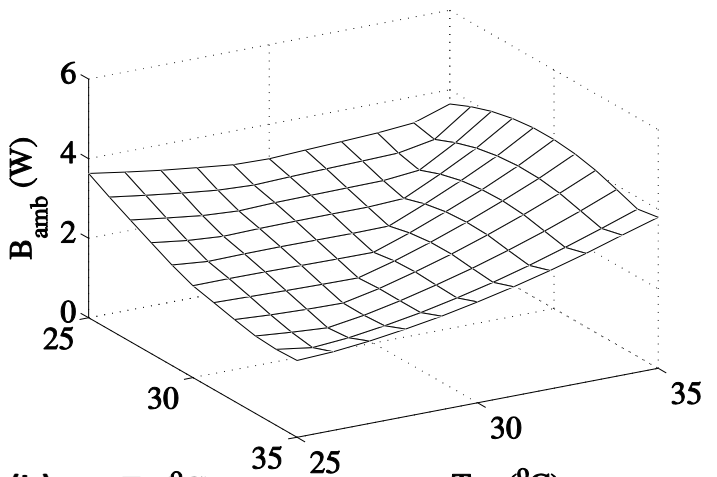

(b) $\quad \mathrm{T}_{\mathrm{a}}\left({ }^{\circ} \mathrm{C}\right) \quad \mathrm{T}_{\mathrm{rm}}\left({ }^{\circ} \mathrm{C}\right)$

Figura 4.12: Fluxo de exergia para o ambiente, como função da: (a) temperatura operativa e umidade relativa; (b) temperatura radiante média e temperatura do ar

Entretanto, para temperaturas operativas menores que a neutralidade térmica, a exergia destruída diminui com o incremento da umidade relativa, e para temperaturas operativas maiores que a neutralidade térmica, ocorre justamente o oposto. A Figura 4.13(b) indica que para cada valor de temperatura radiante média, a exergia destruída tende a decrescer com o aumento da temperatura ambiente e, a partir de um certo valor, a exergia destruída se estabiliza. Comparando-se o resultado da Figura 4.13(b) ao da Figura 2.26, os comportamentos das curvas são similares. Deve-se atentar, porém, que Prek (2004) usou $B_{Q_{M}}$ como exergia metabólica e, desse modo, os valores possuem menores magnitudes, e ainda por ele ter calculado $B_{d}$ estimado considerando-se o uso de roupas, a inflexão ocorre em outra temperatura.
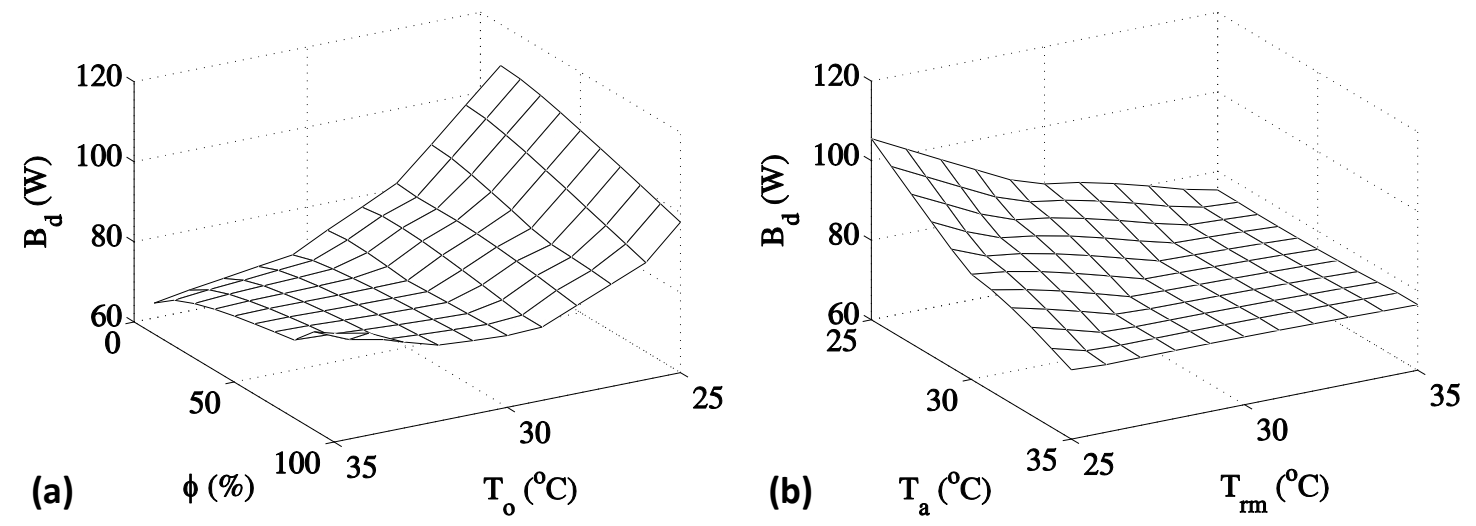

Figura 4.13: Exergia destruída, para o modelo nu, como função da: (a) temperatura operativa e umidade relativa; (b) temperatura radiante média e temperatura do ar

Como mostrado na Figura 4.14(a), a eficiência exergética $\left(\eta_{b}\right)$ tende a diminuir com o incremento da umidade relativa também indicado na Figura 4.9. Ademais, a Figura 4.14(b) demonstra o rendimento exergético em função da temperatura ambiente e da temperatura radiante média, no qual é possível notar que $\eta_{b}$ possui um valor de mínimo no ponto de $T=34^{\circ} \mathrm{C}$ e $\bar{T}_{r}=26^{\circ} \mathrm{C}$ (causado pela pequena transferência de exergia para o meio nesse ponto). Os maiores valores de rendimento exergético e os menores valores 
de exergia destruída são para temperaturas ambientais baixas e temperaturas médias radiantes altas. Esse último resultado pode ser confrontado com a afirmação de Simone et al. (2011), isto é, que temperaturas radiantes médias altas e temperaturas ambientais baixas do ar podem levar a uma sensação de conforto térmico maior. Nas Figuras 4.13 e 4.14, é possível concluir que o corpo destrói menos exergia e é mais eficiente em altas temperaturas e baixas umidades relativas. No entanto, o fluxo de exergia para o ambiente é alto neste ponto, podendo indicar um desvio em relação à condição de conforto.
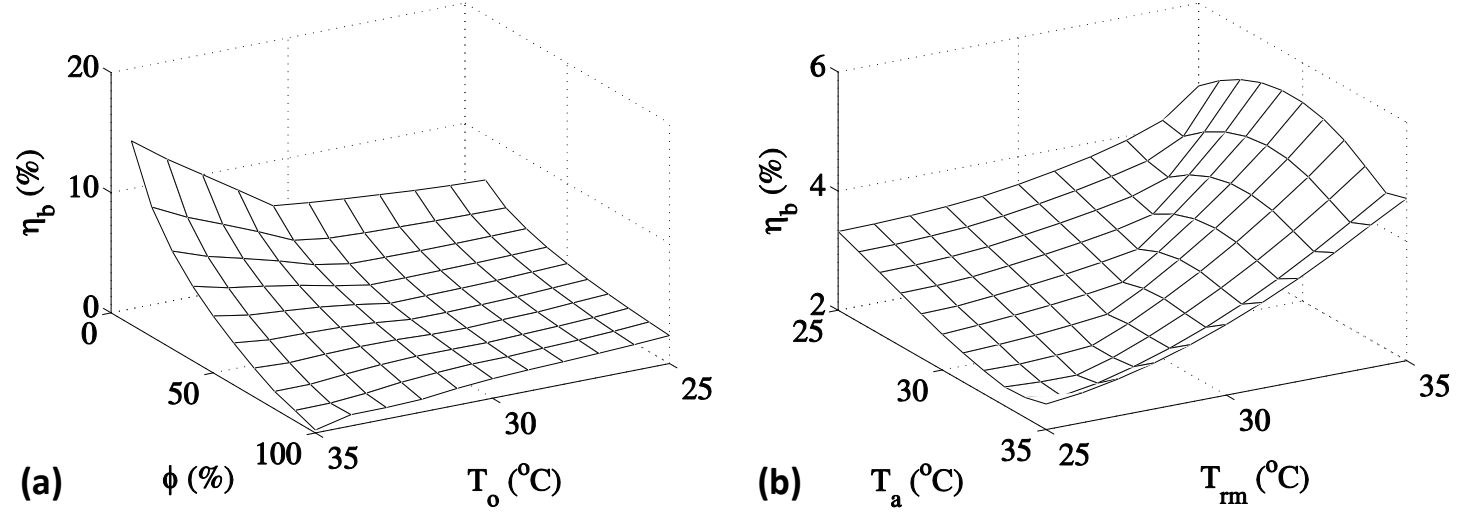

Figura 4.14: Rendimento exergético, para o modelo nu, como função da: (a) temperatura operativa e umidade relativa; (b) temperatura radiante média e temperatura do ar

Nas Figuras 4.13(a) e 4.14(a) é possível observar que a destruição de exergia é máxima e eficiência exergética é minima, no ponto cujas temperaturas se aproximam de $35^{\circ} \mathrm{C}$, e as umidades relativas de 100\%. Nesse ponto, há uma dificuldade de transferência de exergia para o ambiente, no que se refere a todos os tipos de mecanismos, pois a temperatura do ar é maior do que a da pele, e a umidade relativa é de 100\%, o que leva a um aumento do metabolismo (Figura 4.11). Como consequência, há uma elevação da temperatura do corpo e a da pele (Figura 4.10). Outra ressalva a ser feita, verificando essas figuras, se refere ao rendimento exergético que se torna mínimo na neutralidade térmica, ou seja, em condições que proporcionariam o conforto térmico. Tal processo pode ser explicado pelos fluxos de exergia para o ambiente ser mínimo. Dito de outra forma: o ponto próximo às condições de conforto é um ponto de valor mínimo (ou próximo do valor mínimo) fluxo de exergia para o ambiente; então, nessa condição, o corpo "tem menos necessidade" de transferir exergia para o ambiente.

Os resultados das Figuras 4.15 e 4.16 indicam a exergia destruída e o rendimento exergético em função dos parâmetros ambientais para o modelo vestido (resistência das roupas de $0,155^{\circ} \mathrm{Cm}^{2} / W$, ou $\left.1 \mathrm{CLO}\right)$. É importante observar que, em torno da neutralidade térmica, $25^{\circ} \mathrm{C}$, esses gráficos têm o mesmo formato das Figuras 4.13 e 4.14. O uso de roupas desloca o gráfico para regiões em torno da nova temperatura de neutralidade térmica. Ou seja, quanto mais roupas forem usadas, maior será esse deslocamento em direção à temperatura operativa menor. Para temperaturas mais altas (em relação à neutralidade térmica) há 
uma tendência de aumento da exergia destruída e diminuição do rendimento exergético, quando a umidade relativa é alta, e uma diminuição da exergia destruída com consequente aumento do rendimento exergético, quando a umidade relativa é baixa. Novamente, uma combinação de baixa temperatura do ar e alta temperatura radiante média acarretam pontos de mínima exergia destruída e máximo rendimento exergético.
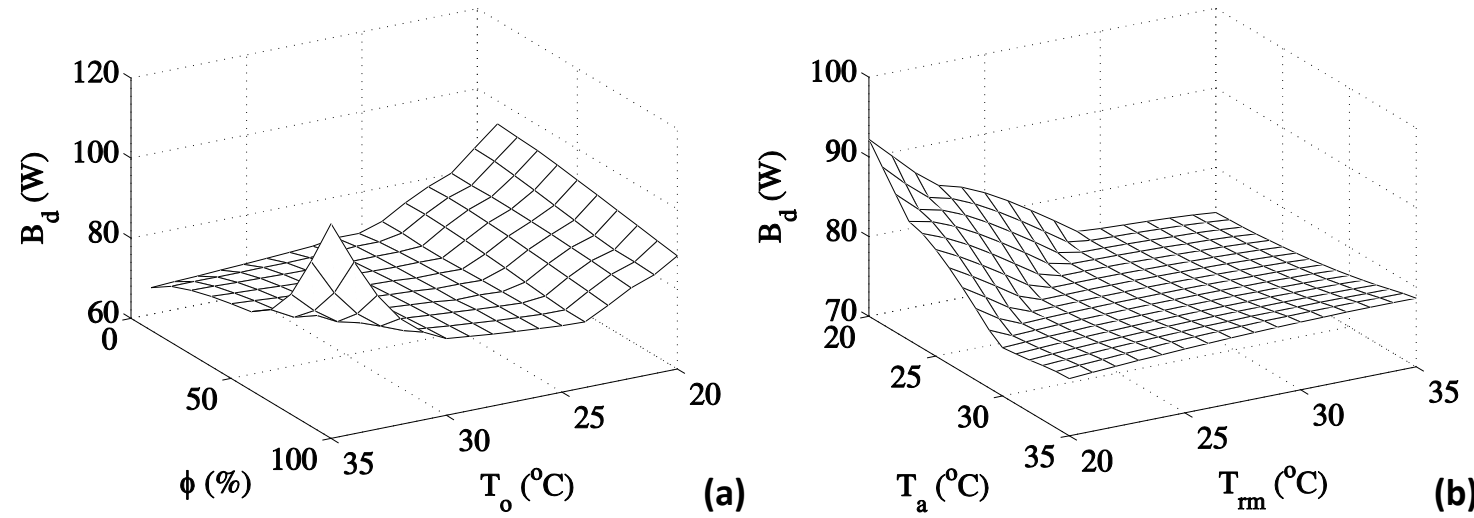

Figura 4.15: Exergia destruída, para o modelo vestido $\left(0,155^{\circ} \mathrm{Cm}^{2} / W\right.$, ou $\left.1 \mathrm{CLO}\right)$, como função da: (a) temperatura operativa e umidade relativa; (b) temperatura radiante média e temperatura do ar
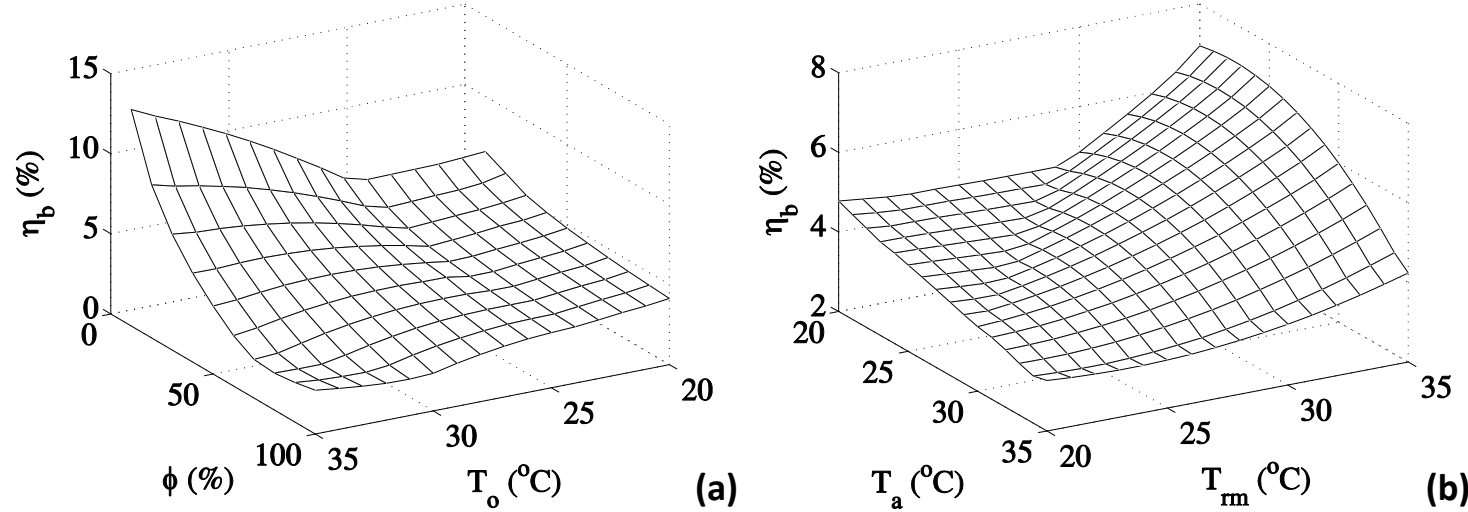

Figura 4.16: Rendimento exergético, para o modelo vestido $\left(0,155^{\circ} \mathrm{Cm}^{2} / \mathrm{W}\right.$, ou $\left.1 \mathrm{CLO}\right)$, como função da: (a) temperatura operativa e umidade relativa; (b) temperatura radiante média e temperatura do ar

Comparando-se as Figuras 4.15 e 4.16 com as Figuras 4.13 e 4.14, é possível notar que, com o uso de roupas, a temperatura de neutralidade térmica e a exergia destruída diminuem para ambientes mais frios. Já para as condições mais extremas, próximas de $T_{o}=35^{\circ} \mathrm{C}$ e $\phi=100 \%$, em que há dificuldade de troca de exergia com o ambiente, o modelo sem roupas tem uma menor exergia destruída e um menor rendimento exergético. Para temperaturas mais altas e umidades relativas baixas, o uso de roupas aumenta a exergia destruída e diminui o rendimento exergético.

As análises apresentadas nessa seção, podem esclarecer que para umidades relativas entre 40 e $60 \%$ (condições que reproduzem ambientes climatizados), as temperaturas 
cuja eficiência exergética é mínima e a destruição de exergia, também é mínima, são próximas a de neutralidade térmica. Essa temperatura corresponderia ao voto médio estimado próximo de $0(P M V)$ e porcentagem de insatisfeitos inferior a $5 \%(P P D)$, ou seja, zonas referentes à condição de conforto térmico. Para condições mais extremas, como temperaturas altas e umidades relativas baxas (climas desérticos) somente a exergia detruída não é suficiente para analise de conforto térmico, pois trata-se de ponto de mínimo, no entanto, esse ponto é carcterizado por um alto fluxo de exergia para o ambiente. Tal resultado mostratira que pontos com alto $B_{\text {env }}$ e baixos valores de $B_{d}$ não caracterizariam conforto térmico. Esse resultado entra em contradição, mas com embasamento físico, a afirmação de Simone et al. (2011), na qual altas temperaturas radiantes e baixas temperaturas do ar proporcionariam conforto térmico. Tal resultado, assim como em trabalhos anteriores da literatura como os de Prek (2004, 2006), Prek e Butala (2010), Simone et al. (2011) e Wu et al. (2012), propõe que a análise exergética com seus indicadores de exergia destruída, exergia transferida para o ambiente e eficiência exergética podem ser usados para análises de conforto térmico.

\subsection{ANÁLISE EXERGÉTICA DO SISTEMA DE CONTROLE DO MODELO}

O sistema de controle tem como principal função controlar a vazão de sangue para a pele, vaporização de suor pela pele e geração de tremores, por meio da comparação da temperatura da pele e do hipotálamo com uma referência. As contantes das Equações 3.64 a 3.66 são determinadas de forma experimental (cujos valores são raros de se encontrar), ou via iterativa para que o modelo tenha a resposta semelhante aos resultados experimentais para uma determinada anatomia do corpo. As constantes $k_{1}$ a $k_{7}$ são variadas uma a uma mantendo-se todos os outros parâmetros constantes. Calculam-se para cada combinação a exergia destruída e o rendimento exergético, como indicado nas Figuras 4.17 a 4.19. Assim, tentou-se mostrar que a análise exergética pode ser uma ferramenta complementar à modelagem de sistemas biológicos, ajudando nos ajustes das constantes do sistema termorregulatório.

A Figura 4.17 demonstra os resultados da variação das constantes $\mathrm{k}_{1}$ e $\mathrm{k}_{2}$ da Equação 3.64 (vazão de sangue para a pele) proveniente da exergia destruída e do rendimento exergético. Percebe-se que, apesar de o efeito de ambas as constantes na exergia destruída total ser pequeno, o mínimo de exergia destruída e máximo de rendimento se dão quando as constantes equivalem ao valor adotado no modelo. Ou seja, as constantes do modelo que resultam em respostas próximas às de resultados experimentais, apresentam valores próximos da mínima geração de entropia e do máximo rendimento exergético. 

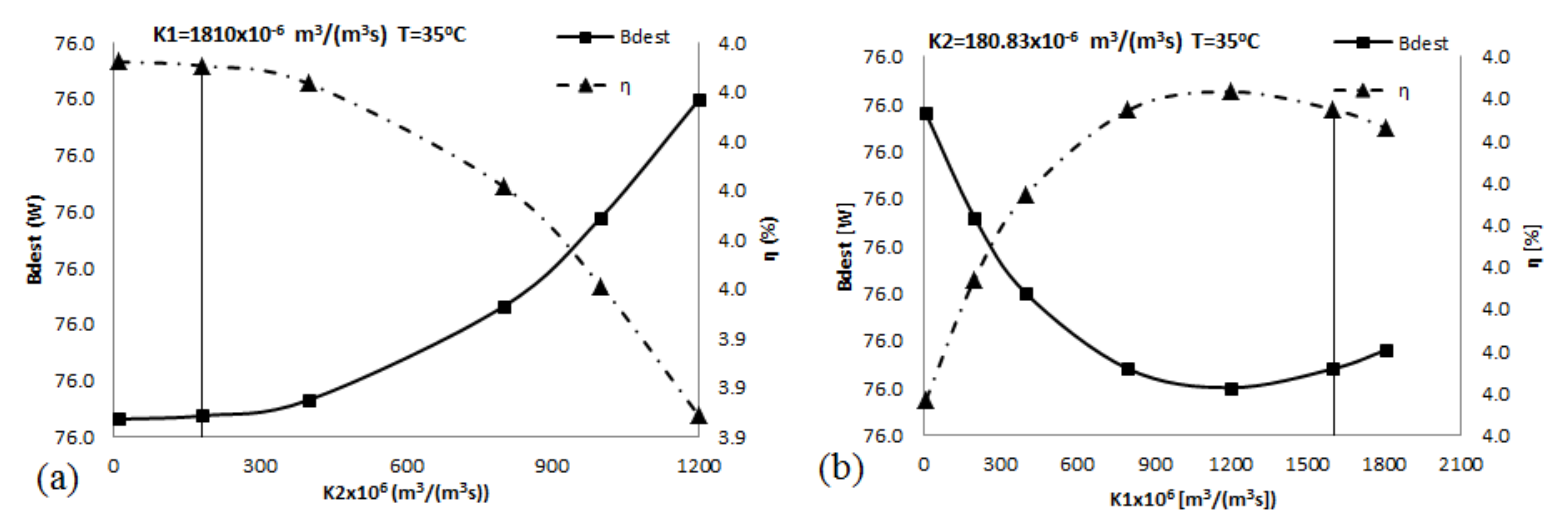

Figura 4.17: Constantes $\mathrm{k}_{1}$ e $\mathrm{k}_{2}$ do sistema de controle, em função da exergia destruída e do rendimento exergético

Por outro lado, na Figura 4.18, a variação das constantes $\mathrm{k}_{3}$ e $\mathrm{k}_{4}$ da Equação 3.65 está determinada em função da exergia destruída e do rendimento exergético. Atesta-se que o efeito dessas constantes é relativamente pequeno, no entanto, mais uma vez, a condição do modelo está próxima à condição de mínima destruição de exergia e máximo rendimento exergético. A temperatura ambiente adotada para os gráficos é de $35^{\circ} \mathrm{C}$, maior que a de neutralidade térmica, para que a sudorese seja ativada no sistema de controle.
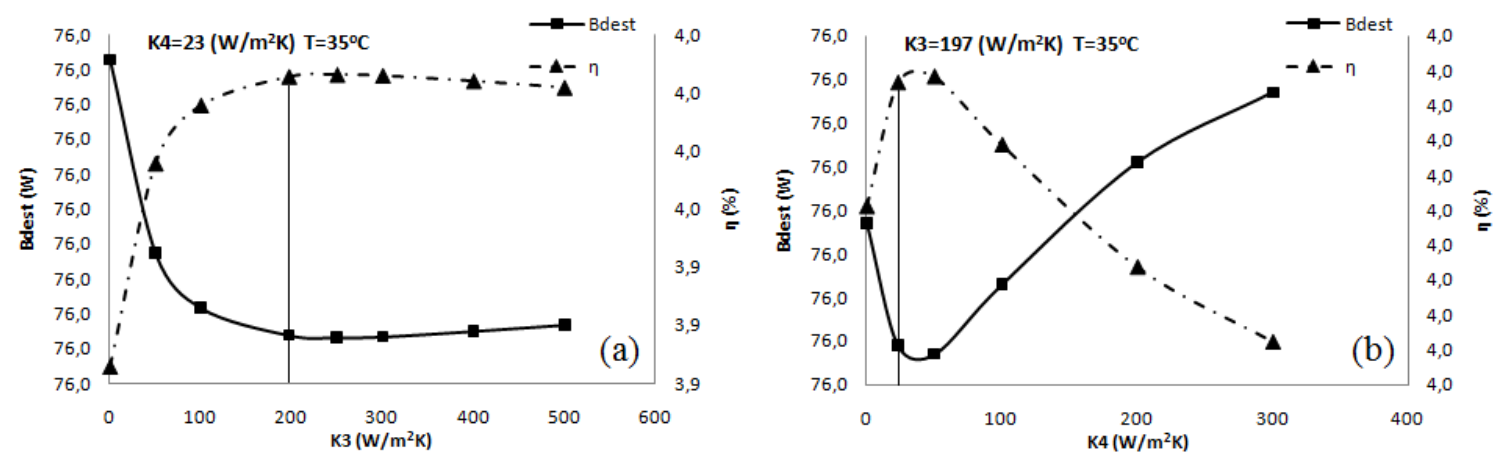

Figura 4.18: Constantes $\mathrm{k}_{3}$ e $\mathrm{k}_{4}$ do sistema de controle em função da exergia destruída e do rendimento exergético

Quanto ao efeito das constantes no acréscimo de metabolismo (Equação 3.66) causado pela produção de tremores (Figura 4.19), é diferente do que foi mostrado nas figuras anteriores, pois as maiores irreversibilidades no corpo humano são relacionadas à oxidação dos nutrientes. A condição do modelo para $\mathrm{k}_{5}, \mathrm{k}_{6}$ e $\mathrm{k}_{7}$ determina que a condição adotada está próxima à mínima destruição de exergia e próxima do mínimo rendimento exergético (exceção da Figura 4.19 (a)). Isso se deve ao fato de que um aumento no metabolismo acarreta um aumento da exergia destruída e uma diminuição no rendimento (o mesmo raciocínio vale para um decréscimo no metabolismo). Mesmo assim, para esse caso, a exergia destruída pode ser usada como ferramenta para cálculo dessas constantes. 

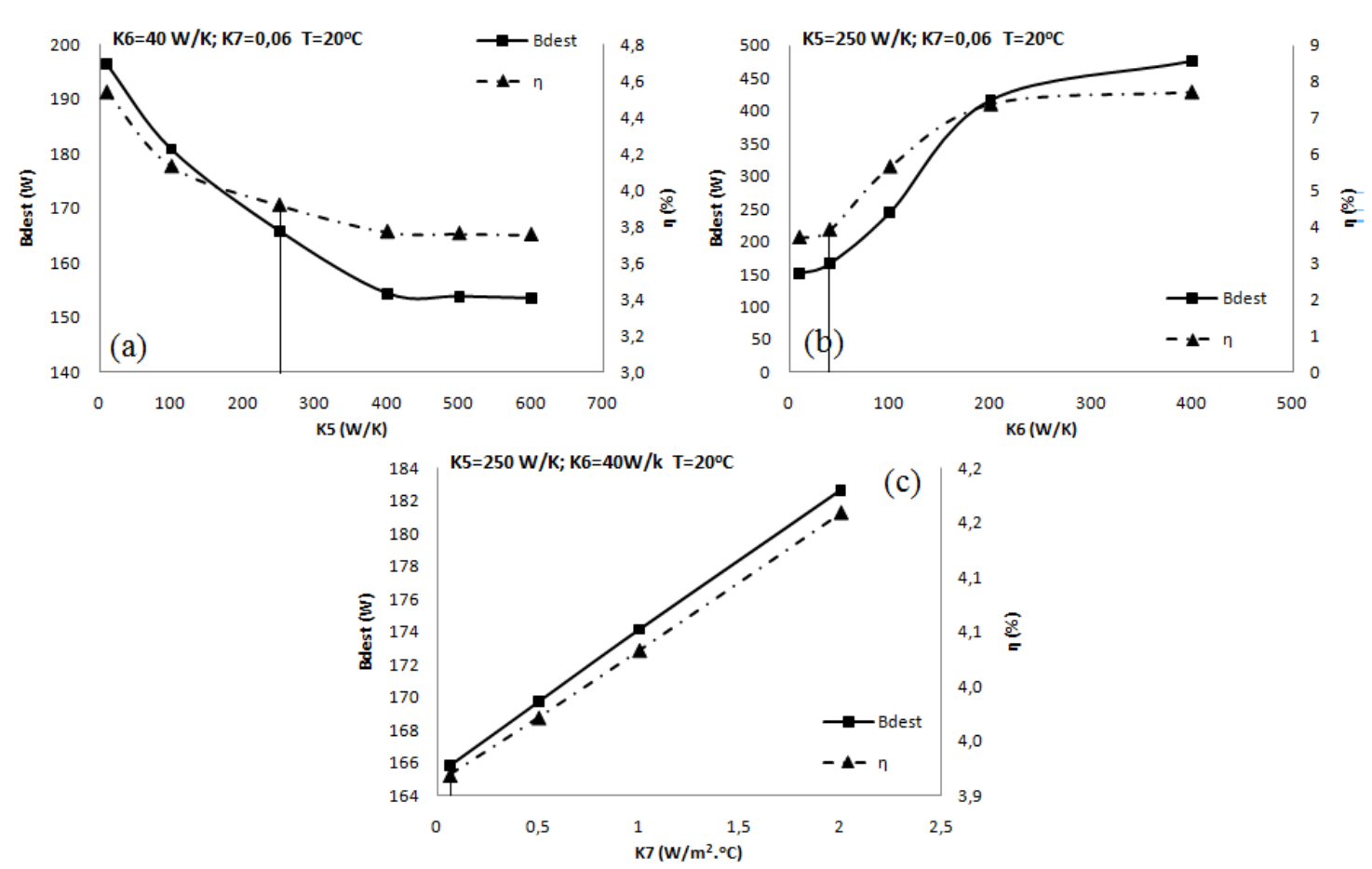

Figura 4.19: Constantes $\mathrm{k}_{5}, \mathrm{k}_{6}$ e $\mathrm{k}_{7}$ do sistema de controle em função da exergia destruída e do rendimento exergético

\subsection{INDUÇÃO DE HIPOTERMIA}

Ao todo, foram simulados três casos de hipotermia: resfriamento extracorpóreo de sangue, inserção de um cateter na veia cava e resfriamento da pele. O objetivo das simulações foi o uso da análise exergética para classificar as diferentes técnicas e parâmetros adotados para indução da hipotermia no ser humano. Para aplicação da Segunda Lei da Termodinâmica, deve-se primeiro calcular os fluxos de entalpia e calor para o ambiente, variação de energia interna, temperaturas interna e da pele, dentre outros. Somente depois do cálculo dessas grandezas físicas foi possível aplicar a análise exergética para essa terapia.

\subsubsection{Resfriamento de sangue via circulação extracorpórea}

Para o estudo da técnica de resfriamento de sangue via circulação extracorpórea foram escolhidos quatro parâmetros de simulação, a saber:

1. Resfriamento a uma taxa de $2,5 \%$ da massa do reservatório central de sangue $(0,05$ $\mathrm{kg} / \mathrm{s})$ e uma taxa de reaquecimento de $2,5 \%$ da taxa de resfriamento $(0,00125 \mathrm{~kg} / \mathrm{s})$. 
2. Resfriamento a uma taxa de $5 \%$ da massa do reservatório central de sangue $(0,1$ $\mathrm{kg} / \mathrm{s})$ e uma taxa de reaquecimento de $5 \%$ da taxa de resfriamento $(0,005 \mathrm{~kg} / \mathrm{s})$.

3. Resfriamento a uma taxa de $10 \%$ da massa do reservatório central de sangue $(0,2$ $\mathrm{kg} / \mathrm{s})$ e uma taxa de reaquecimento de $10 \%$ da taxa de resfriamento $(0,02 \mathrm{~kg} / \mathrm{s})$.

4. Resfriamento a uma taxa de $20 \%$ da massa do reservatório central de sangue $(0,4$ $\mathrm{kg} / \mathrm{s})$ e uma taxa de reaquecimento de $20 \%$ da taxa de resfriamento $(0,08 \mathrm{~kg} / \mathrm{s})$.

Inicialmente se simulou a indução da hipotermia por meio da circulação de sangue extracorpórea. Essa técnica, segundo Behringer et al. (2002), ainda é experimental, porém estudos em animais mostrou-a como mais eficaz do que outras para atingir a hipotermia. Como demonstrado na Figura 4.20(a), pode-se verificar a variação de temperatura do hipotálamo em função do tempo para uma taxa de resfriamento de $10 \%$ da massa do reservatório central de sangue $(0,2 \mathrm{~kg} / \mathrm{s})$ e uma taxa de reaquecimento de $10 \%$ da taxa de resfriamento $(0,02 \mathrm{~kg} / \mathrm{s})$. Na Figura $4.20(\mathrm{~b})$, nota-se o metabolismo energético em função do tempo, no qual se observa que há uma redução deste em aproximadamente $25 \%$ em relação às condições basais. Tal resultado é próximo do proposto por Dae et al. (2003) de que para cada $1^{\circ} \mathrm{C}$ de redução na temperatura do corpo a oxidação dos nutrientes é reduzida em aproximadamente 7\%, ou seja, o metabolismo é reduzido nessa porcentagem.
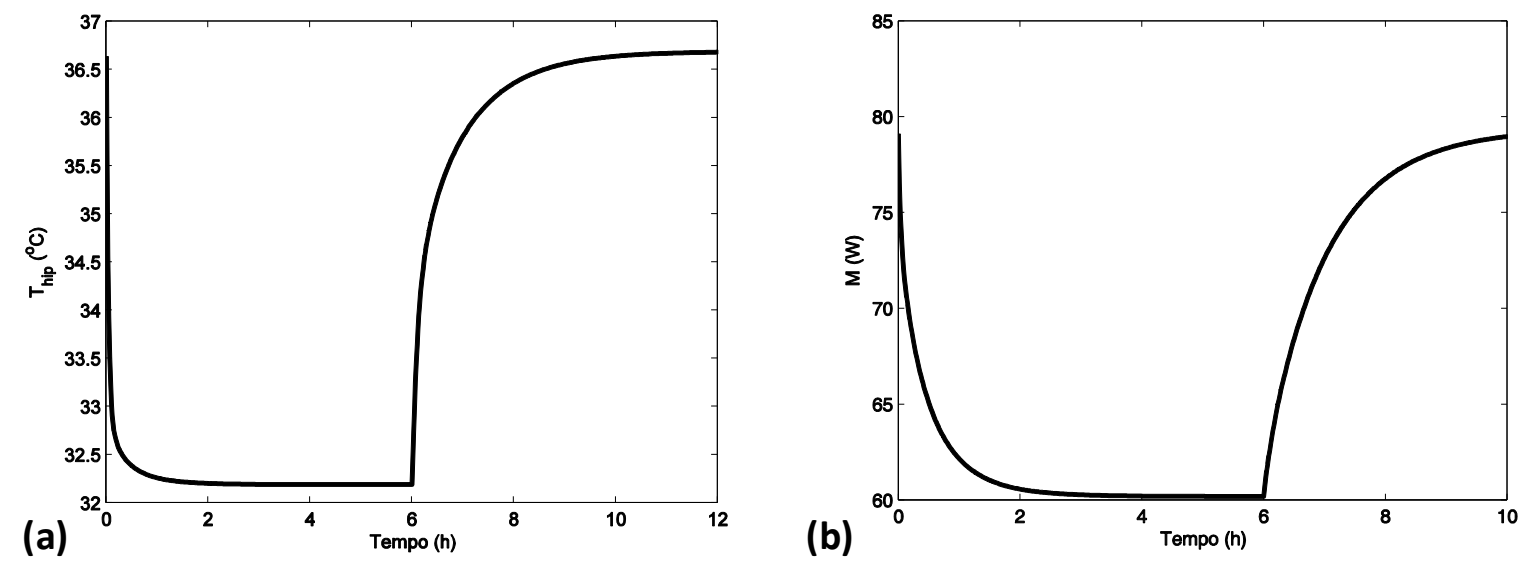

Figura 4.20: (a) Temperatura do hipotálamo; (b) metabolismo energético em função do tempo para uma vazão adotada de resfriamento de 10\% do reservatório central e de reaquecimento de $10 \%$ da de resfriamento

A Figura 4.21 indica a variação da temperatura do hipotálamo, decorrente do tempo para diferentes taxas de resfriamento e retorno, similar à Figura 4.20, porém levando em conta os casos 1 a 4 indicados anteriormente. Da Figura 4.21(b) é possível inferir que todas as taxas de reaquecimento estão dentro dos limites fornecidos na literatura, ou seja, incrementos de temperatura entre 1 e $3^{\circ} \mathrm{C} / \mathrm{h}$. Comparando-se as maiores taxas de reaquecimento, fica claro que, ao se usar as taxas do caso 4, o aumento da temperatura 
do corpo é de $4,5^{\circ} \mathrm{C}$ em 2 horas, enquanto que a menor vazão (caso 1) não é capaz de reaquecer o corpo em 6 horas, instante cuja temperatura equivale a $36^{\circ} \mathrm{C}$, faltando ainda $0,5^{\circ} \mathrm{C}$ para o reaquecimento completo.
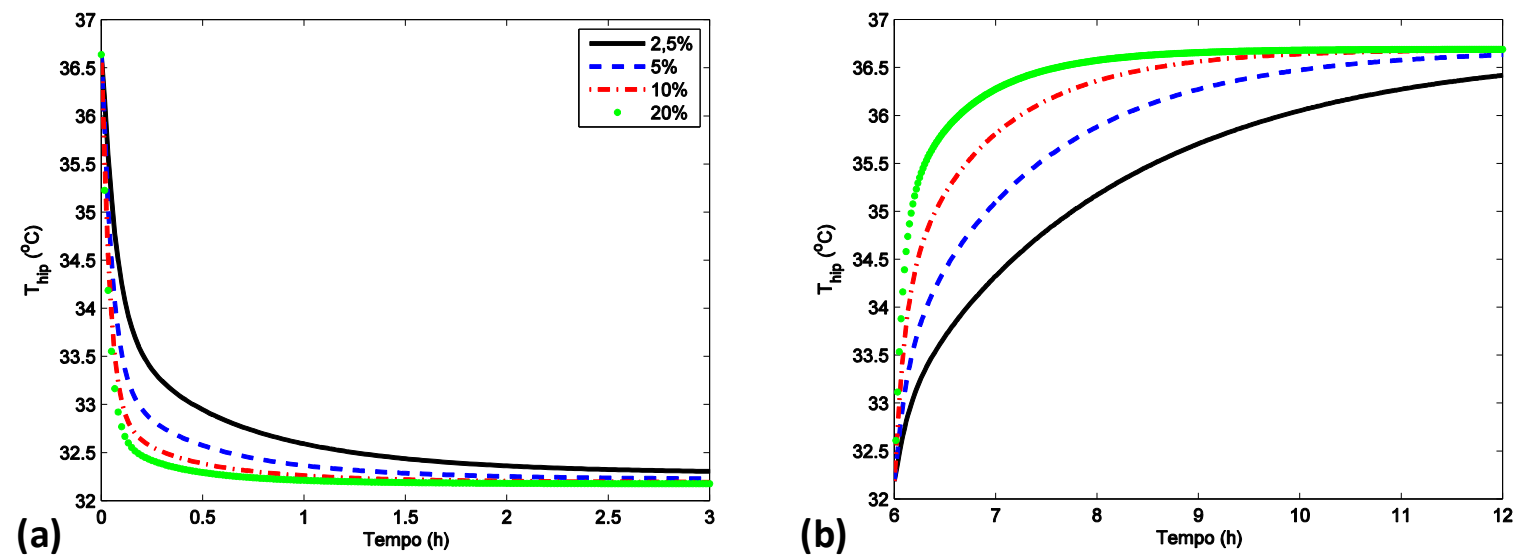

Figura 4.21: Temperatura do hipotálamo em função do tempo para: (a) resfriamento do sangue a uma vazão de 2,5, 5, 10 e 20\% da massa do reservatório de sangue; (b) reaquecimento a uma vazão mássica de 2,5, 5, 10 e 20\% da vazão de resfriamento

(adotada como $10 \%$ do reservatório central)

A destruição de exergia e eficiência exergética em função do tempo estão demonstradas na Figura 4.22 para o modelo sujeito à hipotermia, na qual é possível notar que, no estado basal, o corpo destrói mais exergia ao mesmo tempo que possui uma menor eficiência exergética do que durante a hipotermia. Tal fato se deve à consideração de que o sangue perde certa quantidade de exergia para o dispositivo de circulação extracorpórea $\left(B_{s}\right)$ e retorna com um valor de exergia menor $\left(B_{h i p}\right)$ do que aquele em que saiu. Portanto, certa quantidade dessa exergia deixa de ser destruída no corpo e passa a ser destruída no ambiente. A análise dos fluxos para o ambiente $\left(B_{a m b}\right)$, do fluxo de sangue que deixa o corpo $\left(B_{s}\right)$ e do fluxo de sangue que retorna para o corpo $\left(B_{h i p}\right)$, da Figura 4.23 , indica que, no início do processo de hipotermia, todos os fluxos diminuem, e que $B_{s}$ tende ao valor $B_{\text {hip }}$ dado que $T_{s}$ é resfriado até $T_{h i p}$. No retorno, $B_{s}$ volta a diminuir por causa da redução da vazão, enquanto que $B_{\text {hip }}$ permanece praticamente constante (o que não deveria ocorrer); este é um caso muito particular no qual a diminuição da vazão é compensada pelo aumento da temperatura (mesmo assim é possível notar uma pequena variação de exergia logo que se inicia o retorno da hipotermia). O aumento do rendimento exergético durante a hipotermia pode, então, ser explicado como um aumento dos fluxos de exergia para o ambiente para uma diminuição da exergia de alimentação (metabólica). Portanto, sob a ótica da Segunda Lei da Termodinâmica, o corpo gera menos entropia e é mais eficiente durante a hipotermia. Existe um pico de exergia relacionado à variação da exergia do corpo logo nos primeiros instantes da análise, esse ponto não deve ser confundido com a condição basal. 

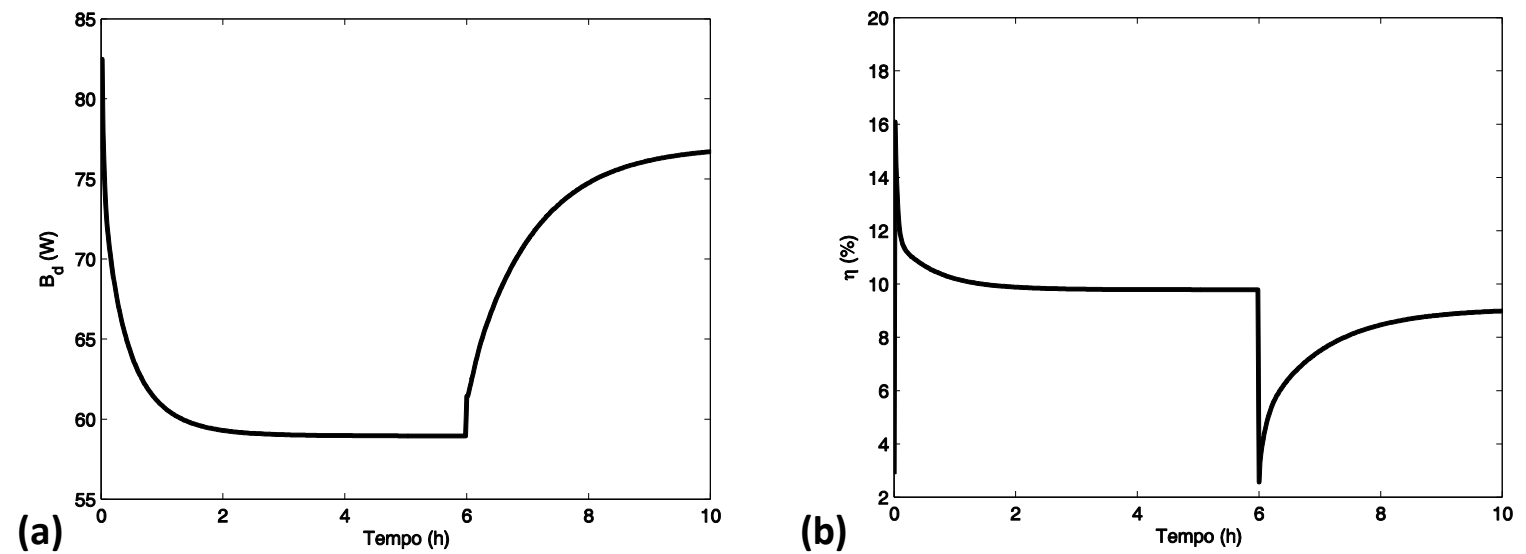

Figura 4.22: Exergia destruída (a) e rendimento exergético (b) em função do tempo para uma vazão adotada de resfriamento de $10 \%$ do reservatório central e de reaquecimento de $10 \%$

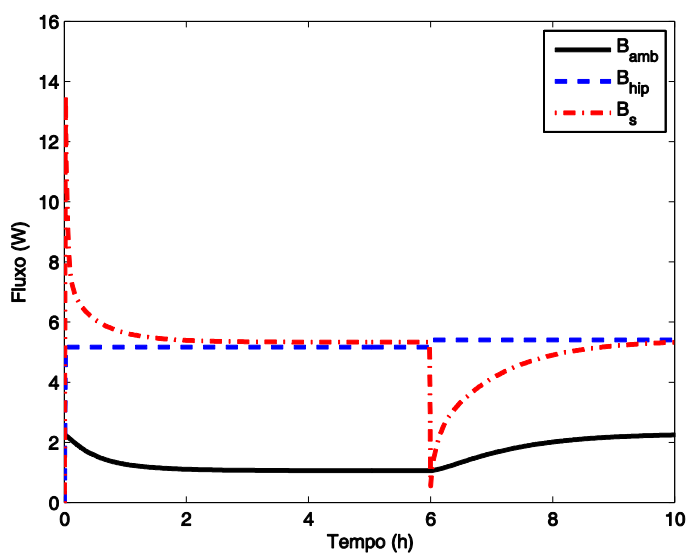

Figura 4.23: Fluxo de exergia para o ambiente em função do tempo para uma vazão adotada de resfriamento de $10 \%$ do reservatório central e de reaquecimento de $10 \%$ 
Calculou-se a exergia destruída e a eficiência exergética do paciente proveniente dos diferentes parâmetros de resfriamento e reaquecimento, como indicado nas Figuras 4.24 e 4.25. O resfriamento mais lento acarretou maiores taxas de exergia destruída e menores rendimentos exergéticos, se comparados com os casos cujas taxas são mais elevadas. Tal fato pode ser explicado pelo atraso para que ocorra a diminuição do metabolismo, levando o corpo a ficar com uma taxa de destruição maior, por um maior período de tempo. No entanto, durante o reaquecimento, essa tendencia se inverte, pois, quanto menores forem as taxas de retorno, também serão a taxa de destruição de exergia e o rendimento exergético, uma vez que o corpo demora mais tempo para entrar em um estado de maior $B_{d}$ e menor $\eta_{b}$.
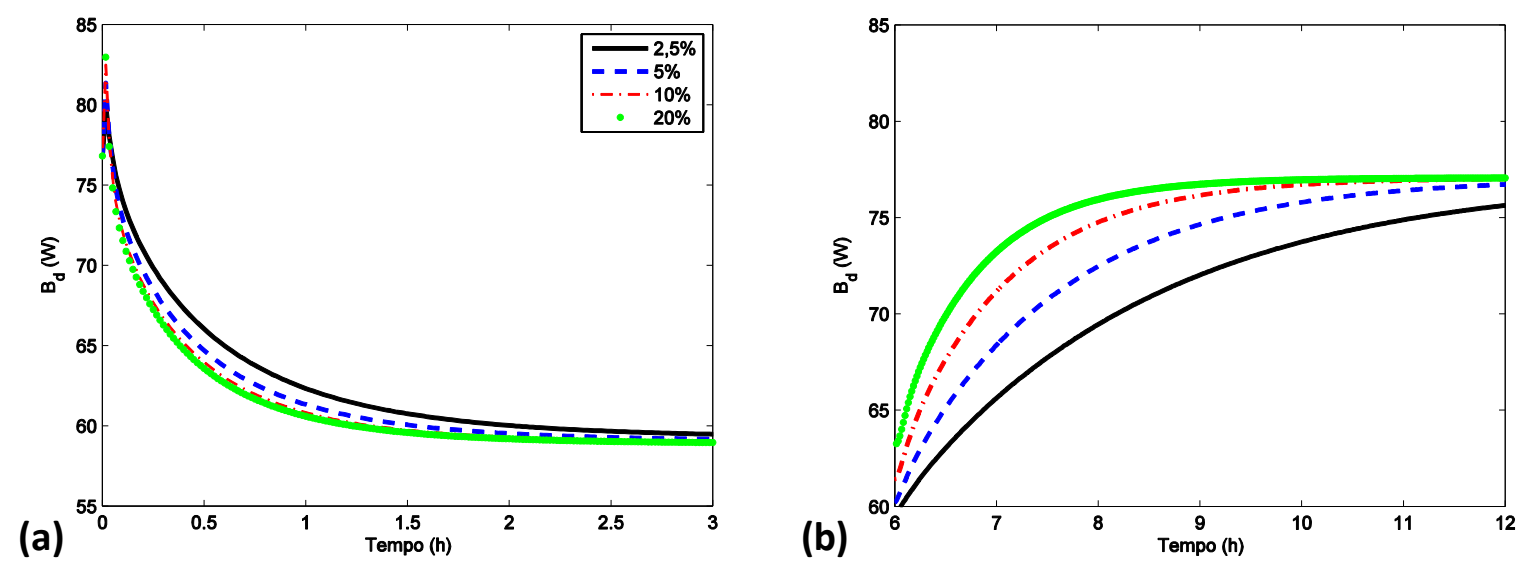

Figura 4.24: Exergia destruída em função do tempo para: (a) resfriamento do sangue a uma vazão de 2,5, 5, 10 e 20\% da massa do reservatório de sangue; (b) reaquecimento a uma vazão mássica de 2,5, 5, 10 e $20 \%$ da vazão de resfriamento
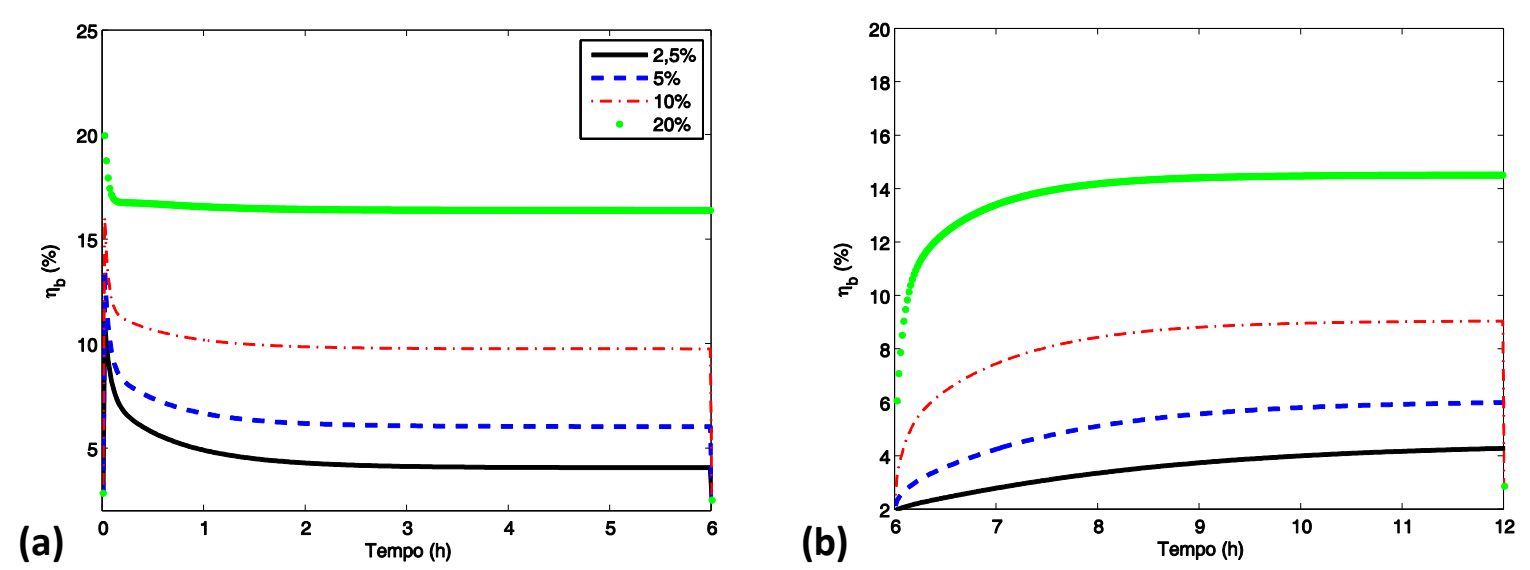

Figura 4.25: Rendimento exergético em função do tempo para: (a) resfriamento do sangue a uma vazão de 2,5, 5, 10 e $20 \%$ da massa do reservatório de sangue; (b) reaquecimento a uma vazão mássica de 2,5, 5, 10 e 20\% da vazão de resfriamento

Para induzir a hipotermia em um paciente que passou ou está passando por uma parada cardíaca, ou sofreu um acidente, existe o objetivo de resfriar-lo o mais rapidamente, independentemente da eficiência do processo. Desse modo, minimizando danos no cérebro 
e em outros tecidos. Para o reaquecimento, no entanto, é necessário que a taxa de incremento da temperatura seja gradual . Como destacado nas Figuras 4.24 e 4.25, considerando-se a análise exergética, um resfriamento rápido e um reaquecimento mais gradual levam a uma menor taxa de destruição de exergia, embora apenas para o primeiro caso haja uma maior eficiência exergética.

Como tentativa de se explicar o reaquecimento lento ser menos eficiente, chegou-se à Figura 4.26, na qual são demonstrados os fluxos de exergia para o ambiente ponderados por $d \mathbf{B} / d t$ (Figura 4.26(a) e (b)) e a variação da exergia do sangue ponderada por $d \mathbf{B} / d t$ (Figura 4.26(c) e (d)). Tirando os primeiros instantes que $d \mathbf{B} / d t_{\Delta T}$ é significativo, o denominador das figuras equivale a $B_{M}$ (afirmação comprovada pela Figura 4.27). Para o resfriamento, $\left(B_{s}-B_{h i p}\right) /\left(B_{M}\right)$ é maior para o caso 4 (vazão $20 \%$ ) e o termo $B_{a m b} / B_{M}$ é maior no caso 1 (vazão $2,5 \%$ ), porém nesse último, todos os casos possuem valores muito próximos. O termo $\left(B_{s}-B_{h i p}\right) /\left(B_{M}\right)$ possui maiores valores percentuais, com $B_{s}>B_{h i p}$. Justifica-se, o rendimento exergético do caso 4 ser maior. Já no reaquecimento, o termo $B_{a m b} / B_{M}$ é maior, justificando a maior eficiência exergética do caso 4.
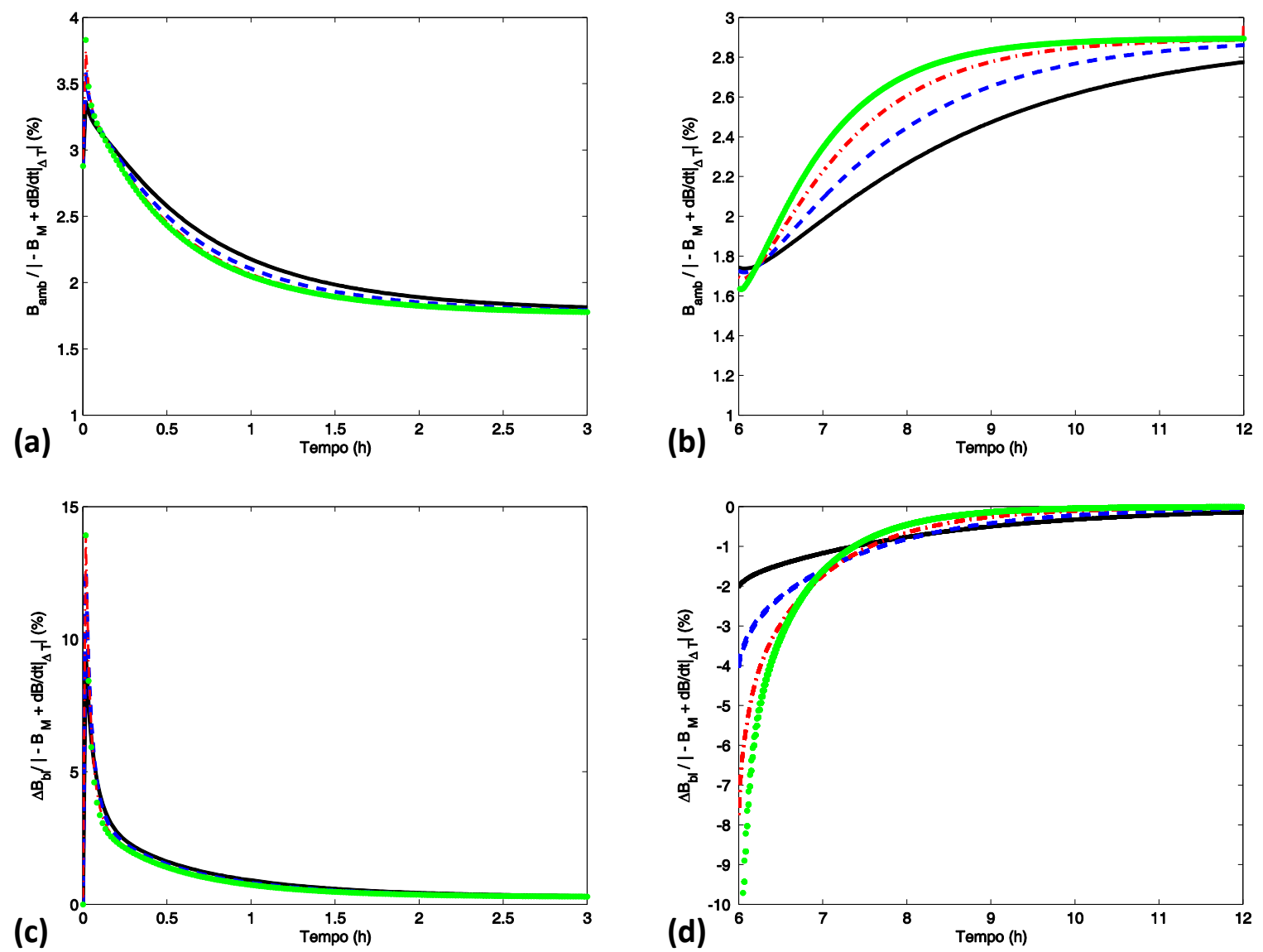

Figura 4.26: Fluxo de exergia para o ambiente (a) e (b) e variação da exergia do sangue (c) e (d) em função do tempo para resfriamento e reaquecimento do corpo, para resfriamento do sangue a uma vazão de 2,5, 5, 10 e 20\% da massa do reservatório de sangue e reaquecimento a uma vazão mássica de 2,5, 5, 10 e $20 \%$ da vazão de resfriamento 
Pode-se ainda ressaltar que, no início da hipotermia, há uma abrupta diminuição da exergia do corpo, devido ao resfriamento, fazendo com que a exergia disponível no corpo para realização de trabalho $\left(\left|-B_{M}+d \mathbf{B} / d t_{\Delta T}\right|\right)$ diminua. A Figura 4.27 indica tal processo, no qual a variação temporal da exergia devido a condições transientes de temperatura é demonstrada tendo em vista o tempo de processo. No resfriamento integrado ao longo do tempo, a variação da exergia do corpo foi de $9,1 \mathrm{~kJ}$, para o reaquecimento $10,1 \mathrm{~kJ}$, sendo a variação da exergia do corpo total foi de $1 \mathrm{~kJ}$ (aproximadamente), Fazendo procedimento semelhante para diferentes taxas de resfriamento foi possível obter a Tabela 4.18. É interessante notar que taxas de resfriamentos menores levam a uma variação maior da exergia, enquanto o oposto é visto para o reaquecimento, taxa maiores de reaquecimento levam a uma variação da exergia maior. Finalmente, quanto maiores forem as taxas no processo com um todo, maior será a variação da exergia do corpo.

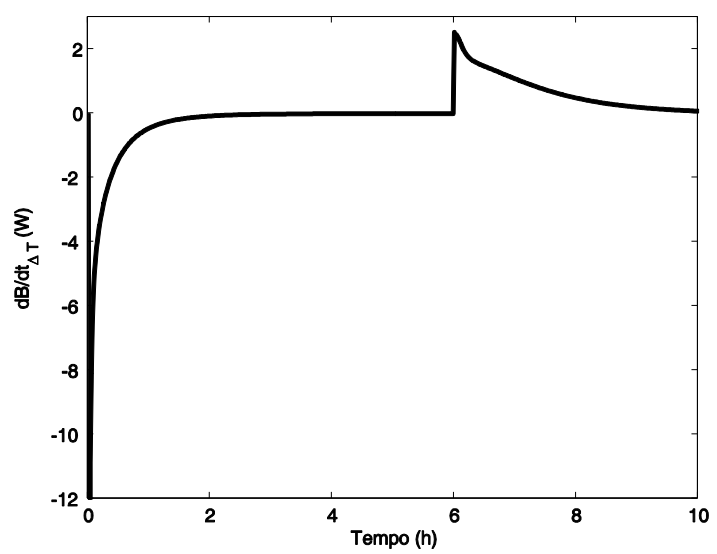

Figura 4.27: Variação temporal da exergia do corpo em função do tempo para uma vazão adotada de resfriamento de $10 \%$ do reservatório central e de reaquecimento de $10 \%$

Tabela 4.18: Variação da exergia do corpo no processo de resfriamento, reaquecimento e no ensaio global

\begin{tabular}{|c|c|c|c|}
\hline Caso & $\Delta B_{\Delta T}^{\text {resf }} \mid(\mathrm{kJ})$ & $\Delta B_{\Delta T}^{\text {reaq }}(\mathrm{kJ})$ & $\Delta B_{\Delta T}^{\text {processo }}(\mathrm{kJ})$ \\
\hline 1 & 9,6 & 9,7 & 0,035 \\
2 & 9,4 & 9,3 & 0,93 \\
3 & 9,1 & 10,1 & 1,0 \\
4 & 8,6 & 10,6 & 2,0 \\
\hline
\end{tabular}

A Tabela 4.19 indica o índice exergético para o processo de hipotermia, que é a relação entre a variação da exergia do corpo associada às condições transientes e a exergia removida (ou fornecida no retorno da hipotermia), em função dos parâmetros de ensaio. Nota-se que, quanto mais lento o resfriamento, maior será esse índice, o que é de se esperar, dado que ele mede o quanto da exergia removida é transformada em variação da exergia do corpo associada às condições ambientais. É interessante ressaltar que, para o reaquecimento, esse índice indica qual seria a taxa de retorno mais recomendada, pois pelo 
ponto de vista do índice o reaquecimento mais lento mostrou-se eficiente em transformar a exergia recebida via o fluxo de sangue em exergia do corpo.

Tabela 4.19: Índice exergético para o processo de resfriamento e reaquecimento

\begin{tabular}{|c|c|c|}
\hline Caso & $r_{\text {resf }}(\%)$ & $r_{\text {reaq }}(\%)$ \\
\hline 1 & 73,8 & 69,3 \\
2 & 36,2 & 30,0 \\
3 & 26,8 & 23,0 \\
4 & 18,7 & 16,3 \\
\hline
\end{tabular}

\subsubsection{Resfriamento por meio de cateter intravenoso}

Outra forma usada para análise da hipotermia corpórea é o uso de um cateter intravenoso resfriado por meio de uma solução salina. O cateter fica na veia cava inferior (ele é inserido na veia femoral), no qual troca calor com o sangue. Como destacado anteriormente a superfície do cateter, por hipótese, está a uma temperatura constante e igual à temperatura em que se resfriou a solução salina e o sangue sai em equilíbrio térmico com trocador de calor. Foram, então, simuladas três situações:

1. Temperatura do Cateter $32^{\circ} \mathrm{C}$ e produto $h A=62 \mathrm{~W} / \mathrm{K}$ (condição retirada de experimentos).

2. Temperatura do Cateter $32^{\circ} \mathrm{C}$ e produto $h A=110 \mathrm{~W} / \mathrm{K}$ (condição com aumento da área de contato, por exemplo).

3. Temperatura do Cateter $30^{\circ} \mathrm{C}$ e produto $h A=62 \mathrm{~W} / \mathrm{K}$ (condição retirada de experimentos).

A Figura 4.28(a) apresenta a variação da temperatura do corpo para os três casos selecionados, na qual é possível notar que, em nenhum dos casos, o sangue chegou à temperatura do cateter, ou seja, existe uma resistência adicional para a transferência de energia se comparado com um fluxo de entalpia entrando a uma dada temperatura. Ao se comparar o caso 1 com o 2, nota-se que um incremento no produto $h A$ de aproximadamente $80 \%$ leva a uma redução na temperatura do hipotálamo de apenas 0,5\%. Já, comparando-se o caso 1 com o 3, uma redução em $2^{\circ} \mathrm{C}$ na temperatura do catéter, ou seja de 6,25\%, resulta em um decréscimo de 5,6\% da temperatura do hipotálamo. Na Figura 4.28(b), o comportamento $d B / d t_{\Delta T}$ é similar com o do resfriamento de sangue extracorpóreo, com dois picos: um no início do resfriamento (variação negativa); o outro no, reaquecimento (variação positiva). 

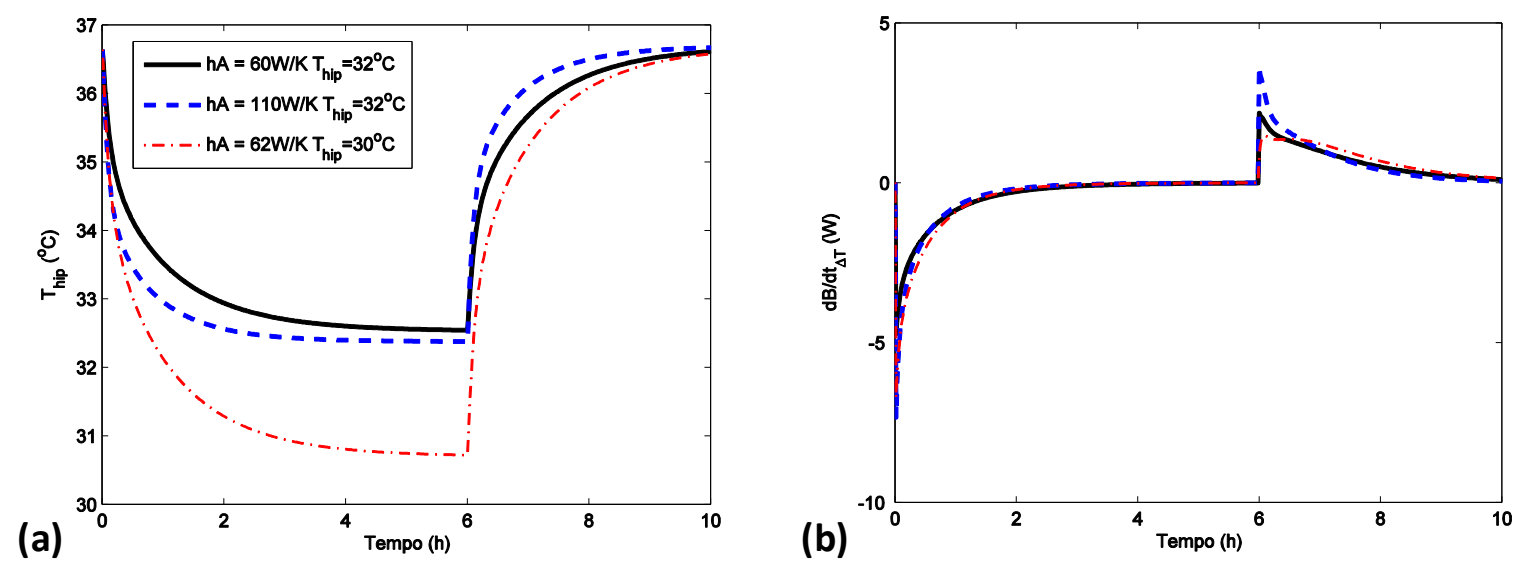

Figura 4.28: (a)Temperatura do corpo em função do tempo; (b) variação da exergia do corpo em função do tempo para resfriamento de sangue por meio de cateter intravenoso

A exergia destruída está demonstrada em função do tempo na Figura 4.29(a), na qual é mostrado um comportamento semelhante ao da temperatura, ou seja, no caso 1 há uma maior destruição de exergia do que nos casos 2 e 3. Explica-se esse resultado pelo fato de o corpo atingir temperaturas mais baixas e manter-se em um estado de menor geração de entropia. No retorno da hipotermia, nota-se que há uma taxa de aumento da destruição de exergia maior para o caso 1, causado pelo incremento de temperatura a uma maior taxa. Um comportamento inesperado representado na Figura 4.29(b), semelhante ao resfriamento de sangue via circulação extracorpórea. Os casos com maiores destruições de exergia resultaram em maiores eficiências exergéticas. Tal comportamento das razões entre o fluxo de exergia para o ambiente e para o cateter com o metabolismo em função do tempo de simulação, está explicado nas Figuras 4.30(a) e 4.30(b), respectivamente. Percebe-se que o rendimento depende desses dois fluxos (considerados como produtos do metabolismo e do processo de resfriamento, destruídos fora do corpo), e que a participação relativa de $B_{a m b}$ no metabolismo é maior para o primeiro caso, enquanto que $B_{Q_{h i p}}$ quase não varia de um caso para o outro (excluindo nos instantes iniciais de resfriamento e reaquecimento).

Na Tabela 4.20, constam os valores do índice exergético para os três casos. Para obtenção dessa razão, os termos da análise exergética foram integrados em decorrência do tempo para o processo de resfriamento e reaquecimento, processo similar ao usado para obter a Tabela 4.18. Nota-se que o caso em que a eficiência exergética de resfriamento é menor (caso 3) acarretou um índice maior. Para o caso em que a eficiência exergética de reaquecimento é maior resultou em um menor valor de índice exergético. Mesmo assim, o reaquecimento mais lento mostrou-se o que possui maior índice exergético. É interessante notar que esse índice agrega informações à eficiência exergética, porque ele mostra o quanto da exergia retirada (ou fornecida) foi realmente convertida em variação da exergia do corpo. 

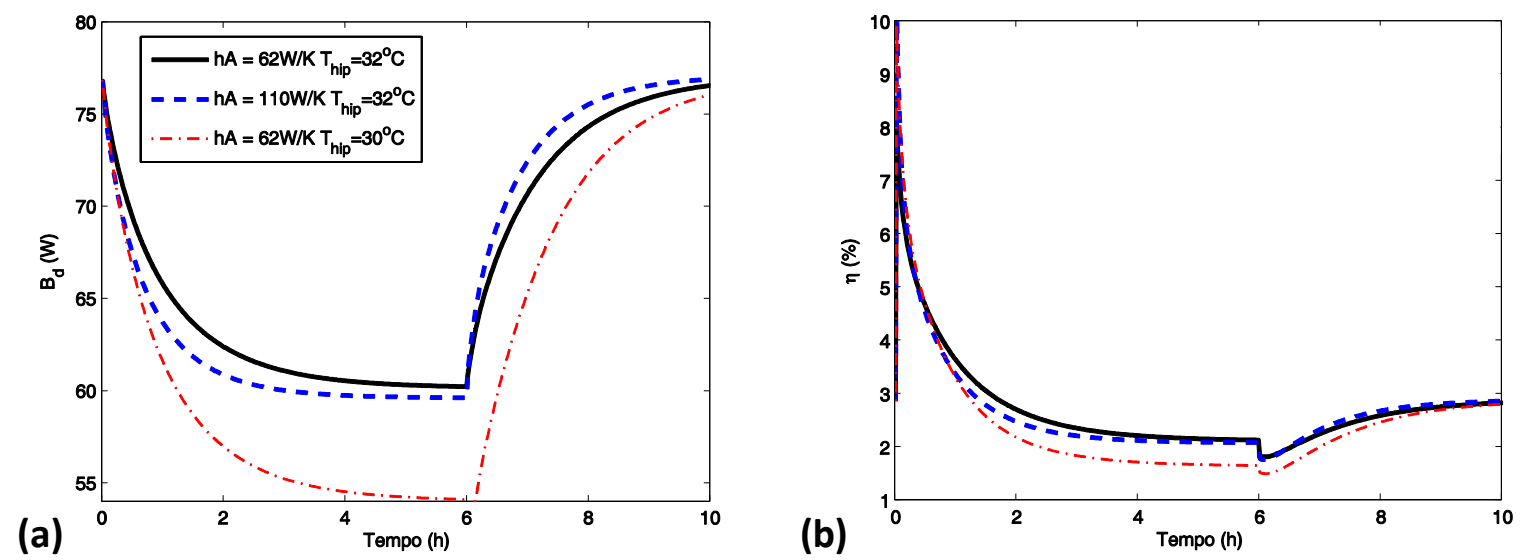

Figura 4.29: (a)Exergia destruída do corpo em função do tempo; (b) eficiência do corpo em função do tempo para resfriamento de sangue por meio de cateter intravenoso
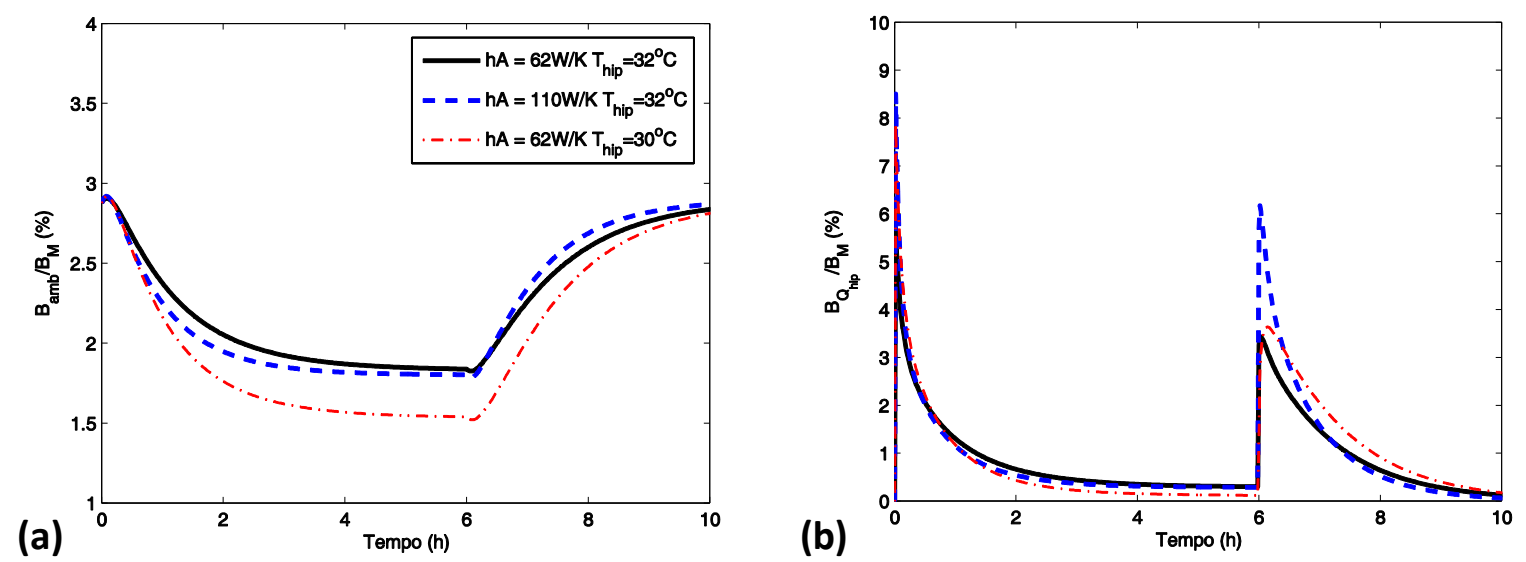

Figura 4.30: Razão entre (a) fluxo de exergia para o ambiente e a exergia metabólica;

(b) fluxo de exergia associado ao metabolismo e a exergia metabólica em função do tempo para resfriamento de sangue por meio de cateter intravenoso

Tabela 4.20: Índice exergético para o processo de resfriamento e reaquecimento

\begin{tabular}{|c|c|c|}
\hline Caso & $r_{\text {resf }}(\%)$ & $r_{\text {reaq }}(\%)$ \\
\hline 1 & 79,8 & 93,3 \\
2 & 81,5 & 89,7 \\
3 & 90,1 & 87,3 \\
\hline
\end{tabular}




\subsubsection{Resfriamento da pele}

A hipotermia via resfriamento da pele foi estudada com o objetivo de compará-la às outras técnicas. Inicialmente, simulou-se esse tipo de resfriamento a uma temperatura da água de $15^{\circ} \mathrm{C}$ com o sistema de controle ligado e desligado. O resultado da temperatura do hipotálamo pode ser visto na Figura 4.31(a). Fica evidente a dificuldade dessa técnica cujo princípio é atuar contra o sistema passivo e ativo do corpo. A Figura 4.31(b) mostra o comportamento do modelo quando sujeito ao resfriamento extracorpóreo de sangue com o sistema de controle ligado e desligado. Nota-se que o comportamento é similar ao sistema de controle desligado (Figura 4.21). Portanto, as técnicas citadas anteriormente são mais eficazes em inibir os mecanismo de defesa do corpo contra a hipotermia com relação ao resfriamento da pele.
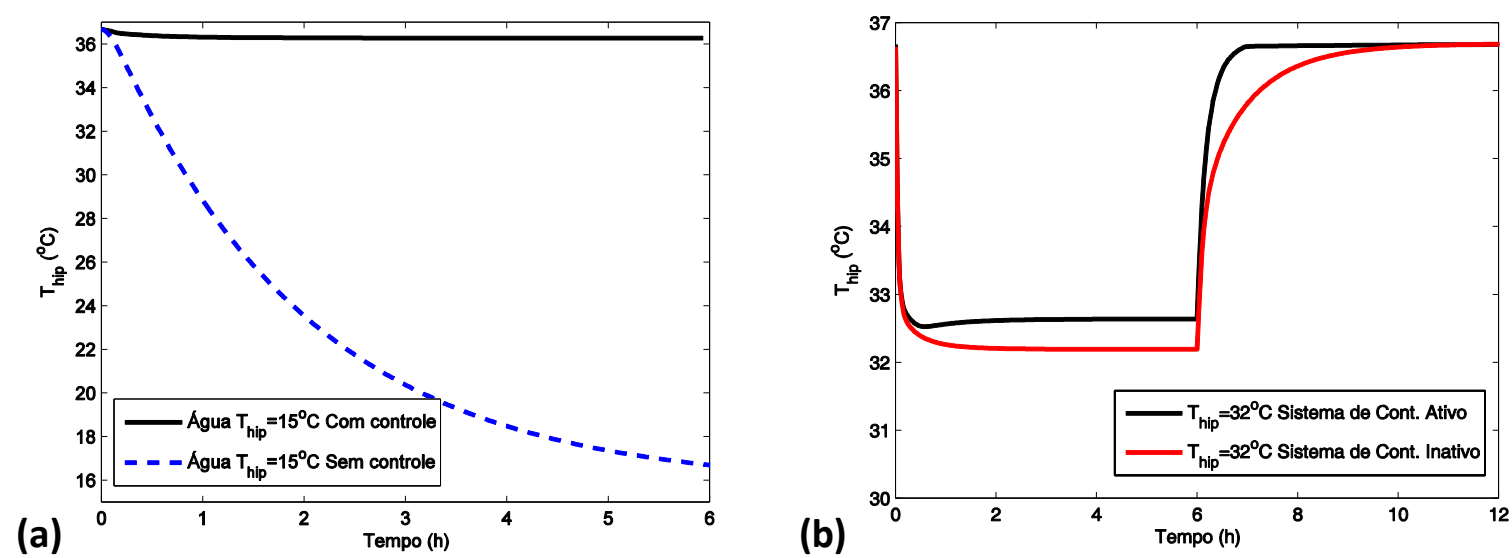

Figura 4.31: Temperatura do hipotálamo para o resfriamento da pele com água sob temperatura de $15^{\circ} \mathrm{C}$, com o sistema de controle ligado e desligado e (b) resfriamento usando-se do dispositivo de circulação extracorpórea com sistema de controle ligado e desligado

A referida técnica, por ser menos invasiva, e tradicionalmente reconhecida na literatura como menos eficaz, foi estudada somente para o resfriamento e para comparação com outras técnicas. Outra desvantagem dessa técnica em relação às outras é o fato de ela agir contra o sistema passivo do corpo (energia liberada pelo metabolismo) e, também, contra o sistema ativo (controle de calafrios). Assim, existe uma considerável resistência natural do corpo que dificultam a aplicação dessa técnica.

Para esta análise, baseando-se nos resultados de Figura 4.31, foi adotado que a pele é resfriada com água a uma velocidade inferior a $0,15 \mathrm{~m} / \mathrm{s}$ (manter os mesmos padrões de quando o modelo Ferreira e Yanagihara (2009a) está em ar atmosférico). Para tal, foram simulados dois casos e observa-se que em nenhum deles usou-se água abaixo da temperatura de $30^{\circ} \mathrm{C}$, pois o objetivo foi comparar técnicas com temperaturas de resfriamento semelhantes: 
1. Inibição de tremores e água a $32^{\circ} \mathrm{C}$.

2. Inibição de tremores e água a $30^{\circ} \mathrm{C}$.

A Figura 4.32 indica o comportamento da temperatura do hipotálamo em função do tempo para quatro cenários, quais sejam, os dois itens descritos anteriormente mais o resfriamento de sangue via cateter e resfriamento de sangue extracorpóreo. É possível notar que a temperatura decresce mais rapidamente no resfriamento de sangue extracorpóreo.

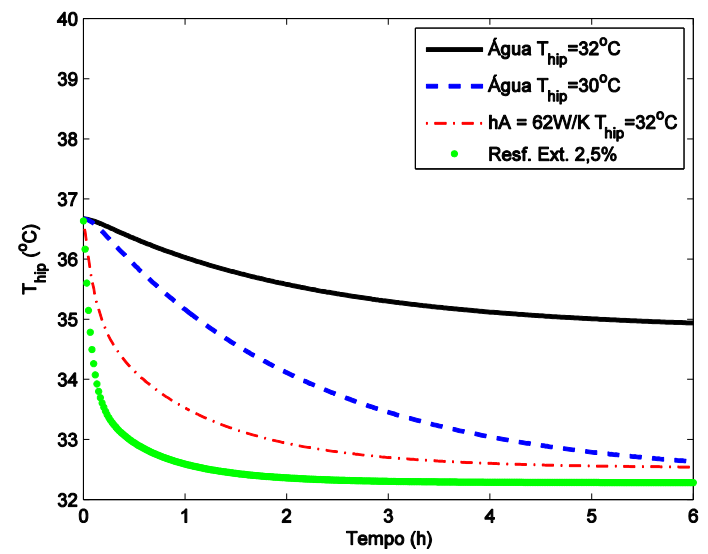

Figura 4.32: Temperatura do hipotálamo para o resfriamento da pele com água sob temperaturas de $32,30^{\circ} \mathrm{C}$, comparando-se às outras duas técnicas de resfriamento

\subsubsection{Comparação dos métodos de resfriamento}

A Figura 4.33 indica a exergia destruída e a eficiência exergética para as técnicas citadas anteriormente, durante o resfriamento. É interessante notar que o princípio do resfriamento de sangue extracorpóreo é a retirada e o retorno de um fluxo de entalpia do volume de controle; como consequência a exergia destruída do corpo é menor e a eficiência exergética é maior devido às menores irreversibilidades dessa técnica. O cateter intravenoso tem como principio um resfriamento a partir de um fluxo de calor retirado do sangue, o que diminui a eficiência exergética da técnica em relação ao resfriamento de sangue extracorpóreo. O mesmo raciocínio pode ser feito comparando-se a inserção de um cateter com o resfriamento da pele o qual remove certa quantidade de calor do corpo pelo incremento do coeficiente de transferência de calor por convecção e redução da temperatura do fluido em contato com a pele. No entanto o fator de Carnot da pele com o ambiente é muito pequeno, ou seja, a exergia removida do corpo nessa técnica é menor do que nas outras técnicas, tornando-a menos eficaz, limitando sua aplicação (eficiência 
exergética do corpo durante a aplicação dessa técnica é muito pequena). Tal fato, justifica que ela seja sempre usada como complementar das outras técnicas de resfriamento.
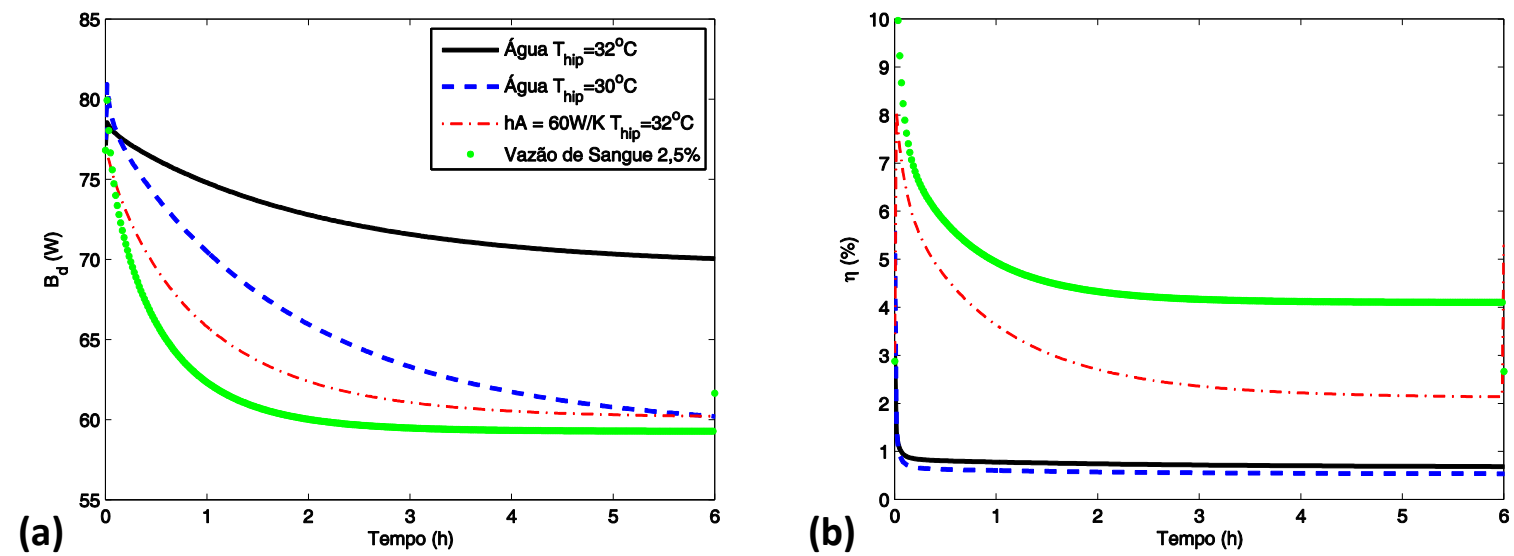

Figura 4.33: (a) Exergia destruída; (b) rendimento exergético para: o resfriamento da pele com água sob temperaturas de 32,30 e $15^{\circ} \mathrm{C}$, cateter intravenoso e resfriamento de sangue

Comparando-se as Tabelas 4.19 e 4.20, foi possível obter informações adicionais à exergia destruída e à eficiência exergética. Processos mais lentos tendem a ter uma razão entre fluxo de exergia de resfriamento/reaquecimento maior. O cateter intravenoso mostrou possuir um valor de aproveitamento maior, o que pode ser explicado pela menor taxa de resfriamento e reaquecimento, portanto, sendo mais recomendado, pois, para induzir o retorno da hipotermia. Esse índice pode ser usado como critério para escolha do parâmetro de reaquecimento, pois reaquecimentos rápidos podem acarretar problemas relacionados à volta da pressão, aumento da perfusão de sangue, dentre outros. Obviamente, o modelo não pode identificar tais efeitos do reaquecimento rápido em variáveis como pressão arterial, fornecimento de oxigênio ao cérebro, no entanto, esse tipo de análise pode explicar qual parâmetro é mais eficiente sob o ponto de vista da Primeira e Segunda Leis da termodinâmica. Análises mais detalhadas precisariam de resultados experimentais e medições dessas variáveis.

\subsection{ANÁLISE EXERGÉTICA DA ATIVIDADE FÍSICA}

Com base nos dados experimentais (Seç̧ão 3.5) foram obtidos os resultados das Figuras 4.34 a 4.41, nas quais os corredores foram divididos em três grupos, baixa (azul), média (vermelho) e alta (verde) virada de lactato (VL) ou limiar de lactato (LL). Os pontos indicam os valores médios para o último minuto de cada nível de atividade física (as linhas entre os pontos são para representar a tendência para o mesmo corredor). Escolheram-se esses pontos, pois indicam um tempo suficiente para estabilização das variáveis fisiológicas. 
Segundo Mountcastle (1974), na literatura médica existe uma convenção de que após três minutos de atividade as funções vitais do corpo se estabilizam. Para melhorar a clareza dos gráficos, os períodos que não são usados para obtenção de indicadores não estão nos gráficos (início, aquecimento e recuperação). As legendas dessas Figuras destacam os corredores do menor valor de LL (1) ao maior valor de LL (11), ou seja, do corredor menos treinado para o mais treinado.

As Figuras 4.34(a) e 4.34(b) mostram os resultados de temperatura interna e da pele dos corredores decorrentes da velocidade do teste para corredores na esteira. O primeiro e o último pontos da temperatura interna do corpo (Figura 4.34(a)) foram medidos; os outros, calculados pelo balanço de energia. Tal procedimento se deve à própria medição da temperatura timpânica (usada como representativa da interna) que atrapalha o corredor ou exige uma pausa na atividade. A tendência das curvas são similares, no entanto, nos corredores com baixo LL se observa uma inclinação menor de aumento de temperatura do que os outros grupos. A Figura 4.34(b) evidencia a temperatura média da pele medida, ponderada pela área superficial do membro. A temperatura da pele é dependente das condições ambientais em que o teste ocorreu. Além disso, houve uma pequena variação durante o teste (exceção ao corredor 4, cuja temperatura varia entre $\left(29\right.$ e $\left.33^{\circ} \mathrm{C}\right)$. O corredor 1, com menor LL, foi o que atingiu temperaturas maiores. Deve-se destacar que esses resultados foram obtidos para corredores na esteira, ou seja, a velocidade do ar não muda em função da velocidade do teste. Provavelmente se o teste fosse realizado em um ambiente externo, a temperatura da superfície da pele seria mais dependente da velocidade de corrida.
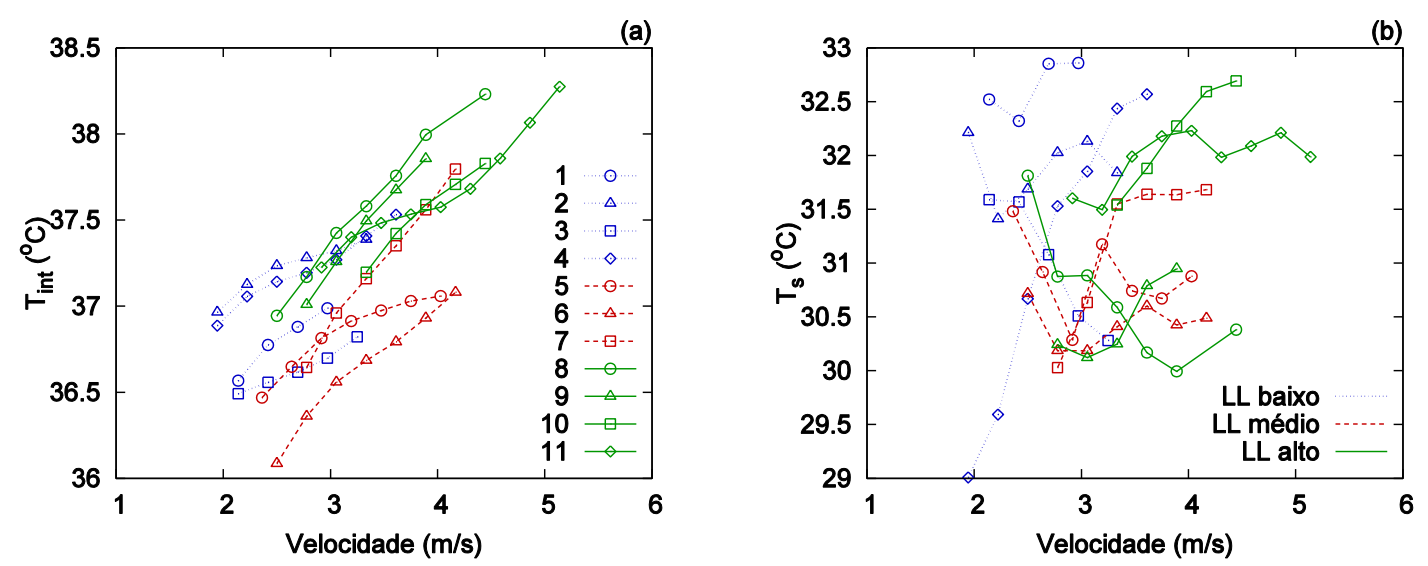

Figura 4.34: (a) Temperatura interna; (b) temperatura da pele em função da velocidade do teste para corredores na esteira

Assim como na condição basal (Tabela 4.17) em que as trocas energéticas com o meio ambiente apresentavam uma ordem de grandeza a mais que as trocas exergéticas, a Figura 4.35 indica o mesmo resultado para diferentes níveis de velocidade. O corredor 1 (menor LL) foi o que apresentou as maiores trocas de energia e exergia com o meio ambiente. Na Figura 4.35(b), verifica-se que, para uma mesma velocidade, os corredores com maiores LL 
têm uma menor troca de exergia com o ambiente do que aqueles com médio e baixo LL. Tal constatação pode estar relacionada com o tempo decorrido de atividade até chegar a uma determinada velocidade, porque esses últimos corredores começam a uma velocidade mais baixa. Para o balanço de energia (Figura 4.35(a)), porém, o mesmo resultado não é verificado. O fluxo de exergia do corredor com menor LL é comparativamente maior que o dos outros corredores, não respeitando novamente a tendência.
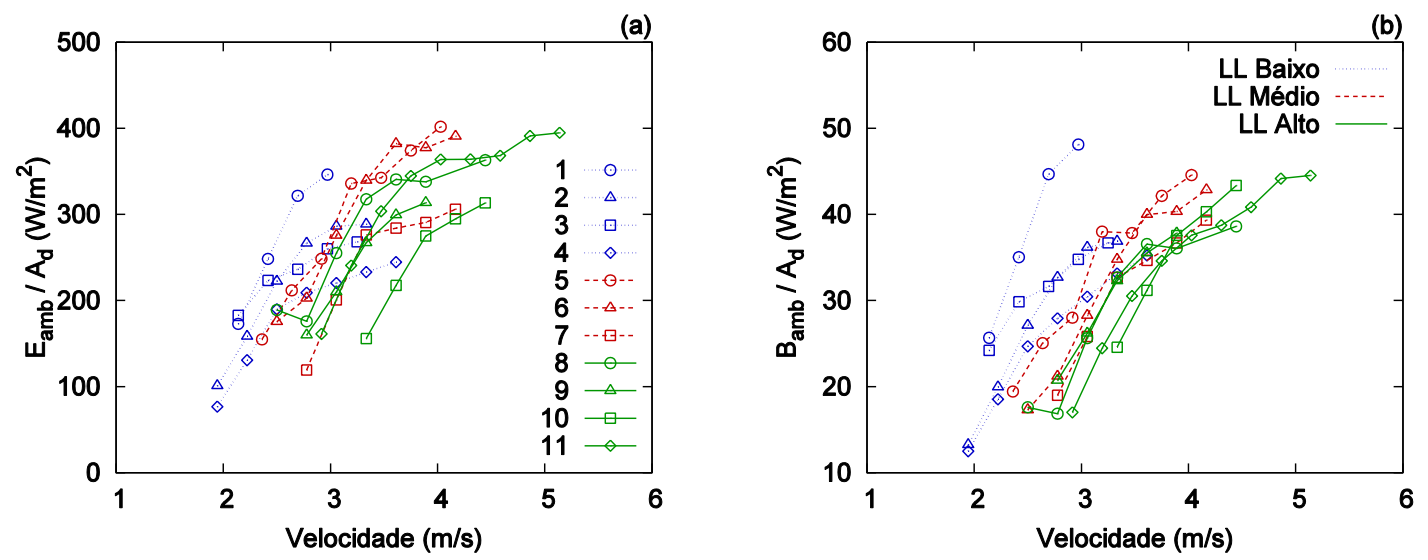

Figura 4.35: (a) Fluxo de energia liberado para o ambiente (convecção, radiação, vaporização e respiração); (b) Fluxo de exergia liberado para o ambiente (convecção, radiação, vaporização e respiração) em função da velocidade do teste

Os fluxos para o ambiente devido à radiação, à convecção, à vaporização e à respiração, em função da velocidade do teste, estão indicados na Figura 4.36. Na condição basal, os fluxos devidos à radiação e convecção apresentam valores próximos aos da vaporização e da respiração (Tabela 4.17). Contudo, pode-se notar que durante a atividade física esse resultado não é mais verdadeiro, o que pode ser explicado pelo aumento da sudorese e da ventilação pulmonar. A vaporização tende a um valor limite, provavelmente relacionado com a saturação de suor pela pele. Outro comentário que deve ser feito refere-se aos termos relacionados à respiração que em razão de um aumento da ventilação, consumo de oxigênio e produção de gás carbônico passaram a ser dominantes.
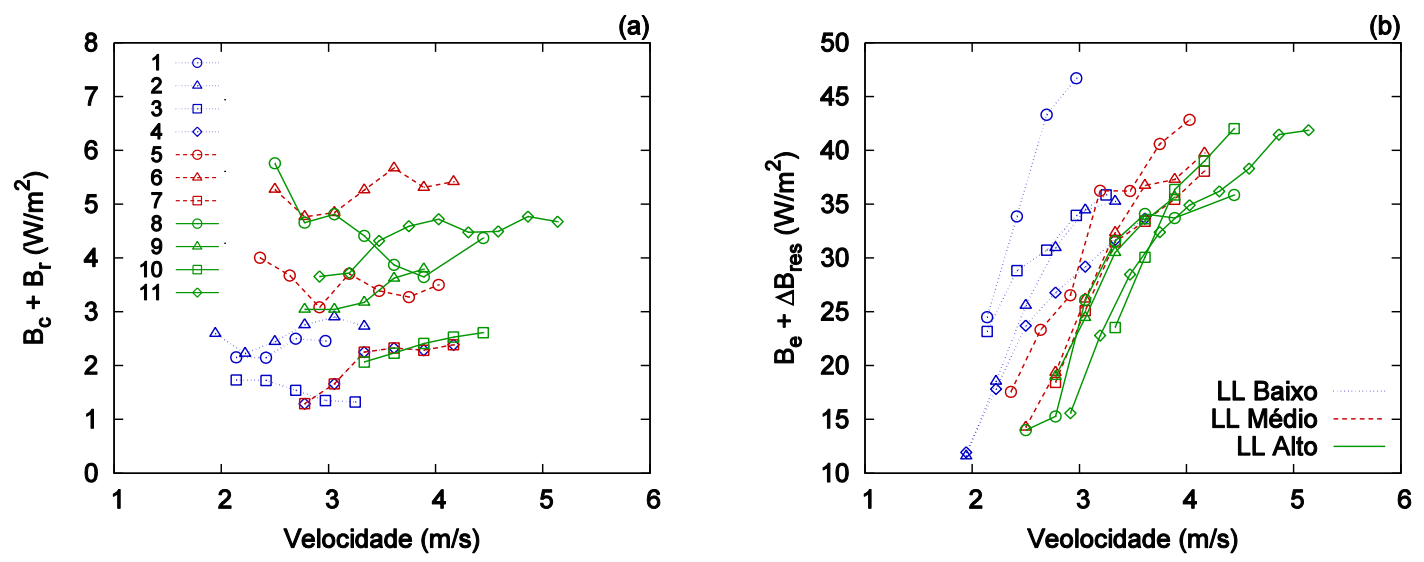

Figura 4.36: (a) Fluxos de exergia devido à radiação e convecção; (b) exergia associada à vaporização e respiração em função da velocidade do teste 
A Figura 4.37(a) indica o metabolismo exergético por unidade de massa para cada corredor em função da velocidade do teste. Novamente, o corredor 1 destaca-se em relação aos outros do mesmo grupo por possuir o maior metabolismo exergético para uma mesma velocidade. Pode-se observar que todos os corredores têm a mesma tendência linear de aumento do metabolismo. A Figura 4.37(b) indica a exergia destruída como função da velocidade, cuja tendência de crescimento é similar ao crescimento do metabolismo. Mais uma vez, o corredor 1 apresenta a maior magnitude, no caso, de exergia destruída; e analisando a Figura 4.37(c), esse corredor possui a maior razão entre exergia destruída e metabolismo, o que pode significar que esse corredor, por ser menos treinado, é menos adaptado a exercícios físicos mais intensos (teria um menor rendimento). Da Figura 4.37 (c) ainda se pode concluir que a razão $B_{d} / B_{M}$ não varia de forma significativa em função da velocidade do teste. A partir desses gráficos pode-se observar que a exergia destruída não agregou informação nova sobre o comportamento do corpo durante atividade física em relação ao balanço de energia, expondo tendência similar ao metabolismo (o que justifica a a razão $B_{d} / B_{M}$ não variar significativamente). No entanto, a análise exergética leva em conta a qualidade no processo de conversão de energia, podendo-se usar o conceito do cálculo de rendimento exergético para avaliação.
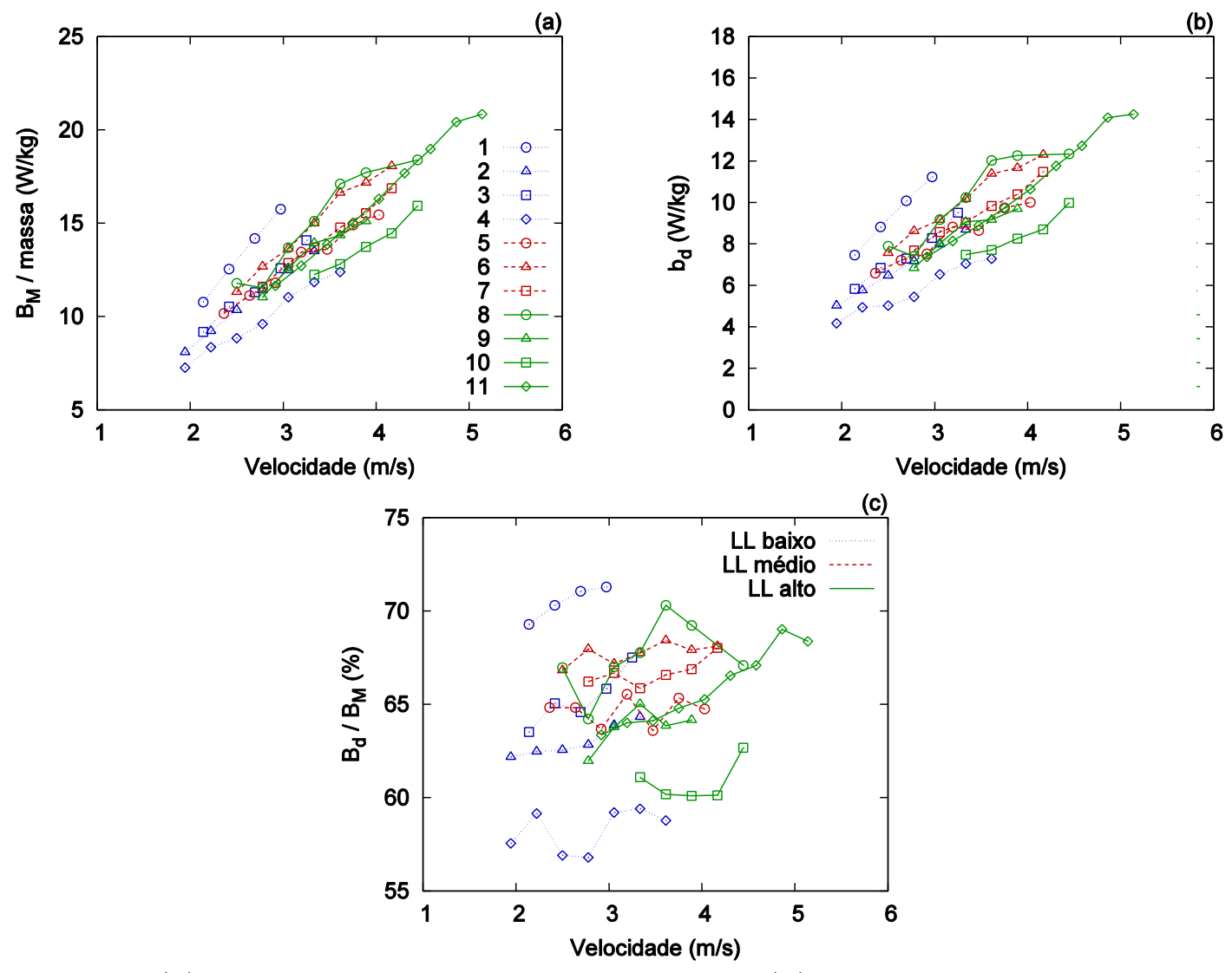

Figura 4.37: (a) Metabolismo exergético por massa; (b) exergia destruída por massa; e (c) razão entre a exergia destruída e metabolismo exergético em função da velocidade do teste

A Figura 4.38 demonstra o rendimento energético líquido (a), o rendimento exergético 
(b), a razão entre estes dois rendimentos (c) e a razão entre o rendimento exergético e energético calculado da forma convencional $(\eta=W / M)(\mathrm{d})$, em função da velocidade. Nota-se que, para a grande maioria dos corredores, há uma tendência de diminuição da eficiência exergética com o aumento da velocidade, o que parece um contrassenso. Entretanto, há um aumento do metabolismo concomitante e um aumento das irreversibilidades associadas às reações de oxidação. O corredor 1 detém o menor rendimento energético e exergético, como constatado pela Figura 4.37(c). Na condição basal, na qual a eficiência energética é nula (ou próxima de zero), o rendimento exergético variou entre 1 e 15\%, e durante atividades físicas esse valor variou entre 30 a $45 \%$. Portanto, houve um expressivo aumento dessa grandeza. Uma comparação entre as Figuras 4.38 (a) e (b) mostra uma tendência similar. Porém, ao analisar a Figura 4.38 (c), vê-se que a razão entre as eficiências tende a um valor máximo, sendo a eficiência energética líquida sempre maior, pois o denominador da expressão é o termo $M-M_{0}$ que é menor do que $B_{M}$. Todavia, a Figura 4.38 (d) indica a eficiência exergética maior do que a energética. Explica-se tal fato pelos fluxos de exergia para o ambiente somados ao trabalho realizado que aumentam a eficiência exergética. Novamente a análise exergética não agregou informações novas com relação à analise de Primeira Lei para os corredores durante atividade física. Ao contrario da condição basal em que a eficiência exergética equivale à razão $B_{\text {env }} / B_{M}$, agregando novas informações ao balanço de energia, na Figura 4.37(c), a eficiência exergética equivale a $\left(B_{e n v}+W\right) / B_{M}$, tendo o trabalho executado ordem de grandeza maior do que a dos fluxos de exergia para o ambiente. Ademais, passa a ser lógico que a eficiência energética seja menor que a exergética, porque na primeira a potência executada pelo corredor é o único termo. Assim, a Figura 4.38 motiva uma análise mais detalhada dos termos da análise exergética, o que será exposto na próxima seção.

\subsubsection{Termos da análise exergética em função do tempo e integração numérica}

A Figura 4.39 mostra uma comparação entre o metabolismo exergético $\left(B_{M}\right)$, a variação da energia livre de Gibbs na hidrólise do ATP $\left(W_{\max }\right)$, o fluxo de exergia liberado para o corpo pelo metabolismo $\left(B_{Q_{M}}\right)$. Comparando-se $B_{M}$ com $W_{M A X}$, verifica-se que aproximadamente $60 \%$ da capacidade de realização de trabalho dos macronutrientes $(\Delta B$ das reações de oxidação dos macronutrientes) são retidos na mólecula de ATP, enquanto o restante é destruído ou eliminado para o corpo na forma de um fluxo de exergia relacionado à uma forma de calor. Se o ATP for usado para realização de trabalho, esses $60 \%$ poderão resultar em fenômenos organizados como atividade física, síntese proteica, crescimento, 

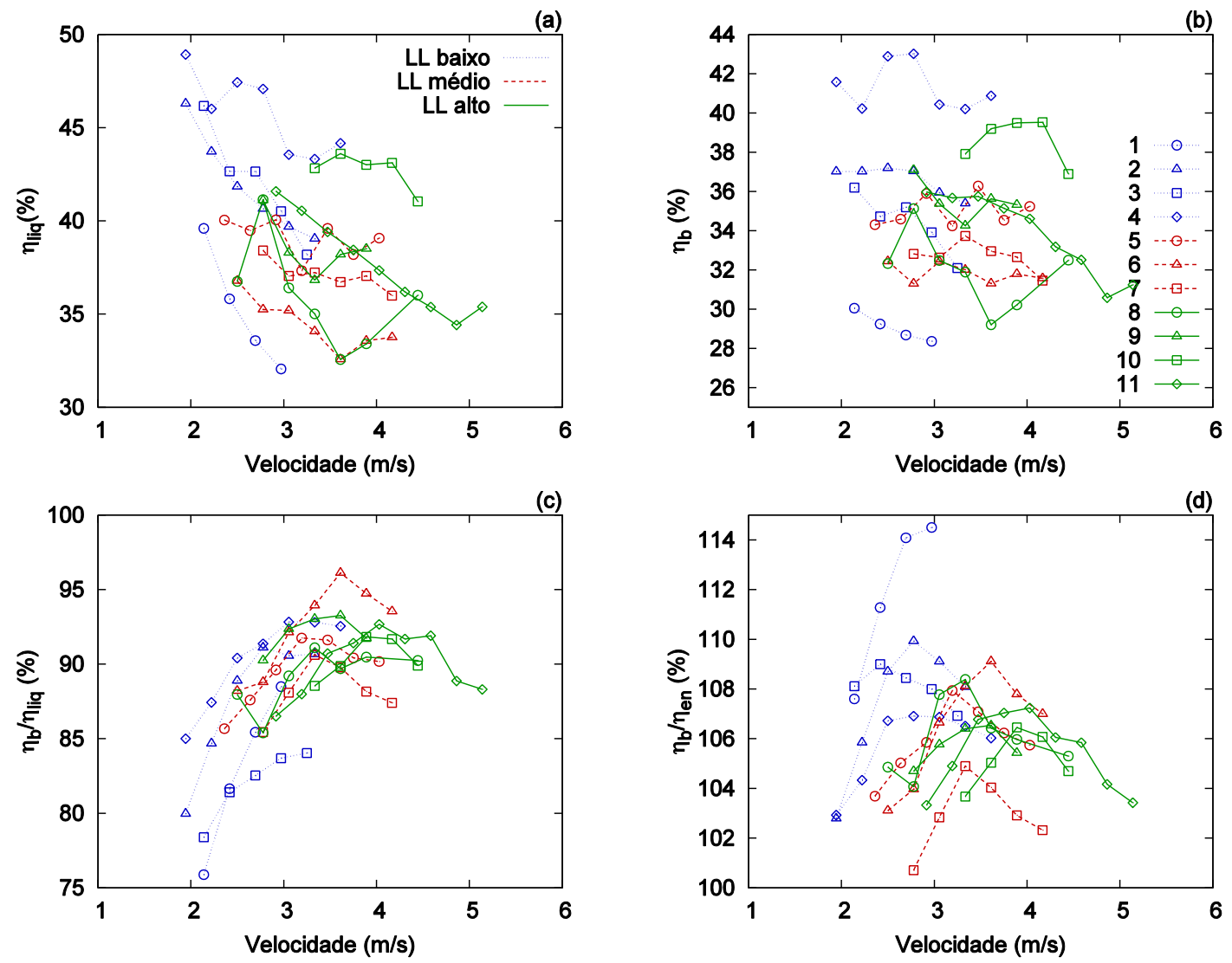

Figura 4.38: (a)Eficiência energética líquida; (b) eficiência exergética; (c) razão entre as eficiências exergética e energética líquida; e (d) razão entre as eficiências exergética e energética em função da velocidade do teste

dentre outros. Caso contrário, esse restante será eliminado para o corpo na forma de calor e/ou destruído. Usualmente, na literatura, tem-se considerado o metabolismo como uma fonte de calor, embora seja possível notar na Figura 4.39 que, ao conservar a energia dos nutrientes na forma de ligações químicas da molécula do ATP, existe uma conservação maior da exergia consumida dos nutrientes, ou seja, um aumento na capacidade de realização de trabalho do corpo se compararmos com o $B_{Q_{M}}$, que corresponde a menos de $5 \%$ da exergia contida nos nutrientes (resultaria em rendimentos exergéticos maiores do que a unidade).

A Figura 4.40 demonstra a razão entre a exergia destruída e o metabolismo exergético (a); eficiência exergética (b); as razões entre os fluxos de exergia para o ambiente e para o corpo com o metabolismo (c); e a razão entre o trabalho realizado com o metabolismo em função do tempo, para o corredor 11.

Para as condições basais $(W=0$ ), a exergia destruída equivale a $95 \%$ da exergia metabólica. Conforme o corredor inicia a atividade (a partir dos 5 minutos), o aumento percentual do trabalho faz com que a participação relativa da exergia destruída diminua de forma "simétrica" ao incremento do trabalho. Nota-se que, após a atividade (5 minutos finais), a participação percentual da exergia destruída se torna menor do que antes da 


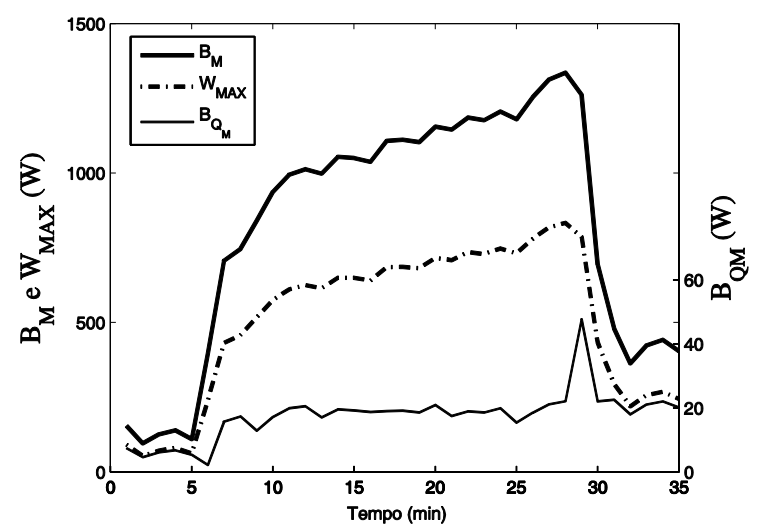

Figura 4.39: Metabolismo exergético, trabalho máximo que pode ser executado pelo corpo (variação da energia livre de Gibbs na hidrólise do ATP) e fluxo de calor causado pelo metabolismo em função do tempo

atividade, o que pode ser justificado pelo alto fluxo de exergia para o ambiente causado pela adaptação do corpo à atividade. Assim, pode-se afirmar que o ser humano sob condições basais, depois da atividade física, é mais eficiente do que antes da atividade (mesmo que por curto periodo de tempo). O trabalho máximo que pode ser realizado pelo corpo, em toda a atividade, equivale a aproximadamente $60 \%$ do metabolismo exergético, visto que esse rendimento depende exclusivamente das eficiências metabólicas e durante atividade física predomina o consumo de carboidratos e lipídeos cujo $\eta_{M}$ equivale a $60 \%$. Já a Figura 4.40(c) mostra que a participação relativa de $B_{\text {env }}$ sofre um aumento em relação à participação de $B_{Q_{M}}$, a partir da metade do teste. A justificativa desse incremento é a sudorese e respiração (transferenência de massa), que atingem valores máximos nesses periodos (Figura 4.36). Observa-se que a participação percentual de $B_{Q_{M}}$ é maior em condições baisais do que durante atividade física (tanto no começo quanto após o termino da atividade).

A partir das Figuras 4.39 e 4.40, é possível afirmar que, necessariamente, $40 \%$ da exergia contida nos macronutrientes é dissipada na forma de calor para o resto do corpo ou destruída; o restante é usado na formação da molécula de ATP a partr do ADP e $\mathrm{P}_{i}$. Se o corredor estiver sob condições basais, o valor de exergia destruída equivale a aproximadamente $95 \%$ da exergia metabólica, e o restante é eliminado para o corpo na forma de fluxo, $B_{Q_{M}}$, e para o ambiente na forma de fluxo, $B_{a m b}$. Já, pela conservação de energia e sob condições basais, $100 \%$ da energia será liberada na forma de calor para o corpo $\left(Q_{M}\right)$ e para o ambiente $\left(E_{a m b}\right)$ na forma de fluxos de calor $\left(Q_{c}, Q_{r}\right)$ e entalpia $\left(\Delta H_{\text {res }}, H_{e}\right)$. No entanto, apesar de esse calor ser um resíduo do metabolismo e ser dissipado, ele deve ser tratado como um produto das oxidações, pois é ele que garante que a temperatura do corpo se mantenha constante.

Integrou-se os termos do balanço de exergia usando-se o método dos trapézios desde o início do teste (tempo de atividade mais o tempo de repouso inicial), a partir do 

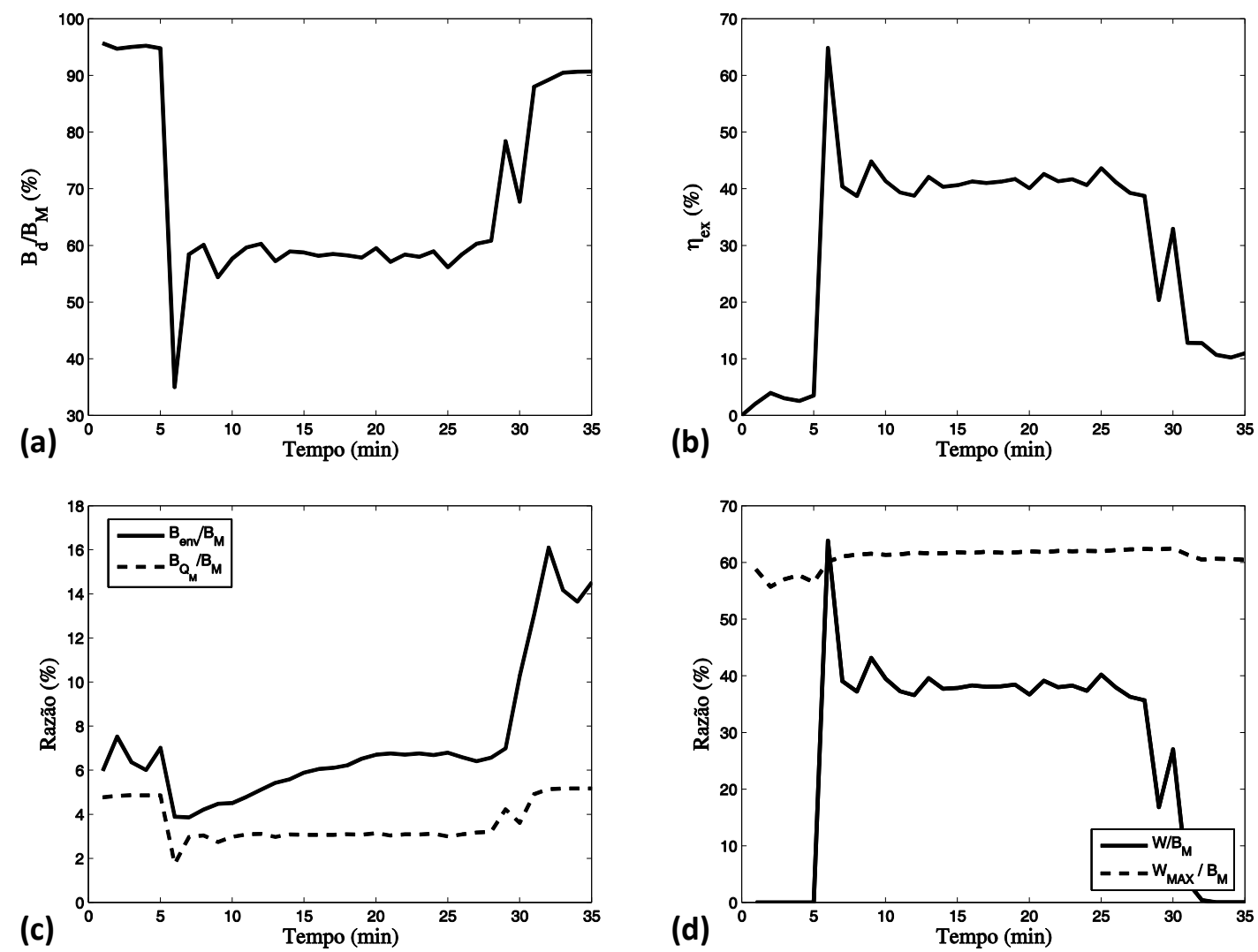

Figura 4.40: Para o corredor 11: (a) razão entre a exergia destruída e a exergia metabólica; (b) rendimento exergético; (c) Razão entre o fluxo de exergia para o ambiente e fluxo de exergia associado ao metabolismo com a exergia metabólica; (d) trabalho realizado e exergia metabólica

qual é possível obter a Tabela 4.21. Nota-se que a exergia transferida para o ambiente e a variação da exergia são de ordem de grandeza inferiores à exergia destruída e ao metabolismo exergético. Para todos os corredores $B_{a m b}$ não corresponde a mais do que $7 \%$ do metabolismo exergético, resultado que também foi obtido para as simulações para uma pessoa nas condições basais. Finalmente, o rendimento exergético de todo o teste variou entre 30 e 45\%. Para o caso basal proposto por Batato et al. (1990), o rendimento durante todo o experimento não chegou a 1\%. Caso somente a parcela do fluxo de exergia relacioanada ao metabolismo fosse usada, o valor de trabalho da Tabela 4.21 seria maior que $B_{Q_{M}}$ (Tabela 4.5), o que resultaria em produtos (considerando o trabalho executado como um dos produtos do metabolismo) com magnitudes maiores que a dos combustíveis , ou seja, rendimento exergético maior do que a unidade. O uso desse termo como fonte de exergia para o corpo, portanto não é apropriado. Nota-se ainda que o fluxo de exergia para o ambiente $\left(B_{\text {env }}\right)$ é maior do que $B_{Q_{M}}$. O primeiro leva em conta os fluxos de calor e massa, enquanto que o segundo se refer somente a transferência de calor, justificando a diferença de magnitudes, contudo pela Primeira Lei da Termodinâmica $Q_{M}=E_{a m b}$.

Correlacionando-se a razão da exergia destruída com o metabolismo exergético, durante a atividade física, em decorrência da idade do corredor, confirma-se que há uma tendência 
Tabela 4.21: Duração do teste, metabolismo exergético, fluxo de exergia para o ambiente, variação da exergia, exergia destruída e trabalho executado integrados por todo o período do teste por unidade de massa para os corredores (1 a 11). Na última coluna, estão indicadas as eficiências exergéticas para todo o teste

\begin{tabular}{|cc|cccccc|}
\hline - & Dur. (min) & $B_{M}(\mathrm{~J} / \mathrm{kg})$ & $B_{a m b}(\mathrm{~J} / \mathrm{kg})$ & $\Delta \mathbf{B}(\mathrm{J} / \mathrm{kg})$ & $B_{d}(\mathrm{~J} / \mathrm{kg})$ & $W(\mathrm{~J} / \mathrm{kg})$ & $\eta_{b}(\%)$ \\
\hline 1 & 29,5 & 17307 & 1400 & 57 & 11601 & 4870 & 33 \\
2 & 34,0 & 17897 & 1160 & 72 & 10897 & 6363 & 39 \\
3 & 29,0 & 16150 & 1130 & 68 & 10299 & 5232 & 36 \\
4 & 36,0 & 17308 & 1042 & 117 & 9771 & 6956 & 44 \\
5 & 43,5 & 27712 & 1815 & 103 & 18383 & 8381 & 34 \\
6 & 42,5 & 30951 & 1894 & 89 & 20571 & 9435 & 34 \\
7 & 41,5 & 26019 & 1532 & 125 & 16718 & 8584 & 36 \\
8 & 42,5 & 30351 & 1745 & 101 & 20079 & 9428 & 34 \\
9 & 37,0 & 23037 & 1348 & 223 & 15224 & 7001 & 34 \\
10 & 35,0 & 21343 & 1416 & 169 & 13285 & 7229 & 38 \\
11 & 52,5 & 43504 & 2661 & 146 & 28937 & 13277 & 33 \\
\hline
\end{tabular}

desta razão de diminuir com o envelhecimento, o que é similar aos resultados indicados na Figura 4.5 para condição basal. Contudo, o rendimento exergético aumentou como função da idade, diferente da condição basal em que tanto a exergia destruída quanto o rendimento exergético diminuem com o passar da vida. Tal resultado levanta indícios que a prática regular de exercício pode levar a um aumento da eficiência, pelo ponto de vista da Segunda Lei, com o passar da vida. Esse resultado de aumento da eficiência pode ser particular aos corredores com certo nível de treinamento.
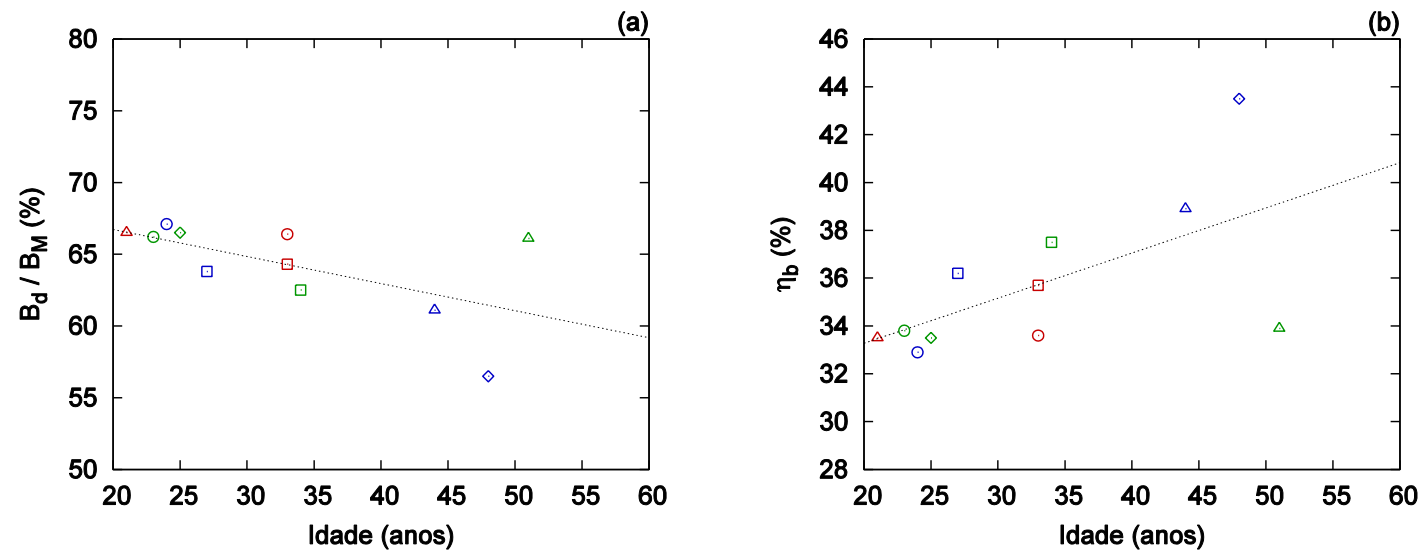

Figura 4.41: (a) Razão entre exergia destruída e exergia metabólica; (b) rendimento exergético como função da idade

A Tabela 4.22 indica os termos do balanço de exergia para os 11 corredores integrados somente nos 5 minutos iniciais, nos quais os corredores estavam em repouso. É interessante notar que a razão entre a exergia destruída e a exergia metabólica é praticamente constante (variação de apenas 3\%). Ou seja, quando no estado basal, o corpo deixa de aproveitar cerca de $96,5 \%$ (com desvio padrão de 0,9\%) da exergia dos marconutrientes, e o restante da exergia é trocado com o ambiente. A variação da exergia do corpo nesse período é muito pequena se comparada com a exergia destruída, porque o corredor, durante os 
cinco minutos iniciais, não está obrigatoriamente na neutralidade térmica, mas pode estar a uma temperatura abaixo ou acima daquela que corresponderia a neutralidade térmica.

Tabela 4.22: Tempo em repouso, razão entre a exergia destruída, trabalho executado, fluxo de exergia para o ambiente e variação da exergia com a exergia metabólica durante os cinco minutos iniciais do teste

\begin{tabular}{|cc|cccc|}
\hline Corredor & Tempo $(\min )$ & $B_{d} / B_{M}(\%)$ & $W_{c} / B_{M}(\%)$ & $B_{a m b} / B_{M}(\%)$ & $\Delta \mathbf{B} / B_{M}(\%)$ \\
\hline 1 & 5 & 95,7 & 0 & 2,9 & 1,1 \\
2 & 5 & 96,1 & 0 & 4,0 & $-0,2$ \\
3 & 5 & 96,1 & 0 & 2,6 & 0,9 \\
4 & 5 & 96,3 & 0 & 2,0 & 1,2 \\
5 & 5 & 96,5 & 0 & 4,6 & $-0,7$ \\
6 & 5 & 97,6 & 0 & 6,7 & $-4,7$ \\
7 & 5 & 97,1 & 0 & 2,6 & 0,0 \\
8 & 5 & 98,1 & 0 & 5,7 & $-3,7$ \\
9 & 5 & 96,4 & 0 & 3,3 & 0,1 \\
10 & 5 & 95,1 & 0 & 2,6 & 1,9 \\
11 & 5 & 96,8 & 0 & 5,0 & $-2,3$ \\
\hline
\end{tabular}

O máximo trabalho que o corpo pode executar a partir da energia contida nas moléculas de ATP foi calculado com a Equação 3.32 e com os valores de propriedades termodinâmicas proposto na Tabela 3.2 (adaptados e fornecidos por Cortassa et al. (2002)). A Tabela 4.23 indica os valores desse potencial, assim como o número de mols que devem sofrer hidrólise a fim de gerar energia para satisfazer esse potencial (lembrando que o $\Delta g_{A T P}=$ $-56 \mathrm{~kJ} / \mathrm{mol}$ ). Nota-se que o valor calculado de $W_{\max }$ é quase o dobro do trabalho apresentado na Tabela 4.21. Da mesma maneira que se verificou para o teste completo, levando-se em conta todos os corredores, em média 61,4\% (com desvio padrão de 0,3\%) da exergia é conservada nas ligações químicas do ATP, sendo o restante liberado para o corpo na forma de calor. Se o indivíduo estiver em condições basais, os $61,4 \%$ tambéms serão liberados na forma de calor ou utilizados para fenômenos organizados (síntese proteica, crescimento, bomba sódio potássio), no entanto, uma análise dos estudos de Hardy e DuBois (1938), Hardy et al. (1938), Hardy e DuBois (1940), Hardy et al. (1941), DuBois et al. (1952) para condições basais, indica que $Q_{M} \rightarrow M$.

\subsection{ANÁlisE DOS PRODUTOS DO METABOLISMO: CONDIÇÕES BASAIS E DURANTE ATIVIDADE FÍSICA}

Ao se analisar o metabolismo como um processo de conversão de energia, pode-se afirmar que resultam das reações químicas: a formação da molécula do ATP e o calor $Q_{M}$ transferido para o corpo. Mesmo que seja um "resíduo" das reações de oxidação dos 
Tabela 4.23: Número de mols consumidos de ATP durante atividade física e máximo trabalho que se pode realizar na hidrólise dessa quantidade

\begin{tabular}{|cc|ccc|}
\hline Corredor & Dur. (min) & $n_{\text {atp }}(\mathrm{mols})$ & $W_{\max }(\mathrm{J} / \mathrm{kg})$ & $W_{\max } / B_{M}(\%)$ \\
\hline 1 & 29,5 & 0,19 & 10891 & 61,6 \\
2 & 34 & 0,20 & 11148 & 61,0 \\
3 & 29 & 0,18 & 10160 & 61,4 \\
4 & 36 & 0,19 & 10788 & 61,2 \\
5 & 43,5 & 0,31 & 17375 & 61,7 \\
6 & 42,5 & 0,34 & 19299 & 61,4 \\
7 & 41,5 & 0,29 & 16385 & 61,8 \\
8 & 42,5 & 0,34 & 18886 & 61,3 \\
9 & 37 & 0,26 & 14336 & 61,2 \\
10 & 35 & 0,24 & 13402 & 61,7 \\
11 & 52,5 & 0,48 & 27264 & 61,7 \\
\hline
\end{tabular}

macronutrientes, esse último termo garante que a temperatura do corpo permaneça constante, ou seja, garante a homeotermia. A Figura 4.42 indica a razão $B_{Q_{M}} / B_{M}$ (Equação 3.35) em função da velocidade e da idade (neste último são usados os valores integrados por todo o teste). Essa razão é a única grandeza calculada que diferenciou os corredores pelo nível de atividade (exceção a dois corredores, um com nível de treinamento alto e outro com nível médio). A mesma tendência pode ser vista em função do envelhecimento.
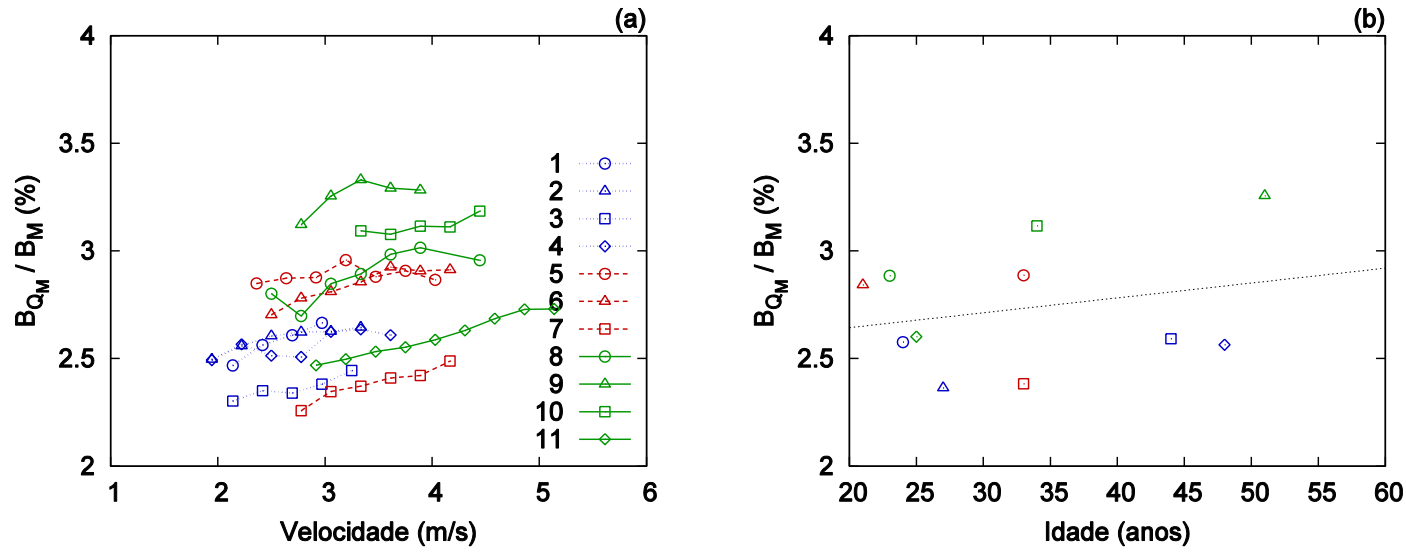

Figura 4.42: Razão entre o fluxo de exergia associado ao metabolismo com o metabolismo exergético: (a) em função da velocidade do corredor; (b) em função da idade do corredor

Para condições basais, a razão $B_{Q_{M}} / B_{M}$ (Equação 3.35) deve apresentar uma tendência linear em função dos parâmetros ambientais, ou seja, a razão da Equação 3.35 passa a ser apenas função do fator de Carnot, como confirmado pela Figura 4.43 e demonstrado pela Equação 4.5. Esse comportamento é justificado por: $W=0$ e $M / B_{M} \approx 1$. O ser humano é um animal homeotermo, portanto o modelo tende a manter a temperatura interna média constante em função dos parâmetros ambientais (válido para faixa de temperatura e umidade relativa analisada da Figura 4.10), assim o fator de Carnot passa a ser uma 
função linear da temperatura do ar, justificando a Figura 4.43.

$$
r=\frac{B_{Q_{M}}}{B_{M}}=\frac{(M-W)\left(1-\frac{T_{0}}{T_{m}}\right)}{B_{M}} \approx 1-\frac{T_{0}}{T_{m}}=a+b T_{0}
$$

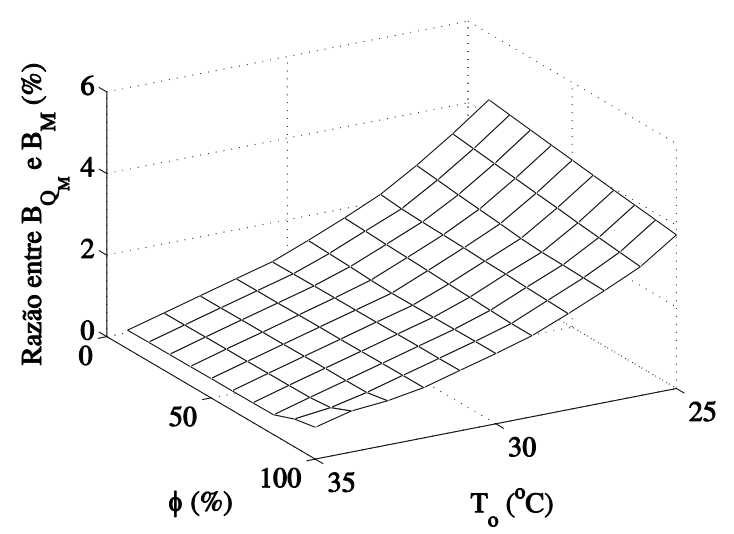

Figura 4.43: Razão entre o fluxo de exergia associado ao metabolismo com o metabolismo exergético para condições basais

Conforme exposto na Seção 3.5, o valor do trabalho calculado pelas diferentes equações da literatura pode variar significativamente. No entanto, a análise termodinâmica indica que para um dado metabolismo existe um potencial máximo para realização de trabalho. Variou-se, então, a razão entre o trabalho executado e o trabalho máximo para analisar o comportamento do corredor causados por diferentes "condições de operação". Assim foi possível obter a Figura 4.44 que compara os dois principais produtos do metabolismo celular $B_{Q_{M}}, W_{\text {MAX }}$ e $W$. Nessa figura, os pontos pretos indicam o valor para condição de trabalho calculado a partir da Equação 3.90, e se observa que ao integrar-se $B_{Q_{M}}$ no tempo de atividade e obtê-lo como uma taxa média durante o experimento, foi possível distinguir os corredores de acordo com o nível de treinamento. Portanto, para uma mesma proporção do trabalho máximo, corredores mais bem treinados apresentam uma dissipação maior de exergia. Mais ainda, para uma mesma dissipação de exergia os corredores mais bem treinados conseguem utilizar uma maior porcentagem de $W_{M A X}$. Já a Figura 4.44(b) indica a razão $W / W_{M A X}$ em função da razão $B_{Q_{M}} / B_{M}$, na qual, apesar de ocorrer uma certa distinção em relação ao nível de treinamento, a tendência não é tão bem definida como na Figura 4.44(a).

A exergia destruída é dependente do trabalho executado pelo corredor, pois demonstra o quanto da exergia consumida não foi convertida em trabalho e nem transferida para o ambiente. Por isso, na maioria dos processos, o objetivo deve ser minimizá-la. Para um mesmo metabolismo, quanto maior o trabalho menor será a exergia destruída. Tal afirmação pode ser confirmada pelas Figuras 4.45 (a) e (b): na primeira imagem é possível 

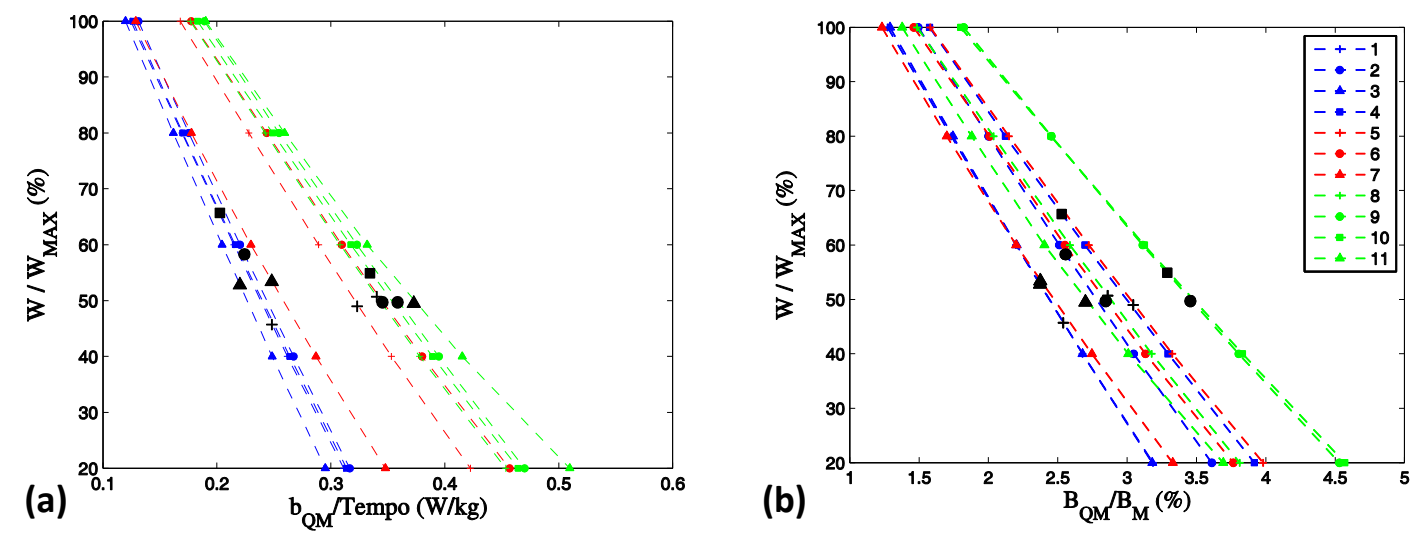

Figura 4.44: Razão $W / W_{M A X}$ em função da: (a) taxa média de dissipação de exergia associada ao metabolismo; (b) razão entre a taxa de dissipação de exergia e metabolismo exergético

notar, novamente, uma classificação em função do nível de treinamento do corredor. A Figura 4.45 (b) indica que de forma semelhante ao que ocorre na condição basal, a exergia destruída independe do nível de atividade física do corredor, sendo os que os valores praticamente não diferem.
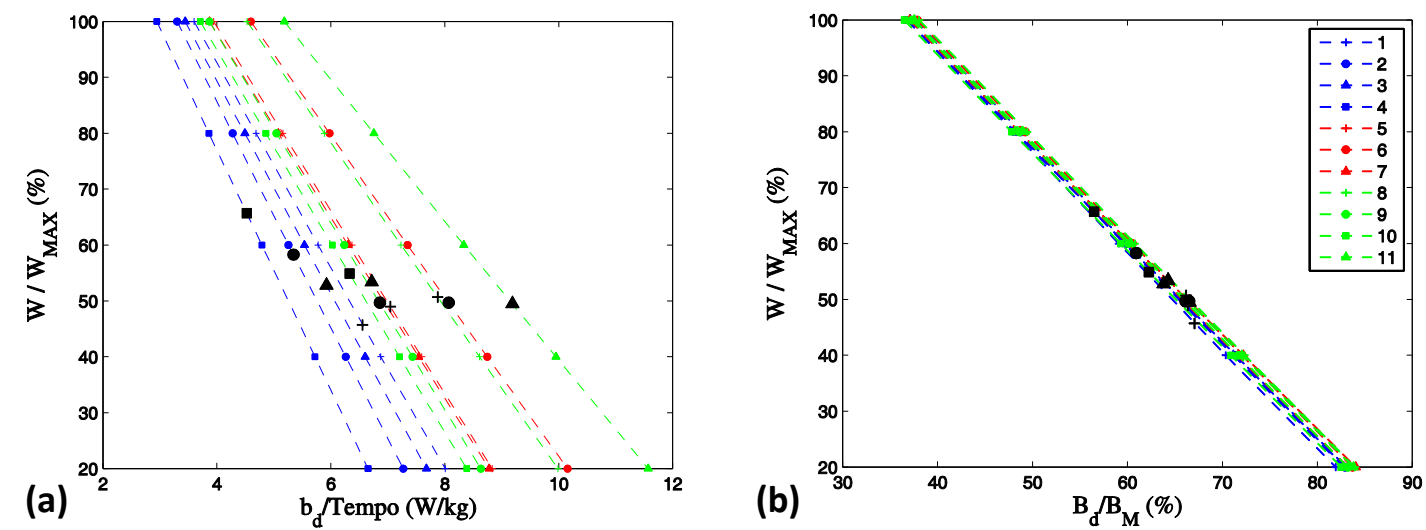

Figura 4.45: Razão $W / W_{M A X}$ em função da: (a) taxa média de destruição de exergia; (b) razão entre exergia destruída e metabolismo exergético

A partir das Figura 4.44(a) e 4.45(a) é possível inferir que para uma mesma taxa média de destruição de exergia $\left(B_{d}\right)$ e dissipação de exergia $\left(B_{Q_{M}}\right)$, a razão $W / W_{M A X}$ é tão maior quanto maior o nível de treinamento e para uma mesma razão $W / W_{M A X}$ a exergia destruída tende aumentar em função do nível de treinamento do corredor. Tais resultados podem ser explicados pela constatação de que quanto mais adaptada a práticas esportivas a pessoa estiver, ou seja, mais bem treinada, maior deve ser o metabolismo para uma mesma atividade, ou razão $W / W_{M A X}$. Portanto, maiores as irreversibilidades relacionadas as reações químicas, justificando $B_{Q_{M}}$ e $B_{d}$ serem maiores para uma mesma razão $W / W_{M A X}$. 


\section{CONCLUSÕES}

Neste texto foi proposto um modelo para obter o comportamento exergético do corpo humano, com o objetivo de se obterem indicadores relacionados à medicina, esportes e conforto térmico. O modelo abrange basicamente duas escalas, uma relacionada ao metabolismo celular e suas ineficiências para transformar os macronutrientes (carboidratos, lipídeos e proteínas) na moeda energética do corpo, denominada de ATP; e a segunda escala, que leva em conta órgãos, sistemas e o corpo em geral. É interessante notar que as duas formas de análise são complementares e integradas.

Este modelo foi aplicado àquele do sistema térmico proposto por Ferreira e Yanagihara (2009a) e para ensaios experimentais de corredores sujeitos a diferentes níveis de atividade física. Desses, foi possível calcular a exergia destruída e eficiência exergética para três casos bases: condição basal, atividades físicas na esteira e técnicas de hipotermia. Com base nos resultados da análise exergética, foram examinados os produtos do metabolismo, no qual foi proposta uma razão entre o fluxo de exergia relacionado ao metabolismo $\left(B_{Q_{M}}\right)$ com o metabolismo exergético $\left(B_{M}\right)$. Para os estudos da hipotermia foi proposto um outro índice que leva em contra o quanto da exergia fornecida no processo foi transformada em variação da exergia do corpo.

Assim, parte do modelo consiste no cálculo do metabolismo em base exergética, baseandose na reação de oxidação de três tipos de nutrientes (carboidratos, lipídeos e aminoácidos), para o qual foram propostas as Equações 4.2 e 4.4. Para condição basal, a razão entre o metabolismo em base energética e exergética não foi maior do que 3\%, o mesmo ocorrendo durante as atividades físicas.

A análise do metabolismo celular e da hidrólise do ATP leva à conclusão de que $60 \%$ $\left(W_{M A X} / B_{M}\right)$ da exergia dos macronutrientes é aproveitada para a síntese da substância conhecida como "moeda energética" do corpo, o ATP, a partir do ADP e do $\mathrm{P}_{i}$. A hidrólise dessa substância fornece um limite superior para capacidade de realização de trabalho pelo corpo, ou seja, a Termodinâmica pode se tornar uma ferramenta complementar para a biomecânica. Se o indivíduo estiver sob condições basais, a exergia contida na molécula de ATP é liberada na forma de um fluxo para o corpo $\left(B_{Q_{M}}\right)$ e destruída $\left(B_{d}\right)$. Caso esteja executando algum tipo de atividade, parte dessa exergia pode ser usada para realização de trabalho e a diferença entre o trabalho real e o máximo deve-se às ineficiências mecânicas e químicas inerentes ao corpo. Outras formas de uso do ATP são destinadas para fenômenos tratados pela literatura como "organizados", por exemplo, crescimento, bomba sódio potássio e funções vitais como débito cardíaco, respiração, dentre outros.

Apoiando-se no modelo de sistema térmico (para várias condições de metabolismo), foi 
possível constatar que a temperatura de neutralidade térmica é mínima para condição de máximo metabolismo (por volta dos 18 anos) e tende a aumentar com o envelhecimento (resultado válido para o modelo de Ferreira e Yanagihara (2009a) e simplificação). Inicialmente, a exergia destruída e o rendimento exergético foram obtidos em função da idade da pessoa. Essas duas grandezas físicas tenderam a diminuir com o envelhecimento, confirmando o princípio de mínima geração de entropia. Levando-se em conta o modelo de sistema térmico simplificado, concluiu-se que os fluxos de exergia para o ambiente, a exergia metabólica, a exergia destruída e o rendimento exergético tendem a diminuir indefinidamente, ou seja, do nascimento até o falecimento do indivíduo. Calculou-se que a exergia destruída durante uma vida equivale a $3091 \mathrm{MJ} / \mathrm{kg}$, para condições basais. O rendimento exergético para essa condição equivale à $3,5 \%$.

Para um adulto de idade média $(M=79,1 \mathrm{~W})$ e respectiva temperatura de neutralidade térmica $\left(T=30^{\circ} \mathrm{C}\right)$ - modelo de Ferreira e Yanagihara (2009a) - tanto o tronco como a cabeça foram as partes com maior valor de exergia destruída, sendo o tronco o de menor rendimento exergético. Membros mais periféricos apresentaram um menor rendimento exergético do que as regiões mais centrais. Na mesma temperatura, as contribuições exergéticas dos fluxos de calor e massa são uma ordem de grandeza menor que as contribuições energéticas, evidenciando que a análise exergética leva em conta a qualidade no processo de conversão de energia. Ao se realizar a mesma análise para diferentes condições de temperatura e umidade relativa, foi possível obter que o corpo torna-se mais eficiente em ambientes cujas temperaturas são mais elevadas e umidades relativas mais baixas. O corpo, também, é mais eficiente e destrói menos exergia sob temperaturas radiantes médias altas e temperaturas ambientes elevadas. As mesmas conclusões obtidas para o modelo nu são válidas para o vestido. No entanto, o uso de vestimenta diminui a exergia destruída para condições com menores temperaturas que a neutralidade térmica do modelo sem vestimenta e aumenta a exergia destruída para condições com maiores temperaturas que a neutralidade térmica do modelo sem vestimenta. Para umidades relativas entre 40 e 60\% (condições que reproduzem ambientes climatizados), as temperaturas cuja eficiência exergética é mínima e a destruição de exergia também é mínima, são as de neutralidade térmica. Tal resultado, evidencia que a análise exergética pode ser usada para análises de conforto térmico.

Além disso a análise exergética mostrou-se uma ferramenta poderosa na determinação das constantes do sistema de controle para determinada anatomia, pois ela fornece as condições de mínima destruição de exergia e máximo rendimento para condições próximas às adotadas no modelo. Essas constantes são aquelas que fornecem uma resposta a ambientes térmicos próximas das experimentais, ou seja, são aquelas usadas na validação do modelo. A única exceção está no aumento do metabolismo causado pela produção de tremores, no qual deve ser usado somente a destruição de exergia para a análise, pois o aumento do metabolismo leva a um consequente aumento da destruição de exergia. 
Ainda para o modelo proposto por Ferreira e Yanagihara (2009a), foi possível comparar diferentes técnicas de hipotermia descritas na literatura e ainda analisar os diferentes parâmetros de resfriamento de cada técnica pelo ponto de vista da análise exergética. Comparando-se resfriamento da pele, resfriamento via cateter intravenoso e resfriamento de sangue extracorpóreo, o último foi o mais eficiente e com menores taxas de destruição de exergia. Além do que, para uma mesma definição de eficiência exergética, o resfriamento de sangue extracorpóreo se mostrou com uma maior eficiência exergética do que as outras técnicas.

Cumpre acrescentar que na literatura médica existe o consenso de quanto mais rápido for o resfriamento e mais demorado o reaquecimento, melhor para o paciente sujeito a essa terapia. Nesse caso, a análise exergética indica que a pessoa entraria mais rapidamente em um estado de mínima geração de entropia e maior rendimento exergético. Já o reaquecimento mais rápido, apesar de levar a um estado de destruição de exergia maior, enquanto realizado, faz com que o paciente fique em um estado de maior eficiência exergética causado por um fluxo de exergia de entrada no corpo maior. O índice exergético mostrou que resfriamentos e reaquecimentos mais graduais alcançam um maior aproveitamento do corpo (variação da exergia) para uma quantidade de exergia retirada, podendo ser usado como avaliador da taxa de retorno da hipotermia e qual método fornece o melhor retorno para o paciente. O cateter intravenoso resultou em maiores valores desse índice para todos os parâmetros se comprado com o resfriamento extracorpóreo de sangue. Esse estudo mostrou que a análise termodinâmica de Primeira e Segunda Leis, colabora com a medicina para obtenção de de respostas do sistema térmico que, se fossem medidos em animais ou seres humanos, necessitariam de diversos experimentos invasivos. Além disso a abordagem Termodinâmica é uma forma racional para classificar os resultados em função da suas eficiências e índices exergéticos.

A análise de Segunda Lei foi ainda aplicada a corredores durante o teste cardiopulmonar, do qual foi possível concluir que, durante a atividade física, a temperatura interna do corpo tende a aumentar, no entanto a temperatura da pele permanece praticamente constante; fato que indica que a pele é mais sensível a variações das condições ambientes do que variações fisiológicas. Assim como para a condição basal, a transferência de energia para o ambiente é uma ordem de grandeza maior que a transferência de exergia. A transferência de exergia associada à radiação e à convecção possuíram a mesma ordem de grandeza da vaporização e respiração em condições basais. Durante a atividade física, as primeiras passam a ser menores do que as transferências de exergia associadas às outras formas. Esse resultado pode ser explicado pelo aumento da sudorese e da ventilação pulmonar, sendo a última proporcional ao metabolismo. Então a destruição de exergia tende a aumentar e a eficiência exergética tende a diminuir (em menor proporção) como função da velocidade do corredor. 
Foram integrados os diferentes termos da análise exergética para os corredores, durante todo o teste, e de forma similar ao que ocorre na condição basal, a razão da exergia destruída com o metabolismo exergético diminui com o envelhecimento. Em contrapartida, a eficiência exergética tende a aumentar como função da idade o que difere da condição basal. O rendimento exergético varia entre 30 e 45\% durante a atividade física, indicando um aumento expressivo em relação ao repouso (1 a 15\%).

Analisando o metabolismo com um processo de conversão de energia, foram realizadas comparações de seus produtos $W_{M A X}$ e $B_{Q_{M}}$, deduzindo-se que o primeiro corresponde a $60 \%$ de $B_{M}$, enquanto que o segundo apresentou uma tendência que classificou (exceção a dois casos) os corredores de acordo com o nivel de treinamento quando relacionado com a velocidade. Ainda foram integrados e transformados em taxa média os termos: $W$, $W_{M A X}$ e $B_{Q_{M}}$. O primeiro foi variado como porcentagens de $W_{M A X}$, pois não existe uma equação definitiva para esse cálculo na literatura. Chegou-se que para um mesmo $\dot{B}_{Q_{M}}$ médio corredores mais bem treinados possuiram uma maior capacidade de realização de trabalho. Esse resultados foram parcialmente repetidos para destruição de exergia, ou seja, para mesma exergia destruída, corredores mais bem treinados possuiram uma capacidade maior de realização de trabalho.

\subsection{SUGESTÕES PARA TRABALHOS FUTUROS}

Esse trabalho, junto com o mestrado de Henriques (2013) correspondem os primeiros passos do grupo (Laboratório de engenharia ambiental e térmica) no entendimento do corpo e suas irreversibilidades a partir da ótica da análise exergética. Como futuros trabalhos nessa linha, destacam-se:

(a) Analisar a entropia gerada por unidade de massa de uma vida ser uma constante. Essa análise envolveria uma abordagem mais detalhada das irreversibilidades do metabolismo celular e suas etapas. Podem ainda, ser realizados experimentos com corredores, pessoas com certo tipo de patologia, dentre outros. Assim poderão ser levados em conta tanto os efeitos negativos do aumento do metabolismo durante atividade física (aumento da entropia gerada), quanto os efeitos benéficos da prática esportiva (adaptação do corpo a prática de esportes).

(b) Comparar, a partir de experimentos, os pontos de mínima exergia destruída e mínimo rendimento exergético com indicadores de conforto térmico.

(c) Avançar na análise exergética do corpo durante atividade física para diferentes níveis de treinamento. Definir os parâmetros dos corredores de forma a igualar o trabalho realizado. 
Aumentar a quantidade de dados experimentais de corredores.

(d) Propor comparação, durante atividades, de pessoas com determinado tipo de patologia com pessoas saudáveis.

(e) Analisar pacientes sujeitos a um nível conhecido de atividade, por exemplo, em uma bicicleta ergométrica, para assim tentar entender o quanto de $W_{M A X}$ realmente é convertido em $W$ e quais as razões dessas irreversibilidades.

(f) Estudar um órgão, por exemplo, coração para tentar desenvolver um indicador de patologia baseado no conceito de geração de entropia e contribuir com diagnósticos de algum patologia.

(g) Tentar mudar a escala do modelo para o ambiente urbano. Outra linha de pesquisa que tem sido abordada na literatura é o uso da análise exergética no ambiente urbano, para assim propor indicadores relacionados com níveis de poluição e ilhas de calor. Portanto, indicadores relacionados aos impactos de uma cidade no meio ambiente.

(h) Mudar a escala do modelo para o nível celular. Estudar a cinética do transporte de massa no interior da célula e assim contabilizar o efeito de diferentes substâncias na exergia destruída, ou até, tentar entender/modelar pelo ponto de vista da Segunda Lei uma célula com câncer.

(i) Estudar um animal ectotérmico (sangue frio), pois a partir dos resultados de hipotermia levanta-se a hipótese se esses animais poderiam ter uma eficiência exergética maior. (sugestão da banca)

(j) Aumentar os resultados de entropia gerada durante a vida para uma mulher durante a gravidez. Estender o estudo pelo ponto de vista do "volume de controle feto" e "volume de controle mãe". (sugestão da banca) 


\section{REFERÊNCIAS}

ALBERTY, R.A. Calculation of standard transformed gibbs energies and standard transformed enthalpies of biochemical reactants. Archives of biochemistry and biophysics, Elsevier, v. 353, n. 1, p. 116-130, 1998.

ALBERTY, R.A.; GOLDBERG, R.N. Standard thermodynamic formation properties for the adenosine 5'-triphosphate series. Biochemistry, ACS Publications, v. 31, n. 43, p. 10610-10615, 1992.

ALBULQUERQUE-NETO, C. Modelo integrados dos sistemas térmicos e respiratório do corpo humano. Tese (Doutorado) - Escola Politécnica da Universidade de São Paulo, 2010.

ALBUlquerque-NETO, C.; PELlEGRINI, L.F.; FERREIRA, M.S.; JR, S. de Oliveira; YANAGIHARA, J.I. Exergy Analysis of Human Respiration Under Physical Activity. International Journal of Thermodynamics, v. 13, n. 3, p. 105-109, 2010 .

ALBUQUERQUE-NETO, C.; YANAGIHARA, J.I.; TURRI, F. A carbon monoxide transport model of the human respiratory system applied to urban atmosphere exposure analysis. Journal of the Brazilian Society of Mechanical Sciences and Engineering, SciELO Brasil, v. 30, n. 3, p. 253-260, 2008.

ANNAMALAI, K.; SILVA, C. Entropy stress and scaling of vital organs over life span based on allometric laws. Entropy, Multidisciplinary Digital Publishing Institute, v. 14, n. 12, p. 2550-2577, 2012.

AOKI, I. Entropy balance of white-tailed deer during a winter night. Bulletin of mathematical biology, v. 49, n. 3, p. 321-327, 1987.

AOKI, I. Entropy flow and entropy production in the human body in basal conditions. Journal of theoretical biology, v. 141, n. 1, p. 11-21, 1989.

AOKI, I. Effects of exercise and chills on entropy production in human body. Journal of theoretical biology, v. 145, n. 3, p. 421-428, 1990.

AOKI, I. Entropy principle for human development, growth and aging. Journal of theoretical biology, v. 150, n. 2, p. 215-223, 1991.

ASHRAE, F. Handbook of fundamentals. Atlanta: American Society of Heating, Refrigerating and Air Conditioning Engineers Inc., 2005.

BALMER, R.T. Entropy and aging in biological systems. Chemical Engineering Communications, v. 17, n. 1, p. 171-181, 1982. 
BATATO, M.; DERIAZ, O.; BOREL, L.; JEQUIER, E. Analyse exergétique, théorique et expérimentale, du corps human. Entropie, v. 26, p. 120-130, 1990.

BEHRINGER, W.; SAFAR, P.; WU, X.; NOZARI, A.; ABDULlAH, A.; STEZOSKI, S.W.; TISHERMAN, S.A. Veno-venous extracorporeal blood shunt cooling to induce mild hypothermia in dog experiments and review of cooling methods. Resuscitation, v. 54, n. 1, p. 89-98, 2002.

BIJEKER, K.E.; GROOT, G. De; HOLLANDER, A.P. Delta efficiencies of running and cycling. Medicine \& Science in Sports \& Exercise, v. 33, n. 9, p. 1546, 2001.

BRETT, J.R. The metabolic demand for oxygen in fish, particularly salmonids, and a comparison with other vertebrates. Respiration physiology, v. 14, n. 1-2, p. 151170, 1972.

CAVAGNA, GA; KANEKO, M. Mechanical work and efficiency in level walking and running. The Journal of physiology, Physiological Soc, v. 268, n. 2, p. 467, 1977.

CESPEDES, J.; OLIVEIRA, S. Análise Termoeconômica de Plantas de Cogeração. Revista Brasileira de Engenharia Química, v. 17, p. 21-27, 1997.

CHEN, MM; HOLMES, KR. Microvascular contributions in tissue heat transfer. Annals of the New York Academy of Sciences, v. 335, p. 137, 1980.

COOLEY, D.A.; DEBAKEY, M.E.; MORRISJR, G.C. Controlled extracorporeal circulation in surgical treatment of aortic aneurysm. Annals of Surgery, v. 146, n. 3 , p. $473,1957$.

CORTASSA, S.; AON, M.A.; IGLESIAS, A.A.; LLOYD, D. An introduction to metabolic and cellular engineering. Londres: World Scientific Pub Co Inc, 2002.

DAE, M.W.; GAO, D.W.; URSELL, P.C.; STILLSON, C.A.; SESSLER, D.I. Safety and efficacy of endovascular cooling and rewarming for induction and reversal of hypothermia in human-sized pigs. Stroke, v. 34, n. 3, p. 734, 2003.

DEAR, R.J.; ARENS, E.; HUI, Z.; OGURO, M. Convective and radiative heat transfer coefficients for individual human body segments. International Journal of Biometeorology, v. 40, n. 3, p. 141-156, 1997.

DEWITT, D.P.; INCROPERA, F.P. Fundamentos de Transferência de Calor e de Massa. [S.l.]: LTC-Livros Técnicos e Científicos Editora SA, 2003.

DIENER, JRC. Calorimetria indireta. Revista da Associação Médica Brasileira, SciELO Brasil, v. 43, n. 3, p. 245-253, 1997. 
DILLER, K.R.; ZHU, L. Hypothermia therapy for brain injury. Annual Review of Biomedical Engineering, Annual Reviews, v. 11, p. 135-162, 2009.

DINE, C.J.; ABELLA, B.S. Therapeutic hypothermia for neuroprotection. Emergency medicine clinics of North America, v. 27, n. 1, p. 137-149, 2009.

DIXON, S.R.; WHITBOURN, R.J.; DAE, M.W.; GRUBE, E.; SHERMAN, W.; SCHAER, G.L.; JENKINS, J.S.; BAIM, D.S.; GIBBONS, R.J.; KUNTZ, R.E. et al. Induction of mild systemic hypothermia with endovascular cooling during primary percutaneous coronary intervention for acute myocardial infarction* 1 . Journal of the American College of Cardiology, v. 40, n. 11, p. 1928-1934, 2002.

DORAN, M.D. Bioprocess Engineering Principles. Cambridge: Cambridge University Press, 1995.

DUBOIS, D.; DUBOIS, E.F. A formula to estimate the approximate surface area if height and weight be known. Nutrition (Burbank, Los Angeles County, Calif.), v. 5, p. 303, 1916.

DUBOIS, E.F.; EBAUGH-JR, F.G.; HARDY, J.D.; SODERSTROM, G.F.; STEVENS, E.I. Basal Heat Production and Elimination of Thirteen Normal Women at Temperatures from 22 \{degrees\} C. to 35 \{degrees\} C.: Sixteen Figures. Journal of Nutrition, v. 48, n. 2, p. 257, 1952.

FANGER, P.O. Calculation of thermal comfort: introduction of a basic comfort equation. ASHRAE transactions, v. 73, n. 2, p. III.4.1-20, 1967.

FANGER, P.O. Thermal comfort. Nova Iorque: McGraw-Hill Book Company, 1970.

$\mathrm{FAO} / \mathrm{WHO} / \mathrm{UNU}$. Estimates of energy and protein requirements of adults and children. Geneva: World Health Organization Geneva, 1985.

FERNANDES, T.L.; SILVA, A.C.B.; SOUZA, L.S.; SILVA, P.R.; IRIGOYEN, M.C.; HERNANDEZ, A. Estudo comparativo dos limiares ventilatórios mensurados pelos protocolos de limiar de lactato e ergoespirométrico em corredores de capacidade aeróbica progressiva. Relatório Técnico da Faculdade de Medicina da USP. São Paulo, 2012.

FERREIRA, M.S. Um Modelo do Sistema Termorregulador do Corpo Humano: Exposição a Ambientes Quentes. Dissertação (Relatório Final) - Escola Politécnica da Universidade de São Paulo, 1997.

FERREIRA, M.S. Um modelo do sistema térmico do corpo humano. Tese (Doutorado) — Escola Politécnica da Universidade de São Paulo, 2001. 
FERREIRA, M.S.; YANAGIHARA, J.I. Unsteady heat conduction in 3D elliptical cylinders. International Communications in Heat and Mass Transfer, v. 28, n. 7, p. 963-972, 2001.

FERREIRA, M.S.; YANAGIHARA, J.I. A transient three-dimensional heat transfer model of the human body. International Communications in Heat and Mass Transfer, v. 36, n. 7, p. 718-724, 2009.

FERREIRA, M.S.; YANAGIHARA, J.I. Análise exergética do corpo humano. In: Segundo Encontro Nacional de Engenharia Biomecânica. [S.l.: s.n.], 2009.

FORREST, W.W.; WALKER, D.J. Thermodynamics of biological growth. Nature, v. 196, p. 990-991, 1962.

GAGGE, A.P.; STOLWIJK, J.A.J.; NISHI, Y. An Effective Temperature Scale Based on a Simple Model of Human Physiological Regulatiry Response. Memoirs of the Faculty of Engineering, Hokkaido University, v. 13, p. 21-36, 1972.

GILBERT, H.F. Basic concepts in biochemistry: A student survival guide. New York: McGraw-Hill, 2000.

GONG, M.; WALL, G. On exergy and sustainable development - part ii: Indicators and methods. Exergy, an international journal, v. 1, n. 4, p. 217-233, 2001.

GORDON, R.G.; ROEMER, R.B.; HORVATH, S.M. A mathematical model of the human temperature regulatory system-transient cold exposure response. Biomedical Engineering, IEEE Transactions on, v. 23, n. 6, p. 434-444, 1976.

HAMMES, G.G. Thermodynamics and kinetics for the biological sciences. Nova Iorque: John Wiley \& Sons, Inc., 2000.

HARDY, J.D.; DUBOIS, E.F. The Technic of Measuring Radiation and Convection: One Figure. Journal of Nutrition, v. 15, n. 5, p. 461, 1938.

HARDY, J.D.; DUBOIS, E.F. Differences between men and women in their response to heat and cold. Proceedings of the National Academy of Sciences of the United States of America, v. 26, n. 6, p. 389, 1940.

HARDY, J.D.; MILHORAT, A.T.; DUBOIS, E.F.; SODERSTROM, G.F. The Effect of Forced Air Currents and Clothing on Radiation and Convection: Three Figures. Journal of Nutrition, v. 15, n. 6, p. 583, 1938.

HARDY, J.D.; MILHORAT, A.T.; DUBOIS, E.F.; SODERSTROM, G.F. Basal Metabolism and Heat Loss of Young Women at Temperatures from 22 degrees\} C. to 35 \{degrees\} C.: Clinical Calorimetry No. 54* Five Figures. Journal of Nutrition, v. 21, n. 4, p. 383, 1941. 
HARRIS, J.A.; BENEDICT, F.G. A biometric study of human basal metabolism. Proceedings of the National Academy of Sciences of the United States of America, v. 4, n. 12, p. 370, 1918.

HAYNIE, D.T. Biological thermodynamics. 2. ed. Cambridge: Cambridge Univ Pr, 2008.

HENRIQUES, I.B. Desempenho exergético do corpo humano e de seu sistema respiratório em função de parâmetros ambientais e da intensidade da atividade física. Dissertação (Mestrado) - Escola Politécnica da Universidade de São Paulo, 2013.

HENRIQUES, I.B.; MADY, C.E.K.; NETO, C. Albuquerque; YANAGIHARA, J.I.; JUNIOR, S. Oliveira. The effect of altitude and intensity of physical activity on the exergy efficiency of respiratory system. In: Proceedings of the 26th international conference on efficiency, cost, optimization, simulation and environmental impact of energy systems. [S.l.: s.n.], 2013.

HERSHEY, D. Entropy theory of aging systems. London: Imperial College Press, 2010.

IBGE. Pesquisa de orçamentos familiares. Antropometria e estado nutricional de crianças adolescentes e adultos no brasil (2008-2009). Rio de Janeiro: Ministério da Saúde, 2010.

INCROPERA, F.P.; DEWITT, D.P. Fundamentos de tranferência de calor e de massa. 5. ed. Rio de janeiro: LTC Editora, 2002.

ISO7730. Ergonomics of the thermal environment: Analytical determination and interpretation of thermal comfort using calculation of the PMV and PPD indices and local thermal comfort criteria. Geneva: International Standard, 2005.

ITO, A.; KOMI, P.V.; SJÖDIN, B.; BOSCO, C.; KARLSSON, JAN. Mechanical efficiency of positive work in running at different speeds. Medicine \& Science in Sports \& Exercise, v. 15, n. 4, p. 299, 1983.

JONES, A.M.; DOUST, J.H. A 1\% treadmill grade most accurately reflects the energetic cost of outdoor running. Journal of Sports Sciences, Taylor \& Francis, v. 14, n. 4, p. 321-327, 1996.

KANDJOV, I.M. Heat and mass exchange processes between the surface of the human body and ambient air at various altitudes. International Journal of Biometeorology, v. 43, n. 1, p. 38-44, 1999. 
KANEKO, M. Mechanics and energetics in running with special reference to efficiency. Journal of biomechanics, Elsevier, v. 23, p. 57-63, 1990.

KOTAS, T.J. The exergy method of thermal plant analysis. Londres: Butterworth Publishers, Stoneham, MA, 1985.

LEHNINGER, A.L.; NELSON, D.L.; COX, M.M. Principles of biochemistry. New York: Wh Freeman, 2005.

LEMS, S. Thermodynamic explorations into sustainable energy conversion. Learning from living systems. Tese (Doutorado) - Technische Universiteit Delft, 2009 .

LUO, L. Entropy production in a cell and reversal of entropy flow as an anticancer therapy.

Frontiers of Physics in China, v. 4, n. 1, p. 122-136, 2009.

MAGNO, L.A. Tratamento inicial do choque por hemorragia controlada: Avaliação tardia do efeito sinérgico de pentoxifilina e solução hipertônica.,. Tese (Doutorado) — Faculdade de Medicina da Universidade de São Paulo, 2010.

MINAKAMI, S.; YOSHIKAWA, H. Thermodynamic considerations on erythrocyte glycolysis. Biochemical and biophysical research communications, v. 18, p. 345, 1965.

MORAN, M.J.; SHAPIRO, H.N. Princípios de termodinâmica para engenharia. 6. ed. Rio de Janeiro: LTC-Livros Técnicos e Científicos Editora SA, 2009.

MOUNTCASTLE, V.B. Fisiologia Médica. 13. ed. Rio de Janeiro: Guanaba Koogan S.A., 1974.

MUÑOZ-DIOSDADO, A. Thermodynamic efficiency of the cardiac cycle and irreversibility in the interbeat interval time series. Revista Mexicana de Ingeniería Biomédica, v. 31, n. 2, 2010.

NADEL, E.R.; BULLARD, R.W.; STOLWIJK, JA. Importance of skin temperature in the regulation of sweating. Journal of applied physiology, v. 31, n. 1, p. 80, 1971.

OLIVEIRA, S. Exergy: Production, Cost and Renewability. Londres: Springer, 2013.

PASSOS, JC. Os experimentos de Joule e a primeira lei da termodinâmica. Revista Brasileira de Ensino de Física, v. 31, p. 3603.1 - 3603.8, 2009.

PELLEGRINI, L.F. Análise e otimização termo-econômica-ambiental aplicada à produção combinada de açúcar, álcool e eletrecidade. Tese (Doutorado) Escola Politécnica da Universidade de São Paulo, 2009. 
PENG, R.Y.; BONGARD, F.S. Hypothermia in trauma patients. Journal of the American College of Surgeons, v. 188, n. 6, p. 685, 1999.

PENNES, H.H. Analysis of tissue and arterial blood temperatures in the resting human forearm. Journal of applied physiology, Am Physiological Soc, v. 1, n. 2, p. 93$122,1948$.

PINHEIRO, P. Obesidade: Calorias para emagrecer. http://www.mdsaude.com/, 2013.

PREK, M. Exergy analysis of thermal comfort. International Journal of Exergy, v. 1, n. 3, p. 303-315, 2004.

PREK, M. Thermodynamical analysis of human thermal comfort. Energy, v. 31, n. 5, p. 732-743, 2006.

PREK, M.; BUTALA, V. Principles of exergy analysis of human heat and mass exchange with the indoor environment. International Journal of Heat and Mass Transfer, v. 53, p. 5806-5814, 2010.

PRIGOGINE, I.; WIAME, J.M. Biologie et thermodynamique des phénomènes irréversibles. Cellular and Molecular Life Sciences, v. 2, n. 11, p. 451-453, 1946.

RABI, J.A.; SILVA, R.L.; OLIVEIRA, C.E.L. Human thermal comfort: an irreversibilitybased approach emulating empirical clothed-body correlations and the conceptual energy balance equation. Journal of the Brazilian Society of Mechanical Sciences and Engineering, SciELO Brasil, v. 34, n. 4, p. 450-458, 2012.

RAHMAN, A. A novel method for estimating the entropy generation rate in a human body. Thermal Science, v. 11, n. 1, p. 75-92, 2007.

SASSON, S. Biologia Celular e Genética. São Paulo: Gráfica e Editora Anglo LTDA, 2002.

SAVAGE, M.V.; BRENGELMANN, G.L. Control of skin blood flow in the neutral zone of human body temperature regulation. Journal of Applied Physiology, v. 80, n. 4, p. 1249, 1996.

SCHRÖDINGER, E. What is life?: the physical aspect of the living cell; with, Mind and matter; \& Autobiographical sketches. Cambridge: Cambridge University Press, 1944.

SCIUBBA, E. Beyond thermoeconomics? The concept of extended exergy accounting and its application to the analysis and design of thermal systems. Exergy, an international journal, v. 1, n. 2, p. 68-84, 2001. 
SILVA, C.; ANNAMALAI, K. Entropy generation and human aging: lifespan entropy and effect of physical activity level. Entropy, v. 10, n. 2, p. 100-123, 2008.

SILVA, C.; ANNAMALAI, K. Entropy generation and human aging: lifespan entropy and effect of diet composition and caloric restriction diets. Journal of Thermodynamics, v. 2009, p. 1-10, 2009.

SILVA, P.; SANTOS, P. Uma revisão sobre alguns parâmetros de avaliação metabólica ergometria, vo2max, limiar anaeróbio e lactato. Efdeportes, Revista digital, v. 10, 2004.

SIMONE, A.; KOLARIK, J.; IWAMATSU, T.; ASADA, H.; DOVJAK, M.; SCHELLEN, L.; SHUKUYA, M.; OLESEN, B.W. A relation between calculated human body exergy consumption rate and subjectively assessed thermal sensation. Energy and Buildings, v. 43, n. 1, p. 1-9, 2011.

SORGUVEN, E.; ÖZILGEN, M. Thermodynamic assessment of algal biodiesel utilization. Renewable Energy, Elsevier, v. 35, n. 9, p. 1956-1966, 2010.

SPEAKMAN, J.R. Body size, energy metabolism and lifespan. Journal of Experimental Biology, The Company of Biologists Ltd, v. 208, n. 9, p. 1717-1730, 2005.

STOWARD, P.J. Thermodynamics of biological growth. Nature, v. 194, p. 977-978, 1962.

SZARGUT, J. Exergy analysis. The magazine of the Polish Academy of Sciences, v. 7, p. 31-33, 2005.

SZARGUT, J.; MORRIS, D.R.; STEWARD, F.R. Energy analysis of thermal, chemical, and metallurgical processes. Nova York: Hemisphere Publishing Corporation, 1988.

TSUEI, B.J.; KEARNEY, P.A. Hypothermia in the trauma patient. Injury, v. 35, n. 1, p. $7-15,2004$.

UZUNIAN, A.; PINSETA, D.E.; SASSON, S. Introdução à biologia e ecologia. São Paulo: Gráfica e Editora Anglo LTDA, 2002.

VAN-WYLEN, J.; SONNTAG, R.E.; BORGNAKKE, C. Fundamentos da Termodinâmica-6 $\mathbf{6}^{\mathbf{0}}$ edição. 6. ed. São Paulo: Edgard Blucher, 2003.

VELáSQUEZ, H.I. Avaliação exergética e exergo-ambiental da produção de biocombustíveis. Tese (Doutorado) - Escola Politécnica da Universidade de São Pualo, São Paulo, 2009. 
VILLELA, G.G.; BACILA, M.; TASTALDI, H. Bioquímica. Rio de Janeiro: Livraria Editora Guanabara, 1961.

VOLPE, B.T.; JAIN, R.K. Temperature distributions and thermal response in humans. i. simulations of various modes of whole-body hyperthermia in normal subjects. Medical Physics, v. 9, p. 506, 1982.

WARD-SMITH, AJ. Air resistance and its influence on the biomechanics and energetics of sprinting at sea level and at altitude. Journal of biomechanics, Elsevier, v. 17, n. 5, p. 339-347, 1984.

WILLIAMS, K.R.; CAVANAGH, P.R. A model for the calculation of mechanical power during distance running. Journal of Biomechanics, Elsevier, v. 16, n. 2, p. 115-128, 1983.

WISSLER, E.H. Steady-state temperature distribution in man. Journal of Applied Physiology, v. 16, n. 4, p. 734, 1961.

WISSLER, E.H. Mathematical simulation of human thermal behavior using whole body models. Heat transfer in medicine and biology. Analysis and applications, v. 1, p. 325-74, 1985.

WU, X.; ZHAO, J.; OLESEN, B.W.; FANG, L. A novel human body exergy consumption formula to determine indoor thermal conditions for optimal human performance in office buildings. Energy and Buildings, Elsevier, v. 56, p. 48-55, 2012.

WYNDHAM, C.H. Role of skin and of core temperatures in man's temperature regulation. Journal of Applied Physiology, v. 20, n. 1, p. 31, 1965.

ZHEN, W. Where Has Entropy Gone: Theory of General System (II). Arxiv preprint quant-ph/9605018, 1996.

ZOTIN, A.I.; ZOTINA, R.S. Thermodynamic aspects of developmental biology. Journal of Theoretical Biology, v. 17, n. 1, p. 57-75, 1967. 